
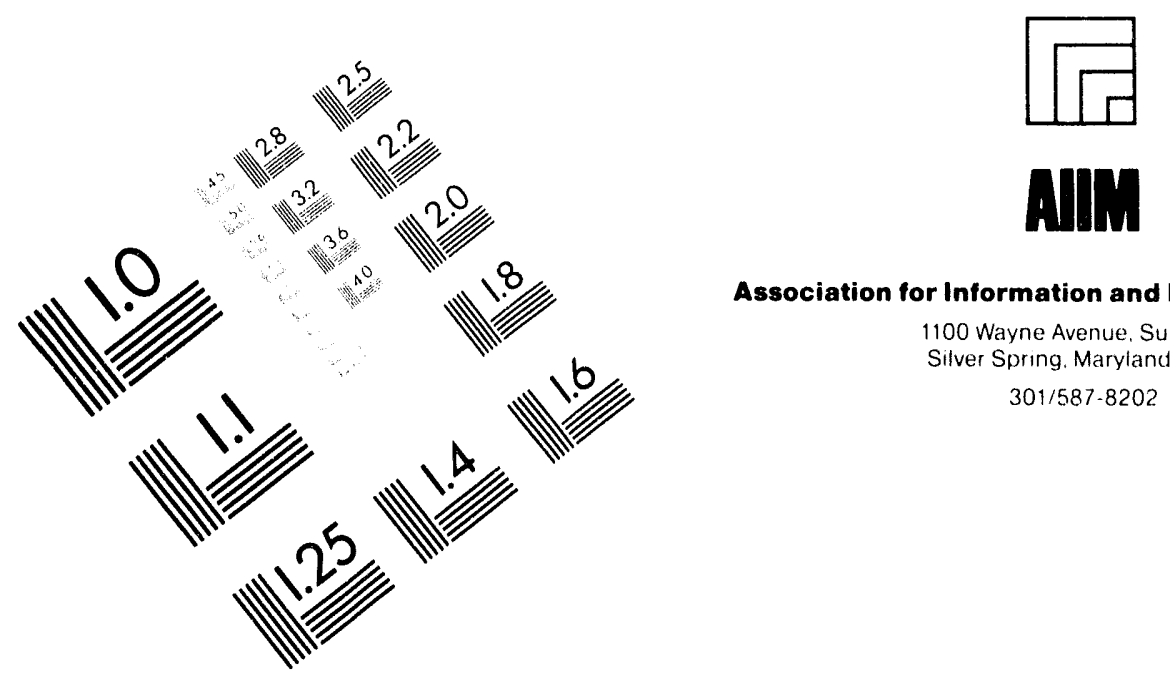

Association for Information and Image Management

1100 Wayne Avenue. Suite 1100

Silver Spring. Maryland 20910

$301 / 587-8202$

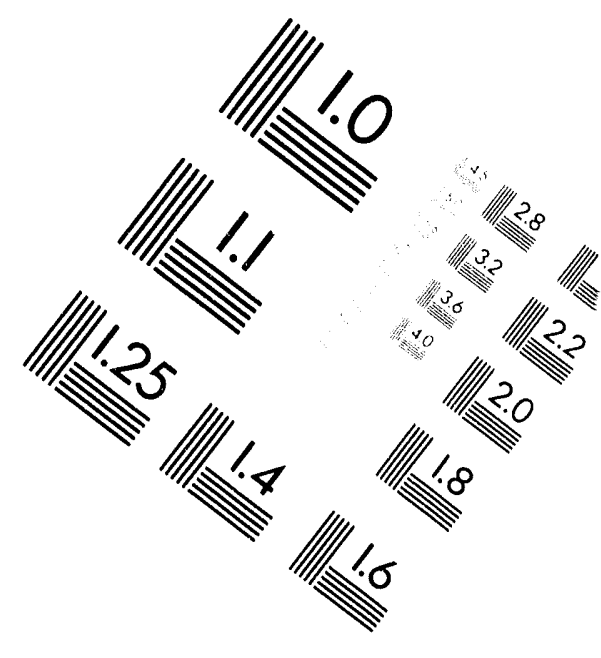

Centimeter

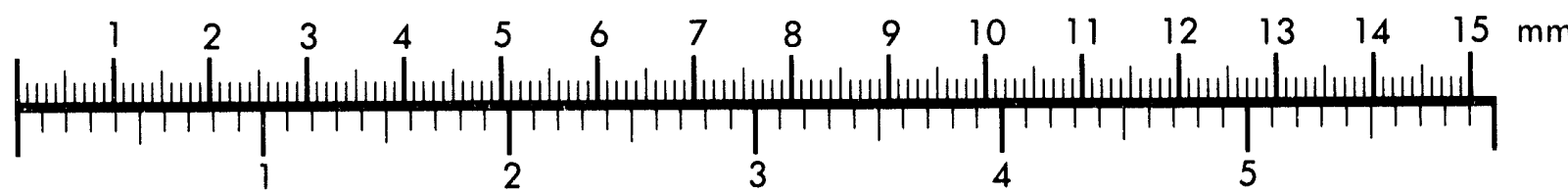

Inches
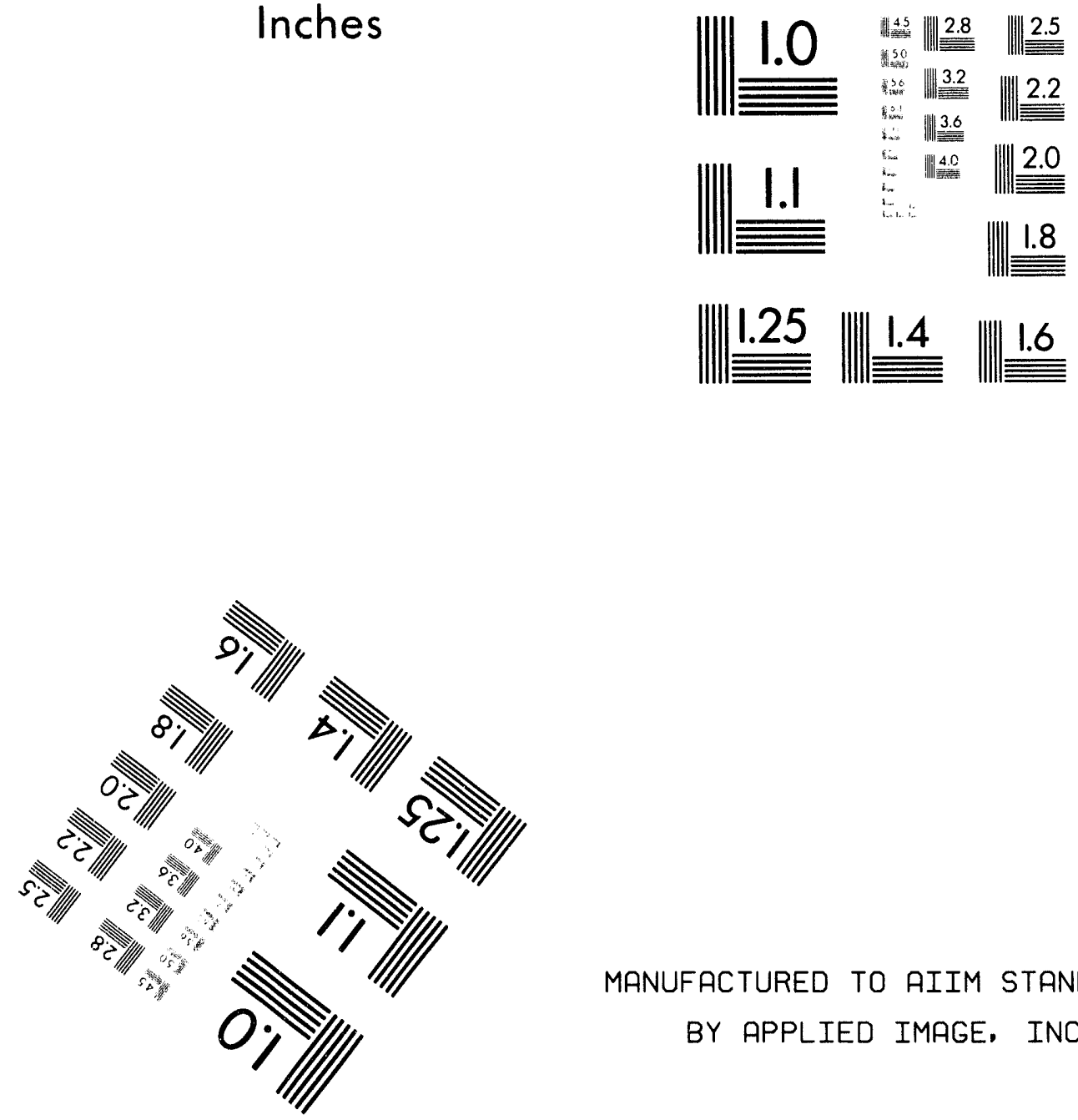

MANUFACTURED TO AIIM STANDARDS

BY APPLIED IMAGE, INC.

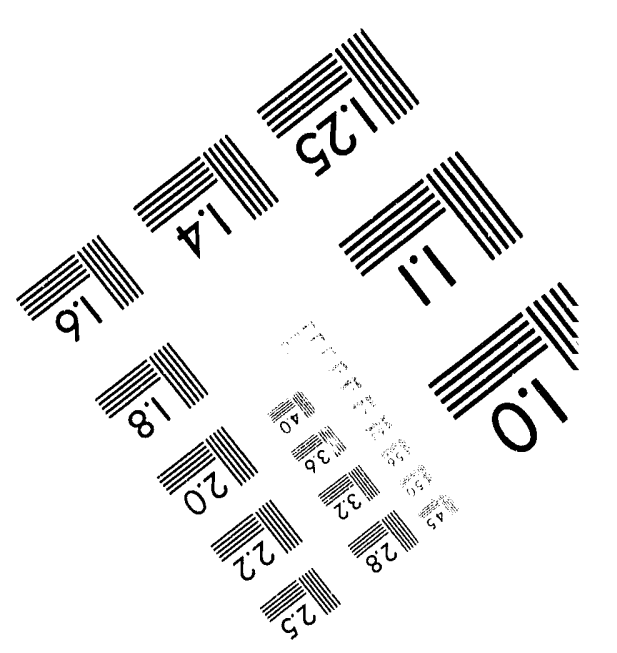



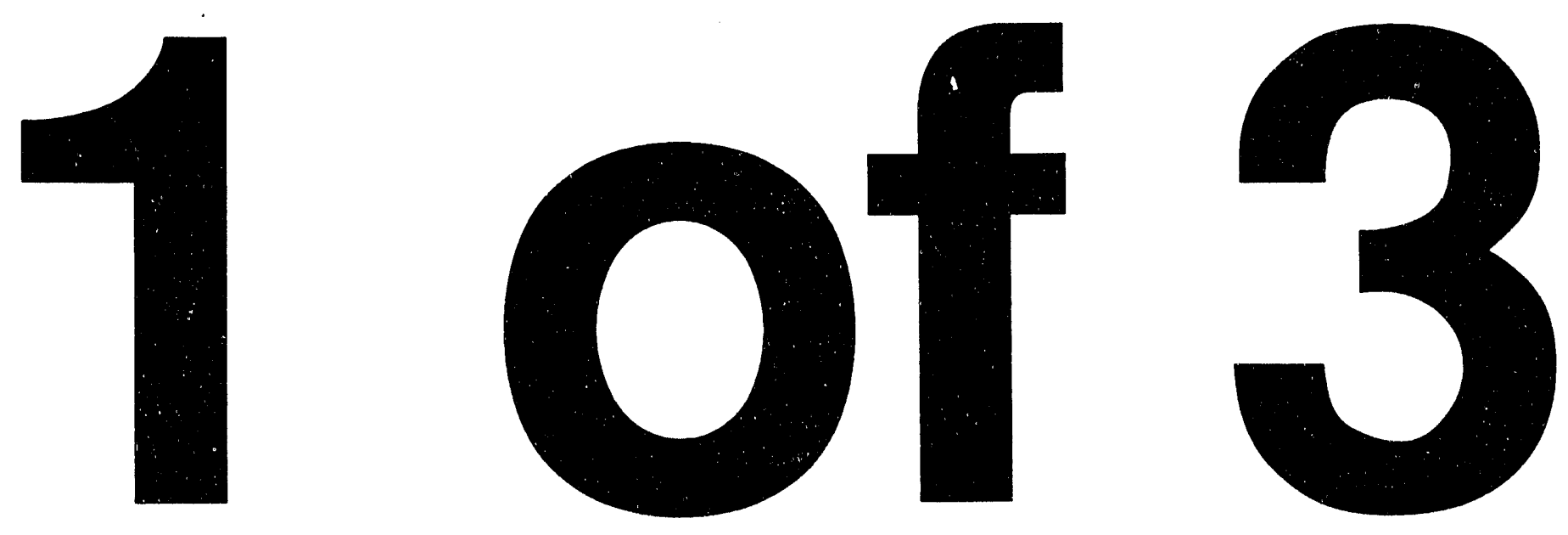


\section{U.S. Department of Energy Environmental Management Advisory Board Public Meeting}

March 15-17, 1994

Held at

Henry VII Ramada Hotel

St. Louis, Missouri

Sponsored by:

RECEIVED

MAY $O 31994$

OSTI

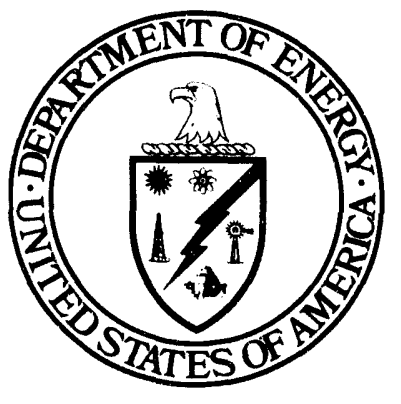

U.S. Department of Energy

Environmental Restoration and Waste Management

March 1994

Dis? 
This report has been reproduced directly from the best available copy.

Available to DOE and DOE contractors from the Office of Scientific and Technical Information, P.O. Box 62, Oak Ridge, TN 37831; prices available from (615) 576-8401.

Available to the public from the U.S. Department of Commerce, Technology Administration, National Technical Infermation Service, Springfield, VA 22161.

(703) $487-4650$. 


\section{U.S. Department of Energy Environmental Management Advisory Board Public Meeting}

March 15-17, 1994

Held at

Henry VII Ramada Hotel

St. Louis, Missouri

Sponsored by:

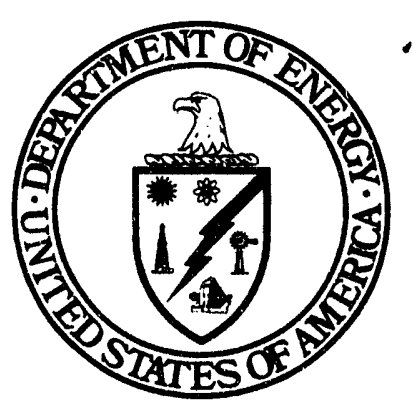

U.S. Department of Energy

Environmental Restoration and Waste Management

Washington, DC 20585

March 1994 


\section{TABLE OF CONTENTS}

List of Participants...........................................................................................................

Monday, March 14, 1994

Opening of Public Meeting and Subcommittee Reports...........................................Pages 3-23

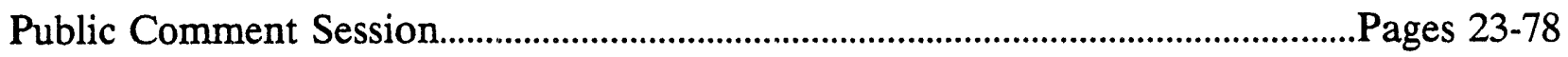

Tuesday, March 15, 1994

Presentation by Thomas P. Grumbly, Assistant Secretary for

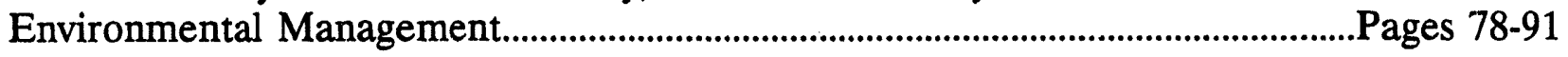

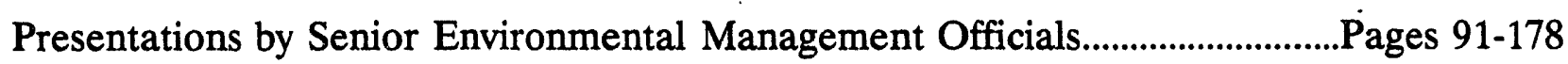

Committee Business...............................................................................................Pages 178-202 


\section{LIST OF PARTICIPANTS}

\section{COMMITTEE MEMBERS PRESENT:}

Mr. Alvin Alm, Co-Chair

Mr. Douglas Costle, Co-Chair

Dr. Lynn R. Anspaugh

Mr. Kenneth W. Ayers

Mr. Richard L. Bangart

Mr. Dennis A. Bechtel

Mr. Jeff Breckel

Mr. Gerald Christean

Mr. Tim Connor

Ms. Vicky Dastillung

Dr. Fred A. Donath

Ms. Shira A. Flax

Dr. William R. Freudenburg

Mr. Ken Korkia

Mr. Ron Kucera

Mr. Tad McCall, Jr.

Dr. Glenn Paulson

Mr. Ron Ross

Mr. Ben Smith

Dr. Jay Sorenson

Mr. Thomas A. Winston

\section{DEPARTMENT OF ENERGY PARTICIPANTS:}

Mr. Tom Grumbly, Assistant Secretary for Environmental Management

Mr. Glen Sjoblom, Special Assistnat to the Assistant Secretary for Environmental Management

Mr. James T. Melillo, Executive Secretary for the Environmental Management Advisory Board

Dr. Carol Henry, proposed Director, Office of Integrated Risk Assessment

Ms. Cynthia Kelly, Director, Office of Public Accountability

Ms. Jill Lytle, Deputy Assistant Secretary, Office of Waste Management

Mr. Randy Scott, Deputy Assistant Secretary, Office of Oversight and Self-Assessment

Mr. Jim Werner, Director, Office of Strategic Planning and Analysis

Mr. Pat Whitfield, Deputy Assistant Secretary, Office of Environment Restoration 
PUBLIC COMMENTORS (in order of appearance):

David Shorr, Director, Missouri Department of Natural Resources

Darid Hayes, Field Coordinator, Laborers Employment Cooperative and Education Trust Loraine Batton, Resident, Berkeley, Missouri

Lee Brotherton, Director, Transportation and Environmental Policy, St. Louis County

Robert Heuremann, City Councilman, Hazelwood, Missouri

Roger Pryor, Missouri Coalition for the Environment

Rebecca Wright, Missouri Coalition for the Environment

Bill Miller, Mayor, Berkeley, Missouri

Joy Guze, Resident, St. Louis, Missouri

Lewis Green, Resident, St. Louis, Missouri

Kay Drey, Missouri Coalition for the Environment

Meredith Hunter, Resident, St. Louis, Missouri

Kathy Collins, Resident, St. Peters, Missouri

Kathy Lewis, School teacher, St. Louis, Missouri

Jay Lewis, Resident, St. Louis, Missouri

Martha Dodson, Resident, Crystal City, Missouri

Ms. M. Gutwein, Resident, St. Louis, Missouri

Arlene Sandler, Resident, St. Louis, Missouri

Byron Clemons, Resident, St. Louis, Missouri

Deborah Wilson, Resident, Berkeley, Missouri

Peter Schmitz, Lawyer, St. Louis, Missouri

Peggy Meyer, City Councilwoman, Bridgeton, Missouri

Leonard Sonnenschein, President, MidAmerica Aqua Center

Dolores Wolff, Resident, St. Louis, Missouri

Gwen Hobbs, Resident, St. Peters, Missouri

Mark Guy, Resident, St. Louis, Missouri

Beth Okenfus, Resident, St. Louis, Missouri

Ed Marr, National Health Food Organization

Seth Carlin, Resident, St. Louis, Missouri 
CHAIRMAN COSTLE: Let me call the meeting to order, please. Just three short announcements before we can head to the subcommittee reports. First item is just to encourage you to stop by the displays out here so that those people who worked so hard to put them together can get our appreciation for it. Secondly, to remind everybody that the forms that were handed out today in terms of meeting availability dates for May, if you could please try to get those back into us this evening so that we can try to maybe have a resolution by the time we leave here tomorrow. And July. The third announcement is simply that we've got a somewhat longer list of people who have asked for an opportunity to address us during the public comment session than originally expected. It's probably about 16 or 17 people. So what I'm going to propose doing when we get to that part of the meeting is invite people to double up if they are of a mind to, since there are several who are here that represent one group, but also to ask for a five-minute rule and ask them to try to confine their presentations to five minutes. Obviously exceptions will be made when we ask them questions. So I don't want to cut anybody off. I'm also mindful of the fact that you all have already had a long day, and by then it's going to seem like a very long day.

With that, at this point what I'd like to do is invite the subcommittees to present their reports to the full committee, and l'd like to start with the PEIS Committee.

MR. SMITH: I had Glen look over a few of the notes we had. So the PEIS subcommittee met last month. It was an excellent meeting, in fact, and it followed on a meeting that was held in Washington earlier. I think the good news is that the Department and its consultants are coming very quickly to the point of having something for us to start reviewing on the PEIS, which you'll remember back a year or so ago was the principal reason for forming this particular committee. We basically asked Glen to go through some items that he had before us, the principal one which is the schedule for completing selected chapters of the PEIS, and in the pile of material that's before you there's a sheet like this that gives you -- that gave us the approximate times and dates that various chapters to the PEIS will be concluded. The subcommittee then discussed options in which they might want to review the PEIS, and it was suggested at that time that since it is a full committee action that what we would bring to the full committee this evening is a recommendation as io how the full committee might consider approaching the review process for the PEIS to give impact or input back to Glen on a draft.

After reviewing the dates and the chart that's before you and after talking with consultants that were there, we arrived at basically a recommendation for this committee to consider. First would be to hold a full committee meeting in May, wholly dedicated to reviewing those chapters of the PEIS that were available at that time. And going down the list that you have there, if you look at the dates, that will carry us through the chapter four environmental restoration chapters of the PEIS, and I might reference you to the last page of this which gives you the full set of chapters so you'll know what I'm talking about. Chapters one through four would be available, and probably chapter eight could be available, if I understand how that's working at this point. 
The major chapter that will be missing is the waste management chapter. We're hoping that some elements of phase one of that chapter will be ready, which lays out the broad playing field, if you may, of alternatives for waste management.

Following that meeting then, we look then -- ask the indulgence of the full committee then to meet again either in July or August, right now it's looking more like August, at a site -- it's called Piney Point -- basically to take on the review of the waste management chapter and the cumulative impacts chapter at that time, and also review the rewrites and materials that we suggest to Glen as part of the May meeting. So essentially the recommendation is to hold two meetings of the full PEIS committee. They would be solely dedicated, or principally dedicated, to the review of the PEIS document itself. I'm sorry. Full EMAB, excuse me. yes. I'm sorry. Full EMAB Committee.

Based upon that, we asked, and I hope Vicky is ready this evening, for a short review along with Dr. Sorenson on the workshop that was held earlier on risk assessment and their input, so I would ask Vicky, if you would, and, Jay, would you follow Vicky?

MS. DASTILLUNG: Basically the workshop started out with a bunch of presentations about the PEIS and the ER and WM alternatives and risk assessment and how MEPAS fit in and benchmarking and the FFCA process and the SSAB's, mostly because it was requested by the folks that had gone to the first workshop. They didn't understand the whole PEIS process and what's been going on. So that was kind of updating everybody.

For myself, it was pretty much the same stuff I was already aware of because of being on this committee, but other newer folks said it was really enlightening. They had learned a lot by the presentations. Others that had been into this process a little longer said it wasn't as detailed as they would have liked, so you can't please everybody, but they tried.

Some people who attended had hoped for some actual risk numbers, a little more really specific data that wasn't yet available. Then we broke down into two sessions. One was to talk about -- a little bit more specifically about the public participation for the PEIS, and we discussed the workshops and the things they had put into their Strawman, and did that in fairly much detail.

I've been sending comments through Jim Melillo and to Glen I guess since last summer about the public participation, so they've been getting some input from me, but now Shira will talk more about public participation later, but we need everybody's input and not just a few.

Then the other break-out session was how to actually present the information, and in your information here they showed us logarithmic charts and ladder charts and bar graphs and pie graphs and what we call the measles chart that had all these little dots on it, kind of like a Consumer Report chart. We got to say we like this and we hate this and this title is stupid and we really got down into the nitty-gritty type detail to give them some idea of how to present this actual information in the document so that the general public can look at it and have some idea of what's going on. So hopefully that helped DOE get ready for that. There were several things that 
hit me as I came out of it, and you can read the summary there. There were lots of different things. One of the things was that the public said that if you're going to hold a PEIS workshop before the actual draft comes out, they only really wanted to attend if they could have some impact on the development of the draft. They just didn't want to go and get presented with things, and that's all fine and dandy. Trey want to actually participate.

Another was that the folks wanted to have a preferred alternative talked about in the draft and not wait until the actual, you know, ROD in the end, even if it was only the current thinking of the time. They realized that it might change as more data was collected and all, but they wanted to have some idea of the direction that DOE was going.

Another thing was they kept saying that risk assessment is all fine and good but it's only one component of decision-making. They wanted to make sure there wasn't an over-reliance on risk assessment. And also there was another thing I was hearing like behind the scenes a little bit was maybe DOE is holding too many workshops. A lot of the stakeholders have been kind of workshopped to death lately. So it's something DOE may want to consider in the future. The best thing about the whole thing for me was that they actually had a computer lab there and they had the MEPAS model on the computer lab, and you could go in and with the help of somebody who knew how to run it pick out like a school scenario and have the computer actually run it and give you a printout. I've got an actual MEPAS printout. For me, that was as valuable as anything, just actually getting to see what comes up on that computer screen as you go through the steps and see what the risk assessors actually do.

That's basically about it. Any questions on that?

MR. SMITH: Just a little teaser to add to the justification for bringing the whole committee into this PEIS review. We've only had a small glimpse at the results of the analysis that's been ongoing for quite some time, but that glimpse I think indicates that some compelling arguments are going to come out, compelling results are going to come out of these analyses.

Already, to me, we're seeing some compelling arguments and cost estimates that would tend to favor the extreme centralization of waste management facilities. We heard presentations last night where the figures would tend to support institutional control rather than digging up environmental restoration sites, some pretty compelling risk assessment figures that indicate those directions. So the point I'm trying to make is that these analyses are going to point us pretty strongly in some directions, and I think it's incumbent on all the members of the PEIS Committee to be involved early in how these arguments are developed and how they're displayed because just the choices on how to make the displays can have a big impression or big difference in public perceptions about this program. So that's the reason we felt strongly that the full EMAB should be involved and dedicate its next two meetings to this PEIS review.

CHAIRMAN COSTLE: Tad. 
MR. McCALL: With the great respect I have for the chairman or co-chairman of that committee, I really disagree. I do not want to be part of writing DOE's PEIS. Don't want to do it, not one bit.

Secondly, I think we usurp our role as public advisors and we've become a superpublic. We've become an elite public, sharing the role of the government, and I don't want to do that either. I'm an advisor. I'll come here, I'll give my advice on what I can give in a regular meeting. That's enough for the government to do. Thank you.

\section{CHAIRMAN COSTLE: Do we have some other people? Jay?}

DR. SORENSON: Vicky summed up the meeting very well. I would like to just add a couple of remarks. Actually Lynn, I think, was responsible for the second meeting, with really some very cutting and profound questions about the whole MEPAS model. And that meeting, the first meeting that we had, you could feel the sense of uneasiness and dissension over the approach and the whole method that we were being presented by Curtis Travis.

So as a result of the uneasiness, we were invited back to a second meeting. It was a smaller meeting, and it was a much better meeting. It had a much more positive note to it. And the tone in part was set by Glen and Cindy and Susan Wilshire, and we got into some very good discussions about the environmental restoration public participation risk analysis and models.

I'd like to share two observations with you, and they are the observations that I tried to share with others who were attending the meeting. The first really has to do with the question of environmental restoration and remediation, and it's a question I would have raised last night and I'm about to give a talk on later on this week at the laboratory directors land use conference, and that is that I have a problem with the free-wheeling use of remediation and restoration in the same breath. I think there's a very sharp distinction between the two, and I think the Department of Energy has been inclined really to think principally in terms of remediation rather than restoration. I think a quick look will tend to suggest that most of the remediation analyses have been based upon human health considerations rather than ecological considerations and that with studies that really have been presented and with the tact offered with regard to unrestricted use, restricted use and limited use, it essentially -- the name of the game really is how to reduce the health risk and remediate a site. There has been very little consideration given to bio and genetic diversity to soil, buildings, and to nutrient recycling or to other ecological considerations that I would seek to be critical to a real restoration question. And I did ask Pat Whitfield at that meeting whether he was talking principally about remediation or restoration, and he said it was remediation.

I think attention has to be given to restoration, and the proposition that I will offer is that we may very well find that the debate how clean is clean and the green fields argument has been really set on its head, that essentially if you look at restoration, particularly with regard to land that will be returned to the public and that will be managed by BLM and the Forest Service, it may be less expensive to go with restoration than with remediation, particularly remediation for 
cleanup to a health standard. There you may have to go in and do drastic remediation, drastic cleanups in a very quick way, and it may be very costly, whereas if you really look at the proposition of restoration, it may prove really that it is by far the less expensive proposition, and restoration I would take to mean intervention to restore a historic bio-system as much as possible, the ecosystem.

But the second observation has to deal with the questions that we dealt with in part today, and it is the question of public participation. And here I would like to preface my remarks with an observation of James Madison in the Federalist Essay, and he wrote that the function of government was first to protect people from one another and then to protect them from the government. And to a large extent that's what I think this whole effort at public participation is all about. And I have to tell you I am worried. I am very concerned. I think there's been a lot of enthusiasm, and I think there's been a rush to get the public participation and the advisory boards going. But given the comments that I hear, given some of the things that I've seen, given the enthusiasm to create a number of different types of advisory boards, I think we're going to be loved to death, and I'm afraid really that the public is going to be given an assignment that it cannot possibly fulfill.

If I can use a different metaphor, I see this whole issue of public participation and the advisory boards as a very fragile flower, and it has to be nourished, and I'm afraid that in our rush really to get them going and to deal with the here and now problems we are going to trample it to death, and so I would urge really that we step back and give a lot of consideration to it. It is terribly important.

We have a chance to do something once again that would build confidence in this country and make it possible for us to move forward. We had that opportunity in the past, and we lost it. We tried public participation in the '70's, and we lost it, in part as a result of some overenthusiasm and as a result of conflict and disagreement within our society. That conflict and disagreement is still there.

So I would urge really that we proceed with caution, but with tender, loving care, and we do what we can to encourage the process. I would like to end by quoting Lloyd Cutler when he took over the responsibility the other day of helping the Clintons through the whole Whitewater problem. And he said that trust was the coin of the realm, and I think that really is the issue at hand for the creation of a meaningful public participation process. The public still has to be brought over. There's still a lot of skepticism and fear out there. But I think it can be done. I really do. And I do want to commend everyone who has really tried to build this public participation process, and I think in that sense the Strawman that was offered was very worthwhile, and I think the meeting that we had was a very productive meeting, and I think really I'd like to see more.

CHAIRMAN COSTLE: Are there people who'd like to react to Tad's provocative comment a minute ago? Glen, you just put your sign down. Tim? 
MR. CONNOR: Yes. I would like to second it.

I don't quite see the urgency to the two meetings on the topic. I certainly admire the work the subcommittee's put into this. I'm very concerned that at this pace, it puts a lot of committee energy into an exercise, which as noble as it is, should not be the focus of our activities. That's a personal belief. I think the committee can be more effective in other areas. And I see the energy going into PEIS has somewhat dissipated that energy.

The other concern is I just think in my limited perception that we are somewhat co-authors of this document, which as important as it may be, I don't think -- Well, it's my personal view that the EMAB ought not be seen as a collaborative author for the PEIS.

CHAIRMAN COSTLE: Ken?

MR. AYERS: I respectfully disagree. The PEIS Subcommittee has been working through, reviewing things and working with development for quite awhile. We feel that it's to the point that it needs to be looked at by the entire committee and not just the subcommittee. If you look back at our original charter, our original charter was to assist and advise, and I don't know -maybe what's changed is we changed our name. I still think that should be one of our main focuses. And our focus was not in the committee discussion, the subcommittee discussion, to be a co-author, but to provide meaningful comments and to assist. And I still think that's part of our main functions, and if we don't approach it in a timely manner, we may lose an opportunity to have a major impact that we should have.

\section{CHAIRMAN COSTLE: Jeff.}

MR. BRECKEL: I'd like to concur with Ken. Although I do agree with both Tim and Tad that we do not want to be viewed as endorsers of the PEIS or co-authors. As a committee member or subcommittee member I've made that point the one snowy meeting in Washington, D.C. here not so long ago. But at the same time, I think we need to look at this as a Programmatic EIS and what that means.

DOE is making a number of rather significant policy choices or airing those policy choices through the PEIS, and I think as a subcommittee member I feel a bit vulnerable representing the desires of the entire committee in terms of what these major policy questions may be that are going to be addressed in this PEIS. And going back again to what Ken said, you know, our initial charter was to look at the Programmatic EIS. If you want to take it a broader reading, as we have here lately, it's to provide DOE with feedback, information, recommendations on major policy issues. I think any way you cut it, the PEIS falls within that arena. I do think we want to maintai an arm's length relationship, and I think it would be unfortunate if we did not as a full committee exercise our prerogative to look at this document, to look at the direction it's going, and in my view give them reasonable feedback.

CHAIRMAN COSTLE: Jerry, and then Shira. 
MR. CHRISTEAN: One of the feelings I have is that PEIS was one of the things when we were put together -- it's one of our, if not the main charge. We've deviated somewhat from that and changed from that, but here we have a subcommittee that's probably worked harder than any subcommittee we have just because of the subject matter, and they ask for us now at this point to get into it and take a look with them. I don't think it's fair to characterize it as helping to write it. Advice is something that we seem to be rather free to give around this table, and that's what they're asking for, and they want us to share in that enterprise. So I'd hate to have us start telling a subcommittee that's worked on a project that comes to us and says, "We need your help, we think you ought to be involved," to say, "No, we're not going to be involved." I think we're bigger and better than that. Thanks.

\section{CHAIRMAN COSTLE: Shira.}

MS. FLAX: I would just like to say that I agree with Jeff. I think Jeff is absolutely right, that there are key policy questions that are going to be aired through this PEIS. If I could just offer this comment. All meetings of the full committee are not mandatory in that if there are members of the full committee who would not like to attend the special sessions to discuss the PEIS, they simply don't have to come.

\section{CHAIRMAN COSTLE: Ben and then Tad.}

MR. SMITH: I think Shira and Jeff and Ken said it very well. I think there is really a need for the individual members of this committee to support this review of the PEIS. It's a very important document and will have -- potentially have some sweeping impacts. I feel like I may have precipitated this debate in what I said a few minutes ago about how important it was that the material in the PEIS convey certain perceptions or that it could create certain perceptions. I didn't mean to imply that we would sit with DOE and try to craft somehow those perceptions to get out a certain message.

My intent there was to look at the perception created by the presentation in these graphs and to make sure it's fair in our view, that it's balanced in our view, and I think there are a lot of different perspectives around the table, and that kind of a balance is only going to come from each of those perspectives having a look at that presentation to see if it's fair, balanced, and not skewed in some way. We found something that looked a little skewed last night. I don't think it was intentional, but there was this composite remediation site where there was a 7,000 year risk analysis done on that site and the radionuclide of concern was cesium, and that has a very short half-life radionuclide. We pointed out that had that been uranium, you know, the risk results over 7,000 years might have been quite different. So, you know, we can be helpful in pointing out those kinds of things without sitting down and crafting some perception that we want to get out.

CHAIRMAN COSTLE: Tad, you were next. 
MR. McCALL: Thank you. I feel better after listening to your recrafting, Ben, of what our role would be, but I still have major concerns. First of all, it isn't an issue of whether we want to be involved or not. We are involved in the PEIS. And I think that's a very important role.

Secondly, the example Ben Smith just brought up about cesium, I'm willing to sign off on that. He's got the subcommittee. That subcommittee is doing that work, and I'm ready to come up and sign off on that work. If their work causes me a problem sufficient enough, I would ask to have that debated, and if that takes two days, all right. I don't need to redo the work they're doing.

Secondly, I think it's going to be very difficult if we have that intensive a review to not get down to this kind of discussion. The chart on page 4-1 is wrong. This is how it's going to have to look. I'm afraid we're going to end up being editors and writers of this document. This does not mean I don't think this is important. This does not mean I don't want to come to committee meetings. It does mean I'm looking for the proper role, and I'm just afraid that we're in our zealousness to do right we're going to take the wrong role, and I ask you to just reconsider how we might do this. I want to participate and help the subcommittee. I think we just need to reconsider what's the best approach on that. I'm not convinced that this is the proposal. I may be wrong.

CHAIRMAN COSTLE: I'm going to exercise the priority of the chair and ask Ron a question. As I understand, part of the issue is that we've not had information before us in terms of some critical analysis, some pieces of this thing, that that's now becoming available, and I'll ask Glen to clarify further. It was my understanding in my earliest conversations with Tom that part of the founding purpose of this group was essentially to advise the Department, whether they take our advice or not is another matter, but to advise the Department in the preparation of their Environmental Impact Statement to try to give them a heads up of what ought to be in it if -- and the name of the game for them is to do a credible job. We represent a set of constituencies that have something to say about that, and I think we have to take it on faith they want to hear it. It i: not, as I would interpret it, Tad, a question of us actually writing or co-authoring, but it's a . question of once we've got enough in front of us to chew on giving them the benefit of our best judgment whether they missed the mark or not, or if there's some skewed analysis or if there's -- it is, from what I've seen of the documentation, an enormous undertaking to try to put that PEIS together. And so I think it's more, as I understand it, it's more in the spirit of trying to make sure that we give them the benefit of our best advice where they've hit the mark, but as much as that, to assure ourselves that what, in fact, goes to the public, at least to the extent that it can reflect our advice and opinion, that what goes to the public is a fair shot for the public so that they are getting the full range of options and kind of analysis they need to make an informed judgment about it. And I think in that sense we're -- again, I don't see us necessarily as co-authors. Now, did I get that right, Ron?

MR. ROSS: I think you got it right in that we are seeing for the first time some of the options displayed, along with the impacts of those, both positive and negative. I think that in my attempt to be brief I missed two marks that I think very important here. First is that after looking 
at this I agree with you we're to help them determine, did you miss the mark and, second, have you been fair with interpreting that mark.

I think that also we have on the recommendation that the second meeting be facilitated, would be an open dialogue between the committee members. It might even be to ask Glen to take under consideration facilitating both meetings so we don't get caught up into certain minutia. Glen did propose a process by which we would look at the impacts, as you say, of the marks, and to attempt to focus on the broader picture here. Have we really interpreted what's there correctly? Does it look like all of the viewpoints around this table? Which is a tremendous resource. Have those been adequately inputted so they are reflected in the document? So in my attempt to be brief, I did miss those two points, and then your point summarized very well the discussions last night.

\section{CHAIRMAN COSTLE: Tom, and then Glenn.}

MR. WINSTON: I'm neither surprised nor troubled by the recommendation for this intensive involvement because I don't really see it as a change in how we operate. I think we have a window of opportunity here. I think we've all recognized that one of our major missions at the outset and continuing will be shepherding the PEIS, providing comment and advice. And as I see that, we have with the draft PEIS coming out in August, we have an opportunity for some intensive involvement. I think we can show some restraint and not become a co-author. But I'm really concerned that we might miss this opportunity. Outside groups view EMAB in many ways. One of the ways in which they view this board is as one committee that's primarily looking at the PEIS. And if the PEIS hits the street and falls on its face, there will certainly be enough concern out there that some of that will fall on our shoulders. And I guess to my mind we have an opportunity to improve the document at this eleventh hour prior to the draft, which I would like to see us take.

\section{CHAIRMAN COSTLE: Glen.}

MR. SJOBLOM: I'd just like to reiterate that we certainly have no right and are not looking for an endorsement of any kind. I'd also like to say that the recommendations made along the process to this point have been critical and I think have helped straighten us out in several ways. I think this is an undertaking that the Department's going to get a chance to do once, and if we do it right it might be worth something to the country. And I really need your help.

CHAIRMAN COSTLE: Ron, at this point, do you feel you need a motion of some kind to get a sense -- I mean, my sense is that there's -- that people are agreeable to a May meeting. Obviously some may come, some may not. But given the timing, the production of reports, a May meeting makes sense if we're to continue to stay involved. If it's sufficient to say that is the sense of the group, I suspect we don't really need a motion unless somebody would like one for the record. 
MR. ROSS: At this point, it's a recommendation from the subcommittee to the full committee, and I'd let you take the lead on that.

MR. SMITH: Last night we did ask for a listing of the exact work products which would be available from META/Berger for a May meeting, and I put on my little notes that they should be available at least two weeks prior to the meeting date so that we'd have a chance to review those. Now, tonight they are still checking with Gaithersburg to see exactly and have a precise listing of what can be produced by the date that we had sort of zeroed in on, and we don't have that yet, but we hope to have that tomorrow is what I'm told.

\section{CHAIRMAN COSTLE: Glen.}

MR. SJOBLOM: Yes. It's our intent to mail by the end of May what you'll be reviewing that third week in -- by the end of April what you'll be reviewing that third week in May, and we will provide details on that before you leave.

CHAIRMAN COSTLE: Okay. We can -- Yes. Tad?

MR. McCALL: You don't need to take a motion for me. If everybody -- I can listen, and everybody who wants to do it and thinks this is good, I can listen to that and say I'll support you enthusiastically. If I can't make the meeting, it wouldn't be sour grapes. It's because I would have another commitment. I'll do what the committee thinks is right. I've listened. I'm willing to participate.

CHAIRMAN CQSTLE: In light of Tad's willingness to graciously fall on his sword, at this point I'd like to invite Glen to respond.

MR. SJOBLOM: As I have done on these occasions before, it is my pleasure that one esteemed peer, Mr. Tad McCall, has suffered through another birthday, and, therefore, is entitled to just desserts. There is a cake in his honor, a simple one, as is our character, in the room where supper originated. So as you take breaks and so forth, please pick up a piece in his honor. Thank you.

MR. McCALL: Thank you very much.

MR. BRECKEL: Mr. Chairman, I think in light of this occasion that perhaps we ought to afford Mr. McCall the opportunity to take the lead in reviewing the program.

CHAIRMAN COSTLE: The next is the SSAB Committee. Shira.

MS. FLAX: The SSAB Subcommittee passed a motion, which they in turn asked me to bring to the full board for discussion, and the motion is in several parts. 
First, the SSAB Subcommittee would like to change its name to the Public Involvement Subcommittee of this advisory board. And, secondly, we want to invite members of the full board who are not on the Public Involvement Subcommittee to join, if they so like.

Thirdly, we would like to direct the work of the Public Involvement Subcommittee to address all issues related to public involvement in each of the projects or each of the tasks that the full advisory board reviews or does oversight with, so that this subcommittee would pay a special eye to public involvement in the PEIS and into any other large project that we would be looking at, and we will continue until the site-specific advisory board's own national committee starts meeting. We will serve with -- if we have their permission, we will serve as a forum by which the individual SSAB's can raise issues of national interest, national importance, to this advisory board and, therefore, to DOE. That's it.

CHAIRMAN COSTLE: That's the subcommittee.

Okay. Without objection.

MR. CHRISTEAN: Mr. Chairman, it's not an objection, but I would like to -- I think the wording is a little awkward in terms of permission. I would like to see it if we're asked. If we're asked to help a SSAB that we stand ready to do that. I feel a little awkward about getting their permission because that's not really your function or theirs. I'd support either way, but I just make that suggestion.

MS. FLAX: Good point, Jerry.

CHAIRMAN COSTLE: Okay. Without objection, subcommittee is renamed. Any other comments on this subject matter? Barriers to Advanced Technology Use.

Tad.

MR. McCALL: Thank you, Mr. Chairman. At the last full committee meeting, we had a presentation from EM-50, the Deputy Gary Voelker, and at that presentation it became clear that devoting our time to looking at breaking and ways to break down the barriers to effective technology development would be a useful project for this committee, and EM-50 indicated they would welcome such activity, and we created a committee to undertake such activity.

What we would like to do in our committee is to identify those barriers that we can effectively dismantle and to come up with a D \& D package, so to speak, to dismantle these barriers presented under the theod (phonetic) of this committee, from the subcommittee to the full committee, for presentation to Tom Grumbly and the administration, the hope being that this would be a step in an eventual opportunity for the Clinton Administration to have a package to stimulate technology development as part of its effort to rebuild American communities, to develop economic strength in America, to develop economic strength based on gcod jobs paying good money, building American competitiveness around the world. 
Now, with such modest goals, it was easy to come up with a set of recommendations. No. With such lofty goals, we realized that as we shot for the moon we couldn't quite get there in one leap, and so we have been, one, supplementing our regular subcommittee members with outside advisors and consultants from the regulatory world, from the business world, from venture capital, people who work both in voluntary organizations to support technology and have businesses to try and develop technology, trying to round out our group to get some more expertise. And with these experts, we are then trying to canvass both the private and the public sector to find out what sort of problems people are having and see which sorts of these problems we can address. I do not have a formal presentation which identifies all the problems for you and gives you all the answers, but I do have one model and some economic considerations that I'd like to just present to you as food for thought and point of departure.

One of the things that we found, if we're going to have a national solution, we have to build regional and community support to get there. One of the models -- and we have not endorsed this model. It is officially known as the -- unofficially known as the orphan model. It's not endorsed, but it is one thought for how you go to a particular site and take a particular problem and get a set of technologies to compete to solve that problem.

Another thing, this model would work in harmony with all the things that EM-50 is doing and DOE EM is doing to reorganize their technology development, to build all their teams, their stakeholders. This could be a method by which the teams with the different stakeholders would actually say, "Savannah River, we've got this particular problem basically with mixed waste or with flume, and this is how we want it. This is how we want you to come in and offer solutions." Well, the first way they get someone to offer solutions is you identify what the requirements will be. We're still talking about what body and how you do this, but you would have a set of requirements to meet. Then you put that in a request for proposals from the private sector, and we would anticipate that the private sector then would form teams to come to compete to solve -- to satisfy that RFP. From those proposals, the top, say, four would be selected, and of those four proposals they would be asked to go -- You'd select those teams and ask them to come in to submit a system site and feasibility study. I'll see if I can get it a little closer. The people identified to be participants in this cook-off or fly-off or bake-off, whatever you want to do, would be required to not only make their presentation, but put some matching enterprise, like capital or some other part of their company or their companies, on line on a 80/20 match, 80 percent government money, 20 percent private money into tnis proposal.

Out of the study of the feasibility proposals, you'd pick the best three. They would come to a demonstration project. Out of the demonstration project, that means the system design, you pick the best design systems and finally get down to two systems demos. Out of that demonstration of field work would come the best product. That product would receive the award, and they would then be able to develop the -- they would be awarded a contract to clean up.

We see these -- the proponents of this system said these are some of the -- this is some of the advantages you get. You get market-driven solutions rather than government-imposed ${ }^{\circ}$ solutions. The government says what the problem is. It's up to private industry to say what the 
solutions are. And in private industry, you could have like a DOE lab or something like that, but people go to problem-solving centers.

They aim the solution not on some abstract thing, but on an RFP that says what needs to be done.

So that's one thing, the private sector. The second thing is even though you only have one person win, you develop teams of people looking at solutions to handle environmental problems, and these teams could produce a solution, which although it may not win this particular proposal, would be ready to go compete with that particular market somewhere else.

And then finally selected proposals would not only have an opportunity to assist the community and clean that site up, but then they would have established a proven record, and they would be able to perhaps develop a market. I haven't looked thoroughly enough into market development on this. That's the idea. Overlying whether this will work are two important things. Can the government develop standards and requirements? We don't know. That's one of the big issues about cleanup, what are your requirements to clean up, and particularly when you're talking about radioactive materials where you don't have cleanup standards.

The other thing is, are the markets there?

There's some question as to whether as big as the DOE market is, whether if we go to a market-driven system you're going to get anybody to show up. And what's interesting is that government cleanup -- This was presented by a consultant that did some work and solicited some input of venture capitalists, some people who put money in.

You see that government cleanup DOE/DOD Superfund is ranked as not a compelling market, compared to water treatment, infrastructure, or recycling or consulting. So we had some discussions in our meeting about this, and the company I consult for said, well, you know, "We're a defense contractor. It's plenty good for us. We'll do it." I took it back to my technology section. They said, "We'd never participate in that scheme because we have to put our own money up. If DOE wants it done, they put the money up and we'll come in and bid for them, and they can pay us." And I said, "Why?" The guy said, "The market isn't big enough." So it's kind of an interesting perspective when you think how big this problem is we have, and whether it's big enough, I don't know. I think if we went to one of the marketing people they would have said it's big enough. But I just put this slide on there as food for thought to give you an idea if you reach out for solutions and how many different parameters to the solution you have to touch before you get something that really makes sense. Whether this model makes sense or some other model makes sense, we'll be sifting through those models, looking at the market. We've got the venture capitalists there. We'll try to have people from the public come in and talk to us so that we have something that will work. We're working with -- luckily we have Ron Ross from WGA and their initiative. The Southern States Energy Boari, another from major alliance of states, wants to participate with us. The Inter-Agency Tecinnology Group that's working right now for the Federal Government is talking to us. The Department of Defense is committed to participating with us on 
this panel. And what works for DOE, they're going to try to make it work for them. But that's where we are. We're getting started. It's ambitious. It's going to be a lot of fun. I don't have anything concrete yet.

\section{CHAIRMAN COSTLE: Jerry.}

MR. CHRISTEAN: Just have a comment. You know, we're kind of used to negotiating with companies, and when it comes to that, their initial position is always going to be, "Hell, no, we're not going to put money into it. We're going to do this and we're going to do that, but we're going to be operating on somebody else's dough." I submit to you that if private enterprise could see that there was going to be revenue opportunities in a reasonable amount of time and they had some assurances that we were smart enough to draw up stuff that would give some assurance of that, that when you're looking at cleanup it's probably wrong to look at cleanup in terms of just DOE. I mean, the slide shows $\$ 200$ billion worldwide. We're looking for things for our people in our companies to compete in the worldwide market, and I think we'll all agree around the table we've lost ground of late and we're looking for ways to be a viable economy. Well, what better way than to clean up all the screw-ups in this country, this world! And so I say to you that we're just not looking at it right for one thing, and we're not looking at it like we're really serious about dealing with the companies. A typical example of this. I don't know the lady. I guess it's a lady. Claire Sink, is that a gentlemen? You can't tell anymore. Lady. Her response -- I just quote one shot out of the letter. "The private sector is focused on revenues for the next quarter." Now, there's no doubt that there are some companies that's exactly what their position is, but you can bet anything you've got that doesn't speak to all companies. But it does show a real negative point of view about somebody that's a pretty important person in this Division of Technology.

So I say we have to look bigger. We ought to be encouraging that. We ought to -- I don't know how we're going to do it, but you can bet that if the Department of Energy was clever enough to outline a program that there was some light on that pot of gold at the end of the tunnel there would be people to go through the tunnel with us because there are plenty of companies looking for new business.

And there is another thing about it, too. The company that's in there first has got a big jump, got a big jump, and I just hope that -- you know, we've always been for a position of encouraging American companies and American workers to do more, better. There was a time when we were the unquestioned leaders of the world. We all have doubts about that of late for good reason. But this might be the great opportunity. Instead of looking at cleanup like it's just one hell of a problem, maybe it's the best opportunity we ever had if we just get the right people engaged thinking rightly and thinking in a big picture way. So I hope that -- I hope we can help in some way. I don't know how, but we've got to keep looking for it, and we certainly can't buy into the only thing that the private sector is looking at is revenue return in the next quarter. That's wrong.

That's a wrong attitude, that's a wrong statement, and I'm done preaching. 


\section{CHAIRMAN COSTLE: Ken and then Bill.}

MR. AYERS: Tad, having to answer to a board of directors about profits and things, your model is good to a certain point, and you're asking firms to invest a large amount of their money and time over a 12,18, 24 month period, and then be eliminated, and then have to go through another round of competition. I would like to suggest that your committee take a look at a different approach to it that's similar. What they can do is -- and this is a problem you're going to have to get around -- is develop a performance criteria without specifying a specific remedy that they have to use. So if you get criteria and then allow the teams to come together to make a proposal where you can select it on the written proposal and go, the problem you have to overcome, though, is how do you get around that record of decision that specifies some kind of a remedy. And that is I think, right now, is one of the real driving factors in this, is keeping a lot of the design firms and a lot of the companies from being very innovative because they see the record of decision coming down, and that's what they're tied to. So if you can find some way, your group or your organization, find some way around the record of decision where you could specify cleanup criteria and parameters, but not a specific remedy, I think you'll find a lot more innovation available.

\section{CHAIRMAN COSTLE: Bill.}

DR. FREUDENBURG: I want to go back to Jerry's point essentially that the private sector is not one kind of critter, and this is brought home to me when two weeks ago I was at a meeting of this cornmittee where we were talking about nothing could be done, there was no technology development, and a meeting of the oil spill group that started meeting after the Oil Pollution Act was passed. And there, instead of having wringing of hands, there were hundreds of new companies out with every hare-brained scheme you can imagine for cleaning up oil spills, some of which looked as though they were actually going to work. It may be telling, however, that I don't believe there was a single defense contractor among them.

And, you know, with all due respect to a company that would hire somebody as distinguished as Tad McCall, you know, if the defense contractors of America are not lining up for this, since I'm a taxpayer, to some extent that's good news for me. I'd rather see a hungry new entrepreneur who has got new ideas that might just work for whom this would be a hell of a lot of money lining up for it, and to some extent I think it's good news. Sorry, Tad.

\section{CHAIRMAN COSTLE: Pat, you wanted to make a comment?}

- MR. WHITFIELD: Please, if it's all right. I just wanted to reiterate our history at Pad Nine and Pit Nine in Idaho, IL, where we used a model very similar to what Tad had put on the board. We went out with a competitive RFP, selected two companies who had to demonstrate proof of principal on their own money and meet the specs or they did not get paid, the cost being about nine or ten million each. And then if they both met proof of principals, specifications, they would then bid for the final completion, and only one of them would walk away with the job. So here's a situation where two companies were willing to put nine or $\$ 10$ million each to say they 
could meet the government needs, and I believe if you look at the Savannah River vendors forum where they invited a wide range of private sector to come in and attack a problem, we've gotten many, many proposals, and we're in the process of letting bids. So I think there's a lot of merit to what Tad had to say, and I believe there are companies out there who are willing to do it. I believe those companies may not be the traditional DOE $M$ and $O$ contractors because they are used to working on our money, but that's all right if other companies want to do it in the interest of getting into business and a new approach. So I would say that from my perspective, I didn't see anything wrong with Tad's proposal. It showed some innovative thinking in my mind.

\section{CHAIRMAN COSTLE: My co-chair, Al.}

CHAIRMAN ALM: I was going to comment that there have been examples of privatizing the environmental business. In the United States, up until 1986 a lot of sewage treatment plants were privatizing, and then with the change in tax treatment in the United States. But overseas you're seeing massive opportunities where basically, people are bidding on fixed price kind of jobs with a guarantee of revenues coming in, mainly in water and sewer projects. I think you're onto something interesting. I think you've got to get to the hard part now, which is, yes, that's a nifty conceptual idea, but how do you deal with problems like -- the problems of committing in our type of business. Are you going to be able to make all these things happen? What are your risks, liabilities, tax treatments?

Now, one suggestion I had, the Mesa Committee at ECI dealt with the same kind of issues, and they have a lot of information that could be helpful to you, Tad.

But I would say to move in this direction you really need to begin with pick and shovel work to understand what it takes to get a private sector combination.

Realize it's something different than what you have now. It will be still some of the same, but there will be a lot of different kind of folks. Really, people with very large amounts of cash, I think the utilities might be interested in this sort of thing because they do spin off a lot of cash.

CHAIRMAN COSTLE: It's also happened at a time where the financial markets are really down on environmental industries generally, partly because we've just proven that they are not recession-proof. Secondly, it's a little like the reaction atter the first big wave of biotech. The environment was the next new wave, and it's been very disappointing. A lot of the funds, mutual funds that have environmental funds are getting out of that business. They are going to reshape their funds into some sort of social responsible investing funds for a broader base because they can't find enough companies to justify a separate fund. And so there's a little bit of a credibility hill to climb on Wall Street, and that's important principally, Jerry, in response to your notion, you know, "Build it and they will come." It's in that business it's raise the money and they'll show up.

MR. CHRISTEAN: There's one little tax bill in Congress could change -- 
CHAIRMAN COSTLE: Could change the entire picture. That's exactly right. I think that will be a lot of the future in this business will be understanding how we raise capital, what we actually invest in and where we expect our return, over what time period do we expect returns, and that will take change -- what I would call a change in industrial policy in this country and that is, put another way, changing the tax code. That is our industrial policy is the Internal Revenue Code.

MR. CHRISTEAN: Only way we know.

MR. SMITH: I just wonder if a little bit of that retrenchment in the financial market and financial supporters comes as a response to that theme that we heard a few years ago. We can't find the technology. We can't do it. The kind of theme that we heard recurring and recurring instead of how pro-active we're going to be to go out there and develop the technology.

CHAIRMAN COSTLE: I tell you, what I hear from them, it's more we saw -- you know, we looked at all this environruental legislation, and we looked at the alleged price tags and compliance, and the government is going to get out and get it done, and none of it has materialized. The fact is a lot of companies are hurting because nobody is buying their services or their products. Buy decisions aren't getting made because there was a period where -- there's always an enforcement lag, and I think Wall Street typically underestimates the lag time it takes for these things to happen. And so now they just -- they don't believe the numbers. That will turn around. Jay.

DR. SORENSON: I'd like to share a concern with you. I heartily approve of the effort to proceed with new technologies and believe the solutions are going to be found with new technologies, but I also believe really that it's larger values that are going to draw the technological considerations. And I guess the operative paragraph in this letter that bothers me is the third paragraph, and it bears on a question that came up earlier in the day and says, "Upon careful analysis of the proposed model, there's community support for the premises of the model. You need to define, communicate performance-based criteria to encourage market-driven solutions, to stimulate economic growth," da-da, da-da, da-da, and develop a center for the private sector. There's nothing really about protecting environmental values, nothing at all. And I think that this committee has as its charter the concern really for environmental protection. So I would like this really to be one of its primary considerations in development of mechanisms to remove barriers to technology.

I guess really what also brings this to mind is that memo that I circulate as part of my letter from DeGrasse. I should tell you that I received a phone call from him just before I left for this meeting and then from one of his assistants, and they are coming out with a new draft, and they have heard really what some of the concerns are, and it's important that since we haven't had a chance to discuss that you do know that they have communicated that to me.

But on the other hand, I wonder really about the community reuse organizations, as much as I do this effort to proceed with technology unless there is, as well, a firm commitment. That is 
explicit. And that's the only thing that I would suggest, just being explicit in the effort to consider environmental protection as one of the basic mechanisms triggering the effort to proceed with technology, and then technology would protect the environment.

MR. CHRISTEAN: Tad, I'd like to respond to that. You know, maybe I'm naive, but I thought the reason for new technology was to clean up the environment, and so, you know, obviously I don't know who in the hell would object to some safeguards to make sure that the technology that they are talking about would be environmentally friendly, but I've always been under the illusion that we need that new technology badly for the very reason we've got environmental problems we need to straighten up.

DR. SORENSON: I would agree wholeheartedly with you, but, again, I would like to draw your attention to the distinction between remediation and restoration. And you can go forward with a number of new technologies that will remediate and destroy the environment. They are not environmentally sensitive or compatible. And some people will really be interested in technology for the sake of technology.

And if I can use in comparison the defense field, you know, the old saying used to be, "It's technology that drives defense." Well, I really would hope that we wouldn't come up with the equivalent of that for environmental protection. I guess I see technology as a means to an end. And the question is what is the end. And certainly for this committee environmental considerations I think are primary.

MR. McCALL: These comments have been very helpful to me and to the rest of the subcommittee. I just can't thank you enough. I think I gained an additional appreciation of why the PEIS Subcommittee might want to come to full committee.

CHAIRMAN COSTLE: That probably is worth some ice cream with your cake. Any further comments on that before we move into Environmental Restoration Cost Effectiveness?

DR. PAULSON: Thank you, Mr. Chairman. That new subcommittee which was created by resolution at the last meeting of the full board had its first meeting today. The membership roster is still open I should tell the full board. The current members, based on expressions of earlier interest and interest today, include Jerry Christean, Fred Donath, Ron Ross, Tom Winston and Ken Ayers. During the course of the meeting, we also had others, notably the two chairmen and Vicky Dastillung, who joined us, as well as some other guests and observers.

We had a full agenda, which included the circulation of a draft scope of work to guide analytic efforts by a not-yet-selected team of individuals or contractors to do analytical work for ourselves, which the subcommittee will be giving comments back to me on before they leave tomorrow. We had an excellent report from Fred Richards of the staff, who will be working with this subcommittee, who reviewed possible sources of information and analyses, not only from within DOE, but elsewhere as well. That was followed by an excellent brainstorming session by the board members present, not just the subcommittee, but the full board, on other sources of 
information from public and private sources. And that in turn was followed by an excellent suggestion from Pat Whitfield, who was also with us, that some of the analytic work that the subcommittee wants to do may already have been accomplished to a significant degree by prior DOE efforts. And so the subcommittee has agreed that most of its members will meet with DOD and DOE subcontractor personnel within the next four weeks to review the work that has been done by DOE, some of which has not yet been embodied in reports, therefore, we haven't heard about it, but which may be highly relevant, and may, in fact, save us a lot of time and money as a subcommittee. We're looking forward to that meeting.

We had a brief but very useful discussion on potential non-board members either to add to the subcommittee or to invite to join the subcommittee discussions. And the names of people that came up were drawn from the ranks of both practicing engineers as well as economists. I would say as chairmen we're interested in other suggestions of resource people from outside the family, as it were, to help the subcommittee in that regard.

And then we discussed, as I said, plans for a near-term meeting and a very rough outline of the schedule for future months' work. I would also like to report because the subcommittee members were very pleased at this that while we started late we ended early.

CHAIRMAN COSTLE: Any --

DR. FREUDENBURG: That's an ominous precedent.

CHAIRMAN COSTLE: Any comments or thoughts?

Jay.

DR. SORENSON: Would you explain a little bit more about the loss, the primacy of cost considerations in your committee's work?

DR. PAULSON: It's not primacy. It's an equal measure. We're interested in the cost and the effectiveness of environmental restoration technologies.

Let's call them traditional Superfund-type technologies as opposed to innovative technologies. And while I don't think the subcommittee has a consensus on this, at least one member thinks very strongly there will be robust data sets available on the costs of these traditional types of approaches, but not very much information on the effectiveness in terms of risk reduction, exposure reduction, and that sort of thing. An interesting prediction. If the prediction is true, it will be quite an important finding for our work.

CHAIRMAN COSTLE: Jeff.

44

MR. BRECKEL: Glenn, I have one question. 
DR. PAULSON: That's a good point, and maybe the subcommittee should think about this. At least the draft of the scope of work envisions cost to mean the cost of the remediation itself, not oversight or transaction costs, but the cost of actual field work, the cost of applying traditional technologies. The board was briefed on that recent report at its last meeting, which you were not at. Were you not there? I can't remember.

MR. BRECKEL: I was there.

DR. PAULSON: So we're familiar with that.

But our focus, at least as currently conceived, is a fairly narrow one to look at the cost of the technologies itself, not ancillary costs. But perhaps we should broaden it to, if we can, try to distinguish between the costs of the work and the cost of ancillary activities, nonremediation.

MR. WHITFIELD: I believe most of the data we've been accumulating will be non-DOE work, which is what you're after, Jim. I think it won't be DOE cost.

DR. PAULSON: Yes. I should have stressed that. I mean, the universe of data that we're after starts, but by no means ends, with what DOE has itself done. In fact, in particular, the removal and interim remedial actions that EPA has either done or induced others to do, particularly private industry to do, is likely to be a large part of the data set that we evaluate. We are interested, by the way, in leads from other board members to what would be the harder-to-get data on private sector cleanups where the data is not available from the public domain.

\section{CHAIRMAN COSTLE: Jerry.}

MR. CHRISTEAN: Jeff, did you want the floor?

Okay. I think he mentioned almost in passing, but if any of the other board members have a name to suggest of somebody that might be a really good addition to this subcommittee that's outside of the family, I know that would be received greatly. It would be a good help.

\section{CHAIRMAN COSTLE: Okay. Ron.}

MR. KUCERA: I have a 30-second update on the Subcommittee for Community Health and Workers Safety. Given the extremely tight schedule this time and with Shira being here and Jim Lapping, the co-chair, not being able to make this meeting, we're going to try to arrange a subcommittee meeting. But we have been working. 
Jim Lapping is attempting to memorialize and formalize in an interim report form our subcommittee's recommendations that were related to two DOE orders that cover the issues of workers safety on a DOE complex. In addition, Jim is also taking the issue of the migration toward OSHA regulation on the DOE complex. It was discussed at our last meeting and I believe is on the agenda for tomorrow. Jerry Christine, who's a member of our subcommittee, has graciously agreed to address the issue of workers safety on off-site -- or facilities that are off DOE sites where the workers don't come under DOE protocols and may not be notified or trained in dealing -- working in areas where there are radiation environments.

At the request -- or at the recommendation of Glenn Paulson, we are in the midst of reviews of the Defense Nuclear Facilities Safety Board publications, which I can tell you is quite time consuming. We are also finishing up reviewing DOE Orders that are relevant to the charge of the committee dealing with community health and workers safety, and we're also looking at NRC regulations that may have a tie. Our intent is to have a draft report to the subcommittee by May 4th, and then -- and I can tell you the report will be concise, it will be short and to the point, and I would hope to have comments back from the subcommittee so that we would be able to get a report to the full committee sometime in June.

CHAIRMAN COSTLE: Thank you, Ron. Glen.

MR. SJOBLOM: Pat Whitfield just reminded me of an item that's come to fruition related to what has just been discussed here, and we've been working on a Health and Safety Plan Guidance for the Environmental Restoration Program, and that has now just been completed, and I would like to get it out to that committee as soon as we get back and can get copies.

CHAIRMAN COSTLE: Okay. We're doing pretty well on schedule. I should tell you that we have I think by at least latest count 24 members of the public who would like to have an opportunity to address us, so I'm going to declare a ten-minute recess, and we'll try, since some of them are clearly here already, try to start the public comment session a few minutes early.

So at this point a ten-minute recess, and then we'll return.

(Whereupon, there was a brief recess.)

CHAIRMAN COSTLE: As we begin this portion of this evening's proceedings, I would like to take an opportunity to thank everybody who was involved in planning and carrying out the site visit that we all had an opportunity to share this morning. We had a number of people along with us. It was not strictly a DOE tour. And I was particularly grateful to the citizen representatives who were with us were there, and it was a very helpful tour for all of us. We saw a great deal in a compressed period of time. And so on behalf of all of us, thank you very much for that help, and to all of our guests who were with us on that tour.

At this point, I'd like to open the public comment section of this meeting and perhaps preface it by saying that we have now I think it's 26.28 ? 28 people who have asked for an 
opportunity to address us this evening. In order to give everybody an opportunity, and mindful of the fact that people have already had a long day before they've even arrived here, I would like to ask that the people who come forward to testify or to comment to us, if they would confine their remarks to within a five-minute window, if they can, that would be tremendously helpful. Now, obviously you will not be penalized if we start asking questions. But I would like to ask you to indulge us and try to summarize your comments in a five-minute period, less, if possible, and to also assure you that we'll take any written materials for the record and are anxious to have them, and also to the extent that any of you have material you'd like to send us subsequent to this evening, we will be happy to receive that as well. The first person that l'd like to ask to come forward is David Shorr from the Missouri Department of Natural Resources.

David, welcome. I also want to thank you on behalf of all the committee members for Ron's assistance in our work. He's been a very valued member of our board.

MR. SHORR: We like having him around. First of all, my name is David Shorr. I am the Director of the Department of Natural Resources for the State of Missouri. DNR is responsible for implementing the various environmental laws in our State. I am very pleased to welcome you all to Missouri, and on behalf of the Governor, we are especially pleased that you could take the time out of your busy schedule to view what we have to deal with right how with respect to our radioactive waste problems. I am especially pleased that you were able to view the sites in this area that have been contaminated with radioactive materials from the results of the country's nuclear weapons program. The first production waste in the atomic age was produced here in 1942 as a result of the uranium processing for the Manhattan Project, and some of them are still here today. We haven't lost any that I am really aware of. Not only are these the first wastes of the atomic age, but they are the most uncontrolled wastes resulting from nuclear weapons production.

Missourians are patient people, but we believe action on these sites is long overdue. Staff members of the Missouri Department of Natural Resources have been working on these sites for over 20 years. That's a long time to wait for results. During that time we've worked constructively, and I emphasize the word "constructively," with the United States Department of Energy and the United States Environmental Protection Agency to find reasonable solutions. After a lot of hard work, the three agencies have come to an agreement on the Weldon Spring site. As you saw today, work is progressing rapidly at that site.

We're very pleased with respect to some of the progress we have seen. However, any successes at Weldon are being overshadowed at the St. Louis FUSRAP sites by the DOE's chronic, unchanging reluctance to accept full responsibility for the cleanup of weapons waste now scattered over miles of our urban streets, drainageways, creeks, and dozens of private properties. Most of these property owners had no connection with the activities that produced the waste. It was careless handling on the part of the Manhattan Engineering District and the Atomic Energy Commission contractors or licensees that caused the legacy that we have today that is uncontrolled. 
The waste is uncontrolled by the DOE except at the Hazelwood interim storage site, and I believe you saw that storage site today, where there is at least a lease agreement with the property owner. In most cases, however, there is no institutional control of these materials, nor is there any physical barriers in most cases to prevent human contact with the waste or to prevent the spreading of the waste. The DOE claims to have no legal authority to prevent continued spreading of the waste. And except for the Mallinckrodt site, these land owners and their employees have no understanding of or expertise regarding the radioactive materials that may be under them.

The DOE's own draft baseline risk assessment for exposure to contaminants at the St. Louis site showed that several risk scenarios produce considerable health risk for present and future workers and contractors and for future potential residents at some of these sites.

At one site, the St. Louis airport site, no one is even willing to assume the ongoing monitoring, maintenance and security at the site. The City of St. Louis owns the property as part of the airport, but for years the DOE was the de facto operator at the site.

In July of '93, the DOE unilaterally announced that it was leaving the site, and the city has not taken responsibility. In a meeting just last week, both the city and DOE again refused DNR's request that they take responsibility for monitoring, maintenance and security at the site. In effect, SLAPS is an orphan site. There is no institutional control of any magnitude.

In the remedial concept that DOE has been discussing for the last year, the DOE has proposed to leave certain "inaccessible," quote, unquote, soils in place under buildings, roads, parking lots, levees, all kinds of other structures, if you will, unless the property owner, unless the property owner makes the soils accessible. The DOE is thus seeking to evade responsibility and liability for these contaminated soils and shift to innocent land owners, who in most cases are totally innocent victims of the careless practices of the Manhattan District and Atomic Energy Commission.

In addition, the DOE has no real plan for institutional controls beyond the vague hope that land owners will voluntarily accept a deed restriction. It is not clear to the department why any land owner would be willing to do this with radioactive material underneath their property.

The State believes that all soils should be cleaned up, or, if this is impractical, the property should be placed under clear and legal enforceable institutional controls which the DOE is responsible to enforce.

In any case, it should not be the responsibility of land owners in our area to clean up these federal nuclear weapons wastes. The extremely long half-life of uranium and thorium radioisotopes means that long-term solutions are required. The waste will become more hazardous over a period of several hundred years with the ingrowth of radium and the production of radon. The DOE's own guidelines for a disposal facility stipulate that it should be designed to be protected for 200 to 1000 years. The DOE proposes to simply place the waste on top of the 
waste at SLAPS, where waste is uncontrolled and in contact with our ground water. The State believes the waste should be placed in an engineered, lined facility which is designed to standards at least functionally equivalent to the Missouri Hazardous Waste Law. These are the same type of standards we asked for at Weldon, and, by the way, received.

In summary, the remedial action at the Weldon Spring site was well planned and is being implemented very well. As a result, Missouri said yes to the Weldon Spring project. We are willing to take care of our own waste problems. We did not ask the DOE to take them away, quote, "somewhere else". The DOE, however, has been unwilling to give the same responsible, reasonable approach to the St. Louis FUSRAP site. Missouri has said no to the DOE's proposal for these FUSRAP wastes in St. Louis.

I have been expressing our serious concerns about the project to DOE for the past year with what I would consider little results. I urge the Environmental Management Advisory Board to recommend that the DOE assume their full responsibility for these defense-related wastes and, quite candidly, quit treating them like an orphan and some subclass of Defense Department materials.

This is not a small level operation, as you've seen today. The waste materials are roughly the volume and scope of what we have at Weldon, yet they are treated as if they don't even really exist overall in the big matrix of all the cleanups that they are doing. I would welcome your questions, and I thank you for your time.

CHAIRMAN COSTLE: Thank you. Would any of the panel like to ask David any questions? David, thank you for coming.

MR. SHORR: Thank you very much, and welcome to Missouri.

CHAIRMAN COSTLE: Sharon Rogers, Missouri Sustainable Development Organization. Sharon, are you present? David.

David Hayes, the Laborers Employment Cooperative and Education Trust. Welcome,

MR. HAYES: Thank you, Mr. Chairman. I do have copies I think in sufficient number for the committee. My name is David Hayes. I'm the Midwest Tri-Fund Fund Field Coordinator, anc I'm appearing here today on behalf of the Laborers International Union of North America, the Laborers-Employers Cooperation in Education and Trust, the Laborers Health and Safety Fund of North America and the Laborers ADC Education and Training Fund.

We appreciate the opportunity to appear once again before this committee on behalf of the Laborers International Union of North America and its associated Labor Management Safety and Health, Training and Cooperation Trust Funds. LIUNA represents over 650,000 members, of 
which some 360 are construction laborers, the principal trade engaged in environmental, remediation activities.

As we have stated at each of your last or at each of your past hearings, our members have been a part of the nuclear weapons complex for half a century. They were part of the original construction crews that built the facilities, and they have been a part of the construction work force ever since, and they are and will be an increasingly significant part of the work force that will participate in the decontamination and decommissioning, demolition and cleanup of these facilities.

LIUNA has a significant interest in the environmental restoration program of the Department of Energy because its members are heavily engaged in the actual cleanup work on virtually all of the major nuclear weapons sites. We presented testimony in our cooperative program with contractors at the first meeting, and we also testified before the committee on LIUNA's model program for training workers for engagement in the hazardous waste cleanup activity. We continued to stress training because the nature of the exposures to workers by the waste generated by the weapons complexes, including substantial quantities of mixed waste, requires that experienced workers possess a high level of competency and proficiency in construction skills before they are hazardous waste trained and placed on the cleanup job. This is the basic requirement to assure environmental cleanup work is undertaken safely and productively.

On various occasions, we have also testified on the safety and health issues at weapons facilities. We do not have a higher priority for our international than to assure the safety and health of our members. We testified at your last hearing that we have particular concerns about the safety and acute and long-term health care of workers who will be undertaking the environmental cleanup in our society, particularly the cleanup at these weapons facilities. Worker, public and environmental protections, are a continuum that begins with the workers as they are first and worst exposed.

Despite the assurances from Secretary Hazel O'Leary, Assistant Secretary Tara O'Toole, and Assistant Secretary Tom Grumbly, we are now more than one year into this administration without DOE having a suitable health and safety and medical surveillance program in place for the environmental restoration activity. The Department has yet to issue a new guidance document on safety and health compliance even though a directive to do so has been in effect for three years.

The existing safety and health program for construction is wholly inadequate, as the DOE claims, and the evidence supports it has no way of enforcing safety and health programs at the subcontractor level. The DOE's urgently-needed construction safety and health program is being put in place, but it has taken three years to do so. The recent Construction Project Safety and Health Management Order DOE 5480.9A, which we assume has been approved, is an important, but only initial step in that regard. The DOE contract reform also requires construction safety and health accountability. It is not clear, however, when or by what process that will happen. The 
Environmental Restoration and Waste Management Program does not yet have in place an OSHA-type enforcement activity.

We continue to present these issues because this committee must stress the importance of health and safety issues during its deliberations. We will continue to offer our experience and expertise to the committee and department in developing the necessary safety, health surveillance standards that will lead to a comprehensive workers safety and health program. Indeed, we continue to see the ERER program undertaking major program review initiatives without taking into consideration worker health and safety. A current example is the February 22nd, 1994 RFA covering the decision-making programs associated with DOE's Environmental Restoration and Waste Management Programs. We are surprised at this omission. We believe that the occupational health and safety must be specifically included in any such program study.

Our joint labor and management Laborers Health and Safety Fund in North America has worked closely with DOE on many of these issues. We would be pleased to discuss with the DOE the inclusion of worker health and safety in these requests.

Our organizations have made multiple appearances before your committee in order to stress the urgency and the problem for our members to make clear to you our belief that worker training and safety and health compliance are the linchpin for success in the environmental cleanup program. We have stressed the integrated nature of our approach in emphasizing comprehensive worker training as well as a significant safety and health program. We have made very clear in our testimony in each hearing that these programs will not be successful without the full involvement and cooperation between the unions and the contractors in a labor management framework.

We now have regular training programs underway for workers at Hanford, Alamos, Savannah River, Oak Ridge, Fernald, FERMI, and Brookhaven, and we are regularly training DOE personnel at our facility in Sterling, Virginia. We expect to have training underway starting at the Nevada Test Site. We continue, however, to observe foot dragging by contractors and DOE field facility management in accepting our Krueger work and training program.

It is still not clear within the DOE as to who is in charge of actually ensuring safety and health compliance by contractors and subcontractors. There is still no comprehensive safety and health compliance program in place. There is still no credible construction safety and health program in place. While the situation has improved somewhat since our last appearances, the DOE continues to defy the will of Congress by not putting a medical surveillance program in place at these facilities.

The issues of workplace safety and health, worker training and worker medical surveillance remain the critical issues for the environmental restoration program. This committee must continue to remind the Department of Energy leadership that these issues must be addressed promptly by action. This environmental restoration mission may indeed prove a more hazardous mission than did its production mission. The time for endless study of worker safety and health 
issues is long past. The time for serious implementation of a comprehensive worker safety, health, training and surveillance program is long overdue. In that spirit, we wish to state for the record that we endorse and support the recent EH cleanup workers safety assistance initiative, which finally begins to establish a basis for environmental restoration, safety and health program execution.

CHAIRMAN COSTLE: Thank you, Mr. Hayes.

MR. HAYES: Thank you, Mr. Chairman.

CHAIRMAN COSTLE: Thank you, David. Would any of the panel like to address a question to Mr. Hayes?

DR. FREUDENBURG: I have what I hope is a simple question. Forgive me. As much as we appreciate your effort to keep this on the table because it's important, I don't know what the ERER program is or what the February 22, 1994 RFA is. Could you give me a one-minute summary?

MR. HAYES: I don't know if I can do it in one minute, and I don't have all the answers for you tonight, and l'd be glad to, if I could, get those answers to you, but it involves the environmental restoration program.

CHAIRMAN COSTLE: We'll be happy to receive additional materials. Glen.

MR. SJOBLOM: I think we have in the room people who can explain the February 22nd RFA. In particular, Michael Heeb can probably describe that later. I don't think we should take time in the public session about that. But it's basically -- it announces the requests for proposals to carry out Tom Grumbly's risk/threat analysis initiative that we have heard about in the past.

CHAIRMAN COSTLE: David, thank you again.

MR. HAYES: Thank you, Mr. Chairman.

CHAIRMAN COSTLE: Loraine Batton from the City of Berkeley.

MS. BATTON: Is it all right to talk there, or do I have to go up there?

CHAIRMAN COSTLE: Wherever you're comfortable.

MS. BATTON: My name is Loraine Batton. I'm a citizen of the City of Berkeley, Missouri. I work and live in the City of Berkeley. I'm representing myself as a citizen of the city.

I like the City of Berkeley. It's 57 years old, and so am I. I like the people. I like the ones I know, and I like the ones I don't know. They come to City Hall, and I give them hell. 
And we're important. We are important people.

We've been impacted already. We've been impacted by a wonderful sour-sweet relationship, but yet a wonderful relationship with the airport. We've gone from 20,000 people down to 12,250 people from 1960 to 1990 because of our airport. And yet we're friends with our airport.

We have a wonderful relationship with our airport. We've lost friends, neighbors, good elected officials, wonderful people to airport expansion, yet we have been impacted already.

We've been impacted by other things, yet we persevere, we hang in there, and we still consider ourselves a good city.

How much more is expected of us? I've been to meetings, a lot of them. l've listened to a lot of words about picocuries, millirems and SLAP sites, and I've taken an education that was brand new to me, and l've forgotten a lot of the words that mean this radiologic mess that we're in. I've talked to nice people. I've typed, petitioned, marched. I've listened to lawyers and listened to specifically very nice people. Why? Because they're talking about building a hot dirt bunker in our town. Where? On our ball fields, on our festival ground.

We are a uniquely wonderful city. We have the unique privilege of being 65 percent Afro-American, 35 percent white. Now our ballfields are closed. Now our festival is shut down. When we were playing together, we didn't care who we were. We played hand in hand, laughed hand in hand. I saw this because I was there. People came from all around. It wasn't a great big festival. It might have been one of the smallest festivals in money and prestige, but it might have been one of the greatest in human service rendered and the getting to know you, getting to know all about you. It was a valuable festival. The last one was in 1987. The last parade was in 1987. I went around that festival getting to know people with a great big button that said "Laurie Batton, City Clerk," gone up to people and said hi. You didn't know them. We were getting to know eack other. Sitting around listening to good music live, bad music live, going to circuses, little-bitty circuses and carnivals. I'm trying to paint a picture here of a very small hometown thing that was a good thing that surrounded us and impacted more than just the City of Berkeley that we have nc more. We don't have the land. We're land locked. That was our land. And, frankly, I loved the festival, and I loved the ballgames. I think we were better before they closed that down, before they shut us down, and I frankly think it's a sad thing. I wish I could be more dignified in this, and I certainly wanted to maintain my composure tonight.

But let us be environmentally sound in the greatest sense of the word by those wonderful social enhancing powers that can occur only out in an open field, together, united. We need this thing back, folks. We need it back. Should they replace this with a bunker? Can you do this thing? Should they replace this with a permanent storage of radioactive material?

They could do this thing. They could pour cement over this thing. They could gouge the land. They can put in steel and rock and they can put in the muck and the mire of radioactive material in this ground. They could cover it up and seal it until it is sealed no more. But if this 
happens, if this truly takes place, if you stand there on a quiet evening and you stand there looking at this bunker where we played in the still of the evening, if you listen very quietly, you may be able to hear the laughter of people at play. You may be able to once more hear the happy phrase, "Let's play ball!"

America, this could happen to all of us, all cities in America. This could establish a precedent placing other radioactive bunkers in other metropolitan places in the midst of people. I could give you statistics, and others will do that. I don't need to do that. All the statistics and criteria that you would maybe want to know why this should not happen. I left fliers back here if anybody wants them.

You think it's a Berkeley problem, a North County problem? Uh-uh. It's an American problem. It's a problem for all Americans to address. Tell them no.

People, yell, scream, holler, kick your feet, if necessary, but do it with dignity for the dignity of the cause. I'm saying give us back our land, let us play ball.

Lee.

CHAIRMAN COSTLE: Thank you, Loraine. Lee Brotherton, St. Louis County Executive.

MR. BROTHERTON: Thank you very much. I'm Lee Brotherton. I'm the Director of Transportation and Environmental Policy for St. Louis County. Welcome to St. Louis County. I'm representing Buzz Westfall, who is the County Executive.

I won't take a lot of your time. I'm aware that you've been to see the downtown site and the sites in St. Louis County, and we want to bring you the message that this community, the County Executive in particular, as the leader of this community of a million people, feels that it's simply inappropriate to have permanent storage of radioactive waste in the middle of a highly populated area. We don't consider our community simply a NIMBY situation. We believe that it's simply inappropriate to put 900,000 cubic yards of radioactive waste in the middle of the largest metropolitan area in the state of Missouri. The citizens of St. Louis County and also the citizens of the City of St. Louis, which are completely distinct jurisdictions, which you may have wondered today, in 1990 voted overwhelmingly, in majorities above 80 percent, that they did not want this radioactive waste permanently disposed of in our community. That's a pretty strong statement. It's rare that you get numbers like that in a community.

We feel I think on a nearly unanimous basis that the people of the St. Louis area did their duty for our country during World War II. We produced what we were asked to produce, and now it's the moral responsibility of the Federal Government to clean up the waste permanently and to remove it from our community. We are not saying that just anywhere but here. We simply think that overall it's inappropriate for the Federal Government to pursue policies that place large amounts of radioactive waste in densely populated areas. That's the bottom line here. And if there were wide-open spaces left in St. Louis County, perhaps that would be an appropriate place for the waste to go, but we don't have that anymore. As I said, we have a million people. The 
City of St. Louis has nearly 400,000 people. We'd like you to take the message back to Washington very clearly that in terms of policy the Federal Government should not pursue a policy of placing large amounts of radioactive waste in populated areas.

Thank you very much.

CHAIRMAN COSTLE: Thank you, Lee. Mr. Robert Heuremann. I hope I pronounced that correctly, City of Hazelwood. Welcome.

MR. HEUREMANN: I'm Bob Heuremann. I'm City Councilman for Ward 4 in the City of Hazelwood. On behalf of the Mayor, Council and citizens of the City of Hazelwood, I want to thank you for the opportunity to comment to the board members concerning an issue of environmental management which we feel is extremely vital to our community.

Radioactive waste generated by agencies of the United States Government in the processing of uranium and thorium for use in nuclear weapons production is currently located in highly populated areas in the City of St. Louis, St. Louis County, Missouri, including Department of Energy remedial action sites identified as the St. Louis downtown site, the St. Louis airport site and the Latty Avenue Hazelwood interim storage site.

This waste impacts upon transportation in the metropolitan St. Louis area, being located along major railroad and truck routes as well as St. Louis Lambert Airport, where 19,000 people are employed to handle the 1200 flights serving more than 52,000 passengers on a daily basis. In addition to the more than one-half million people who reside within a ten mile radius of the St. Louis County remedial action site, approximately 30,000 people, many from outstate areas, work at McDonnell Douglas Corporation facilities here and thousands more work at the Ford Motor Company assembly plant and numerous other major businesses located in the area.

In 1990, an advisory proposition was submitted to the voters of the City of St. Louis and St. Louis County for their guidance as to what should be done with this radioactive material. The voters responded overwhelmingly with 85.6 percent in the county and 80.7 percent in the city urging removal of the waste from this highly-populated area so it could be located permanently and safely processed in an area remote from the citizens. The Hazelwood City Council remains adamantly opposed to any interim location of any radiologically-contaminated soil in the City of Hazelwood.

Each time there is a so-called limited cleanup, additional material is distributed along the streets of our city. We feel the only time the soil should be disturbed is if you were actually going to move it out of Hazelwood and away from this urban area to a much less populace area for its permanent storage. We are frequently subjected to requests from the United States Department of Energy and from the Missouri Department of Natural Resources to authorize more limited interim cleanups and to bring materials from such cleanups and from any other contaminated locations to the Hazelwood interim storage site. 
We oppose moving another cubic yard of contamination to this property. The DOE has advised us this could perhaps accommodate at least perhaps three times the number of cubic yards of material currently stored there. We are totally opposed to any such increase in contamination in this area and vigorously object to any proposal which would import waste to these sites. We understand the need to remove the contaminated soil from various properties around these storage sites, but we must protect the health and interests of all citizens of Hazelwood and again urge you to take action to move this dirt away from this area. Each time soil is moved, more contamination is created. That does not seem like a practical, productive or efficient way to resolve this problem. The DOE is now suggesting it might be effective to make a permanent storage site at Lambert St. Louis International Airport. We are for the reason previously stated totally opposed to any such development which would keep this contamination in the midst of so many people and greatly increase potential for catastrophe for all of the citizens, both Missouri and other States, who work here and travel through this area.

Again, thank you for the opportunity to share our views with you. We feel it is imperative this local contamination be removed from the greater metropolitan St. Louis area as quickly as possible. Thank you.

CHAIRMAN COSTLE: Thank you, Mr. Heuremann.

MR. HEUREMANN: Any questions?

CHAIRMAN COSTLE: Mr. Roger Pryor, Missouri Coalition for the Environment.

MR. PRYOR: Thank you. It's rare you walk into a meeting and get called the same moment. Thanks for the promptness.

It's good to be with you again. I enjoyed being with most of you this morning on the tour. l've had a chance to relax and refresh myself. I hope you have as well. Not yet. I see a lot of shaking heads.

Well, I won't belabor all the comments that we -- that Kay and I had a chance to make with you this morning. I did hand out some written remarks, and I know I ran out, and I brought some extra copies, and I thought I'd just pass those around. Anyone who did not get one this morning, I'm sure you'll anxiously read this before you turn in tonight. We also -- I don't know who your hearing officer is or who your chief person is, but we have one other document I wanted to leave with you, and I don't have multiple copies of this, I'm sure you're thankful, but back in 1990 there was a hearing on the St. Louis sites as part of the Programmatic Impact Statement, and we, the Coalition for the Environment, or Resent, produced what we call our little red book here, which is a collection of some of the citizens' comments that were presented at that time, and we think they are still valid today. I pass this over.

CHAIRMAN COSTLE: We'd be happy to have that for the record.

44 
MR. PRYOR: Very good. Thank you. I think some of the folks that are in there no doubt are in the room still here again, once again. I think that you'll find, and I'm sure in the comments you've heard already this evening, that there's been a high level of consistency of public concern over the last decade or more that there's been active consideration of what to do with the material at the airport, at Hazelwood, at the downtown Mallinckrodt site, and at West Lake Landfill, the various vicinity properties, the haul routes, and, of course, the Weldon Spring properties. I think that the tour today -- I'm not going to address my comments right now to the Weldon Spring property, but to the St. Louis sites because I think the tour today showed you both the diversity of sites, the fragmentation of authority for those sites, in some cases the lack of clarity about authority for some of those sites even, and the situation in St. Louis because of that has added to the apprehension that people have about this material, has added certainly to the frustration that everyone has, including I'm sure DOE. Some order needs to be brought out of this chaos of these 80-plus properties that are in St. Louis city and county. I think my understanding -I haven't read a lot about other FUSRAP sites. I have read about some of them. My understanding, this collection of properties in St. Louis is fairly unique among the FUSRAP sites in that it is so spread out, there are so many different properties, so many different ownerships, with so little actual federal entitlement to anything.

The people in St. Louis City and County have spoken through referendum. They've spoken through their elected officials, some of whom are here tonight. They've spoken at countless meetings and gatherings by the Department of Energy and others. One of the comments I heard made on the bus today was that there was no way that -- someone was actually saying that people's attitudes haven't really changed much since the material was hauled from St. Louis out to the quarry out at Weldon Spring. At that time it was considered away.

It was away from downtown. It was an area of St. Charles County that was not heavily developed, and it seemed liked an away -- and I agree. There is no away. In fact, one of the -probably the most insidious things about the material we're dealing with here, whether it's nuclear bomb waste or whether it's civilian-produced nuclear waste, is that there is no away.

Frankly, from an environmental point of view, the most important thing we could do is stop making the stuff, and that should be the first step. That still doesn't answer the question of what - that doesn't answer the question of what to do with all the material, the legacy that we've been stuck with. It's very difficult -- I consider myself to be fairly egalitarian. I consider myself to be someone who worries about -- tries to worry about being fair. And one of the problems that we always have when we address this waste is if we take it somewhere else, aren't we just screwing somebody else. And ultimately the answer is yes. Someone, whether it's, you know, a lonely rancher spreading over thousands of miles of, you know, desert territory somewhere, or whether it's just jackrabbits. Ultimately someone else's habitat and home is going to be threatened by this material.

Having said that, it seems only prudent, and common sense would dictate that if the material has to stay in isolation and under surveillance and monitoring for decades, for centuries, for millennia, the last place it makes sense to do that in is a heavily populated metropolitan area 
like St. Louis. We're not special. We have no -- St. Louisans aren't entitled to treatment that is better than anyone else in the country. But there are places that this material could be taken, where the exposure, the risk to the population, would be greatly reduced simply because the numbers would be greatly reduced. There are many places in the country where geological integrity of potential sites would be much greater than the sites that you saw today. I can't imagine in today's world, in today's standards, and what we now know about this material, which we didn't know just a decade or two ago when this material is being so cavalierly moved around from spot to spot.

UNKNOWN SPEAKER: Not true, Roger. We knew about it back then. We knew as much back then as we know now.

MR. PRYOR: I disagree. And the public didn't know. And if there were some officials and some scientists who knew, they certainly kept their mouth shut. That's not the case today. The decision to keep this material in St. Louis is a terrible decision. It is a decision that will never be supported by the local population. We realize the Federal government may have abilities to force this on us, but it's not something that St. Louisans are going to take lightly. It's something that will ultimately have to be moved at some point in the future. You may put off this decision a decade or two decades or a century, but all you're doing is making a very narrow-minded stop-gap measure, and I hope that this advisory board would express the concerns that you'll hear tonight and you have heard today already to the people that you advise and urge them to look for a solution that makes more sense, has more community acceptance, and really addresses some of the issues that need to be addressed.

The thing that right now is driving this issue is dollars. You heard that today very clearly that if dollars weren't an issue, there are a lot better suggestions of what to do with the material than are being actively considered.

People are very frustrated with the government because of the kind of money they waste on things which they think are unnecessary. I put it to you the folks in St. Louis do not think that spending money to clean up this material and get it out of our neighborhoods is an unnecessary expenditure. They would support that wholeheartedly, as would citizens in any such community with this kind of material. And I think to use the dollar value as a criteria for what will ultimately affect a large area of St. Louis is a wrong criterion, and I would just urge you to consider that very carefully and report to the folks that you make your knowledge available to to urge them to think differently about this and act accordingly. Thank you very much.

CHAIRMAN COSTLE: Thank you, Roger.

MR. SMITH: Can I ask you a question before you --

MR. PRYOR: Absolutely. 
MR. SMITH: Just from our look at the site today and our questions about the situation, it appears to me that the current structure of the Atomic Energy Act severely limits the ability of other people to leverage a decision on what to do about these radionuclides spread around the city. Since they aren't hazardous constituents, it's basically a self-regulating situation for DOE to make the decision about what to do here. That's my understanding of it.

There's a movement on in Congress. It's specifically in the Committee on Natural Resources Subcommittee on Energy and Mineral Resources to look at external regulation of Department of Energy facilities, and I happen to know from talking with counsel of that committee and members or other people who have gone to testify before that committee that they are looking for examples where the current structure of the Atomic energy Act prevents an effective partnership between the Federal government and local communities and States to deal with situations like this. This is a situation where essentially the Department of Energy can wrap itself in the cloak of the Atomic Energy Act and make these decisions unilaterally, and on their own time frame. So I wonder if you might want to consider and have your people consider making some contact with the Committee on Natural Resources. The counsel to that committee is a gentlemen named Dean Tousley, T-O-U-S-L-E-Y, and they might like to be made more aware of how the Atomic Energy Act plays into situation like this.

MR. PRYOR: Thank you. I have just one suggestion. Let me just add that it's not only the AEC Act, but it's also Superfund, CERCLA, SARA Amendments and the fact these Superfund sites -- that they are owned by private parties or city governments or whoever, and the potential responsible party aspect of that has also made it very difficult and complicated and has held sort of a veiled threat, maybe a real threat, certainly a veiled threat over the heads of many people on these sites. I don't think that was the intent of that law either, but thank you for the suggestion.

CHAIRMAN COSTLE: Thank you, Mr. Pryor. Just a reminder to everybody that given the number of people who would like to express themselves tonight, we'd like to try to honor the five-minute rule. As you can observe, I'm not being terribly strict about it, but I'm going to ask my colleague, Bill, if you would just slip people a note so they know that they've had five-minutes, and we'll trust that everybody's interest --

DR. FREUDENBURG: He made me do it. He made me do it. Hello.

CHAIRMAN COSTLE: Tony Green, Councilman, City of Berkeley. Rebecca Wright?

MS. WRIGHT: Hello. My name is Rebecca Wright, and I'm a citizen of St. Louis. I moved to St.Louis -- or I moved to S-rissouri in 1958 from downwind Hanford in Washington State

Across the river in Illinois stands Cahokia Mounds, the remains of an ancient civilization. The people who built the mounds inhabited the largest known population center on the North American continent in the 12th Century. It was larger even than London at the time. 
Those people vanished over 700 years ago. Archaeologists speculate that the civilization broke down due to the exhaustion of the environment and resources and because of poor judgment of its rulers. In part, they base their speculations on what they see happening to modern population centers.

Today our population center, the City of St. Louis, is facing critical choices that will affect the health and vitality of its people now and in the future. Today, scientists and citizens are making choices which may affect whether St. Louis continues to be populated or is abandoned by our descendants. We are considering what to do with a million cubic yards of radioactive waste.

In spite of the non-binding referendum in 1990 in which citizens voted overwhelmingly against the airport site, the government is again proposing to establish a huge mound of radioactive waste at the airport which will stand as monument and be radioactive for tens of thousands of years. This waste was left from the Manhattan Project over a quarter of a century ago.

Scientists, engineers and bureaucrats can visualize the atomic structure of radioactive isotopes, computer generated structures, equations and schematics, but they have lost site of the human context and the real effect of ionizing radiations. Very few are willing to acknowledge the tell-tale line connecting clusters of disease to the radioactive debris left from manufacture of the bomb.

The atomic bomb was developed because it was devastating. We in St. Louis were spared the catastrophic detonation of a bomb, but we now live with a micro-timebomb of malfunctioning strands of DNA affected by ionizing radiation, this waste. Scientists have written volumes of the ill effects of radiations. The government has developed a huge bureaucracy to deal with radioactive waste. The United States is crisscrossed with trucks hauling radioactive waste trying to get rid of it to remove it from population centers.

No expense was spared in developing the bomb, but ever since then officials have been trying to get away with minimum effort, cheap stop-gap remedies in dealing with the waste, putting tarps over piles of dirt, buildings gabbian walls that leak like sieves in an attempt to contain this stuff. For almost half a century it has been blown by the wind, carried off into creeks, sinked through soil into ground water. It has been hauled legally and illegally from one place to another, dumped and spilled, contaminating roadways along the hauling routes.

Today, there are still several contaminated sites in St. Louis. The proposed airport dump site is 90 acres. It includes 20 acres which already contain some of the radioactive waste. If all the materials were collected from St. Louis sites, there would be about one million cubic yards of waste from the Missouri side of the river. In all probability, there would not be enough room at the airport site. Storing this waste in a bunker at the airport would require monitoring of the air and water. It would also require the security, integrity of the facility for the foreseeable future. It would require continuous surveillance. 
A mound of radioactive waste would bring land values down. It would stymie prudent development of businesses and neighborhoods and expansion of the airport. A site at the airport would detract from the desirability of St. Louis as an international port of call. There's also the danger of a plane crash which could breach the security of a waste site. In addition to accidents caused by human activities, the facility could be damaged by flooding, which St. Louis knows well. Flooding is a frequent occurrence on the Cold Water Creek, which runs through the area, not to mention the potential for earthquakes.

It is criminally irresponsible not to consider the potential hazard of such a site to current and future generations. The waste should not remain in the city. The government is proposing to move this waste. Once a truck is loaded, it should be hauled out of St. Louis to a site that has already been sacrificed, such as the Callaway nuclear plant site. It already contains 20 billion curies of radioactive materials in a reactor vessel and hundreds of millions of curies in the pool where they store the highly radioactive spent fuel rods. That site already must be forever secured and monitored for air and water and for all of the foreseeable future. In Texas, Colorado, New Mexico, and Arizona, all over the west, trucking companies such as the M.K. Ferguson, have developed harbor trucks in which the waste can be contained for transportation. The trucks do not drip. The waste is sealed in. And each truck can carry hundreds of cubic yards. Such trucks can be used to carry St. Louis' waste, but once the waste is loaded on the truck, get it out of town.

The proposed dump in the middle of St. Louis is no more than an experimentation on human beings without their consent. Remove the radioactive waste from St. Louis and haul it to an area such as Callaway which has already been contaminated beyond restoration. Given that nothing we can build will last for the length of time it will take this radioactivity to become harmless, get it out of town. Thank you. Mayor.

CHAIRMAN COSTLE: Mr. Bill Miller, Mayor of the City of Berkeley. Welcome, Mr.

MAYOR MILLER: Thank you very much. Good evening, everyone. I just want to take just a few minutes to sort of offer a reflection. I don't want to be one that will come before your board and swear that I know all about the situation here. It just appears to me that for some 17 years of my life as an official with the City of Berkeley I have sort of grown up either playing softball on this field or relatively in the last ten years, rather, being a student of first the NRC, then DOE, then EPA, and then DNR, which is Missouri here, about the situation. I have heard all of the reasons first that we should not have any concerns about what was out there. As a matter of fact, we were told kids play on the diamond, and in order for it to affect them, they would need to eat a certain amount of dirt.

This was what was told to us initially.

Well, what we did is we closed those fields to those kids because we were concerned about the inherent danger, especially in light in going back and seeing these newsreels of all these peopl watching this mushroom cloud that supposedly was not going to do any harm to them. And so 
consequently we decided that it would be best for the health of our people and those individuals that were on that field to close it.

I say that to say in looking at your resumes here or vitaes, you guys are much more knowledgeable.

The reflection that I want you to just take back to Washington when you do your final -- or your proposal is to first look at the law that mandated cleanup of that site. When Congress first mandated that cleanup, they only talked about 25 acres. It was the 25 acres.

That's like you saw the little triangle. That was the site that Congress initially intended, is my interpretation in talking to one of the Congressmen that was there, that that's all it really meant. And I heard someone else say under AEC guidelines that perhaps the DOE right now has taken this and has expanded it. My concern is that it has been expanded way, way beyond what Congress intended, and I ask that you go back to look at the intent.

I also want to kind of stress the rights of the local citizens. I have some serious concerns with what I hear is about to happen, and I want to share one thing with you. The City of Berkeley zoned that area, the area that is being proposed for the site, the site to construct this bunker, that area is zoned a park. I am under the belief that in the State of Missouri and under the Constitution of the United States that citizens have a right to zone and live how they wish to live. This property was zoned way, way before anyone knew that it was contaminated. And I ask that you consider in your deliberations that if this site is permitted to be built it would first have to go through some legal maneuvers because it is still zoned a park. It is not permissible to build such a bunker on a park. If, in fact, the Federal government is permitted to come in and do away with local zoning for this purpose, then by right they can do away with any local zoning anywhere in this country for any purpose, and I don't think that that was the intent for local jurisdictions when they zoned to have others to simply come in. I realize there's an eminent domain, but we're not talking about taking land. We're talking about the use of land.

And I guess last I just want to just remind you of that land to me sets in a floodplain. It sets in a glide path. It sets in one of the most densely-populated areas, areas that grew after -that soil was brought there not knowing that it was contaminated. It sits in the middle of one of the largest employers in the State of Missouri. It sets within a three-mile radius of probably a half a million people. And I am convinced that once the construction of this type of thing were to occur, not only will the businesses suffer, but also those residents who have property. No one is going to want to move into that area. Therefore, it will lower the property values and the quality of life of those individuals that live near there.

I would like to see that recommendations go out so that there is not erosion of local zoning, that it not be attempted nor condoned. I would also like to see the immediate action -that immediate action be looked into to remove all waste from the site, not try to find a place to store it on an interim basis or on a permanent basis, but simply be removed. It is an American problem. It is not necessarily a problem of Berkeley, Hazelwood and St. Louis County and St. Louis City. 
And, last, I would ask you again to go back and review the Congressional mandate to do something with the site because I do not believe that they intended this site to probably grow into more than 100 acres. Thank you, and I'll answer any questions.

CHAIRMAN COSTLE: Thank you, Mr. Mayor.

Shira, you had a question? I'm sorry.

MS. FLAX: First off, I really want to thank you and all the people who have preceded you. You have told the board a very important message, and, quite frankly, a message we did not get when we toured the site this morning.

I have a question for you. I work for an agency of the U.S. Public Health Service. Can you tell me when was that ballfield closed?

MAYOR MILLER: May I refer to my City Clerk?

MS. BATTON: Our last festival, our last parade, our last ballgames were in 1987. It was our fiftieth anniversary, and it was a sad day.

MAYOR MILLER: 1987.

MS. BATTON: We wanted to keep them.

MS. FLAX: I understand that my agency is doing work at Weldon Spring, and I will ask them to contact you because the children who played there on the ball field should have their health, you know, looked at because my understanding is that the ballfield was over an air path.

MAYOR MILLER: I may have to add, I think you're looking at a very large problem. Not only was it people that played there from Hazelwood and the City of Berkeley. They are from all over St. Louis County. McDonnell Douglas had at one time 30 different teams that played ball on those fields, and from all over the area, people played soccer from all over St. Louis County. So I would have to suggest that you're looking at a very huge problem and a concern that we all have.

CHAIRMAN COSTLE: Jerry.

MR. CHRISTEAN: You raised the issue of zoning. Have you guys given any thought to taking them to court, challenging the constitutionality of that question?

MAYOR MILLER: At this particular point, all we've asked for is for the property to be cleaned. 
It was about that time that we learned that the St. Louis area was in the path of fallout from a great many nuclear tests and that strontium 90 was arriving in our babies' bones by way of their mothers' milk because their mothers drank milk, which came from cows which grazed on grass in the fields where the radioactive debris was falling. That was when we founded the Committee for Nuclear Information. And most of you are too young to remember it. Of course, you were one of the founders; weren't you? And we began to prove that long-lived strontium $\mathbf{9 0}$ was in our children's bones by examining the mineral content of their baby teeth, the Baby Tooth Survey. And some of you are young enough so that if you lived in St. Louis then your baby teeth would proudly have gone to the Baby Tooth Survey instead of the Tooth Fairy or both. That strontium 90 no doubt is still there in the bones of those children, now grown.

But we halted above-ground testing and we learned to speak truth to power, the Quaker saying, "to take citizen concerns to officials in power." We didn't know then that a major part -- or what a major part nuclear energy would play in our lives, nor of all the secret activities engaged in by the Atomic Energy Commission. We didn't know that nuclear weapons were being produced in the City of St. Louis or that there was a uranium processing plant at Weldon Spring. Well, we had no warning when dangerous debris was being hauled from the Mallinckrodt plant in the city to the airport and scattered, the same debris being scattered all along the sidewalks and pavement and playgrounds along the way. And it was long before we understood the hazardous nature of what 
was stored underground near the airport and what had been dumped in the quarry at Weldon Spring.

Now under Secretary O'Leary, under her good, new openness initiative, we learn more and

And under this administration I believe there's a spelling out of the vulnerabilities of spent fuel storage, so that an informed public will be able to influence policy. As the Department builds better rapport with the people, I urge it to pull away from nuclear programs, both weapons and energy, and focus on safer, simpler, saner forms of power that are more people friendly.

Nuclear energy has not been friendly, whether in war or peace. Always it menaces us with colossal devastation, not only from the bombs of a future enemy or terrorist but from the potential of flammable gases in waste storage tanks. The cleanup and storage costs are so great that our great-great and great-grandchildren will be paying for the nuclear waste from World War II. And they will still be worrying about guarding, protecting themselves from it. They may then know more about the harm nuclear energy has done to us or, more correctly, to them for if we have caused substantial genetic damage our great-great-grandchildren will know it. Leo Duffy, a former Assistant Secretary of the DOE said clearly that we simply don't know what to do with our radioactive waste.

I have one suggestion, though it may not be taken seriously. If NASA wishes to justify its cost to the taxpayers, let them carry a payload of spent fuel on each mission and dispose of it far out in space. As long as we are to continue to support one space voyage after another, we may as well gain a slight diminution of nuclear waste on each flight.

It seems perfectly clear that we must end the use of nuclear power as soon as possible. First, put your nuclear weapons scientists and engineers to work to perfect effective cleanup technologies, then your most inventive minds to work on new technologies for energy alternatives.

It is certainly the job of the Department of Energy, one, to find the alternatives that pollute the least and, two, to educate the country in the importance of using alternative environmentally-sound fuels. Even subsidizing such fuels will be less costly than continuing to create the waste. Furthermore, it is certainly immoral for the government or industry to put communities at risk as we have, places like St. Charles and Hazelwood.

I'm submitting a fact sheet on childhood leukemia in St. Charles County which shows that from 1980 to 1990 there was a significantly higher number of deaths among girls under 15 , seven deaths compared to the expected number 2.8 based on national data. It also shows the number oi new cases of leukemia from 1985 to 1990 for females under 15,12 cases, significantly higher than 
the expected number of 5.4. And in women aged 15 to 44, there was a significantly higher number of cases, 14 versus 6.3. And again in females and males combined at the same age group, 23 cases versus 14.5 expected.

Now, we cannot show that these deaths, cases of leukemia, are related to the radioactive content of the quarry adjacent to the water supply, but many other factors besides radioactivity can be implicated, but it's unfair to subject parents in one community such as this to fears that are created by the numbers of leukemia cases when our government is not doing all that it can to eliminate the buildup of additional piles of menacing contaminants. Thank you.

CHAIRMAN COSTLE: Do we have a copy of that for our record?

MS. GUZE: I left that with John; is it?

CHAIRMAN COSTLE: Thank you. Lewis Green.

Welcome, Mr. Green.

MR. GREEN: Thank you, Mr. Chairman, and members of the board. I appreciate the opportunity to appear here today. I have a copy of what I propose to say, which I can leave with you. My name is Lewis C. Green. I'm a lawyer with offices in St. Louis, Missouri.

And I'd like to ask you to give your attention to two problems of substantial concern to us here. I'm afraid you've already heard a good bit about some of them, but I would like to urge that you do what you can to persuade the Department of Energy to bring a little bit of common sense to bear on the problems that we have here. You've learned by now and seen and heard a lot about the radioactive waste here in St. Louis County at the airport and associated sites. I think you are well aware of the fact that everybody acknowledges we have a problem here, that everybody acknowledges something has to be done about it. The DOE plans to scrape it all up and do something with it. To do anything with it, it has to be scraped up from where it is and . collected and put somewhere. The question is then where is it to be put. The fundamental part of the answer to that question should be obvious to everyone. The worst possible choice of a site would be a site in a heavily-populated urban area. These wastes have very long lives. No matter what the scientists may tell you, no one can be sure that these wastes will be adequately monitored in future centuries and that they will not in one way or another leak out and cause harm in future centuries.

Efforts to insulate these wastes from the environment will not necessarily be entirely successful. Nobody can guarantee that they will be successful. Therefore, it follows, I think to almost anybody's common sense, that those efforts to insulate these wastes from the environment should be made in a location which is not densely populated. One such location exists less than a hundred miles west of here. At that location in Callaway County, we already have large quantities of high-level nuclear waste because of a nuclear power plant located there. That plant produces more than 99 percent of the radioactive waste in terms of radioactivity in Missouri. It will be 
there for the indefinite future. Although the government likes to talk about plans to dispose of it, nobody has found any satisfactory way to do that. It will be many, many years at best before it's put anywhere else. So it will be there for a long time.

In addition to that waste, of this waste here from St. Louis and St. Louis County, contained as best we can contain it, would add little in terms of risk to human health. The risk added by transportation of that short distance with good highways would be relatively limited. There are more than 6500 surplus acres available around the Callaway plant site. The people of the St. Louis area, as consumers of Union Electric's electricity, have already paid for those acres, which are now owned by Union Electric, and they keep on paying for them every year with supporting Union Electric's recovery of the property taxes which financed the Callaway County government and the schools. Union Electric could make the needed acres available.

Alternatively, both the Federal and the State governments have the power to condemn whatever portion of those acres would be needed for the disposal of this wastes.

In summary, radioactive waste should not be retained in the middle of a densely populated area. There are alternatives, including one obviously sensible alternative readily available, and I respectfully urge that you advise DOE to bring common sense to bear on this question, choose a site removed from urban populations, and evaluate in detail the Callaway County site.

The second point to which I want to direct your attention concerns the terrain at the Weldon Springs site, with which I believe you are now familiar, and I think you understand that DOE proposes disposition of hazardous waste at that site.

The Weldon Spring terrain is karst. That may not be familiar to all of you. You probably didn't all grow up in Missouri. Karst is limestone with percolating ground waters and underground streams. That's what it is. And there's no dispute that's what we have in St. Charles County. Everybody agrees with that.

Karst terrain is obviously unsuitable for the disposition of hazardous waste because it leaks out. It leaks through all this limestone, through all these percolating underground streams. Everybody agrees with that proposition. Until recently, the regulations of the Missouri Department of Natural Resources explicitly listed karst terrain as one of those kinds of areas where hazardous waste sites were simply forbidden, a very sensible regulation. Nevertheless, DOF embarked upon an effort to dispose of hazardous waste in this karst terrain or contain them for many years there, and recognizing the absurdity of this proposal, various government officials have attempted to conceal this folly. For example, DNR was persuaded to amend its regulations to take out the word "karst" from those areas listed where it's prohibited, where disposition is prohibited. Similarly, a governmental report was being prepared to assess the environmental impact of this proposal, and, of course, the preliminary draft recited a number of times that this terrain is karst terrain, and the higher government officials carefully went through it and deleted the word "karst" wherever it appeared. 
Now, this sort of flim-flam does not fool any of us in Missouri. It's certainly well-known to the DOE staff. Whether it fools any top officials of DOE I don't know, but the proposal to dispose of hazardous waste in the that terrain is clearly unacceptable, and I urge this board to advise the DOE to abandon all thoughts of creating a hazardous waste site at Weldon Spring. Thank you for your consideration.

CHAIRMAN COSTLE: Thank you, sir. Tad.

MR. McCALL: I would just like to say I believe this information on the Callaway site, which we've heard twice now, is helpful in the parameters you presented to us. I wonder if we could get some more information for our committee on that Callaway alternative. Not now, but for the record.

MR. GREEN: From me or from them? I'll be glad to supply whatever you want.

CHAIRMAN COSTLE: I mean, we'll be happy to receive what you can supply. We'll also undertake to get some additional information.

MR. GREEN: Thank you.

CHAIRMAN COSTLE: Thank you. Kay Drey.

MS. DREY: Ron said I should bring this up.

It's not very dignified, but these are buttons that say "Mountain of Waste 50 Years High." Some of you have them, and then this is a proceedings of a seminar, a symposium we had on when the St. Louis waste turned 50 years old. And you're welcome to take this.

CHAIRMAN COSTLE: Thank you, Kay.

MS. DREY: You may have as many buttons as you want. If you want, I'll bring more tomorrow. I'll be interrupting your meetings tomorrow just the way I was today. I'm sorry.

My name is Kay Drey. I live here in St. Louis County in University City. We are here this evening to welcome you to St. Louis, the home of the oldest radioactive waste of the atomic age.

On April 24th, 1942, 52 years ago, engineers and other workers at Mallinckrodt Chemical Works, a couple of miles north of downtown St. Louis, began in total secrecy to try to figure out how to produce tons of pure uranium. At that time, only a few grams of pure uranium existed. That is less than a quarter of an ounce. That math took me about a half hour. Fifty days later, the Mallinckrodt team was successful, and they went on to purify all the uranium that went into the world's first nuclear chain reaction under the football field at the University of Chicago on December 2, 1942. The Atomic Age was born. Mallinckrodt continued to process uranium and thorium and to generate radioactive waste for 
about 25 years. As a result, we now have some two and a half million cubic yards of radioactive waste in metropolitan St. Louis on both sides of the Missouri River, and no one has found a safe, permanent disposal location or the technology for even the first cupful.

My appeal this evening is for you to advise President Clinton and his Administration, including the Department of Energy and the Congress, that the time has come to admit that atomic energy has not worked and that unless and until we find a safe solution for the first $\mathbf{5 2}$ years of radioactive waste we should stop generating more. I would rather bet that our scientists and engineers will be able to create a safe, financially feasible alternative energy source than that they'll be able to find a safe way to keep radioactive wastes isolated for the biosphere for the requisite billions of years.

As St. Louis citizens, we live in the airshed and watershed of the downtown Mallinckrodt

I'm very happy you came to visit our St. Louis messes.

Goodness knows we need your help. Thank you.

CHAIRMAN COSTLE: Thank you, Kay.

MR. KORKIA: I'd just like to say I thank you for your button, Kay, and I put it on in solidarity with you. As we learned, regardless of where the material goes, it's always going to be there. I was really interested in seeing these sites because I grew up in (inaudible) Canyon, where they had a waste processing plant.

MS. DREY: My dear. That's our waste. Half a billion dollar lawsuit you've got against. I guess you know that.

MR. KORKIA: So I've seen what that has done to the neighbors and the kids I rode the bus with in the schools today. (Inandible.) The wells have been contaminated, and the different sites, the railroad corridor that was going through where they ship the materials in and out and seeing the mess it made there and the way it impacted peoples lives, so I feel a solidarity with the people here in St. Louis. 
I mean, none of this is -- but, you know, then you went by Nyflot or were near there today, this street like where there are eight houses I think and nine cases of cancer. And I'm really sorry I'm not sure about those numbers, plus one Down's Syndrome, right near where Laddy Avenue is. And even thinking about St. Charles County and whether this -- not all those families I'm sure get their water from the Weldon, but they are also drinking the air, pardon me, breathing the air that can have radioactive dust, radon gas and the radon gas products, and I just think, you know, there's a lot -- Yes. I guess Dr. Blumenthal would like to.

DR. BLUMENTHAL: Yes. I'd like to say something about that. I don't know of any instance where there have been clusters of cancer cases, even those near atomic power reactors, where anyone has said that's due to radiation exposure. You know, the last one that got the whitewash was the one over in England, Cellafield.

MS. FLAX: Yes. 
DR. BLUMENTHAL: So I think if you're going to go into the public health aspect of this and try to track it down, you know, somebody is going to say, "But you can't prove that it's statistically significant." I think the issue ought to be turned around. I think the authorities ought to be put to the test and say, "You prove to us that radiation didn't do it."

MS. FLAX: Could I just ask a question of the public? Is there someone from the high school near Weldon Spring? We drove past a high school right near Weldon Spring. Is there someone from that community that's going -- fine. Thank you. Looking forward to hearing from you when your name is called.

MS. HOBBS: I'm not from the high school, but I have a child -- I live in St. Charles County, and I have a child who has leukemia, and I know of four cases within a mile radius of me who have been diagnosed. I'm not an expert on this. I don't have statistics, but to me that doesn't seem right. Now, the three main grade schools that surround the community I live in, there's like three, and each one of them have leukemia. I think it's a cause for concern.

CHAIRMAN COSTLE: Could I ask you for your name, please, for the record?

MS. HOBBS: My name is Gwen Hobbs.

CHAIRMAN COSTLE: Hobbs.

MS. HOBBS: Hobbs.

MR. MCQUEEN: I'm John McQueen. I'm the consultant for the school district. I have not seen any statistics on the cancer occurrence, at least in the immediate vicinity of that high school or that area.

MS. FLAX: Thank you.

\section{CHAIRMAN COSTLE: Yes.}

MS. HUNTER: My name is Mary Lou Hunter and I live in St. Charles County and I work for St. Charles County. I mostly came tonight to listen, but since the subject has come up and you were wanting some answers, I felt like I must speak up. I was the citizen in St. Charles that did the first epidemiology study, citizens epidemiology study, in 1982 and 1983, with the guidance of a doctor from St. Louis Children's Hospital. The parameters of that study were approved of by the Missouri Department of Health, which at that time was the Missouri Division of Health, and the results of that study were that where they would have expected to find six leukemias in the time frame that was looked at, there were 13.

From the citizen's point of view, what we did is we asked to have an incidence study done. The State of Missouri embarked on that. After a lot of work, there was the results that were said 
that overall in the time frame looked at they would have expected 21 cases, which to us seemed phenomenal. Why would they expect 21 cases? We never got a good answer on that.

And then -- but what was really important was they looked at -- they asked me, they said there was a time cluster between 1975 and 1979, and Dr. John Fellin, who was -- who is now with ATSDR, buit who was with the Missouri Department of Health at that time, said that -- asked me, he said, "What was going on at Weldon Spring at that time?" We said that that was really the peek period when the Army had been doing characterization studies. There were a lot of drill tests. They were seeking a lot of information.

There's a lot about Weldon Spring that is very different from any other Department of Energy site because of transfer of ownership between the Department of Energy and the Department of Army. Because of this, there's a lot of information about Weldon Spring that doesn't really exist about any other site.

At this point, I had not heard about clusters. Having done the first epidemiology study, which was basically just a consistent thing of communication to people, and what I did, since I did not have access to confidential documents or medical documents, I put a newsletter -- note in the newsletter of St. Louis Children's Hospital and Cardinal Glennon, which are the two main pediatric hospitals in St. Louis. All -- I was told all leukemia would have to go through these hospitals. We did find one case that went through St. Jude's in Memphis, Tennessee. I put a note in their newsletter, and those parents called me. Parents that know other parents that talk in emergency rooms and things like that are -- they form a grapevine. And out of the 13 cases, I myself had talked with 11 of the parents of those leukemia cases.

The medical -- I need to take a sip of water. The medical community was surprised that a community could come up with -- someone who did not have access to confidential records could supply that information.

But people are concerned, and there needs to be an ongoing. What this tells me is the biggest lessons that can be learned about any clusters -- and what I learned when I did that was that many times St. Louis is a place where a lot of people are moving in from other places, and there's over 20 world-class headquarters of corporations that live here. It has to be determined whether or not these cases moved here from someplace else before they got sick. There is a lot of different things.

My four children graduated from Francis Howell High School, and I think that there should be a focus. This high school presents almost a classic workshop laboratory of graduating classes that could be consulted that lived through times when the plant was in active operation, as a worst case scenario, when it was inactive, then what was going on before. In our newspapers out there, there are reunion notices this year for the class of 1979 and the class of 1974, the 15th and 20th years. One thing I about Francis Howell is that these kids that went there, a lot of times their parents went there. I don't know. I'd be glad to talk to anyone about this. I don't want to take up anymore time because this is a subject in itself. But I think that if there is a problem, the 
1 . lesson that can be learned is the extreme care that must be taken when activities are going on

Department of Energy in Weldon Spring on the work that they are doing, and they have worked with us on developing and listening to our fears because I think they're more than just fears. But it is a very difficult thing to establish and say, "Yes, this caused this." Well, you can't do that, but you might be able to prevent another cluster from coming down the road in a few more years, and that would be the purpose for it. And if there isn't any health problems, for goodness sake, let those students that graduate from that high school know that their classes are fine. My kids -- I had three sons that played football. The visiting teams, sports teams -- they played football, soccer and wrestling. The sports teams brought their own water with them to that school, and they all -well, the thing is we had tested -- as a citizens group, we had tested the public water that came. At one time it ran right through the site before it got to the high school, and we tested it on a regular basis, and it was safe. There wasn't a problem with it. If there's a problem, personally I feel it's more of an air exposure than a water exposure. But the kids there, you know, when boys play football, the opposing teams call them names and all this. Well, to razz them up and get them excited, they call them names about, "Well, you know, it'll be easy to find you glowing in the dark" and things like that. These kids halfway expect problems. If there is good news, please let's tell them good news. If there's bad news, let's deal with it as adults because there's a lot of generations carrying on out there and have been for 35 years that that plant was in operation, and this school is like between a quarter and a half mile downwind of it.

\section{CHAIRMAN COSTLE: Thank you very much. Cathy Collins.}

MS. COLLINS: I moved down to St. Charles County for the clean air as I work at Mallinckrodt Chemical Company. I would like to thank the Department of Energy Advisory Committee for taking the time to hear the citizens' concerns in the St. Louis area. My name is Cathy Collins. I was a 20-year loyal employee of St. Louis Mallinckrodt Chemical Plant, site of the first uranium processing for the atomic bomb. I'd like to give the word "first" special emphasis. Ironically it seems that many of the Department of Energy plants have since lined up to take that credit. Although most of the workers from the 1942 to 1947 were indeed very proud to be part of their country's weapons development in the Manhattan Project, I'm not so sure that today anyone would be so enthused to take credit for being the first. But still, being first is very important because it designates the oldest radioactive contamination site that the Department of Energy has failed to clean up.

Mallinckrodt is an operating plant that has converted Buildings 50 and 51 , originally used for uranium processing, to make food grade chemicals. In 1976, Department of Energy Radiological Survey took a dirt sample from the floor in Building 50 and indicated a uranium 238 concentration of 1400 picocuries per gram. It is inconceivable to me how a manufacturer like Mallinckrodt or the Department of Energy could allow this level of exposure to workers or risk the general public in the form of food additives.

At Mallinckrodt, the Manhattan Project has become a skeleton in the closet. If any employees ask questions, they quickly learn that the company is in the stage of denial. In 
FUSRAP meetings, the company tells employees that they are exposed to nothing more than background radiation, and they use the analogy "like you would get from the rays of the sun". Sounds safe enough. In 1990, Department of Energy radiologic characterization indicated that some areas of Mallinckrodt have walk-over gamma readings of two million counts per minute. Is that safe? Is that also like the rays of the sun? The study also indicates there are service readings of thorium 230 of $14,000,18,000$, or how about 98,000 picocuries per gram. I'm so relieved to know that this must be the mild background radiation that Mallinckrodt speaks so readily of. Or how about surface readings of uranium 238 at $20,000,89,000$, or even 95,000 picocuries per gram? I can tell you, in my 20 years at Mallinckrodt, without the assurance of the company I could have never have felt so safe.

In the past seven years, I have attended a considerable number of meetings on this subject. I've written a considerable number of letters and submitted a statement for a congressional subcommittee hearing. I totally wasted my time trying to get our labor union involved in health and safety of the workers.

Last year Mallinckrodt forced me to leave the job I loved. On the up side I have more time to continue my commitment to health and safety of the workers. No one knows exactly what levels of radiation are safe. Everytime the Department of Energy scientists, Goffman, Mancouso, Wilkison come along saying that even low levels are not safe, the Department of Energy shuts them up. It is clear by now that the corporations that were contracted by the Department of Energy cannot be held accountable for punitive damages, negligence or even criminal actions. Under sweetheart contracts with the Department of Energy, the corporations have government guarantees of total immunity. Mallinckrodt can say what they want, but the workers don't have to believe it.

I urge the Department of Energy to take the responsibility to tell the workers what their potential exposures are. I urge the immediate removal of the radioactive contamination. I urge airborne monitoring to be done, and I urge that the radioactive contamination be taken away to Callaway County. Thank you.

CHAIRMAN COSTLE: Elaine Blodget, Coalition for the Environment and League of Women Voters. I'm sorry, Tom.

MR. WINSTON: Cathy, I had a question for you. You mentioned Mallinckrodt forced you to leave your job. Is there more you want to share with us on that?

MS. COLLINS: I believe that my questions about the Department of Energy and exposures to workers was behind it.

MR. KUCERA: I have a question.

CHAIRMAN COSTLE: Ron. 

Sorry.

MR. KUCERA: Would you be able to give us any better reference to that DOE radiological characterization where you have reference the high gammashine of two million counts per minute? Is there some other way that's described so we can get a hold of it?

MS. COLLINS: It was the 1990 survey.

UNKNOWN SPEAKER: It's a three-volume survey.

I have it or Cathy has it.

MR. KUCERA: Thank you very much.

CHAIRMAN COSTLE: Elaine Blodget. Cathy Lewis. Jay Lewis. Oh, here's Cathy.

MS. LEWIS: I'm Cathy Lewis. I am a school teacher, and I've been a graduate student in environmental studies. I have two young sons. First I would like to express my gratitude to the Environmental Management Advisory Board for coming to St. Louis, and also to Ron Kucera for lobbying for you all to come here to include the St. Louis sites in your review because I just feel like this is the most positive thing that's happened since I've been aware of this issue.

Secondly, I'd like to state my opposition to the recurring proposal of the Department of Energy that the airport site become a permanent site with consolidation of radioactive waste from the St. Louis area. My opposition is twofold: It is both because of the geology of the site as well as the site's proximity to the most densely populated metropolitan area in Missouri.

Thirdly, I would like to express my ongoing concerns about the Weldon Spring site. I am concerned about the quality of drinking water in St. Louis and downspring from Weidon Spring due to the release of treated water from the quarry, and eventually the water that will be discharged from the raffinate pits above the drinking water intakes for St. Louis City and County and numerous other communities that are downstream from the site. I am also concerned about of the record of decision to a permanent waste site at Weldon Spring.

The source of the radioactive waste which is spread across St. Louis is the former Mallinckrodt Chemical Works, which processed uranium under contract with the Federal Government, in the 1940's and '50's, some of that waste was spread to the airport site, then in the '60's to Latty Avenue, and in the 70's to West Lake Landfill. Over this period of time, unknown quantities of the waste along the truck routes between these sites. The waste is a product of a contract between a private corporation and the Federal Government, and as a part of the Federal Government's original agreement with the corporation, the Federal Government was to be responsible for the waste.

However, the land was quit-deeded to the City of St. Louis in 1973, and now no one wants to take responsibility for monitoring and managing the waste. 
I feel that for the public good it's imperative the Department of Energy accept responsibility for the site without dictating that the waste scattered throughout the St. Louis community be consolidated at the airport site permanently. After accepting responsibility for the airport site, I feel that the DOE should immediately place a fence as close as possible to McDonnell Boulevard along the normal boundary of the property and clearly mark the area as being radioactively contaminated. Then, with citizen input, I feel that the Department of Energy must locate a geologically stable area where the waste from each of the St. Louis sites, the airport, Latty Avenue, the contaminated truck routes, Mallinckrodt and West Lake Landfill, can be consolidated and entombed with barriers to minimize the migration of radioactive contamination into the soil, ground water, surface water and air. I don't know if this site of the Callaway nuclear power plant in Missouri would be geologically and hydrologically stable, but feel that it should be considered since it is a site in the state where significant amounts of radioactive waste continue to be generated.

As stated earlier, my concerns about Weldon Spring include the treatment and discharge of radioactively-contaminated water into the Missouri River, the type of radiation to which we are being exposed and the plans for permanent storage of radioactive waste at the site. In St. Louis, as well as in all other communities along the Mississippi downstream from Weldon Spring after the Missouri and the Mississippi Rivers converge, people use the river as a drinking water source and irrigation source to water crops and as a food source. Due to the treated water that has been and continues to be released from Weldon Springs, I feel that we are facing chronic exposure to radiation rather than a short-term exposure.

The type of radiation to which we are being exposed also concerns me because we are being exposed to alpha particles, which are internal emitters. Most cancer and leukemia is due to internal emitters. When we as humans or other animals breathe or swallow alpha-emitting particles, the high energy particles which they give off can affect the cells of sensitive internal soft tissues, creating serious damage to the cells and ultimately to the health of the individual. Alpha particles can be deadly, even if inhaled only in minute quantities, and cancer and leukemia are not the only health effects which radiation exposure promotes.

Birth defects, genetic mutations and immune system disorder are others. We are continuing to learn more about the impact of radiation on immune system disorders, which become apparent as individuals experience sicknesses more often, and these illnesses linger for longer periods of time.

The two primary radioactive materials present at Weldon Spring are uranium 238 and thorium 230. Both of these elements will continue to emit radiation into the environment for eons. Uranium 238 has a half-life of four and a half billion years, which is the age of planet earth. Thorium 230 has a half-life of 80,000 years.

I find it very unsettling, though, that although it is known that 90 cubic yards of thorium 230 were disposed of in the quarry and 700 cubic yards were disposed of in the raffinate pits, thorium is not detected in either the treated or untreated water. I find it hard to believe, as we were told 
today about the $\mathrm{pH}$, that the $\mathrm{pH}$ remains constant throughout the quarry, the raffinate pits and the treatment process.

In regard to the permanent radioactive waste site at Weldon Spring, my concern is with the innocuous design appearance of the final site as well as the geology of that area. It seems to me that there must be some way that the long-lived danger of this site must be communicated to future generations. People speak about building water treatment facilities, which take into consideration 500 year flood levels, and yet the people who lived in this area 500 years ago kept no written records about the flood levels, and they certainly were not generating radioactive waste.

In conclusion, I feel that the only definitive action which we as human beings can take is to stop generating radioactive waste. It is truly criminal that people consciously continue to produce waste for which there is no safe disposal and which will remain radiotoxic for more lifetimes than we can imagine.

CHAIRMAN COSTLE: Thank you, Cathy. It's now 9:30, and we've been at it for about two hours. I'm going to propose we take a ten-minute recess and let everybody get up and walk around. But before we do, Cathy, Dick Bangart had a question for you. Dick.

MR. BANGERT: One question. It's come up in several comments that the Callaway site should be considered as a disposal alternative. Has anybody talked to Union Electric to see whether they'd be willing to use their facility for such purpose?

MS. COLLINS: I haven't personally. I feel certain that they've probably heard about it at some point in time, but I can't imagine that they had a very positive response. But just logically it seems to me like a place that would be appropriate given they're continuing to produce radioactive waste.

DR. FREUDENBURG: The follow-up would be (inaudible) you hear toxins was too dangerous for St. Louis, but we don't count so much, so it's not too dangerous for us.

MS. COLLINS: I think the people there are convinced the nuclear power plant has a life span which is limited. I don't think the people there realize the longevity of the waste that they are being exposed to.

CHAIRMAN COSTLE: Fred.

DR. DONATH: There certainly would be on record an extensive report of site investigation there that would give the information about the suitability or lack of suitability there. But it's possible, Ron, do you happen to know, is that not a site that's also by invaded by limestone?

MR. KUCERA: I am aware of some of the geologic reviews at the Callaway site, and I believe it suffers from some of the s ame basic similar challenges you find along the north side of 
the Missouri River for many, many miles, basically because of the carbonated rock. There's also a study having to do with lake sites in the Callaway area that yielded up some additional information about the potential karst in the Callaway area. I don't think it would rule out a footprint for a similar facility to that at Weldon, but I think there are similar challenges in those areas.

UNKNOWN SPEAKER: Ron, why didn't you bring that up when they were licensing the Callaway site?

MR. KUCERA: I guess I'll respond to a general question from the general audience. I still hold out hope that those aren't the same things. I hold out hope that the high curie counts that we heard mentioned here today at Callaway are not going to remain there in perpetuity. I hope they will be moved out of Callaway County, and I believe that is -- That is the hope of the residents of Callaway County, too.

\section{CHAIRMAN COSTLE: Kay.}

MS. DREY: I just wanted to answer the question the gentleman from the Nuclear Regulatory Commission asked. I think when Union Electric was asked the question about how go you feel about having the waste from St. Louis taken there, their response was that they are not allowed to have waste at their plant site, and that was not what anyone was suggesting.

They're talking about 6500 surplus acres, really 7,000 surplus acres, not the Callaway 200-acre plant site. So they never did address the question. I mean, obviously it's not very pleasant to say to the people at Callaway County, you know, "We'd like to send our waste to you," but they do literally have billions of curies of radioactivity there. We're talking about maximum 2,000 curies or a thousand curies. I mean, compared with billions of curies, there's a tremendous difference. Maybe some day there will be a place to take their fuel rods, but at this point even Yucca Mountain, if it's ever built, which I certainly hope it's not, will not take the Callaway rods because our plant was one of the last four reactors ordered in the United States, July of 1973. There have been no orders, by the way, for 20 years, which is great.

\section{CHAIRMAN COSTLE: Fred.}

DR. DONATH: Just asking for a point of clarification. The waste you're referring to at Callaway is part of the fuel rod study; is that correct?

\footnotetext{
MS. DREY: Right. There's also no place at the moment for the so-called low level waste either.

(Whereupon, there was a brief recess.)

CHAIRMAN COSTLE: We can reconvene, please. I realize, given the hour, there are a number of people who have signed up who have indicated they will not be able to stay. We have 19 more people. And so -- and one of the witnesses has just left her statement with us for the
} 
record, and we will obviously accept statements from anybody who wishes to leave it if they are unable to stay. But given the fact that there's 19 more on the list, I would again encourage -obviously we're interested in hearing you, but I would again encourage that we try to keep your remarks to five minutes. The next person is Jay Lewis. Welcome, Jay. Louis.

MR. LEWIS: I'm Jay Lewis. I'm from St. Louis, Missouri. I was born and raised in St.

Welcome to St. Louis. I'm certainly glad that you're here, and thank you very much, Mr. Chairman, for convening this panel.

The very fact we still have no definitive plan to solve the radioactive waste problem 50 years after the waste was created seems to speak for itself. I do not believe that storing radioactive material in a densely-populated area is a good idea. Clearly, all of us, those in government and the citizens, must find an answer and agree on a solution regarding the storage of radioactive waste materials.

The single most dangerous site in the state of Missouri that is still creating large amounts of radioactive waste is the Callaway nuclear power plant. I urge the Department of Energy Environmental Management Advisory Board to advise the Department of Energy to locate all high level and low level radioactive waste to the Callaway site.

Quite frankly, there exists a credibility problem that the Department of Energy has created. Even last night, as I watched the 60 Minutes news show about young children being, quote, "treated," unquote, with high doses of full body radiation, it was very clear that the medical staff at the Oak Ridge Hospital and the government personnel with NASA and the Department of Defense not only misled the parents of the children, but lied to them. In this Department, how can the present day Department of Energy expect citizens to have trust in government agencies. Please stop the foolish discharge of Weldon Springs' radioactive waste water into the Missouri River. The discharge is above the St. Louis County drinking water intake. I ask you now, why do you persist in continuing these experiments with citizens' health?

Apart from the St. Louis sites, which I do feel are very important, is another issue upriver that greatly concerns me. Quite frankly, if I did not know that what I say is, in fact, true, I simply could not believe anyone could be so foolish. The people of Minnesota and everybody downstream who gets their drinking water from the Mississippi River, which is 18 million people -ladies and gentlemen, this 18 million people comes from the Upper Mississippi River Basin Commission 1992 study -- has a serious threat existing in the plan to store or dump high level radioactive fuel rods in dry cast storage at the Prairie Island nuclear power plant. Unbelievable as it may seem, the current plan is to store spent fuel rods on an island in the middle of the Mississippi river in a floodplain.

As I said before, if I did not know this is in fact true, I could hardly believe it myself. I car understand the waste generated during the Manhattan Project that we are now trying to deal with 
in St. Louis 50 years later. In the heat of a war and the threat of possibly losing the second World War, I can understand how and why the radioactive waste was created, but the fact remains that we still do not know what to do with the waste that we created 50 years ago. My question to you tonight is, why are we still allowing radioactive waste to be created today? I have seen aerial photographs of a nuclear power plant at Prairie Island during this last summer's flood, and, quite frankly, a real fear gripped my stomach.

In closing, number one, please do not store exceedingly long-term radioactive waste in densely populated areas. Number two, move all Missouri's radioactive waste to the most severely impacted site of our State, which is the Callaway nuclear power plant. Number three, stop tie discharge of Weldon Spring's quarry water into the Mississippi River for the St. Louis City and St. Louis County drinking water intact. And, number four, a common sense plea, do not allow or permit the dry cask storage at the Prairie Island nuclear power plant on an island in the middle of the Mississippi in a floodplain. Thank you for hearing these comments and thank you for coming to St. Louis.

\section{CHAIRMAN COSTLE: Thank you, Jay. Martha Dodson.}

MS. DODSON: Thank you. I'm sure I'm exactly who you want to hear from because I have another site.

About 30 miles south southwest of St. Louis in the floodplain of the Joachim Creek is located the oldest nuclear fuel plant in the U.S. This plant is owned and operated by a Asea, Brown, Boveri, a Swiss -- a Swedish corporation, the products of which are -- the products are nuclear reactor cores, and they are sold in the Pacific rim countries. Therefore, if the U.S. in its wisdom were to abandon nuclear power, my problem would still be here.

The plant was built in 1956 by Mallinckrodt for highly enriched fuel for experimentation and operated as United Nuclear Corporation. It was sold to Gulf Oil in '71 and operated until '73 when the site was determined to be contaminated and it was scheduled for dismantling. However, it was purchased by Combustion Engineering and reopened in '74. In 1989, it was purchased by a Asea, Brown, Boveri and expanded to include the package and assembly of fuel rods.

In the early days, the plant was operated in total secrecy. The public has no way of knowing what sort of materials were used. We do know that a lot of nuclear waste is buried on the site. The powers that be claim that no records were kept, so they don't know exactly what or where it is kept, but they admit freely that there's a lot. There are also two settling ponds which have been scheduled for cleanup for as long as I can remember.

All of this is within the floodplain of the Joachim Creek, which flows into the Mississippi about five miles downstream. Our water supply comes from Rainey Wells, about one mile downstream from that confluence. All of us in Jefferson County would appreciate your attention to this highly contaminated site. Thank you. 
CHAIRMAN COSTLE: Thank you. Martha, could I just ask a quick question? How was that site affected by the flooding this past spring?

MS. DODSON: It is far enough away from the river that it was not flooded as such. It was not included in the flood.

CHAIRMAN COSTLE: Thank you. Margaret Hermes.

MS. GUTWEIN: My name is Roberta Gutwein, and I'm speaking on behalf of Martha Hermes, who is out of town.

The Department of Energy's conclusion that the St. Louis area radioactive waste should be bunkered at the airport site was inevitable given that that was the presumption from which all its studies began. None of the DOE's findings in this matter are unbiased. The DOE includes or excludes relevant data on a scientifically arbitrary but politically selective basis. For example, DOE spokespeople say that the reason the downtown Mallinckrodt site and its wastes are included in their cleanup is because these wastes are quote "historically related," as indeed they are, and because the community will be better served by one bunker rather than multiple containment facilities. But when asked why the radioactive waste at West Lake Landfill, which are transported from another of the St. Louis sites and illegally dumped, are not also being included in any DOE proposal, the DOE no longer points to the direct historical relationship between these wastes and those at other sites, nor does it in this instance insist on the efficacy of one containment facility for all the related wastes.

The DOE disclaims any responsibility for treating these wastes as part of the area-wide problem because West Lake Landfill remains on the Superfund list. West Lake Landfill was bequeathed to the Catholic Archdiocese of St. Louis, which under Superfund can be held financially responsible for cleanup of these toxins despite its complete lack of involvement in contaminating the site.

Those who have worked on this issue for a number of years recall it was not so very long ago that the DOE denied any obligation to include the downtown Mallinckrodt site in its cleanup effort, but the Mallinckrodt site came under DOE authority in a politically expedient off-the-record trade. The DOE agreed to assume responsibility for the chemical plant's cleanup, and, in exchange, some officials in a past administration of the City of St. Louis agreed to support the permanent bunkering of radioactive waste at the airport. It is highly questionable that even excluding the waste at West Lake Landfill, there is enough property available at the airport to bunker all the other St. Louis City and County wastes in a manner acceptable to the local communities and the state Department of Natural Resources and still keep the bunker out of the floodplain of Cold Water Creek and yet low enough not to interfere with the flight traffic in and out of Lambert Airport.

If the West Lake Landfill wastes are included, as they must be historically, practically and morally, then the DOE must look elsewhere to bunker the enormous volume of contaminated 
rubble and soil. And where else ought the DOE to have looked? Again, the DOE biased the outcome of its studies by pre-selecting the options that we'd consider. The DOE continues to claim ludicrously that it considered the airport site only because it was mandated to by a congressional directive back in 1985. Logically, the directive is no longer relevant as the airport site delineated in the 1985 water development and appropriation bill consisted of 21.74 acres, a mere fraction of the land the DOE now admits it requires for the volume of materials to be bunkered.

The DOE continues to cleave to this geologically inappropriate, vastly expanded airport site because it is a lower cost alternative and because department officials believe that political opposition here can eventually be eroded. Well, we are worn down by more than a decade of citizen labor, documenting the inadequacies and the inaccuracies of the DOE, but we're not yet worn out. Many of those active in this issue have for years been calling upon the DOE to examine the extra land owned by Union Electric adjacent to its nuclear power plant in Callaway County approximately 100 miles from St. Louis. Instead, the DOE chose to examine a quote "generic site" in outstate Missouri.

First of all, there is no such thing as a generic site. It is the specifics of a site that determine whether it is potentially usable or absolutely inappropriate for radioactive waste storage. The DOE claims to rule out this generic site primarily for cost reasons. However, we find if we examine the specific Callaway County site, whose distance from St. Louis is relatively short, whose geology is far more suitable than that of the airport site, and which because of its proximity to a nuclear plant would remain far from commercial, recreational or residential use anyway, a more viable alternative to the airport site does exist.

In addition, any discrepancy in cost between the Callaway site and the airport site would be further reduced by a reconsideration of transportation costs if one acknowledges that even with bunkering the waste at the airport site all the radioactive waste would have to be dug up and loaded into trucks anyway in order to bed the waste on top of the clay liner.

The DOE is not looking for a solution for all of our areas atom bomb waste, nor is it looking for the best solution for even those wastes for which it accepts responsibility. It has neither honestly or openly examined the most basic options. In the matter of the St. Louis area nuclear weapons waste, the DOE seeks only to implement the politically expedient solution. Thank you.

DR. FREUDENBURG: Is it possible to get more information on the agreement with the St. Louis City officials, or is that --

MS. GUTWEIN: I think we could probably try to get that.

CHAIRMAN COSTLE: Elaine Samon. Byron Clemens.

MS. SANDLER: Is that Arlene Sandler? 
MS. SANDLER: Arlene. My name is Arlene Sandler, and I am speaking for myself and as a drinker of radioactive water. The cover story of the New York Times Magazine March 6, 1994, announces a feature story in the following words: "Nuclear Waste Buried Down in Haste Will Still Be Deadly in $12001 \mathrm{AD}$. What's the rush?"

Though I'm tired from my 15 year involvement with this issue, I would not like to see a hasty or imprudent attempt to solve the nuclear waste dilemma at the various sites in the St. Louis metropolitan area, and I regard as imprudent any decision that leaves significant questions unanswered and significant alternatives unexplored.

The most pressing question for me, because it seems to so grossly defy all logic, is why is a permanent radioactive waste dump being built near water and near people at the St. Louis airport. The general wisdom is to locate dumps away from water and people. At the Weldon Spring quarry, why wasn't a water treatment pilot plant built first to test the safety of the process and the suitability of the equipment? Why should an already operating plant, which has the potential for permanently polluting the drinking water of a large population be the pilot plant for the whole country and local citizens the guinea pigs?

\section{I have questions about monitoring equipment.}

There is documentation that thorium was dumped into the quarry and raffinate pits at Weldon Spring, yet it was not detected by monitoring equipment and has not been found in the nearby well field. Either the equipment is not sensitive enough or something is responsible for masking the detection of thorium. In both cases, further research is necessary.

Why are the geo-hydrological features of the airport site being ignored? The site is located in a floodplain above porous limestone. Why aren't alternatives fully investigated? Why has only lip service been paid to another site in Missouri, a generic site, while the airport site, an illogical choice, one that was resoundingly voted down by both St. Louis City and County voters, has been given the most serious consideration.

Given that radioactive waste has been in the St. Louis metropolitan area for many years and the Federal government's cumbersome remediation procedure at some of the sites at least has been underway for a long time, current decisions may not seem hasty. However, the many citizens who have left the many public meetings with the belief that their input into the decision-making process is inconsequential must feel, as I do, that not enough research has gone into the planning. We would be willing to wait longer if our questions could be answered and our fears put to rest. There would be many more people here tonight if citizens involved in the process hadn't worn them down.

There is too much at stake to do anything less than a carefully made decision with real public input. Very long-lived materials are present in the waste. 
Contamination of ground water is irreversible. Not enough is known about the long-term health effects of exposure to these wastes and about the effectiveness of the constantly changing standards for human exposure to radioactive materials. What is known is that we will be leaving a toxic legacy to future generations. As that New York Times Magazine article emphasizes, quote, "Rushing to bury nuclear waste doesn't take the problem off future Americans' hands so much as it takes the solution out of their hands." And I'd I'd like to submit for the record a series called "Legacy of the Bomb" that was done in the St. Louis Post Dispatch in 1989, which gives the complete history of the waste here. Thank you.

CHAIRMAN'COSTLE: Tad.

MR. McCALL: I'll be brief, Mr. Chairman. The speakers have mentioned this great hope for change that they're envisioning as they speak to us, and the latest speaker just mentioned the cynicism about speaking to boards that don't do anything. I hope you all realize that we're just you. We're citizens. We're not government. We don't make any decisions. Okay. All right.

CHAIRMAN COSTLE: Byron Clemens.

MR. CONNOR: Mr. Chairman, could I just interject something?

CHAIRMAN COSTLE: Sure.

MR. CONNOR: This issue of the thorium 230 has come up several times today, and I had hoped that we could have some time tonight to deal with questions like that. We obviously don't have the time. But I would like to say for the record that I think it's one of those questions that is simply resolved and should be resolved in timely fashion. I will be submitting a letter to the DOE staff to simply describe what's going on there in the way of a sampling program, what is the techniques that are being used to look for this material and see if we can get some technical satisfactory resolution. There's no need for a question like this to go on for years and years and years and increase the cynicism and skepticism of the government. So I just wanted to let the record show that at least some of us have heard of that problem and want to take some strives to see if we can resolve it.

\section{CHAIRMAN COSTLE: So noted. Mr. Clemons. Welcome.}

MR. CLEMONS: Good evening. My name is Byron Clemens. I live at 7310 Bruno in St. Louis County. I'd like to thank the Environmental Advisory Board for letting us comment here. Yes, there's some cynicism out here, although we have a little hope. The faces look different. I've seen Ron before over at many of these hearings the Department of Energy and the NRC has sponsored. I'm a little disappointed in the Federal government in how all of these sites have been treated. The first hearing I testified at was in 1979 out at Berkeley. I became interested because some friends of mine at the St. Louis Police Department were concerned that they were going to put a police driver training school on top of the FUSRAP site at the airport. 
One of my first frustrations with all this is trying to get the NRC to post signs at the Latty Avenue site. There were children playing out there. Piles of uranium mill tailings. William $T$. Crowe at the NRC at the time, and I quote, says that "The thistles and weeds would be a deterrent to trespassing at the site." Well, after the NRC didn't move on that, I had a friend of mine who works at a prominent chemical company that's not Mallinckrodt gave me a moon suit and some friends of mine went out and posted signs. Relatively soon afterwards, the NRC did fence the site and put up signs. But in the meantime I met people, children who played out there, rode bicycles up on the uranium mill tailings. I met that Gene Jarbow who owns Futura Coatings out there. Tonight I met someone out in the audience whose child has leukemia now. These numbers have faces for me. They are real people out there. And I'm sure you're aware of that.

People wrote letters, voiced concern. The Federal government finally closed down the Berkeley Khoury League baseball field. Well, it's contaminated.

It was the right thing to do to close it down. But it is a huge disappointment to the people in that area to take away a common recreational area for a wide swath of people across the county. 
The first time I came to testify, as I said earlier, is about the driver training school. Then I helped try to get the Missouri congressional delegation to stop the dumping of untreated radioactive water into the Missouri River. They were just going to dump the water from the raffinate pits and the quarry into the river untreated. The Missouri congressional delegation listened to us, and for the first time I think they all voted together, Democrats and Republicans, to say that's not a very good idea. That proposal was scrapped. That's the second proposal that was scrapped. I think that was an incompetent proposal.

Our then Governor Kitt Bond once upon a time was willing to trade off cleaning up one of the sites in the St. Louis area to create a five-state radioactive waste site at the Weldon Spring site. That was not a very good idea, and that was scrapped.

The Federal government hasn't cleaned up the very first nuclear waste from 1942 at Mallinckrodt. The Federal Government oversaw the transport of waste from Mallinckrodt from the airport from ' 46 to 1958. The new dump site created at Weldon Spring on karst topography, they don't call it Weldon Spring because it's a desertified area. It's filled with springs, and it is on limestone. I've seen pieces of limestone with huge holes in it. Meanwhile, Carter Corporation, a subsidiary of Commonwealth Edison, moved a lot of material and made a profit from moving some of the material to Colorado. And some of it was lost. B and K Construction Company took some material to West Lake Landfill, which now looks to be the responsibility of the St. Louis Archdiocese because the DOE doesn't want to take responsibility for that site even though it was generated by the Federal government.

Storage at any of the aforementioned sites does not seem reasonable and prudent and is short-sighted. I worked on a case that I'm not supposed to talk about. I did some research for an attorney named Richard Schwartz locally who filed suit for a worker who had three different kinds of cancer who worked as a painter at the Mallinckrodt site downtown.

Mallinckrodt did settle out of court. More than 3685 workers were exposed to radiation at the Mallinckrodt site, some at levels 195 times background. Some were exposed to gamma radiation as high as 1,000 millirem per hour. Let's not irradiate any more workers at the Mallinckrodt site.

To cut to the quick, I think my time is running out here, but I think we have a long history of incompetence, Federal agencies abdicating the responsibility. When the government has taken action, it's done poorly. Scientifically or technologically, the airport site is not a good site. There's a large amount of water that runs through that sight. It's on a floodplain. The material has leached out of the site next to the ditches next to McDonnell Boulevard. It's blown on to the Berkeley Khoury League field. It's not a good site. The West Lake material should be included with all of the FUSRAP sites in the St. Louis area and, of course, my recommendation is that it be taken out of this area, away from a major metropolitan area, and I think to a Department of Energy licensed site would be a good one. And I'd like you to keep in mind that the people of St. Louis and St. Louis County have overwhelmingly voted, 85 percent of the voters of St. Louis 
County and 80 percent of the voters of St. Louis City have said, "Move it out. Move all the waste from all six" sites. Move them out of the population area and away from water sources.

And this issue of how much it costs, which was I think addressed very nicely earlier, that wasn't a concern when the waste was developed. It's not our waste. It's the Federal government's waste. They have a moral obligation to move material out of here.

I am concerned that locally, what used to be the ALARA, as low as reasonably achievable idea, is now more acceptable in public health protection. I heard a hearing with some local DOE officials a couple weeks ago where they talked about averaging things out, adding clean fill to radioactive material, which creates more radioactive material. It concerns me.

And I have one thing I'd like to enter into the record that has to do with faces. It's an article in the St. Louis Post Dispatch about reports of leukemia in North County on Nyflot Drive, and there's a huge clustering of leukemias at that site. I've seen it again and again. I know this is anecdotal from my point of view, bui it exists. I mean, there are real people out there that this impacts. Thank you for your time.

\section{CHAIRMAN COSTLE: Thank you. Deborah Wilson.}

MS. WILSON: Hi. I'm Debbie Wilson, and I'm a member of the Missouri Coalition for the Environment, but I'm here representing my own little family.

As you know, the radioactive waste in the St. Louis area has affected many families, and my family is one of them. My husband played softball for years on the contaminated ballfields by the airport. He was a pitcher. He would frequently pick up the dirt, rub it in his hands, dust it on his pants. He was really well-known for his attempts at sliding into home, and he's a big guy. He kicked up lots of radioactive dirt.

I sat on that contaminated dirt, and I enjoyed his games. I sat there through my first pregnancy. Then, innocently, I watched my first baby play on that toxic ground with the other small children. My child didn't eat that dirt, but many other children did. It is possible that my little family was poisoned by the radioactive waste at that site. Thousands of innocent young families may have been poisoned. You can't go back and fix that. Don't risk the families of this area any further. Don't build a radioactive waste dump in their community.

I'm also concerned about the radioactive contamination at Weldon Spring. Currently at Weldon Spring the Department of Energy is dumping millions of gallons of supposedly-treated radioactive waste water into the river just a short way upstream from the drinking water intake for our area. I say supposedly treated because I have a basic mistrust of the DOE due to my experiences at the ball fields and the experiences of citizens all over the country. Unfortunately the DOE does not have a good track record regarding protecting the safety of innocent citizens, and public relations plans will not fix that. Beyond this mistrust I feel, there are some questions that nag at me about the treatment and release of this radioactive waste water. 
Is it possible that after over 50 years of mixing and brewing together the wide variety of chemicals and toxins found in this waste water soup we have developed dangerous substances that the DOE has never dealt with before? If there are new toxins, is it possible that present technology is not able to detect them. If they cannot be detected and monitored, is it possible that these toxins are being released into the river and then sucked up into our drinking water intake. Is it even remotely possible that the DOE is again poisoning St. Louis families. Years from now, the DOE will not be able to fix that either. Thank you.

\section{CHAIRMAN COSTLE: Peter Schmitz.}

MR. SCHMITZ: My name is Peter Schmitz. I'm a lawyer here in St. Louis, which has nothing to do with the reason why I'm here to talk to you. You've heard a lot of anecdotal evidence this evening about health problems and health risks. I want to give you a little anecdotal evidence of my own about citizen input and bureaucratic response, and it has very much to do with the subjects that have been talked about here by a number of previous speakers.

About five years ago, I participated in a citizens group that challenged to some extent the plan for disposing of the quarry or cleaning up the quarry problem at Weldon Spring. For reasons that I don't quite remember at this point, the best shot that we had for challenging and questioning what was going on out there was the State NPDES permit, and we filed an appeal from the granting of the NPDES permit, which got us a hearing and a series of meetings that were attended by both the State DNR people and the DOE people who were planning the disposal project at Weldon Spring's quarry site.

And there was -- this is a problem that you're more familiar with now than I am because you've probably been there to see it today. You remember that there were thousands of drums of various toxins that were stored in that quarry over a long period of years, both from the time of the TNT plant and the time of the uranium processing, and everything was put into that dump, and there was a long list that we had been given of all the toxins and radioisotopes that they thought were in there, and it was pretty impressive. And we were told that the problem was that there were not only these thousands of drums down in there, but there were millions of gallons of something called interstitial water. And the engineering problem was that they had to somehow drain this water out, and, of course, there was a big flush toilet effect. They had to get it out of there faster than the rainfall could fill it up again.

And we were there simply to ask a lot of questions. And what I want to tell you and what is important was that we were not very well received and we were treated like the enemy. We were treated as though we were interfering with some God-given process that they were about to embark upon. And over a series of about four meetings -- Incidentally, we had some pretty highly qualified people on this little citizens panel. We had some biologists and some chemical engineers and some people who knew more than I knew certainly. I just knew about processors.

I came to three conclusions over the course of these meetings. I want to tell you what those conclusions were. The first conclusion was that our participation and interest were not 
welcome, that they thought they had been given a job to do, that they knew how to do it, and they didn't need or want any help from us.

The second conclusion was, I'm talking about not only the DOE people, but the DNR people. I'm going to lay it on you guys just as hard. The second conclusion was that they really didn't know how to do it, but they did know how to talk as though they knew how to do it.

My third conclusion was that they were going to do whatever was needed to get through with the procedures that required them to talk to us and then go ahead and do pretty much what they had intended to do in the first place. Now, what was it that we were trying to get through to them? What was this big message that we had? We were trying to suggest to them that they didn't have the technology for separating and isolating all the problem substances that were in those drums and in that water and that we didn't think that they should be dumping it into the Missouri River as long as they weren't sure that they were getting everything that was in that water out of the water.

Now, I'm relating this to you because we were trying to help five years ago, and we didn't get very far, and they listened to us and then they went right ahead and they did what they were going to do, and they are doing it still today. And you heard about the thorium 230, and, Mr. Connor, please do ask your questions about Thorium 230, but get ahold of that list.

And there's more than thorium 230 that's involved there that they can't measure, that they aren't testing for, that they don't know how to deal with in a process situation. Sure, I'm certain that in the right kind of analytical laboratory you can isolate and identify all this stuff, but this is a process. Can you do it in a process situation? And we have been suggesting from the beginning that the answer to that is no.

Now, there's a big question here as to where the burden of proof lies, and they in effect were saying to us, "Well, can you prove that this is really a problem?" and I don't think the burden should be on us. They're the people with the know-how. They are the people with the facts. They are the people with the experts. They're the people with all the available technology. And they shouldn't be putting it on a citizens group, who's asking legitimate questions, to solve the problem for them.

Now, we got into the predicament that we're in today because we trusted government agencies who told us that they knew what they were doing, and I'm simply suggesting that one of the best protections that we as citizens can have is a good process whereby citizens are empowere. to come forward and ask the hard questions and get listened to and get decent responses and not get the kind of reaction that we had from these group of people, who essentially told us that we were a bunch of intruders on their process. And it's not their process, it's our process, and the citizens should have an input on should be listened to and the hard questions that they raise should get answered.

CHAIRMAN COSTLE: Thank you, sir. Peggy Meyer. 
MS. MEYER: My name is Peggy Meyer. I serve on the Bridgeton City Council. And welcome to Bridgeton. I know you're just as tired as I am, so this is going to be short.

I have served on the City Council for approximately 11 years, and it seems like every year or so I come and speak in front of a group very similar to you all, and I'm getting very tired of doing that.

We say basically the same things. I've listened to a number of the people in the audience throughout the night, and we keep repeating ourselves. It's like, well, maybe if we keep having another meeting, less and less people will show up and finally decide it doesn't make any difference and we'll do what we want to do anyway. That's kind of the idea we have.

I have a number of resolutions that our City Council has passed in the last 15 years. There are approximately nine of them. They address two things basically, cleaning up the radioactive waste sites, all of them. How many of you saw West Lake? No one? Well, there are a couple of you who I think are local.

Probably you have seen that. I think you've heard tonight that this is one of the sites that comes from the original atom bomb material.

For those of you that don't know about our area, it sits in the major aquifer in the State of Missouri, the Missouri River. So this material is unconfined. We are concerned certainly about the migration of materials into our ground water. We know, for instance, radon gas is being emitted into the air. I live not very far from here, and some days the landfill, which still is an active landfill, you can smell it. And if you can smell that, you can probably pick up some radon gas, too.

My petition to you is I would love for this to be the last meeting that I come to on this. I would really appreciate if we could get West Lake addressed as well as all the other sites. And I thank you for your time. I hope you have an enjoyable visit and everybody gets finished pretty quick.

CHAIRMAN COSTLE: Thank you. Mr. Leonard Sonnenshein. I'm sorry. Shira.

MS. FLAX: If I could ask a question of the Councilwoman, please. When we have gone to other DOE sites, there has not been -- generally there's not been such unanimity between the City Council people, the State environmental officials and the activists and the community members, so I have a question to ask you.

Who is the member of Congress in this area? And if there's such a united position, I'm sure you've gone and spoken to the member of Congress.

MS. MEYER: If you'll check those resolutions for the last, what, 15 years, we have constantly sent it to whatever current member of Congress there is. We have sent it to the 
Department of Natural Resources, in some cases Nuclear Regulatory Commission. Jack Buechner at one time had a bill up that would have addressed this. He no longer is in Congress.

It's not that we haven't tried. It's just basically I think most of us feel like we haven't been

It gets very, very frustrating. We can see some very major problems existing, and they are allowed to continue to exist for year after year after year.

And I'm sure you run into that, too. But this could be very dangerous stuff, and we would like to feel a lot better about our community. This particular landfill that I'm so concerned about, there is a subdivision right next to it. The prevailing winds come from the southwest. It blows right across our community and through the northern part of St. Louis County. So we have tried. You know, when you all came, I thought, well, there's a glimmer of hope, we've got somebody else to talk to, but we have talked and talked and talked. Thank you.

\section{CHAIRMAN COSTLE: Leonard Sonnenshein.}

MR. SONNENSHEIN: I'm president of this region's operating public aquariums, and we have worked with thousands and thousands of kids in educating them about our water resources. I'm coming to talk to you after many empassioned, intelligent and fact-bearing people, so I'm not going to try to repeat what they had to say. I'll give you some new information.

My great-grandfather owned part of the site you're looking at on Latty Avenue. He moved my grandmother to that site from the city to raise her in a healthy way. It's no longer a healthy place to live. Our water resources are directly impacted by Cold Water Creek and Weldon Spring, and what we drink, but, more importantly, or in a different way, what we eat is also impacted. The fish tend to amass heavy metals, and if there are heavy metals, which I'm sure there are, which are radioactive, the fish that we eat will be amassing those heavy metals.

The flooding issue is something we're just now finding out a whole lot more about. Not only is flooding important in terms of what overflows but also what underflows and how it affects percolation. I don't think that was brought up yet either. I think it's a very important point to understand the very special nature of flooding in this region because we're going to see it again.

We don't know what is safe anymore. Certainly what is safe today may not be safe for our kids in the future. And for those kids and for our future, please understand what these empassioned, intelligent people who bear facts, who have given you information before me, and please also concern yourself with the information about flooding and the information about how fish and how our food resources are impacted in long-term effects that we don't know yet, but I can tell you for sure there have been studies and will be more studies. Thank you very much. 
MS. WOLFF: Thank you, Mr. Chairman. I'm Delores Wolff. I reside in St. Louis County. I'm a physician and have been practicing medicine since 1959, specializing in anesthesiology. I'm here to represent myself, the people of St. Louis and the people of Missouri.

I wish to express my severe concern and fears for the future generations of St. Louis and Missouri as well as of our entire country. I appeal to your good conscience and your humanitarian responsibility. I empathize with your position in facing such an unprecedented burden. If you make the wrong decision and allow the continuous discharge of radioactive waste materials into the waters of the Missouri River, you will contribute to a clandestine prank perpetrated upon all mankind. If you allow our drinking water to be contaminated with any level of radioactivity, most of us will suffer no obvious ill effects for many years; however, our children and grandchildren will have an unforgettable legacy early in life.

Small multiple doses of radiation over a period of time create as great a hazard as one large acute dose. The only difference is the rapidity of the onset of the disease process and the length of suffering prior to demise. It is true that we are constantly being exposed to radiation both from the atmosphere and medical examinations. Must we add to this exposure by drinking radioactive water, radioactive milk and eating radioactive fish, fowl and cattle, all of this being the end result of the presence of radioactive pollutants in our drinking water? As our bodies accumulate these nondisposable pollutants, we will become victims of an irreversible situation. Man has great defenses over infectious diseases with antibiotics, but he has no defenses or cures for radioactive-induced maladies. The medical profession respects the benefits of diagnostic radiation and therapeutic radiation, and indeed treads with great caution when using them because it uses them because it realizes that radiation, radioactivity is a two-edged sword. Physicians take various precautions when exposing patients to radiation. Lead aprons are placed over the pelvic area when possible to avoid radiating the reproductive organs. Pregnant patients are not exposed to any sort of $x$-ray procedures unless it is an emergency. There are signs in the radiology departments that state if you are pregnant do not enter or if you think you are pregnant notify us. When $\mathrm{x}$-rays are taken in the operating room, all persons either wear lead aprons or leave the room during exposure. Dr. Dan Boliff, physics professor, and Dr. Fred Valiote, Professor of Cancer Biology, both at Washington University of St. Louis, state that all radiation can be harmful. All responsible national and international radiation protection bodies are on record rejecting the idea that there is a safe amount of radiation.

I repeat and emphasize there is no safe level of radiation exposure. Why then must it be placed in our drinking water? Why must radioactive material be stored in our urban areas proximal to our citizens? We know the devastating events of acute large doses of radiation from our experiences with the atomic bombs. We thereby reject this. We must also reject the destructive effects of small chronic doses of radiation. It is an accepted fact that low-level radiation increases the incidence of cancer, leukemia, congenital malformations and congenital diseases. Studies relating to this are being carried out by Thomas Mancouso of the University of Pittsburgh and Alice Stewart and George Neil of the University of Birmingham in England, all 
noted scientists. Dr. Stewart has definitive evidence that the fetus in utero is 50 times more sensitive to cancer or leukemia when exposed to radiation. Dr. Mancouso's studies verify an increased incidence in leukemia and cancer after five to 30 years following radiation. Linus Pauling, prominent scientist and winner of two Nobel Prizes, predicts an extra 96,000 cancer plus leukemia cases based upon the Atomic Energy Commission safe dose estimates. Professor Joshua Letterberg, prominent geneticist and Nobel Prize winner, has calculated at least 25 percent of our healthcare burden is of genetic origin. If we are continually expcsed to doses of radiation which are currently allowed by federal regulation, we can increase genetic deaths by 150,000 to 500,000 per year. We can thereby incur an annual cost of ten billion dollars for healthcare.

Mr. Clinton's health plan will not take care of this. Low dose radiation is responsible not only for cancer, leukemia and congenital anomalies, but it causes gene damage and destruction, so that future generations will be affected with health problems, and, if they survive, they will perpetuate them.

Is there any valid reason to permit increased radiation exposure to the people of Missouri? Why should we knowingly increase human suffering? We spend millions of dollars and expend much energy trying to eliminate or ameliorate genetically-related diseases, such as cystic fibrosis, multiple sclerosis, cancer, leukemias, atherosclerosis in an attempt to increase the quality of life. We do amniocentesis during pregnancy to diagnose and hopefully eliminate various genetic disorders. We use unleaded gasoline. We do not burn leaves. We protect our wildlife. We try to control the dumping of chemical pollutants so we can protect our environment thereby. Then why should we desecrate our drinking water with radioactive pollutants, a permanent form of garbage?

I believe that it is immoral and suicidal to allow our federal, our state governing bodies to continue our ingestion -- to allow our ingestion of indestructible poisons, that is any form of radioactive waste, in the same manner as we are subjected to an allowable dose of rat hairs and feces in our manufactured food stuffs.

Yes, we learned to split the atom and create unimaginable power. Yes, we committed immoral acts when we conducted radioactive experimentation on uninformed children and adults. Yes, we neglected to determine the manner in which we could dispose of radioactivity safely. Yes we continued to destroy ourselves and our environment. Please do not allow us to continue drinking water that contains radioactive materials, and please do not permit storage of radioactive materials in our cities. Remember, there is no safe level of radiation.

CHAIRMAN COSTLE: Thank you, Dr. Wolff.

Delores Wolff. Sorry. Gibbon Hobbs.

MS. HOBBS: My name is Gwen Hobbs.

CHAIRMAN COSTLE: Gwen. 
MS. HOBBS: That's okay. People do that all the time.

CHAIRMAN COSTLE: I apologize. It got translated wrong here.

MS. HOBBS: I live at Nine Spencer Trail in St. Peters, Missouri. I'm here not as an expert, but as a mother of a child who lives in St. Charles County who has leukemia. I'm here to voice my opposition to the storage of radioactive waste at the Weldon Spring site. I feel that we in St. Charles County are already sitting on top of a time bomb in that there is an increased incidence of leukemia in children in our area. I personally know of four children, including my son, who were diagnosed within an eight-month period and who live within a one-mile radius of each other. I also know'several medical professionals that I have spoken to who also have voiced their concerns about the number of cases of cancer in children that come from St. Charles County.

Because radiation exposure is a known cause of leukemia, it's only natural for me as a parent to wonder whether or not the increased rate of leukemia that I have seen is related to radioactive material that has already leaked into the wells that supply water for the City of St. Peters. Although the DOE testing has not shown contamination of ground water, I feel that I need to -- I feel that a question needs to be addressed. That question is: Is it possible that the DOE is not able to detect the level of radiation that is present in the water wells that supply St. Peters and St. Charles County?

In light of the problems that I have already seen in St. Charles County, I feel that it's ludicrous and irresponsible to use this site, which is next to a high school, many newly-constructed homes and in the middle of a community of growing families to store radioactive waste. Thank you.

\section{CHAIRMAN COSTLE: Mark Guy.}

MR. GUY: Thanks. I know everybody's very tired right now, so I thought I'd liven things up with a little game, a game called "Let's Play Radiation." It's a little true/false. The purpose of is game is not to test your knowledge, but to make a point, so please play along even if you don't think you're going to get any of the answers right. It's going to take just a couple of minutes. In this particular game, there's the proverbial 20 questions, but I'm only going to do a small number of those.

Okay. So pick true, false or misleading for the following statements concerning radiation and human health. Radiation health effects for humans have been confirmed only at relatively high doses or at high dose rates with large populations. At low doses, health effects are presumed to occur, but can only be estimated statistically.

Three. Risk estimates are strictly applicable only to large populations because the appearance of health effects after an exposure is a chance event.

Four. Predicting health effects with certainty for small populations is not possible. 
Five. For purposes of radiological impact assessments, potential health risks are expressed as the increased incidence of cancer in the exposed population.

Six. Risk estimates in the low dose range are uncertain because they are extrapolated from high doses using unconfirmed assumptions regarding dose response relationships and the underlying mechanisms of carcinogenesis. Seven. And this is the final. You're off the hook now. In fact, studies of populations chronically exposed to low-level radiation, such as those residing in regions of elevated natural background, have not shown consistent conclusive evidence of an associated increase in the risk of cancer. The answer I would like to submit to you is that all seven of those statements are either false or misleading. I'd like to touch on just one. And I have all of this in writing, which I will submit to the committee.

CHAIRMAN COSTLE: We'd be happy to take the entire thing.

MR. GUY: Okay. Now, this is one of my favorite ones. This is really probably the favorite of mine. Risk estimates in the low dose range are uncertain because they are extrapolated from high doses using unconfirmed assumptions regarding dose response relationships and the underlying mechanism of carcinogenesis. Okay. The Hiroshima and Nagasaki Life Span Study was by far the largest and most complete human epidemiological study that we have to date on the effects of radiation on human health, comprising over 90,000 individuals followed since 1950. The largest cohorts of this group, totaling over 60,000 , received what are considered low doses, 30 rads or less, some with an average in the area of three rads of total exposure. These groups show conclusively there is an increased cancer risk, even at low doses. This conclusion is not extrapolated using unconfirmed assumptions. It is the best observation of the best human evidence we have available. Because these groups are the largest, their numbers are also the most reliable of the entire study. Nor is this the only evidence we have from human epidemiological studies about the measurable carcinogenic effects of low level radiation.

This is not the time or the place to review the evidence. However, the statement quoted above is unequivocally and absolutely false. While we may not be able to delineate the exact mechanism of the carcinogenesis, as we cannot for asbestos and smoking inducing lung cancer for that matter, we have solid evidence from low dose and low dose rate studies of the quantifiable risks associated with exposure to low level ionizing radiation. Any statement to the contrary is a sham and is motivated by something other than science. Now, what l've just read to you are the first two paragraphs from the baseline risk assessment entitled "Radiation Toxicity". This is dated November 1993. There are three other sections in here.

"Radiation Toxicity," "Radiation Toxicity Related to the St. Louis Site," and "Methods For Evaluating Radiation Toxicity." They're all garbage. These are the underlying assumptions that go into this entire book, and they're garbage. This whole book is not worth the paper it's printed on. Their numbers -- to get to the numbers, and there are numbers in here, they're off probably by a factor of anywhere from a hundred to a thousand. So garbage in/garbage out. That's a phrase we use in computers. 
The kind of thing that this leads to is the kind of thing -- in fact, I want to let you know you are really all wasting your time because this is a FUSRAP St. Louis site, Department of Energy, July 1993. You're all wasting your time because "We have more good news about the health risks associated with living near sites contaminated with low levels of radiation. The waste sites do not appear to pose a threat to residents." Really, we can probably just all pack up and go home here. "The types of radiation found in the area and the most likely routes of exposure to the current residents are not likely to lead to the types of cancers found in the residents." This concerns a cancer cluster that has been mentioned on Nyflot Avenue, and my comments in this paper are part of a refutation of this stupidity. And then it finally concludes, "DOE's risk assessments are accurate and are based upon conservative assumptions."

Well, they are conservative all right because they ignore the last 30 years of human epidemiological evidence. They are ridiculous.

I like to call the DOE the Department of Evil, and I would like to finish with a joke. It's an old one. We know the DOE is lying because its lips are moving. And the reason the DOE has no credibility is because it deserves no credibility based on what it's writing and giving to us right now. So thank you.

\section{CHAIRMAN COSTLE: Jennifer Pulitzer? Andre Stevens? Beth Okenfuss.}

MS. OKENFUSS: Hi. Good evening. I guess I should say good night. I really appreciate all of you being here and being here so very late at night and listening to this big world of burdens.

I'm Beth Okenfuss, and I live in Chesterfield at the moment, but I grew up off of Latty Avenue, and I'm here representing myself as a mother, a wife and a family member. I lost both of my parents. My parents both had a form of cancer in their lives. This morning I sat down with my brother, and we figured in the two street area that we could think of, and I haven't lived there for some time, so I'm sure that I don't even know, I'm not even aware of all the other instances, but we figured 15 people in two streets that we knew of with some form of cancer, including leukemia. My brother's four-year-old son died, I believe it was two years ago, with a form of cancer. My brother delivers items to McDonnell Douglas and daily drives through the area of the waste site. Growing up as children, we played in the area. One year ago I found a lump in my thyroid, and I went to see a physician at Barnes to whom I was referred, and this is a physician who served as a consultant during Chernobyl, so his area of expertise is people who have been exposed to radiation. And I was -- excuse me. I was told that I should have surgery. I chose not to. I chose to use holistic and natural means that I knew about. And the compromise was that we would watch it for one year. I recently was in to see another physician who found another lump, and so I will be having that biopsied. But at the time, one year ago, I was told that forever, the rest of my life, I would have to watch for these lumps, that I would be at high risk for malignancies. 
At the time that I discovered that radioactive water was being dumped into our drinking source, I did phone a gentleman at the St. Louis County Water Company, who was very nice, but who had a very public relations style speech, canned speech, that he gave me about how I didn't have anything to worry about. I think the people in St. Louis can deal with the facts if we're told the facts. I think we're adults. I think we're grown up. I know that you all don't maybe personally have the solutions, and I don't expect you to, but I think that perhaps I would like to see us serve as a model site for working together with agencies and with citizens in a very open way dealing in a very open and honest way.

I think we can come to a solution. But I would like to say that I would like -- I would like in the future to see that things are not covered up. In my studies as a graduate student in environmental science, I study a great deal about the environmental devastation in the Soviet Union, and what astounded me was the great amount of cover-up, but then when I began to look here in St. Louis and in our United States, I found that we're not really so very different, and that concerns me a great deal. And so I really call on you to take our message to whomever you're planning to take it to in the government, and also, one last thing, to think of it in terms of I believe that if we clean up our environment, not only here, but across the United States, we can, in fact, reduce our health bill in the United States that we're so concerned -- this administration is so concerned about. Thank you very much.

\section{CHAIRMAN COSTLE: Thank you, Beth. Ed Marr.}

MR. MARR: My name is Ed Marr, Jr., and I've been associated with the so-called quack health food groups for about 25 years, and a lot of what they said back then is now more or less in the mainstream of I won't say medicine, but at least home healthcare, that sort of thing.

I agree with what has been said here, but I want to raise everybody's attention off of the problems that we're now facing, and let's go about ten, 15 years in advance because there's something waiting out there that no one is really addressing right now. I did the same sort of thing with the airport waste water run-off. They have a problem with runways. They have culvert: under the runways. They can't move or extend the culverts because the airplanes are too heavy and the amount of bureaucracy is too great. So Mr. McCracken and company have started to do something on the other end of the airport to take care of this water waste that occurs every rain. It's been doing this -- I'm 60 years old. They've been doing it at least 40 years. They've always had cops out there after the rain. And most of this water right comes by the Latty Avenue site and the McDonnell Boulevard site. Cold Water Creek is where most of it goes into. 
So this problem is unique around the country because they cannot really regulate the amount of waste water after a rain that goes by these two sites, and all they can do is build these baskets of rods to more or less contain the water.

All right. Now, that's an aside. Now, with this thing that is coming ten years in advance, 15 years in advance is really a more major problem than what we've been discussing this evening, and that's the decommissioning of all of these nuclear plants. The amount of contamination that this problem is going to present in the future, it makes this seem like nothing. Unfortunately, history goes rather slowly.

From what I understand, the atom was first coined as a word back in classical Greece, and it wasn't until Einstein came along and put some mathematics to it that this whole thing got underway. The reason no one has been able to solve what to do with the waste is because everyone is in the applied science field. There are very few pure scientists around. Maybe Linus Pauling is one that will come up with something. But all of the people working on the sites here in St. Louis are engineering people. What they do is take formulas out of books just like you did in grade school. The information is already in the books. All they do is take it out and either apply or misapply it. We don't have very many pure research people that have come up with anything definite. So if the problem's here now, it's going to be here in 10 or 20 years for the nuclear reactors.

But, unfortunately, it may be here much sooner than 20 years if we get a Chernobyl. They had to face that problem overnight, and it could happen here, although, God forbid, you know, nobody wants that to happen. So it seems to me that all the engineers that are applying the applied science are simply scattering the waste about. They don't have a solution for it.

They are just spreading it out in the oceans. They dump all the nuclear reactors, our Navy does, Russia does, England does. They dump them in the oceans. And some people say some of the Weldon Spring stuff is going down the river into the Gulf of Mexico, and somebody recently found it in the Gulf Stream going up alongside of Florida.

Let's say that the raw ore came from within the ground and it was there without causing too much of a problem. We mined it, we brought it up, and we didn't know what to do with it, and we put it in places here and there. Unless you get a pure scientist to solve this problem, I propose that we should dump it underground. Now, there's a ground water problem, but there was a ground water problem before. Or another way, another corollary of this, would be to say that --

Let's suppose we have a nuclear plant. We can take this thing apart, like they are doing out there at Weldon Spring, and we can bury it, or -- Well, also the wind will blow -- Whatever is loose, it will blow it around and the rain water will blow some of the contamination into the river and so forth. An alternative to this would be what they started to do at Chernobyl and will probably yet do, and that is cover up the whole mess. They'll do it with concrete. They'll do it 
with steel. They'll do it with lead bars. They'll do it with anything that will keep the radioactivity contained.

And most probably we'll have a mountain of concrete and steel that will be a football height, football field height, and that, in essence, would put it under the ground. Now, what you're going to do with the acres of stuff, I have no idea, but the major contamination would be from the flants. If there is an emergency, it would behoove someone I would think to have an emergency plan.

All you would have to do is see what type of pad the nuclear plant is on. If it's on a satisfactory pad, then you simply build some pyramids around it, great big pyramids.

So I'm not opposed to burying the waste, but unfortunately we're trying to bury things that have been spread around. What I'm saying is if we treat the future problem like we've treated this, it's just going to be all over the place. So let's just localize it. If the ground-bearing conditions are such that you can build the mountains, then let's put it under 300 or 500 feet of concrete, steel, lead and earth and just make this a mistake, and until the theoretical scientist comes around to do better. I mean, we're all in the field of applied science, and there's nothing easier than lead, concrete and earth, and that's it.

CHAIRMAN COSTLE: Thank you. Mr. Marr.

MR. MARR: Oh, by the way, one other thing. I don't know if all of you are familiar with John Gofman, but it was mentioned earlier they did these studies on Nagasaki and Hiroshima. Now, according to his credits, he is not only a medical doctor, but he's also a doctor of nuclear and physical chemistry and he was working on the Manhattan Project, and he was the one sent by the United States Government to categorize and get all the information for those two atomic bomb blasts. So he's written several books. The name is G-O-F-M-A-N, and I recommend if you're trying to see -. He's probably closest to an organizer than any of the applied science people that are trying to take his work or not use his work. Thank you.

CHAIRMAN COSTLE: Seth Carlin. Seth, you are the last witness this evening.

MR. CARLIN: Thank you very much. I appreciate the opportunity to be here. And I'm here tonight to speak on the Weldon Spring water issue. I've been a resident of St. Louis since 1979. I'm the father of two children, ages 12 and 15.

Both as a concerned citizen and more especially as a parent, I would like to voice my strong objection to the current policy of releasing the water which has been exposed to radioactive contaminants from Weldon Spring into the water supply of the greater St. Louis metropolitan area: Although we are assured by the authorities that this water is safe, the past history of governmental safety assurances does not inspire confidence. One wonders if the citizens of our community are not, in fact, being utilized as unwilling subjects of a large-scale experiment on the effects of water which at the least has a likelihood of being radioactively contaminated. 
The magnitude of the problem should not be underestimated, and I believe that the public at large is not aware of how serious the situation actually is.

In the past, 90 curies of thorium 230, a highly radioactive substance with a half-life of 75 to 80,000 years, were dumped into the quarry at Weldon Spring. In addition, 700 more curies were deposited into four raffinate pits nearby. By comparison, the entire radioactivity of experimental materials utilized by the approximately 850 laboratories at Washington University, Barnes Hospital, and Jewish Hospital combined is only two curies per year. It is difficult to believe that some of this large amount of contamination has not already found its way into the 12 million gallons of water that have been released to date. However, governmental tests have not even detected thorium 230 radioactivity in Weldon Spring water prior to treatment.

In view of the presence of such a large quantity of radioactive material, it shakes one's confidence in the monitoring system if it fails to show any pretreatment radioactivity.

The government has placed the public at risk through its past actions in depositing radioactive materials at Weldon Spring. At the very least, the Department of Energy owes the public a satisfactory accounting of what has happened to this quantity of radioactive material since it was deposited. In fact, this has not been forthcoming because the situation has not been properly elucidated from a scientific point of view. With a highly toxic substance, the situation should be studied until scientific facts are understood beyond doubt before any potentially-dangerous action is taken.

Since the government has not yet provided a satisfactory explanation, it seems clear that the prudent course is not to put this water in our drinking supply. Government agencies have emphasized that because the release point is nine miles upstream from St. Louis any hazardous materials would be disbursed before entering our drinking supply. The public, too, seems willing at times to accept this dispersal theory, according to which we can safely release toxic materials in the Mississippi because the great volume of water flow would sufficiently dilute any potentially hazardous substance.

In fact, we may not be able to count on dispersal as a solution. The experience of the floods of last summer brought this home in a dramatic fashion.

In September after the floods, researchers from the Rosenstass School of Marine and Atmospheric Science of the University of Miami found a current of fresh water from the Mississippi some ten miles wide and 60 feet deep in the Gulf of Mexico just offer the Florida coast. In effect, the devastating summer flood of the midwest was being felt 1500 miles away. Dr. Zeka of the Rosenstass School, stated that he observed as a result of that water, "a dramatic change in the chemistry and biology off the South Florida coast," According to Dr. Zeka, the fresh water along with its chemicals and other pollutants and unwanted nutrients had the potential to grow organisms you don't want to see, such as red tides which can cause fish kills. It can affect lobster and fish larvae. These organisms don't do well in fresh water. Zika found it amazing that this river of water was holding together as well as it was hundreds of miles from the mouth of the 
Mississippi. Although in this instance radioactive substances were not a factor, this experience in the aftermath of the floods cast serious doubt on the so-called dispersal theory and provides yet another example, if such an example were needed, of just how interconnected and fragile our aquatic ecosystem is.

Our family's personal response to the water supply problem has been to purchase bottled water for drinking purposes. There is really little else the individual citizen can do when the safety of the water supply is in question since fresh, potable water is such a basic, ongoing necessity of life. Because of this expense, however, bottled water is at best a partial solution, even for a middle class family, and for poor families it is entirely out of the question. It is extremely unfair to penalize a significant portion of our population in the name of what may ultimately be a matter of administrative convenience or political expediency.

In conclusion, I would urge the Department of Energy Environmental Management Advisory Board to advise local authorities to cease immediately their policy of releasing water from Weldon Spring into the water supply of the greater St. Louis metropolitan area. The decision to release this water before the scientific facts are fully ascertained seems to me particularly unwise. In this already dangerous world, it's unconscionable to place ordinary citizens and their families needlessly and further at risk. Thank you very much.

CHAIRMAN COSTLE: Thank you. That concludes the public comment period. I want to thank everybody who came tonight. It's been a long evening, and I appreciate the fact that you had the patience and stick-to-it-ness to come and bring your testimony to us. I think I will entertain a motion to adjourn for this evening.

MR. MCCALL: So moved.

CHAIRMAN COSTLE: Do I hear a second?

DR. DONATH: Seconded.

CHAIRMAN COSTLE: All in favor? We are adjourned. Thank you again, everybody.

(Whereupon, the hearing was adjourned until 8:00 a.m., March 15, 1994.)

CHAIRMAN ALM: The baton is passed to the older generation of Americans. I'm going to be running today's session. Let me mention some changes in the schedule. First of all, between now and nine o'clock, Tom would really like to talk about our discussion last night and get the reaction from the members of the committee with regard to the public comments on the FUSRAP sites we lonked at yesterday. Then from 9:00 to 10:30, we would cover the site-specific assessments. It was on the agenda. And, by, the way, in that context Barbara Bass will join the committee at the table. Barbara is somebody who's done a lot of risk assessments, not only for EPA, but for outside groups, and I think her perspectives will be useful. 
MR. GRUMBLY: Thank you, $\mathrm{Al}$ and Doug. I want to thank everybody for all the time that they spent here yesterday, and also I'd like to thank all of the people who came forward to talk at the public meeting last night. I understand it was very interesting meeting. We obviously have major problems here in the St. Louis area. As $\mathrm{Al}$ indicated, I would like to spend at least a few minutes hearing from members of the committee your perceptions of what you both saw and heard yesterday.

Before we do that, I guess I'd also like to welcome Tim Fields from EPA and Barry Green, if he's here. I don't know if Barry's here. Tim, we welcome you as an observer at this time. Tim, we need to have some new members of this committee from the Environmental Protection Agency, and Tim is taking over on the federal facilities responsibilities along with Barry, and we hope to incorporate them into the committee subsequent to this meeting, but they are here in an observer capacity at this time.

I've got my own sort of views about the so-called FUSRAP program based largely upon my experiences in New Jersey over the last few months, which I'd like to share with you, but first I'd like to hear from anybody on the committee who has some perspectives about the nature of the problem and what we might do differently in this very vexing program at this point. Does anybody want to take a first --

MR. McCALL: I'll be a guinea pig, Tom. It's pretty clear that what you're doing now isn't working and putting this pile of radioactive dirt in the middle of St. Louis isn't ever going to be a popular solution here, and it's fraught with a lot of problems. On the other hand, having the City of St. Louis stand off with you and not participate with you isn't constructive on their part either. I would suggest that you need to form a partnership, and you're pretty good at this, with the City of St. Louis and then seek a third party to that partnership, because I frankly can't take sympathy with people who want to put their radioactive waste someplace to spite someone they don't like, like a nuclear power plant, if that nuclear power plant doesn't wants to receive it. However, there is a possibility that a nuclear power plant or somebody else might want to receive safely entombed nuclear waste if they entered into an agreement with St. Louis like a license or some other sort of fee that St. Louis could pay. I'm not saying that St. Louis should pay. I'm not saying what you should do. I'm just saying it's an intractable political situation when you've got a really fairly easy cleanup remediation issue. This isn't a Hamberg. This is scoop it up and stick it somewhere. That should be easily solved. So I commend you to a partnership in St. Louis and the folks around here and then look for another partner to enter into that and get a constructive solution to where this stuff gets rested.

CHAIRMAN COSTLE: Thanks, Tad. 
MR. SMITH: Something that certainly aroused my curiosity, it may just be an information where I need more information, but in looking at the handout materials yesterday, the numbers of hypocuries per gram of the material out there that's scattered in the environment with no contamination controls, there seemed to be a disconnect between the stringency with which we are dealing with contamination control in other situations and doing nothing to deal with these materials that are out in the environment becoming airborne. They're in parking lots where cars are stirring them around. Maybe I just need more information to understand it, to know that that's not a problem, but it certainly appeared to be a problem without the information I don't have. That's a short-term thing, but it's a thing that could be dealt with more immediately.

MR. GRUMBLY: Jeff.

MR. BRECKEL: Tom, I guess the thing that struck me about the situation last night was the utter and total breakdown of communications between DOE and the community. It was pretty clear from listening to these people that I don't think there's anything that DOE can say that these people would believe. They talked about the discharges from Weldon Spring to the river, and, you know, noting that DOE was not detecting any trace radioactivity in those discharges, but they don't believe it. They talk about thorium being placed in the quarry and now DOE can't detect it, and they don't believe it. It just seems to me -- I guess I would second Tad's notion that somehow you need to get out and talk to these people face to face very personally. This cleanup should be a real straightforward one, and I think it's an instance where parties came together with very technical perspective and came up with what they thought was the right answer, but there was no ownership of that answer in the community.

\section{MR. GRUMBLY: Shira.}

MS. FLAX: Before I make concrete suggestions, I'm going to do something I've never done before, which is commend DOE. I mean, in the past, I have not been shy. But then, Tom, I think your decision to face this problem immediately is just terrific, and I really want to commend you for it, and all I can do is build on what my predecessors have said. To go along with what Tad has said, in your negotiations with the City of St. Louis, if you would get the maintenance issue resolved quickly, I think if the community could see better posting of signs, a restrictive fenc: that covers -- that begins with the ditches, these are very concrete things that I think illustrate the type of leadership that you're trying to bring to DOE, which is results oriented.

I really want to second what Jeff said about the thorium issue and suggest that if an independent -- if a scientist that is credible in the eyes of DOE and the citizens can be brought in to answer the question of why thorium, which is in such high concentrations in the solid waste in the quarry, is not showing up in the water samples and, therefore, is not being treated in the wate treatment system. I want to note that five years ago there was apparently a citizens advisory committee that was set up, and one of the members of that advisory committee spoke to us last night, and I think he would be a good person to bring into your dialogue about the thorium issue as well as well as all the other issues. 
MR. SJOBLOM: I don't have comments on this FUSRAP issue, although I have to say there was some sense of deja vu all over again because when I was in New Jersey state government, I had that site, too, and its various legacies.

Regarding the Weldon Spring situation, where I have sat and been there for three years, and I was personally very pleased to see the progress and the approach and so on and so forth, clearly the level of concern about discharges up there personified by percentage by the thorium, although I think it's probably a little broader than that, is a key issue, and I think Shira has got a very good idea for a way to approach it, which I'd like to amend slightly.

I'll preface it by saying this community, as was mentioned by one of the speakers last night, has a long, long history of highly knowledgeable, well-informed citizen concerns about matters radiologic. The Baby Tooth Survey, which was mentioned last night by one speaker, is I think one of the outstanding examples of involvement of citizen involvement constructively in a major U.S. policy issue over the last half century. In this city, there are world class scientific institutions with world class scientists, and it seems to me that this discharge question from the Weldon Spring treatment plant should be amenable to some sort of technical review/mediated approach that would involve experts from DOE and its team, experts from the community, from institutions in the community trusted by the community, perhaps with some neutral outside third party that could really dig into the monitoring techniques, what's been done, whether actinide chemistry has been properly addressed and so on. My sense, by the way, what little I know about actinide chemistry, is that it may well be correct, that no detectable thorium is getting out. I say that as a hunch. But there's a set of issues there that I think are well enough definable in a technical sense that people of good will and the right kind of a structure could dig into that issue and resolve that issue by prompt -- it should be I think more than just the thorium because the discharge point is critical in the minds of many, and they'll be worried about other things, too. But I think that might be a good definable topic and one that could be dealt with promptly, constructively, and in a way that if the technical parts have been done right would probably lead to a good deal of credibility on other issues in the community.

MR. GRUMBLY: Let's see. Jay maybe.

DR. SORENSON: Well, I think what you have is really a price of conflict. You have a public really that believes that it is not being listened to, and it feels really that it's being asked to accept a social bargain on the question of waste disposal that's inequitable. That's quite apparent.

I think really what is necessary is to build on the mechanisms not only of communication, but also of consensus building. And so what I would urge really would be, to supplement Tad's proposal, would be to reach out for members of the congressional delegation, who obviously would wish to see this problem addressed as well, and join forces with them, identify not only the individuals who were here and then have some conversations with them, but reach out then for some of the key organizations and slowly but surely begin to use that approach as a vehicle for 
establishing the confidence levels that are necessary for them to be at least be willing to perceive it to be an equitable arrangement and be open to suggestions.

MR. GRUMBLY: Down here, and then I'll come back to Tom.

MR. CONNOR: Thanks. I second everything that's been said, but I just wanted to put something very concrete on the table with regard particularly to the activity at the St. Louis airport site. If before you and the Department's caravan leaves St. Louis this week, you can make a commitment to answer Mr. Shorr's concern about the lack of monitoring, maintenance and security at that site. That would be extremely helpful.

MR. GRUMBLY: Is Mr. Shorr here? Why don't we ask him to come up to the table.

MR. CONNOR: The reasons -- I don't quite understand the reason that's not happening. It seems they were rather legalistic in nature. But this to me would be a first step to getting at the crisis of confidence problem. If that step could be taken this week, if there's any way you could make that commitment this week, I think it would be extremely helpful.

MR. GRUMBLY: Richard.

MR. BANGART: All of the options that were discussed last night seemed to be the haul-away disposal cells, put a cap on it. The question was where should that disposal cell be. And perhaps this is an opportunity also to bring in advanced technologies or development technologies wherein you could at least remove the higher concentration activities, reduce that to a smaller volume, where it might be affordable to send it to Utah, or wherever they are willing to accept it, and gain greater acceptance for a disposal cell that had lower concentration materials in there, and I would urge you to consider that possibility as well.

MR. GRUMBLY: Tom.

MR. WINSTON: Last night I heard, more than I have at any other site, the fact that people come out to meetings for years and years without really any satisfaction whatsoever, and whatever strategy you put together to, whether it's a third party intermediary, I would suggest that you set some sort of specific schedule because I think you need to send a message that this is a different approach, that the Department is going to make a decision, and it's going to have to be ? timely decision, or else I really sense despair on the part of the people that they really do not feel there was going to be an opportunity in their lifetimes to get on with this business.

MK. GRUMBLY: Fred.

DR. DONATH: I think it's important to recognize that there are both short-term and long-term aspects to approaching development of confidence and trust. I was very impressed by the strength of feelings of the public last night, and some excellent suggestions have been made this morning as to how to approach it. I think there's an immediate aspect that needs to be dealt 
with to hold out some hope to start to increase confidence, and I'd like to second what Glen had suggested. It's important, long-term, I think for the public to have individuals who they feel represent them or are part of them. There's excellent scientists and work being done in this community, and I think if these individuals can be identified, apprised of certain specifics, being brought into the discussion process, that would help develop the trust and lead to confidence in the statements that DOE makes with regard to what they are doing or are supposed to do.

MR. GRUMBLY: Anybody else want to? Jerry.

MR. CHRISTEAN: You know, for all the gloom about this problem in St. Louis, there's at least one advantage here that we do not have in many other areas, and that is at least we have the technology to solve this problem. Some of the areas that you have problems in today, you don't have the technology to solve those problems. So at least there's that part of it that's hopeful.

I think there are really kind of two aspects to it in St. Louis, and that is the real problem that's out there that's a real danger, present danger, and it could be scientifically proven to be so, and then there's kind of the emotional thing that's out there in the community that is really strong. And somebody has already said they were really touched by how to-the-bone concerned folks are about what's going on here and how they've been in their view mishandled and mistreated. And I saw in a commercial on TV what I thought was really kind of clever. It kind of fits here in a sense, and that is -- And I'm going to paraphrase a little bit, but the citizens of St. Louis surrounding areas don't care what DOE knows until they know that DOE cares. And so I think you've got -- That's your first charge is to make damn sure of that they know what we know about you and your folks, that now -- now DOẼ cares.

MR. GRUMBLY: Mr. Shorr, you want to comment at all on what you've heard? Oh, I'm sorry. I apologize.

MR. BECHTEL: One task you seemed to have charged ahead on is land use, and I think this is really kind of a classic land use dilemma. You've got a community who is not able to use land for what they've defined as what they would like to use it for. We heard last night about park land that can't be used now because the land is contaminated. There's some uncertainty about some residential areas that have been contaminated. And I think this is an opportunity for DOE to sit down in partnership, in the partnership perhaps that Tad mentioned, to be able to solve some of the problems and get some of the land back to the residents of the area so they can use it for purposes they've defined it as.

MR. GRUMBLY: Mr. Shorr, you want to comment on everything you've heard and also give it to me directly what you want?

MR. SHORR: I think the biggest thing to us has been that we have tried to be -- When I say "us," the State of Missouri and its citizens, have been what I would consider a good partner. We're embarking on an almost billion dollar cleanup in one portion of our operation today. This is not a community that shrugs its responsibilities, and I found, having been a transplant, here I 
have found it very difficult for me to understand why we have such a differential between what we are doing in our Weldon scenarios and what we're doing on our FUSRAP scenarios. It's almost like it's two different worlds. I don't believe that's intentionally on your end's part, but it's reality. It's what we refer to as the stepsister syndrome, and there's something we have to do to bring the FUSRAP sites into the true realm that it is a nuclear weapons production facility. That is number one. I need that; the people here need that. And they need that from you.

I think the other thing is, unlike some of our citizens groups, we have never flat-out rejected any strategy presented as long as it met the criteria that we originally set out at Weldon, and those criteria were basically related to our hazardous waste, our hazardous waste laws and certain containment structures. We have nothing on FUSRAP anywhere near what we're talking about with Weldon, and there's something we have to do to resolve that. I like some of the suggestions here. I think you need to build some community support. I think you need to build some support. We're schizophrenic with DOE, so it's hard for us to imagine our public not being in a very bad situation here at FUSRAP. We need to build some new relationships on FUSRAP. We've got a good relationship on Weldon, and it puts me in a very difficult position because some people are talking mediators. As I think you are aware, I do not now except any funding from DOE regarding FUSRAP, and the reason is because it is very difficult for me to be credible with my constituents on any commentary on FUSRAP if I am both being assisted, and it makes it even harder for us to turn around and help you when we don't have money to assist you. Okay. So until we start helping the community understand that the FUSRAP site is a real site and a real concern and something that you're going to do something about, we're going to be in a problem area.

MR. GRUMBLY: When is the next formal opportunity for the citizens who are -- or even an informal opportunity -- for the citizens who are most interested in this problem to get together and express their concerns? They did this last night. What I'm trying to think about is the schedule issue that Tom brought out, brought up. Is there a -- Remember when I met with Representative Talent about this, he put into my mind that there was something in late May per chance that was with respect to this project.

MR. SHORR: Tom, I wouldn't know that.

MR. GRUMBLY: You don't know that. Let me say this. Actually I'll tell you what I'm going to do first, or what I'm proposing to do, and then step back and tell you a little bit about the constraints I'm under. But rather than tell you about the constraints first, let me tell you what I think we're prepared to do.

First, it seems to me we should either not go forward or withdraw whatever the proposed plan is that we have. It's clear that's not going to make it. So whether it's in or about to be in, it's out at this point.

I think, secondly, at the first viable opportunity I'd really like to sit down together with you and your colleagues in Missouri, with the relevant people in the political community, as well as 
with representatives of the citizens organizations, to, you know, hear directly about the long-term strategy as well as to share with you the constraints I'm about to share with you personally so we can develop potentially a new strategy not only -- that can serve as a model not only for the St. Louis sites, but also for some of the rest of the FUSRAP sites around the nation.

Third, it seems to me we need to hear from you right away and also from our colleagues in the EPA about what immediate actions need to be taken at these sites in order to stabilize them, in order to deal with the dust issues, because that strikes me as an immediate potential public health concern that we really do need to deal with.

Fourth, I'm quite'open to Glen's idea of putting together an independent review, a group on sonie of the sampling, to review all the sampling that we do, so that experts from this area or experts that the citizenry trusts can get in and take a look at what we're doing.

Fifth, what I'd like to do is see if we can begin to separate these problems into some pieces. I'm not satisfied -- I'll say this forthrightly. I'm not satisfied that the public interest is served by the current total assumption of responsibility in this area by the U.S. Department of Energy. It seems to me that the private sector, in this case Mallinckrodt, needs to step up to the plate a bit, and we need to engage them. If that means we have to go back to the Congress for more authority, we may have to do that. I mean, but it doesn't seem to me that we ought to continue to let our colleagues in the business community run away from problems that while we may have helped them create they also created themselves, and this is a problem that goes beyond here. It goes to a number of other sites around the nation where theoretically we have the ability to bring private parties in, but, in fact, we haven't done that yet.

I guess what I'm saying fundamentally is we need to relook at this entire site. We need to deal with some of the immediate problems right now, and l'd like to work with our regulators and citizens to come up with a set of actions we can take in the near future to deal with that while we work out a longer term strategy for dealing with this problem.

Let me tell you the problem we have, and then I need your help, and I would actually like this committee's help at the next meeting which have which, I understand is going to be in May and, I know it will be fundamentally devoted to the PEIS, but I think it's something we need to think about. And that is either a strategy for expanding the pie or for dealing in a more prioritized way with the FUSRAP sites. The reason why there's this huge distinction between the Weldon Spring sites and the FUSRAP sites is because the Weldon Spring site is funded as a line item in the budget. As a result, we're able to amass the resources against it to do it. The FUSRAP sites, inciuding the St. Louis sites, the other St. Louis sites, are in a pod of 44 sites that compete for right now $\$ 54$ million every year. So this is not -- The money does not come out of the defense side of the budgets the way most of our money does. It comes out of the civilian side. It's a program that I've described to some other people as Methadone for members of Congress because it provides a small amount of money every year to a whole lot of programs so that everybody is sullen, but not mutinous in this. And I for one think that that's not an effective strategy for the long run. 

program. First of all, in the 1995 President's budget, I was able to propose an increase of about $\$ 25$ million in the appropriation, from $\$ 54$ to $\$ 78$ in this area, to try to take care of some additional work at some sites.

Secondly, the pod of money that this ccmes out of includes not only FUSRAP but UMTRA, the uranium mill tailings program. Unfortunately, we're on the tail end of that program. So the total pod of moncy potentially to deal with; FUSRAP and UMTRA could in the next three or four years be as much as $\$ 130$ million if we can persuade the Congress to leave us with the overall appropriation in tbis areà that we have.

So, we will have, I hope, sorne expanding resources to deal with. The St. Louis sites are the victim of their size at the moment. Until we can amass enough resources on the problem, it's been perceived by my colleagues as not worth making much of an investment because we really couldn't do very much against it, and as a result it's gotten deferred to the outyears While we've dealt with some of the smaller sites where we could actually make real progress first. We need to obviously find a way to reconceptualize that problem with you.

So we do have some limitations. I think that the suggestion that was made to try to reduce the volume fairly dramatically is one that we're trying at a number of sites in New Jersey at the moment. We hope that's going to have a pay-off so by the time we come up with a plan, we may be able in fact to reduce the volume through soil washing, various other kinds of technologies, so that we can minimize the number of trains that we have to take to Envirocare in Utah for these kinds of -- these kinds of problems.

Fundamentally, it seems to me we're going to have to work together to do one or a number of things. We're going to have to focus on technology development in this area of the problem to make sure we've got technology that can, in fact, reduce the volume.

Secondly, I think we're going to have to decide whether the current strategy of a little bit every year to a lot of these, which punishes sites like the St. Louis site, can be changed. That only be changed with the help of the members of Congress, both House and Senate, who are involved in this, which is to say the members have to be willing to step up to the plate and work together and decide what is the strategy we're going to use as opposed to simply making DOE into the bad guy when at least part of our problem is due to the amount of money that we've got to deal with this.

Now, one other way to deal with that problem is potentially $t: 3$ move this from the civilian side of our budget to the defense side of the budget, and that was tried unsuccessfully a couple of years ago, and you say, "Well, why would that help?" Well, the constraints on the defense side aren't quite historically as tough as they are on the civilian side, although with the budget caps, everything is getting tighter and tighter and tighter. 
But fundamentally I think we need a new strategy for this program as a whole, a strategy that would benenit sites like the St. Louis sites. I think we need to work together with the members of Congress and the local community around here in a partnership arrangement that you're talking about so that we can come up with something that ultimately satisfies the needs of the people here as well as in concert with the amount of money that we have, which means that the political community needs to work together with me to make sure that we have the resources to deal with this problem once we've got a strategy for dealing with it.

So I would propose we get together here in the St. Louis area for a serious workshop among those of you who have got day-to-day responsibility for working this out, including the members of Congress who are interested in this, to see if we can't come up with a strategy that will work for the St. Louis sites and will also work for the FUSRAP program in the long run, and I would challenge this committee to gather your ideas and come back to me with how you think we might work.

But right now I think we can -- You know, we'll withdraw the proposed plan, get engaged in -- We won't try to engage you on what the solution -- the long-term solution ought to be. I'd like to hear about what immediate actions we can take to mitigate any immediate risks. And I'm happy to begin to work to impanel some independent folks to take a look at the data that's coming out so people have more trust and can look at the data themselves. Tom.

MR. WINSTON: Tom, out of all the things you mentioned, I think they're all sound approaches. The last one, which really was addressing the funding issue long term for FUSRAP is probably the most important because I'm afraid all the other steps are going to be meager if the funding levels, if you take a look at the burden out there, are just --

MR. GRUMBLY: I think we should be absolutely clear, the cost of this is going to be -- If we have to take it all away, the cost is going to be -- over time is going to be in the same vicinity as the Weldon Spring money. It's going to be a billion dollars. Right now, if I were to go in, because I've just been there, and I have to go in tomorrow. If I go in and say, you know, "I've another billion dollar cleanup underway," most of the members of Congress on both sides of the aisle are going to tell me to go away. They don't have the money because the budgets caps that were passea last summer is the law of the land. I mean, I'm going to have trouble, and we're going to hear it, about sustaining the budget that I already have on the table, which is lower than the President's budget request last year. And the mood in the Congress is you're still asking for too much money.

So I agree with you. We have to solve this problem together so that we come up with a proposal to make to the Congress that's got the support not only of the members in this district and the members from Missouri, but some other key people in the vicinity so we have a shot at getting the money. I mean, I would like to shrink the amount that I have to send or that we have to get out so we can potentially lower the cost of the remedy, but I think we can't hide from this problem anymore, and we can't propose remedies that we think are okay technical solutions, but that clearly don't pass muster with the customers. 
MR. GRUMBLY: Well, I don't think we'll be able to expand the funding until we have a new intellectual strategy for dealing with the problem. At least my experience is that bellying up and asking the Congress for just more money for more sites isn't going to cut it. It's only if we can kind of say, "Look, we've got a better idea about how to do this." Then you have something to market. And when I have something to market, then I think that we can potentially make some progress in the game.

So the way I think that this committee can best help, aside from, you know, utilizing the contacts that you all have -- I have to be careful about urging you to lobby since I'm not allowed to urge you to lobby, -- is to help me formulate, you know, what you think the most appropriate strategy for this program in the long run might be. If we do that, then I think there will be some willingness to listen on the part of the defense committees as well as the appropriators who -- So it's both the authorizers and the appropriators that we've got to persuade in this.

\section{Maybe two more comments.}

MR. CHRISTEAN: Thank you very much, Al. Tom seems to always be looking for what's right, and I can't argue with that, but the guys on the left (inaudible).

Seriously, though, Tom, let me say to you that because I'm really almost totally ignorant of the way the Department does their legislating for funding and the whole process, I'm going to offer you a suggestion. It seems to me that if you can't get the stuff put over on defense and you have to stick with the present formula, that if there's some way the Department could engage the community in the funding of individual programs for their area, that you'd do a couple things. You get the leaders, the political leadership of a given area involved in a process they ought to be involved in. And, secondly, which maybe is more important, if they have their shot at getting the money for the project, at least they wouldn't be blaming the department.

MR. GRUMBLY: Well, they might anyway, but that's exactly what I'm proposing to do. I am proposing to sit and meet and engage, whether it's in a partnership or a set of meetings, with the appropriate elected and unelected officials in this area to try to come up as well as with the citizenry to try to change it away from let's sit and, you know, people beat on us and then we sit here and respond to one, in which we try to creatively try to solve this problem, so that we have a strategy for dealing with it so that then we can go, you know, whether it's Representative Talent 0 the other members in the State, we give them something to sell in the process. I think that's -- Sc I'm vowing agreement with you, Jerry. 
MR. AYERS: Tom, in preparation for our May meeting, could you have some of the DOE staff folks give us an up dated list of the FUSRAP sites.

MR. GRUMBLY: Absolutely.

MR. AYERS: The status, projected cost, those kinds of things? It would help us to prepare mentally to help you with some priorities.

MR. GRUMBLY: Sure. You know, when you see the size of the problem against the size of the resources we currently have -- As I said the only other option is to turn the St. Louis sites into the same kind of line item that we have on the Weldon Springs.

\section{MR. GRUMBLY: A compliment or comment you want to respond to this?}

MR. SHORR: I'm sorry. I apologize. I appreciate you letting me participate. I think that's been part of the problem is that the State, as an agency, and the citizens are convinced that this is a defense site, that this is defense-related waste, and it should be treated as the legacy of the defense side, not the civilian side. So it makes it very hard for the public in this community to understand why are we doing such a tremendous investment because it happens to be on the former ordinance work site than they want to do in their back yards, and I think that is a mindset that somehow we have to adjust in the budget in order to make it more easy for you and your staff to have the resources to carry out a reasonable --

MR. GRUMBLY: Naturally. I do have to -- You know, a cautionary tale is the defense budget has gone from $\$ 339$ billion to $\$ 270$ billion. My $\$ 5.1$ billion of the defense budget has gotten to be a larger percentage. So, I mean, this is a very hard problem for the Congress to deal with, but I think if we don't -- It's obvious that the problem here is substantial and we need to address it in a way that we haven't addressed it so far. The things we can do near term is let's figure out some ways to mitigate what's happening so people begin to see some action happening at this site as quickly as possible.

One last comment.

DR. FREUDENDURG: It's actually a segue. I was going to say a compliment, a comment and a question. The compliment is I've been watching DOE, and frankly using DOE as an example in my classes for 15 years, of how to get people pissed off and to be unresponsive. Frankly, Tom, have seen more action in the couple of months since you've been in than the whole 15 years I've been watching DOE. And I mean that literally. I've heard similarly good things about your responsiveness at WIPP. I'm just so amazed I can hardly express myself.

MR. CHRISTEAN: It screws up your class.

DR. FREUDENBURG: Yes, it screws up my class. I can't blame you enough for it. Fortunately, there are a lot of huge examples out there. There are just none that are quite as 
good as DOE. Exxon Valdez may come next. The warning is, I'm not someone who studies either health or physics or chemistry. I study people. From what I hear from people who do seem to understand the issue better, the water from the Weldon Spring site might not be so much a problem, but I think the technical review may have to take some concerns about leukemia cluster. There are enough people out there that you are, in fact, finding something that may be airborne. There's no proof, but it's sure does look suspicious to us. There's at least smoke, if not a smoking gun. You may need to be prepared for that. That should be looked into. The question Mr. Shorr started to answer for me. You mentioned stuff that is not military. Can you explain to me how the initial production of the nuclear weapon became be part of the non --

MR. GRUMBLY: It's all part of the sa'ssage-making process. I don't have any better explanation. I'm sure there are people who are students of this program would who could tell you more. Frankly, we're probably fortunate at some level that -- you know, we've got some responsibility here. I mean, I am not .- I'll reiterate again .. not pleased at this and at other sites around the country that, you know, major private organizations have been able to totally unload their responsibilities onto the taxpayer. As a tax payer, I can't agree more. Now, whether we can do anything about that, we'll have to see, but I think we ought to take a run at it.

Before I leave this, I want to say one thing about our own staff who works these difficult problems. I personally believe, having spent, frankly, an inordinate amount of time on the FUSRAP program in my first nine months in office relative to all the other responsibilities that $I$ have because of the intensely local nature of this that I think we have some really very fine people working on this who, in fact, have in the Weldon Springs case and a lot of other places around the country and I'm sure have really struggled with how to deal with this problem between the magnitude of their responsibilities and the amount of resources that we have, and whatever the problems that we have at this site. I want to make it clear to my colleagues who are either here or for the record and in other places that this is not really a problem of the DOE people who are working here. They have been confronted with an enormously difficult, maybe even impossible problem. Quite frankly', in this program in other parts of the country, we actually have made a fair amount of progress in cleaning some of these places up. And so I want to kind of, you know, give a pat on the back to encourage the people to who continue to work for us in this to keep going. It's a very hard problem. They understand, you know -- some of these people -- these are folks -a lot of them are not defense sites. They have to carry around the burden of what we've done in the defense area on things where we really didn't have any responsibility at all, and I think they dic it in a fine fashion. But it's clear to me that we need to move out and do something different on this site, and, you know, I'll reduce my statements in writing to you, Mr. Commissioner, so that, you know, within the next couple of weeks you'll have a letter from me that indicates what we're willing to go, and I would very much appreciate it if you and my colleagues from the EPA, and we'll get Tim Fields in a moment, although maybe it's not exactly his responsibility, to get back to me about what kind of immediate action do you think we ought to be taking to deal with some of the immediate risks that were at the site and see what we can do. Okay?

MR. SHORR: Yes (nodded).

MR. GRUMBLY: Okay. Thank you. 
MR. GRUMBLY: Part of this committee's charter to -- not part, the whole committee's charter is to give us good advice about how we ought to move this program, and during the next roughly three hours, while I have the opportunity to be here before I have to go back to the shark tank, we'd like to discuss a couple -- well, really three very kind of interesting and serious issues that we've got to confront.

The first is how we undertake to meet NOT only the commandments of I, think it's Public Law 103.123, which is the appropriations bill of last year, and that's the assignment to come up with a site-specific set of risk assessments, but more importantly about how do we build an appropriate melding of scientific and kind of social capacity around our sites to help inform the citizens, ourselves and everybody else who's involved in this problem about what the problems are so that we can address the many concerns that people have inside the beltway and other places about whether we are appropriately -- giving appropriate priority to how we spend our money.

Secondly, we'd like to discuss with you the emerging spent fuel crisis in a variety of ways and get some of your views about how to deal with the problem and give you a sense of where we're going in dealing with that, and then obviously we'd like to talk with you about the budget, and the budget for this year is an interesting budget, but there are harbingers of things to come in this that we need your advice about how we can best deal with it.

To deal with the problem of -- To begin to deal with the problem of risk, we're fortunate to have attracted really one of the outstanding practitioners of the art of risk assessment in the United States, Dr. Carol Henry, from the State of California. Dr. Henry has just joined our staff. She's still officially a consultant winding her way through the smack-dash, absolutely quick White House approval process. So if she seems a little tentative today, it's only because we're still moving through the process, but Carol and I are working together. She will be the director of the office of what we're calling Integrated Risk Assessment, and it's going to fundamentally be her immediate responsibility not only to put together a program to help us deal with the commands. of the Congress but to put together a long-term program to help us deal with the problem of how we bring the best of science to what it is that we do. She is ably assisted, by the way, by Mr. Mike Heeb, who's been carrying the fort until Carol got here. Mike, stand up. Mike has done a really outstanding job as we've tried to get this thing off the ground to begin the process of working together. And Carol is also obviously going to have to be working very closely together with Cindy Kelly, who's our Director of Public Accountability. I think many of you know Cindy, as we try to merge what we're doing here with the work that we're doing in our site-specific advisory boards. So what we'd like to do is begin this discussion with a relatively brief presentation by Carol. Some of you know a lot about this program already. You may know that the National Academy's opined on it in January. But as a stimulus to our discussion, I thought we'd let Carol make us a reasonably brief presentation about this. Thank you.

DR. HENRY: Thank you very much, Tom. I do feel as if I many walking right into the lion's den. Many of the issues you just discussed I think are one of the reasons that Tom has asked 

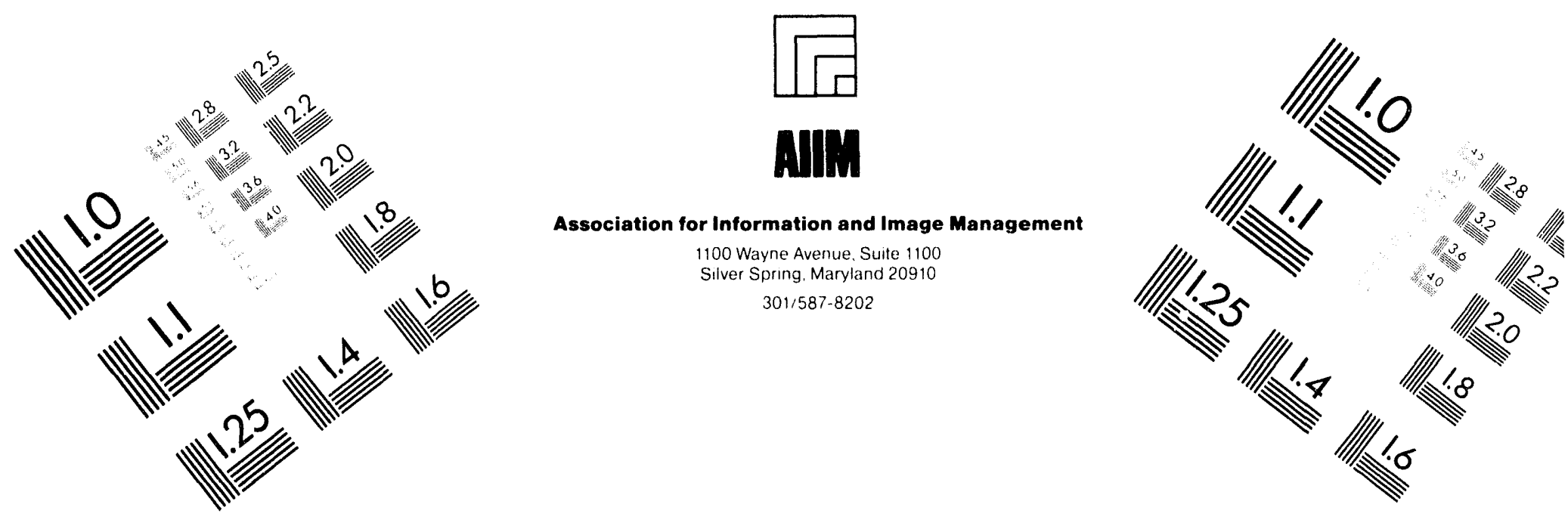

\section{Centimeter}

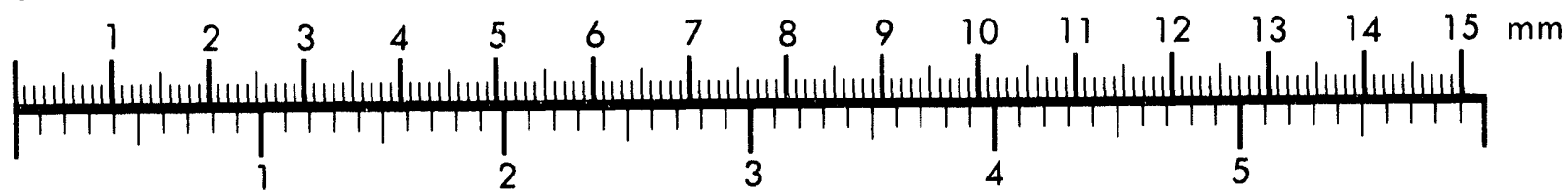

Inches
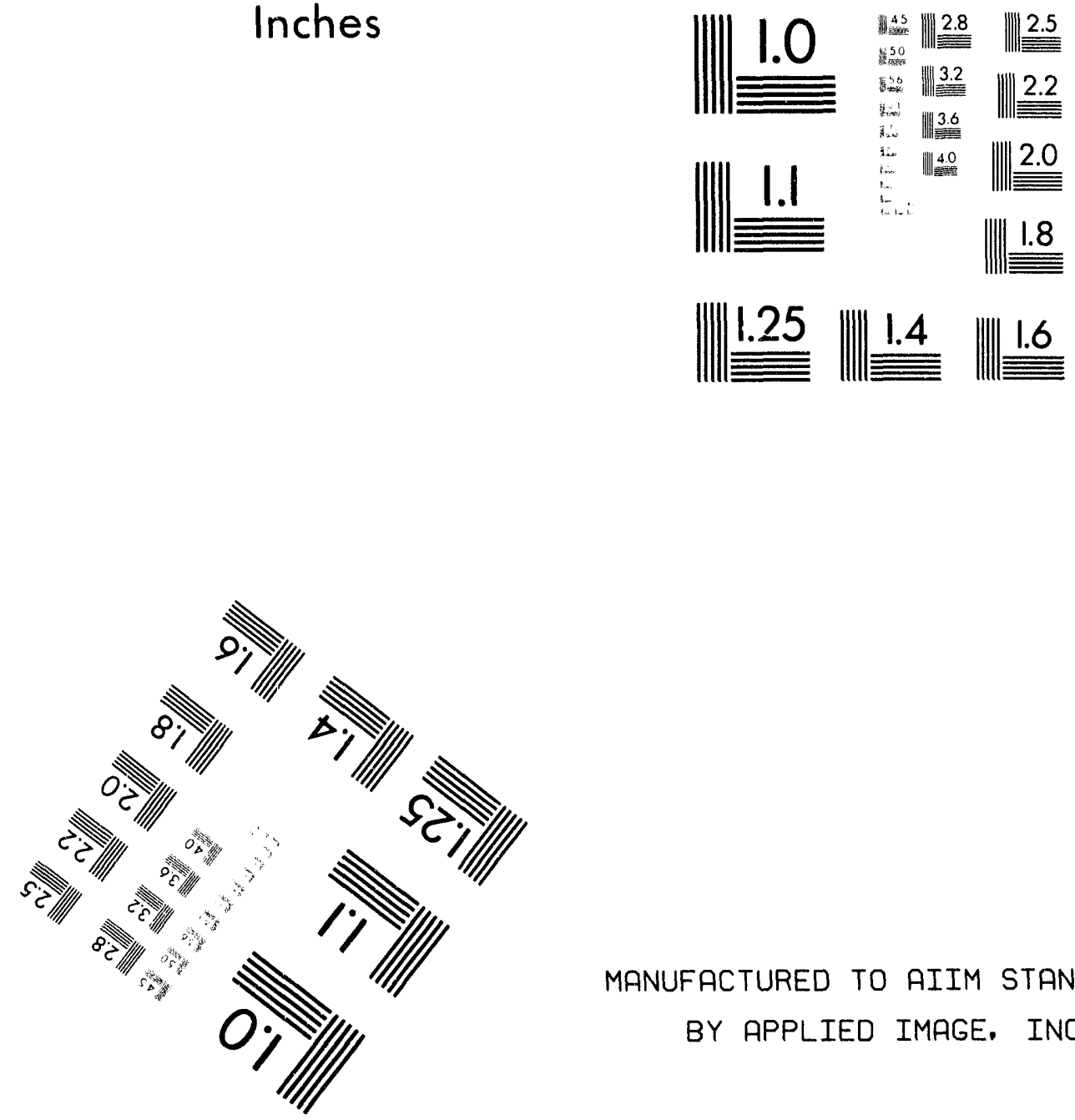

MANUFACTURED TO AIIM STANDARDS

BY APPLIED IMAGE, INC.

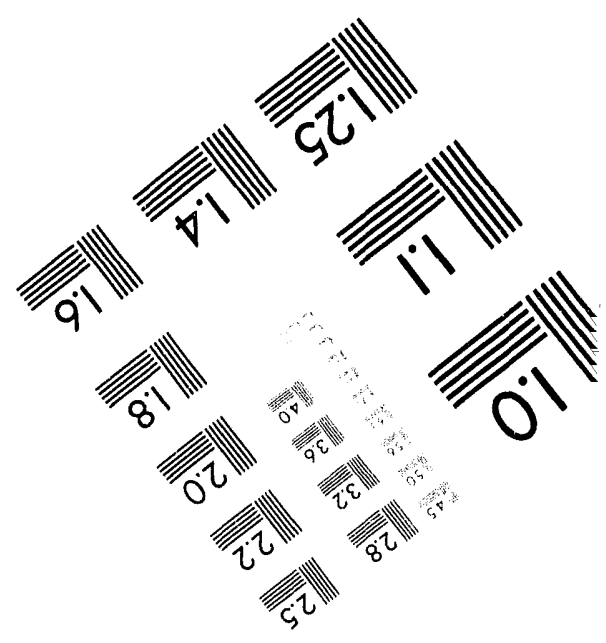



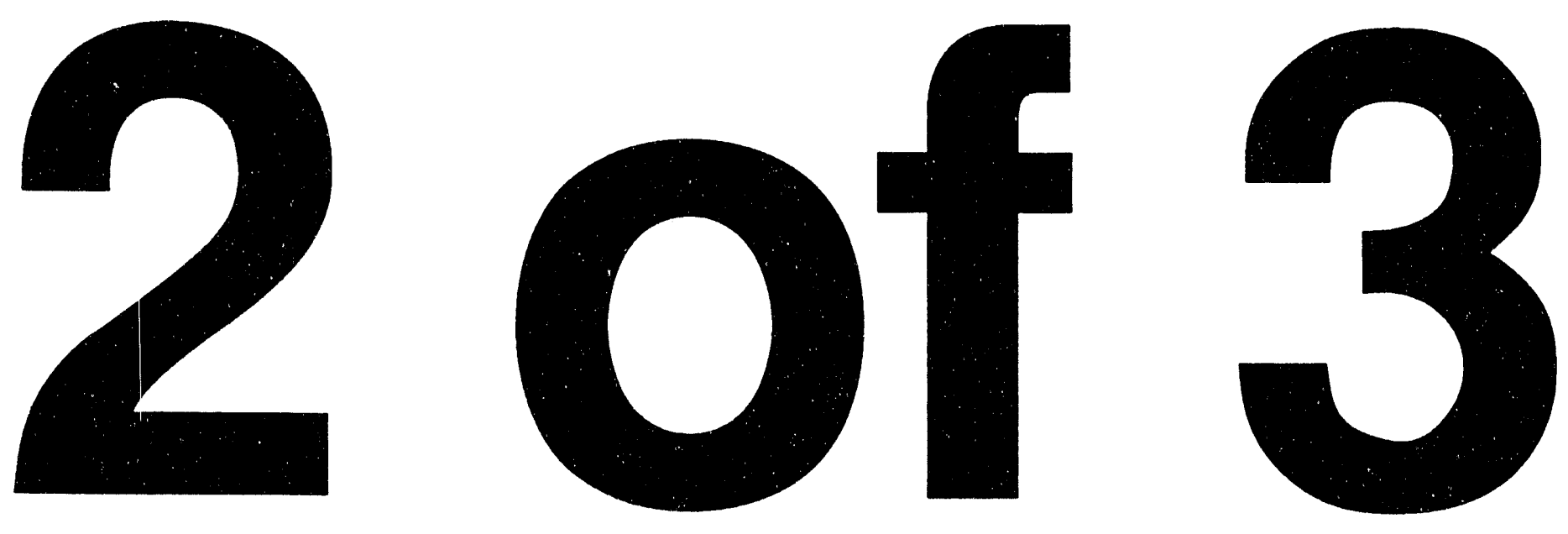
me to try and help. The issue you discussed earlier of having some good, perhaps good technical issues, but nobody believes them, or there's no confidence in the technical information that's being provided, there may, in fact, be something wrong with the technical. I don't know that, but the issue of having technical information and not having anybody believe it is, I think, at the crux of most of the problems that we'll be dealing with, and that is a management issue. I'll try and provide you with my -- sort of some personal experiences as we go through this. I have a lot of scars on my back where I can certainly show you where someone has tried to -- wounded me and you have to get back up and learn from these issues.

f. $S$ Tom mentioned, I am in a DOE consultant at the moment and that puts me under some other restraints so that I can only give advice somewhat in the fashion that you are giving advice. The materials that I just want to go over briefly are primarily -- and actually let me just tell you what's in your handout. In the handout I think behind tab seven, is a brief description of Public Law 103 and the basis for which Tom has created the Office of Integrated Risk Management. Another acronym seemed to be reduced to ORIM or something like that. I'll try to not to do that. I really like Secretary O'Leary's habit for charging 25 cents or a dollar for every acronym. I'd be cheap. I'd take a nickel for every acronym because I can't keep up with them all either.

So there are a couple of pieces of information in your book about this, but the issue here was that Public Law 103 suggests to the -- or dictates to DOE -- that the Department review compliance agreements and submit to the Congress by June 30,1995, a report evaluating the risk to the public health and safety posed by the conditions of the weapons conflicts. What I'm going to provide is a brief overview of after that was passed and what actions were taken to try and understand how that could be done.

And just to give you a little bit more information, most of the remarks I'm making are coming from this publication from the National Academy of Sciences called Building Consensus. Those of you who would like to have this report, it was issued in January. If you would either see me or Mike Heeb, we'd be happy to provide you with a copy of that.

If there are any questions as I'm going through this, please stop me so that I can make sure we can be clear on what's happening. Can this be seen? I want to review briefly for you, you may have already done this, but the goals for DOE's Environmental Management Program are three, at least as they've been articulated. To protect the public safety, health and environment, to be technological leaders in environmental restoration, and to be outstanding stewards of public resources. And the issue of credible risk assessments are probably key to those three goals. What we're going to try to talk about the how does one attain credible risk assessments and perhaps why don't we have them now.

I'd like to make sure we all understand that much. Many of these goals have to be achieved by good risk management, and good risk management cannot happen without good risk assessments, and that this is critical to program success. I am a scientist who has been a practitioner of risk assessment. There's a question whether that's an art or a science, and I know 
there are a lot of folks who say "risk assessment, shisk assessment". You know, what does that mean, and how can it be used? And it's really being used as a process for not having any action.

DR. SORENSON: Can I go back and ask you with regard to protect public health, safety, and environment, do you draw much of a distinction between health and the environment? Are they separate categories, or do you even essentially see protection of health to mean protection of the environment. Are you using a human basis?

DR. HENRY: Am I using a human health based criteria to protect the environment?

MR. GRUMBLY: Or both.

There are different criteria by which you would judge the viability of human health and the viability of the environment. Generally, in my understanding of the regulatory process, and I don't -- They're with us.

DR. HENRY: The issues that we have I think proceeded to date is that we're using human health as the driver to quote "protect the environment." As you're probably quite aware, the issues that we need to address, by what criteria is the environment healthy in terms of critters or plants or health of the soil or health of the air, we have not addressed very well. Technically and scientifically we've not done a whole lot. We're doing a lot now. But, for instance, there's not an agreed-upon set of guidelines for ecological risk, how those ecological issues might interface with human health risks. While we have a lot more information on human health risks, I would say we haven't always implemented those as well as we might. If that's what you mean, do I draw a distinction? Certainly. And I would also like for those of you who have more experience in the environmental area and ecological issues, we need to get a lot more brain power in that whole area.

DR. SORENSON: Would you agree, though, the picture might come out very differently if there were no health-based considerations?

DR. HENRY: Oh, absolutely. There are many systems that I'm passively familiar with that are far more sensitive to adverse effects in terms of concentration of toxic materials.

DR. SORENSON: But it's still a harm consideration that you're looking at when you look at risk, whether it's just to human health or to ecology, and harm may not be the principal consideration.

DR. HENRY: That's also true, yes. Yes. I'm not trying to draw boxes here. I'm trying to -- my view, and I believe the Department's view at this stage, is that the health and the environment are two separate, but probably interrelated, and how we are going to deal with that in terms of the risk assessments I think is a very critical issue because so far risk assessments are generally conceived of as being health driven, and yet we don't have quite as extensive a history with ecological risks or environmental risks. 
MR. GRUMBLY: Jay, if you could elucidate your point a little bit more. I'm not sure I'm picking up on it. Are you saying that there are other criteria other than harm generally that we ought to be --

DR. SORENSON: If you are looking at risk, you are basically asking for consideration of harm and the acceptance of harm at acceptable of levels of harm. That when you talk really about public health and safety, it is a standard -- your presumption is you are looking at human beings and what you are trying to protect is human health. Essentially what you may find is if you're talking about restoration you may be talking about an ecological system, and you may be thinking in terms of bio and genetic diversity, soil buildup, nutrient cycling, and it may be something other than human health. That if you go in and remediate the human health standards, you may find that you're going in to protect for unlimited use, and that can mean very Draconian remediation methods, very expensive, and you may end up really doing tremendous harm to the environment. Whereas if you go in for restoration, you may not really have to spend as much or do as much with Draconian methods. But there's a big difference between remediation and restoration, and I requested a few minutes this afternoon, if I may. I've had some slides made up, and I would like to illustrate the point that most other Department of Energy projects have been remediation oriented with little consideration to ecological considerations, and that is really not a restoration program that has been followed.

\section{MR. GRUMBLY: What were you saying?}

DR. HENRY: I welcome your remarks. I think that kind of a conversation needs to be brought into these discussions because we just haven't had those, at least not in my experience:

\section{MR. CHRISTEAN: Carol?}

DR. HENRY: Yes.

MR. CHRISTEAN: Number one, public health and safety, do you make a contrast between workers, their health and safety?

DR. HENRY: They are part of our public. I mean, in terms of workers safety is an absolutely critical issue here. I mean, I'm not meaning to exclude.

MR. CHRISTEAN: I appreciate your comment, but it's not exactly implicit in it. I mean, sure, we're part of the public, but I'm sure you recognize also that workers on those sites have peculiar needs that are separate and apart from that. I think they're mad.

MR. GRUMBLY: Jerry, if you're saying that sometimes problems or threats to workers would be the dominant problem that we have to deal with, I think that you're right.

DR. HENRY: Right. 
MR. GRUMBLY: I don't think that Carol means in her motherhood, apple pie and American flag statement to protect the public safety, health and environment to exclude any of these important initiatives,

MR. CHRISTEAN: You know, Tom, you have to be damn careful with consultants.

MR. GRUMBLY: I'll remember that.

DR. HENRY: Let me also say that one of the things I'm trying very hard to do is work very closely with the Environmental Health and Safety Office, or under Tara O'Toole's group, so we all actually understand what we're trying to do because from my view that while -- I mean, the sites are very awesome in terms of size and the potential exposure, but the workers are the first line, and that we need to spend a lot of time focusing on that issue. Well, if I can get -- Can I get past this now? Are we okay?

MR. GRUMBLY: Yes.

DR. HENRY: This was not my design. Let me try to go a little more quickly here.

MR. GRUMBLY: Carol, how would you like to proceed? Would you like people to ask you questions during the presentation?

DR. HENRY: Well, I said that because I wanted to make sure they were clear, and since I'm the new kid on the block, you know, you're going to get a shot today, and I'm going to be moving pretty fast. The point -- let me just say where I'm trying to get to, is to conceptualize the problem, which is to define what the risks are on a site-by-site basis. Outlined for you how the National Academy of Sciences was impaneled a group of respected experts to comments on this. Understand what kind of recommendations they gave to us and how we're going to try and implement that.

Now, there will be lots of interesting things along the way that you might wish to comment on. You have copies of these overheads that were handed out, and I can kind of go through rapidly, and then we can have a discussion or I can go through kind of one at a time.

MR. GRUMBLY: State your preference.

DR. HENRY: Well, I'll go through this rapidly then, and you have copies of the overheads at your place.

The problem as we are defining it is that we don't know what the risks are on a site-by-site basis. What the Academy helped us do was to define what the obstacles might be to solving this problem. We do not have a good idea what the risks are. We don't have and we should have a systematic way to review and define the risks. Who does the risk assessment matters? Whether 
you do them, or I do them or someone else does them matters. There are many methodology questions about how to do these, and there weren't as many answers.

So the charge that was given to the Academy was determine if a risk-based approach, which was not a given before we started this, determine if a risk-based approach to evaluating the consequence of alternative actions in DOE's environmental remediation program is feasible and desirable. There are other ways to do this other than using a risk-based approach. Further, to consider whether an institution outside the Department might perform the risk assessments associated with remediation in a more credible manner. I think there have been a number of comments this morning that underscore why we believe we needed to pose this question. The Academy did a very rapid turn-around, in less than three months, I believe, and it's really due to Mike Heeb and Paul Gilman's close cooperation in trying to get this report issued.

The other further obstacle the NAS identified to the risk-based approach is the use of risk assessment for some priorities for remediation is viewed with skepticism. That if you end up coming up with a list of numbers and then assigning, allocating resources, people are having a little problem with that. And I can give you a lot of personal experience about that if you want to hear about it.

It's viewed as a process without opportunities for public input. Major problems. And it's viewed as a mechanical process. You know, check off the boxes.

The further obstacles that the academy identified is it does not give proper weight in using a risk-based approach. It might not give proper weight to those effected stakeholders, but it's viewed with concern by stakeholders. For allocating financial resources between facilities, there's a little bit less concern, but still some concern about allocating within facilities. And I point out that the Academy recommended the Keystone report, which was issued last year in February, where there were consensus provisions agreed to by the stakeholders in terms of a fair share process for allocating funds.

So we might have to revisit that, but the Academy identified that this was a reasonable thing to include of now. What good are risk assessments? Well, they could provide stakeholders with a mechanism for considering their cultural, socioeconomic, historical and religious values. They could help to consider risks to human health and the environment associated with the contamination of DOE facilities, and they could provide a mechanism for consensus building. Risk assessments might help identifies risks that are easily reduced or eliminated. They could also -- the process could help clarify what is known and what is not known about waste sites, and it could provide important quantitative information for decisions to allocate. And I would underscore that it could provide some of the information for decisions, not be the only information.

So what are the critical issues and risks associated with performing a risk assessment that might need to be addressed? One of the major issues when one is using either risk assessment process or referring to a risk assessment or trying to use this assessment of human health or 
environmental risks, and that's understand and state very clearly what the limitations are. It's just one part of the overall decision-making process. and in order to make any decisions, assumptions about -- And in this particular case, since we're talking about environmental management issues, that the remediation, or perhaps I haven't been clear enough about the difference between remediation and restoration, that the future use of the land has to be clearly stated and that these assumptions are determined -- are absolutely credible to determining what the future risks might be.

The Academy further considered what the barriers to implementing a risk-based approach might about. Certainly one of the major ones is coordinating various risk management programs within DOE. We're in the process of trying to identify all those. That's been -- we're not going to spend a whole lot of time on that because we could spend our lives doing that, and we really want to try and move forward. Implementing common methods and approaches to risk assessment for the different facilities. There are different methods in use now. And so trying to understand what those differences might be and why they are there, whether we can actually change and make a consistent approach. I'm reminded of, you know, consistency is the hobgoblin of little minds, but it's also occasionally useful when you're trying to deal with very broad-based programs.

Coordinating methodology and developing working relationships with other Federal and State agencies will absolutely be critical and will be a major barrier if we don't do that since DOE has to form partnerships and agreements with both State and the Federal EPA. And understanding by the stakeholders and DOE managers of the strengths and limitations of risk assessment is again --ilf that isn't done, it's a major barrier to implement.

While the Academy did say that it is feasible, a risk-based approach, and recommended that a risk-based approach was feasible, even with little current information provided that a risk-based approach would have the purposes and limitations defined. And if risk assessment is conducted as an iterative process, then the initial analysis could help define where more information is needed. Let me just give you another sort of word from the trenches. I believe that one of the major reasons we're having such a crisis, and it isn't only in DOE's purview that they're having a problem with this issue of separating risk assessment and risk management, and then something else we call it risk communication. In the past, managers would say, "Okay, science-based folks, go do your risk assessment and when you're done, bring me the number." Then management would sit and say, "I can't make a decision until the risk assessors come back and tell me what the number is." And the risk communication folks were never brought in at all. So they are waiting until it's all done. Then the risk assessor's," Here's the number, manager," and the manager says, "Hmm, all right. Well, the scientists are telling me this is what I have to do. Okay, risk communicators, now go explain what we're doing." This is not going to work. That's why we're where we are. The iteration has got to be -- everybody has kind of got to get in the same room to start with. And we're not trying to say, depending on who's going to do it is going to coming up with a different number. What we're going to say is what is the purpose of the risk assessment? What are we trying to do? And the folks that are trying to do that need to go back to the managers, need to go back to the stakeholders, need to go back to the public so everybody understands what the goals are, and occasionally one actually changes what you're doing. Not for 
the wrong reasons I hope, but because you have more information or you need to get different information. So that will be something that I will be harpy about because it's really critical.

Risk assessments can help set priorities. They can provide input for managing risk for worker public health and safety. There are times when if you have -- if you're trying to actually do a comparison issue, they can look at the potential outcomes and cost effectiveness of possible actions. And there is a way to bring in full public participation, including the planning of process and defining the scope of the assessment.

The Academy recommended -- I really love little boxes here. But I think the point is, while this is cumbersome when you first look at it, what it's trying to stress is the information flow has to go in many directions. Risk management has to really be very cognizant of public participation and the public policymakers, and it also needs to be talking to the risk assessors. As you might remember, back in 1985 or ' 3 , when the red book came out, there was great concern that the risk management was influencing to an undue degree the scientists to try to come up with the assessment. So there was a real structure there to keep that separate. I'm not suggesting that the managers are going to tell the risk assessors what numbers they want to come up or what approach to take, but it's really that you have a scientific exercise, you have a management exercise, you have communication exercises, and they just have to be iterative and talk a bit so that you get the best product you can.

Now, one of the issues we asked the Academy was -- because there seems to be a major obstacle in the credibility of the assessments that DOE has performed, or there's some difficulty in having them implemented, what did the Academy think about an outside institution? The Academy thought that outside institution might be a good way to go, and they actually provided some characteristics of what an integrating institution should have if they were going to be effective. And I list these here, and in your handout is as well a Federal Register notice that we put out to invite proposals from the outside world to come in and help us do this, and we're evaluating those proposals right now, trying to understand how in the outside scientific public health and environmental community we might draw on resources that have not been used in the past and try and implement this concept of having an outside group help us. Not that we're trying to reduce our responsibilities, but to review, critique, suggest and help us move this whole issue forward.

At the very back of the handouts are some recommended steps that the Academy suggested for performing the risk assessments. I won't go over those, but I would invite your comments on the concept. We're moving forward with this. If you have other suggestions, or I'd like to see what sorts of things you might have or what your reactions to this whole area might be.

CHAIRMAN ALM: I guess we'll start with Tad and then Jay. Tad.

40

41

42

43

44

MR. McCALL: Carol, your remarks on your assessment of risk assessment and risk management and risk communication are really pressing. I'm glad to hear them. I can see why you've been anticipated with such high expectations at the Department. 
I want to put down a marker I still think is falling short. I'm not an ignorant person that can't understand risks, and sometimes those of us who challenge risk are put off in the know nothing category. I'm not that kind of person. I don't think a lot of us are. The problem I still see with the model is you're producing information that's going to drive results, and then you're going to tell people. Okay. It doesn't come through to me in the graphs, but the public participation is kind of out here. I think when you put the --

DR. HENRY: Let me just interrupt. The public has to be involved at the onset.

MR. McCALL: Alright.

DR. HENRY: Whether we do that at the site-specific issues, where the public and the sitespecific advisory bcards or the interested public is there when this is started.

MR. McCALL: Thank you very much. When you do that -- if you do that, then you can get all these benefits from risk assessment, and the public can make those same decisions that the highest paid bureaucrat can make.

DR. HENRY: Let me say that I am very much in favor of draft reports going out so the public can see it, so that there has to be a responsiveness to questions, either written or otherwise, that there is some sort of record that we heard. That doesn't mean we have to do what is being suggested, but we have to explain why. My concerns are whether we have actually the resources to do this. I mean, I know what I think we need to do, and what I'm now trying to structure with our staff is how to get this moving forward. I didn't mean to cut you off.

\section{CHAIRMAN COSTLE: Tad.}

MR. MCCALL: It's very good.

CHAIRMAN COSTLE: Tad, I think the question you raised also gets to one of the reasons I thought we needed this session. We've got Cindy out organizing site- specific advisory boards. We've got a public that needs to feel that there's a credible risk assessment going on, and you've got Carol having to put together a risk assessment program. And these things have to come together in some fashion, and my sense is that this group in particular can help sort of illuminate the problems that are going to be associated with trying to make that happen. It seems to me it's going to be a very complicated thing to stitch together, which is I think what you're saying.

MR. McCALL: Actually that's an excellent view of how we can all work together and a good view of the problem, too. It's going to be -- I'm really going to look forward to participating in this.

DR. HENRY: Let me just say some of the things we've thought about is do the sites need to identify a technical person to work with them? I mean -- I'm saying these things without fully 
understandings the implications for cost and actually finding people who have both the capability of interacting with the sites and the understanding of what the technical issues are. Working with Cindy as she tries to establish this wide variety of site-specific advisory boards, which have broader issues to deal with than just this. There's certainly going to be some site-specific advisory boards that are going to feel overwhelmed. That's another issue that we're not trying to make them -you know, when you ask for a report, you get two feet of reports. I mean, I made little peeps before I got there. Well, I'd like to see about that, and in they would come the next time. Whoa! People don't have -- their job is do be responsive to the site, but they can't be expected to wade through all of this. We've got to try and help them and get them through the critical issues.

CHAIRMAN ALM: I was going to make a comment that in the United States, we've done a lot of risk assessment in programs. EPA has done it for years, FDA and others.

DR. HENRY: And States have, too.

CHAIRMAN ALM: And states. And we've had a lot of experiments in public participation. To my knowledge, there's not been a lot of examples where you've blended together risk assessment and public participation. I just lay that point out. I would like to -- Cindy is going to have to catch a plane I guess at 10:30. I thought if you were going to say something, you better have your chance now or you might miss it altogether. Cindy?

MS. KELLY: I think it is critical that we try to figure out ways to integrate these decision-making processes at the sites. As I've talked to many of you already, without Carol and Sjoblom, Clyde Frank, stakeholder involvement process, people are saying that are feeling that DOE is asking too much of the stakeholders. What we need to do is really decide what are the decisions that we're going to make, and how do the stakeholders -- when does the stakeholder's input need to be on these various issues. I think that the stakeholders have to -- and I think it's going to put a lot of burden on DOE to figure this out first so we can explain it clearly to stakeholders. How are we planning to make decisions at these sites? Right now we have one process, which is driven by the cooperative agreements, but many of the site-specific advisory boards are saying, "Wait a minute. We don't want to be swept in that process" because that's the old paradigm. That's the old way of thinking about these sites that the Superfund program has used for years. We want to go to a more risk based, more value, what are the public's values and vision for these sites for future uses, for economic revitalization, all those factors, and we want the public to help define that vision for us and to have a shared sense of the future and of what risks they want to address first. So I think we have a burden to try to figure out how this process -- all these processes that we have begun to introduce all fit together or could fit together at these various sites. And I guess that in a way is what Shira's subcommittee, which is now called Public Participation Subcommittee, talked about taking on is how these initiatives fit together, one thing I know that many of you have identified as an issue. But I think it comes up as a key issue for the relationship between Carol's risk assessment and risk management projects and these site-specific advisory boards. 
CHAIRMAN ALM: I'm just going to ask Barbara, have you come across successful models along the line Cindy talked about? Barbara?

DR. BASS: No. Absolutely. No period. Maybe an exclamation.

CHAIRMAN ALM: How about unsuccessful?

DR. BASS: Yes. Exclamation points, several, dozens and dozens. And even when I've seen the public being brought in later in the process, the public has not been treated well, and the public often, because they aren't -- they don't have a Ph.D. after their names, they go and have to hire their technical exerts who have the Ph.D.'s after their names, and often the Ph.D.'s are sitting there saying the same things citizens are saying, but now maybe the $\mathrm{Ph} . \mathrm{D}$. will be listened to. Often I've found, though, I'm not even listened to by EPA and the agencies I've been in the states, depending on where the site was. I find that the citizens -- I also get asked, "Well, gee, risk assessment is complicated, you know, and you've got a Ph.D. in toxicology. How do you explain these issues to the public?" Well, I think last night if anybody had a question of how you explain it to the public, I think you watched the public explain things to us.

I find that in the citizens groups that I worked with, yes, there are those who have very high levels of formal education, and then what you find are the citizens who are self-educated, and they often know a lot more than these experts at these sites. And I think we saw some of that yesterday. One little example even on the tour, just having to do with the site history, someone asked a question and it was -- even the government officials turned to a citizen, I believe it was Kay right here, and said, "Kay. Kay will know the answer to that." I think that's very telling. So, no, I have not seen successful cases, even when it's been later in the process. I'm encouraged by DOE's stance and Tom Grumbly, what he's trying to do from the get-go, getting the citizens involved, and they are certainly capable I think as we've all seen this site alone, I've seen it every site I've dealt with, of being full participants in the process.

CHAIRMAN ALM: Do any of the members have a comment on this point? I've got a large number of people who are going to get to speak, but I just --

DR. SORENSON: It really goes to a larger point because I think the target has been missed. I don't think it's so much a technical approach, and I think really -- You said it's a management issue, and that's really where I would fundamentally disagree. I think -- and would disagree with the comments that have been made so far. I see it really as an equity issue. You are asking people to accept a social bargain. It's a trade-off between really their level of protection and the risk of health, so they have to feel that within the context of scientific uncertainty that their equity needs are being met, and they really do not feel that. So essentially what we're dealing with is not a management question, not a technical question. You are really dealing with equity issues, and in the context of scientific uncertainty, if you do not really have public support, then you are going to have the perception of a coerced decision, political inequity, and then you will have resistance. People will fight. And I think this is really what is happening on the local level as well and with the desire that other values be interjected into the picture. 
I should also tell you that the fear of the community that I speak to and come from with regard to this whole methodology is really captured in an old joke. It's the joke about the drunk and the lamp post, and that is really that the drunk used the lamp post more for support than illumination, and our fear really is that's exactly what's going to happen with data that is scientifically uncertain. There is no consensus, and then risk analysis will be used by decision makers to justify the easing of standards, the raising of risks, a higher level of acceptable harm to individuals and the environment in the name of reducing costs. And it will not be for illumination, but it will be for the support of something else. So the reservation about risk analysis really stems from this problem of equity and the kind of social bargain that is struck. If a social bargain is struck that the public sees to be acceptable, then I think you're home free. If not, you're going to have this problem all the time, and attempting to integrate is important, but it's not going to work.

DR. HENRY: Can I just -- Jay, I really agree entirely with you, and the equity or justice issues have to do with the partnership and bargains. What you phrased was if the public believes the social bargain is acceptable, and I'll go back to that. The public or concerned folks have to define what's acceptable. DOE can't define what's acceptable. DOE can in a scientific way say what's significant and what's not, in a technical/statistical way, but significant has many social terms. There are a whole lot of value terms that are associated with -- you know, acceptable, minuscule, reduced risk, all these kinds of things which we tend to use pretty indiscriminately, but I will go back to saying that if we can't get the public to define acceptable as they understand it, and we still have to provide some information, then I agree with you. We're lost. But I still think that in order -- there will be information. Science does provide answers. Not complete, not, you know, across the whole board, but there will be information, technical information, and what I really am pledged to do is try and make sure that technical information is valid and is presented at -- that it's available so that it can be used.

DR. SORENSON: I would like to say I agree, along with Tad and everyone else there, I love the work.

DR. HENRY: Another issue -- let me speak to what Barbara has said. I actually think -as I say, I'm not aware of Federal programs where the public participation has worked to the extent that I believe this group seems to be encouraging us to do. I think it's worked at some states, in some projects, and I think it's worked in some local, and I think we're going to have to take some lessons from that. I think that Cindy has good ties to that to help us try to model that. And we're going to have -- at least I hope she does. I have some. Maybe together we'll do that. I think we're also looking for input from this group to try and do that because this has not been done before.

CHAIRMAN ALM: Jeff, do you have a comment on this point?

MR. BRECKEL: Yes, I do. It's a comment that goes back on the basis of how do you establish an effective dialogue with the public on this issue, because this has been a contentious issue, not just in DOE facilities, but in a myriad of other areas as well for years. 
I think one of the key aspects, it was touched upon here lightly, is it has to be driven by public values. That's what establishes what is acceptable. You can go out and do your measurements against those values. I think what that counsels is being out very early in the process before you start doing the calculations and ask what those public values are to make sure that the risk assessment that you're going to conduct ultimately is in sync with what the public sees as acceptable or unacceptable. What are the basic values that they bring?

So I think, you know, being out and talking to the public, you know, is virtually the first step that needs to be done on these processes, and given the history of risk assessment in general, I'd say that's particularly important here. It's got to be user friendly. And the people that are doing it have got to be responsive and accountable to the public as they go through this. Those are the basic ingredients in terms of what's going on here. But I think, you know, you run into a situation right at the outset in terms of dealing with the public is why are you so aggressively pursuing risk assessment, and you need to have an answer for that, you know. You know, the answer here may be DOE has got to respond to a lot of external forces. Congress told us we have to do risk assessment. Now, help us do risk assessment in a way that reflects your values. But early on, early on with the public before we get too enmeshed in terms of specific methodologies.

DR. HENRY: Let me share with you one concern I have, and that is that there are already a tremendous amount -- there are a lot of documents. There are a lot of efforts that are out there, and trying to understand who's done them and what do they say and what would an outside board say about them if they were distributed. There are going to be a lot of technical problems without a doubt because you can't do these kind of technical issues without those kinds of problems or without those kinds of issues being raised and trying to resolve them. And the report to Congress is, you know, June 30, 1995. That's not a long time away. And the Congress actually asked us to give some estimation of what we think the risks are. So what would your view be of sort of risk assessment versus some other method or qualitative approach? Do you have some?

MR. BRECKEL: I guess I would go back and say you have to weigh the risks of satisfying Congress and doing the right thing to aid in your own decision-making process.

CHAIRMAN ALM: You know, I've got a lot of names on the list. I've tried to go from side to side and get them when they came up, but let me just say, I've got Glenn Paulson, Bill Freudenburg, Shira Flax, Vicky Dastillung, Tim Connor, Lynn Anspaugh, Richard Bangart, Jeff Breckel. I guess you've spoken, so I'm take that one off.

DR. PAULSON: That means I'm first?

CHAIRMAN ALM: That means you're first.

DR. PAULSON: Thank you, Al. I'll be brief. Obviously there's a high level of interest in this subject, and there was a high level of interest when Tom floated the initiative to the board at our last meeting. 
I want to make only two brief points. First is I very much agree with Al's observation a few minutes, there's a dearth, maybe a total absence of an effective process at any level, local, state or federal, that's linked I'll say a technically credible risk assessment or risk evaluation process with an effective public iteration process faith. So in that regard this is sort of -- this fusion is plowing new ground, and there's not a lot of comprehensive lessons to be learned from.

On the more technical side, I guess I should mention I was a member of the Academy's Board on Radioactive Waste Management that conceived the committee that led to the report that you mentioned, and I was also a participant in that, and I've also seen a number of sites. I'll give you a working mental picture on the technical side as to what you'll find as you go around the sites to reviewing the risk evaluation work that's been done. I think you'll find it's been done more in fits and starts than comprehensively at any of the facilities. I think you'll find major, even glaring omissions in what's been covered. And in particular I think you'll find a pattern of low technical attention to zones that have probably had low actual impact of releases, but have a high potential value to the public. If Jeff is in the room, I would mention the areas at the north and the south of the Hanford reservation, for example, as instances of that. And I think you'll find that technical efforts done on problems within structures, within buildings, have been given short shrift. I think in the $\mathrm{K}$ basins, particularly at Hanford, several of the buildings at INEL and problems within buildings at INEL at Savannah River that I've looked into that. That would be my hypothesis for you to have in mind as you look at what's been done.

CHAIRMAN ALM: Bill.

DR. FREUDENBURG: I'm going to have a hard time being brief, although I'll try. This is what I study for a living, and I have presentations complete with cartoons that I make for people.

But I am a member of the Society for Risk Analysis. My latest effort to try and talk about this is in a book coming out in three weeks called "Oil in Troubled Waters" that tries to learn lessons from the offshore oil leasing program.

What I guess what I would try to say is that you clearly recognize, and as Jeff Breckel has pointed out, you've got facts and values, and the public needs to be brought in terms of values, bui there also a serious problem of blind spots in any technical questions such as this. The best we can hope to do is narrow it down to three questions. One is how safe is it, which theoretically we can answer scientifically.

DR. HENRY: I don't agree with that.

DR. FREUDENBURG: Theoretically.

DR. HENRY: I think safe is a value judgment. 
DR. FREUDENBURG: What is the level of "probabilistic" risk? You can answer theoretically. You can answer scientifically. The second question is is that safe enough, which you can't ever answer scientifically. You can only answer as a human being. And the third is the one you just mentioned, which is blind spots. And the blind spots include the stuff that we as scientists know about and say we don't have any data on this, but they also include the stuff we never even thought about, the kind of thing where the day after you say, "Jeese, how could I have missed that?" The answer is you just produced something that's three feet thick. There have been studies of technical experts where you show a list of everything that could possibly go wrong with an automobile. If the list is complicated enough, you can leave out the transmission the electrical system, the gear box. You can leave out all kinds of stuff, and nobody will know that it's missing even if you have a roomful of experts just because of the human brain, maybe especially the expert human brain, can only hold so much.

DR. HENRY: I've heard of that.

DR. FREUDENBURG: Part of the problem, therefore, of the skepticism of the public has, part of it has to do with where, in fact, risk assessment has in the past been pushed hardest versus where it really makes the most sense. Rough rule of thumb, risk assessment makes sense where technology is very well known, where experience and data are vast, and where the people who get the benefits are the same as the people who have the risks. So when my doctor tells me, "Here's a drug that you can take, and it has this probability of helping you, it has this probability of side effects." I make that decision for myself. But if you look at where risk assessments has usually been pushed the hardest, it's for technologies we don't have much experience with, where there's a whole lot of expert guesswork involved, and where the beneficiaries are in one camp and the people that are bearing the burdens are in another. It's no wonder people get suspicious about that. But, in addition, you have the problem of statistical blinds spots, expert blind spots, the unknown unknowns, in addition to all the stuff that people normally worry about. So three of them I guess I would urge you to pay particular attention to. One is the fact that as a general rule of thumb locals are going to be very guod sources of information, frankly, data on empirical regularities. Scientists tend to be a little more skeptical about how well people understand the underlying theories, but when people tell you, "We've seen this color in the water," you can bet that they probably seen that color in the water, and probably with a higher likelihood than you can from -- you can believe that people like me who wear ties. Right?

The second is that there tend to be systematic blind spots among the people who do risk analyses about organizational factors, and that relates very much to things like institutional control. One of the most predictable things in the world, for example, is the atrophy of vigilance, which is a fancy way of saying not only do individuals get lazy over time, but organizations do. DOE we've heard today is facing budget cuts. Every two years there's a new Congress elected. Ever four years there's a new President elected. And when you set something in place today that's supposed to protect the public health in 80 years you need to realize that going to be 40 congressional elections from now and the senators 80 years from now will be deciding whether they were going to be building jet ports for their own constituents or protecting public health in some far-away 
area that doesn't affect them. You know, if citizens are skeptical about that it's probably because they have observed reality in politics over a period of time.

And the final one is uncertainty bands, and this is one I'm sure you know very well. But it's

one where it would be worth tying in more closely with the PEIS process, Programmatic

Environmental Impact Statement. You know, there are some folks working very very hard to come up with at least a first cut at comparing different approaches and different ways of managing risk, quite frankly in a way that is closer to being transparent to normal mortals than a lot of stuff, but that winds up producing numbers that look very, very precise when, in fact, as Sjoblom said yesterday, probably the only significant digit is the exponent. You know, the difference between $\$ 14$ billion and $\$ 17$ billion looks like a whole lot, but it may just be smoke. It's a best guess. The best guess really is if those are our two estimates, maybe you add them up and you'll be close to what the right number will be. The uncertainty bands, however, are not represented at least in the stuff we saw two nights ago, and I don't know if we've allowed enough time for that to be done. But I think anything that's presented to the public, you really do need to have those uncertainty bands present. And since you're new to DOE, you may have better luck than some --

DR. HENRY: Or I won't last long.

DR. FREUDENBURG: -- of convincing those who have been there longer, that uncertainty bands do need to be recorded and that's a sign of lack of moral fiber or manhood. It's a sign of the how the world is, and that uncertainty is real.

CHAIRMAN ALM: The next comment is Shira.

MS. FLAX: Carol, I have a question for you, and I have a brief comment, and then I would like to make a motion to set up a task force from this committee to give you the input that you want.

DR. HENRY: Great. That would be great.

MS. FLAX: The question is the risks. Are they cumulative? Are you going to be looking at cumulative risks or just current risk?

DR. HENRY: I can't even answer that. I certainly am very concerned about cumulative risks. Do we have good models for cumulative risk? Do we know how to deal with that? No. What we can do for the report to Congress has got to be looked right now and then try and figure what might be the recommendations for after that. I mean, as you're probably very well aware, or: the technical side, the cumulative risk issue or cumulative exposure to a variety of toxins that may have the same mechanism, may not, differential exposures to different types of folks, at which time is it more of a problem in your life to be exposed than other times, sensitive populations, those issues have got to be addressed and technically have not been very well addressed in the past. 
MS. FLAX: Let me just mention that when you go to the public and talk -- introduce your project and mention public health, what we have learned is that they are thinking in terms of cumulative risk.

DR. HENRY: Uh-huh.

MS. FLAX: And they are very much interested in past exposures. And also to talk to -raise issues of public health at DOE facilities at this particular time is going to also be raising some sensitive issues, and I think this just begs for maybe setting up a task force.

Instead of my going on and on and on and on, maybe the best thing is for us to set up this task force, and for a second reason is that I want to go back to what Jeff Breckel said, which is when you go to the public to explain your project, they're going to be asking why is so much importance being given to risk assessment, and they're going to be also very skeptical of the intent of the public law which was -- which is to encourage re-examination of the cleanup agreements.

DR. HENRY: Right.

MS. FLAX: Because the public at these sites generally feel that their State and Federal regulators were too easy on EPA -- on DOE. And for you to go in and then intimate that the actual risk at their site might be even lower and, therefore, the cleanup agreement has to be renegotiated, you've got a big task ahead of you.

DR. HENRY: Uh-huh.

MS. FLAX: Good luck.

DR. HENRY: Actually, you said you were going to do a motion.

MR. GRUMBLY: I'd like to second it.

CHAIRMAN COSTLE: What is it?

MS. FLAX: The motion is -- I don't know whether, Mr. Chair, this is the right time you want me to do the motion, but the motion I was going to put on the table is we establish a task force of individuals who come to this committee with expertise on risk assessment and then members of two subcommittees, the Public Health Community and Worker Public Health Subcommittee and the Public Participation Subcommittee to assist Dr. Henry in this incredible task that you have to do by 1995.

DR. HENRY: I don't know how strict your points of order are, but can I emphasize that I'm responsible for management. There's a big difference. I mean, the risk assessors are still going to go on with their food fights. And, I mean, I know those fights. I participated in them. They're great fun, and they really helped in a couple of areas. But, you know, Tom Grumbly made this 
the Office of Integrated Risk Management, so that is a tool. The risk assessment and the science and the stuff over there is a tool, but the management decisions have to be made, and that has got to include the stuff that's been discussed here in terms of public values, the equity, justice, these issues of cumulative risk, current snapshot. And let me say that I think -- you know, before two years ago I didn't know from -- well, I still don't know much about politics because there aren't very many people with a scientific background that are drawn into this, but if I don't do this right, Tom Grumbly fires me, I'm gone. I mean, the point is that he has asked me to come in and try to draw help from all of the various constituents to try and bring -- really change something because we can't keep doing it the way we've done it. I don't have all the answers. But it is not risk assessment. I cannot fix risk assessment in my lifetime. I might be able to help with risk management. And so the issues that Dr. Freudenburg brought up, absolutely true. Uncertainty bars, absolutely true. But I'm a member of the public. I hate those things. You know, ten to the fourth, ten to the fifth, ten to the 14th. I mean, it's gobbledygook. And if you actually go back technically and you categorize the assumptions that got you to do that, it's absolutely gobbledygook I mean, RSTP in 1982 published a list of 35 common assumptions used in risk assessment. Guess what. We're still using those 35 common assumptions because it's in the absence of data one has to make a decision. Now, all we're trying to say is for the risk assessors let's be real explicit about how we do that. So, you know, I apologize if I've kind of gotten on my high horse here, but it is management, and that's what I'm trying to do is bring the best recommendations for management to Tom because he is the ultimate one who has to kind of decide how this is going to work, but, you know, office directors -- I have a little saying I've changed from California where I also directed an office that had lot of public participation. In fact, it was a revolving door. Secretaries do good things, assistant secretaries do good things, and directors do what they're told and go when they are told to go. And so it's kind of a political expediency here that I will try and bring the expertise I can, but it's management. So that if you want to change your motion to be management, that would be great because that does cut out a whole bunch of folks.

CHAIRMAN ALM: Shira, let me make a suggestion, rather than trying to get specific, maybe a sense of the committee that something needs to be done in the area of risk assessments, then we can have further discussions about how that would work. Does that make sense?

DR. HENRY: Yes. I like that.

CHAIRMAN ALM: Do I have a second?

DR. DONATH: Yes.

CHAIRMAN ALM: It's pretty controversial. Should I call for a vote?

DR. HENRY: How about volunteers? next.

CHAIRMAN ALM: All those in favor say aye. Before we move on -- Vicky, I think you'r 
MR. GRUMBLY: I think we need to figure out how to people the task force, but I would like do associate myself where Carol just was, which is this exercise, which is more than a year-long exercise, a lot more. In my view it's about changing the whole way in which we look at issues of risk away from people saying they're only doing it in order to figure out ways to spend less money and do fewer things into a whole set of activities in which we try to create a new kind of common language for the public, the scientific community, bureaucrats like us and the regulatory community to talk to each other intelligently about what it is we're trying to do with these places, and it's got to take into account all the values that you were talking about as well as the scientific side of the equation. So this is as far away from a scientific black box approach to this as I can possibly imagine. But we will try to bring the best science to it in order to create the kind of I think sense of priority and the sense of trust and confidence that I think we need to have, but it's only a tool. It's not the only way. It's not the decision itself. It's a tool to help us make decisions.

CHAIRMAN ALM: Yes. Visky, you're next.

MS. DASTILLUNG: I briefly wanted to express three fears that I think a lot of the people in the public have and that you'll have to deal with as they underlie a lot of how the public responds. One is I don't think the public's going to just accept that Congress said do risk assessment. They're going to want to know why, what are the benefits of doing it. And considering that risk assessment hasn't been considered necessarily certain and valid in the eyes of the public, that's going to be a tough thing to do. There's also the fear that you'll compare within a site which risks are most important to prioritize, but then there's the fear that you'll start -Congress will mandate or whatever that you start comparing site to site, and that will end up putting citizen groups around each of the sites pitted against each other, which is something I would hate to see develop in the country.

Another thing is that for sites I think the citizens feel the risks have already been fairly well discussed, assessed and looked at, as in the case of Fernald. We know which ones are the worst the ones. We don't need exact numbers even. We can prioritize it on a piece of paper real quick. I mean, we've done it with our EPA and said, "Which things are we most concerned about?" I'm afraid that the risk assessment could be used to slow down our cleanup process or change the priorities around when we already see ourselves as having a process that's working, so we don't want to see that fail.

The other thing is you keep saying it's only one component of the values that we'll use in decision making, but the question is how big a component? Is it five percent, 95 percent? I think that's the underlying fear of how much credibility you'll give to risk assessment and decision-making processes.

And the last thing is when you hire these groups to do the risk assessment, I think you're going to have to go in site by site and very carefully find out from the stakeholders what the history of the site has been because certain individuals or institutions, either rightly or wrongly, are perceived as being in DOE's pocket or having done poor work in the past. And if you accidently 
pick those individuals or institutions, the public will not accept anything that comes out, you know, no matter whether it's wonderful work or not. So those are the three things.

MS. DASTILLUNG: I appreciate those. Those are very good comments.

CHAIRMAN ALM: Okay. Tim.

MR. CONNOR: You know, just to continue along through the tunnel of fear, I think the underlying anxiety, if I had to pick the big one, it would be that the public has a sense that DOE is trying to serve two masters and that is really difficult, if not impossible, to do. On the one hand we're hearing presentations on how risk assessment, risk management is going to be developed as tools that stakeholders can use to help them better understand their sites and how to -- different lengths with which to look at the problem. On the other hand, there seems to be very little ambiguity about what Congress wants out of that. I think it's in stated in the introduction to the handout in our briefing when you say that the conferees on the Energy and Water Subcommittee agree that DOE needs to develop a mechanism for establishing priorities among competing cleanup requirements. What that tells us at the sites is that Congress wants to revisit this commitment and see if there's another way of looking at this tremendous national commitment in a way that can reduce the resources being spent on it, and hence the anxiety that was noted in the NAS process, which stakeholders are very reluctant to participate in and lend their support to a tool that's going to be used to cut their throats in the way of going back and revisiting the cleanup agreements.

DR. HENRY: If I could just address --

MR. CONNOR: I had another point. Since I'm intellectually challenged at this hour in the morning, I'd just sort of like to try to continue to try to make it.

Part of the promise that -- And I think that DOE has responded to the criticisms that risk assessments cannot incorporate all the values that shareholders have. Stakeholders have.

Shareholders. Wrong meeting. Loraine Batton was here last night. She's the City Clerk for the town of Berkeley, and she spoke very eloquently and emotionally about the area around the St. Louis airport site, particularly the loss of the festival ground and the ball field. Now, risk assessment might show there's very little risk to that site because people aren't playing there anymore, but what she was relating to us was the loss to that community of that site.

Now, it's very ambitious for DOE in this process to say that it can capture those values in risk assessment, and oddly enough, I've been one of those who said you've got to try to do that, but the more I think about it, the more I think it's just impossible. I mean, trying to quantify a health risk --

DR. HENRY: I don't think -- I mean, I don't see how that -- that's not -- The issue that you raised about particularly around St. Louis is, all right, maybe it's not, quote, a high risk, and sc 44 that maybe then something isn't going to happen. I think the loss you're talking about, the loss to 
the public, what I understand is going to have to happen is a decision is going to be made that that's an important issue, how do we recapture the use of that land, and what do we have to do to make that land usable. I don't see that the risk assessment issues are contrary to that. It's going to tell you what's there, and maybe we're talking about trying to develop other terminology because risk assessment has gotten so much -- has not made the progress that we need. I mean, I use the term to be a process of gathering technical data. I don't mean it to.always go to a quantitative, you know, exponential number. I happen to find that in general is not very useful. But to tell me how much and who is exposed and to what level and what measurements do I need to find out about who is exposed and, you know, how big a buffer zone do we need to clean up or how many sampling sites, all that kind of stuff, which is what my sense is of how the scientific stuff comes into the decisions you're talking about.

MR. GRUMBLY: I also think in another forum we've talked about how to bring into the equation issues that are now going under the term of environmental justice. And by that I mean, you know, there's a whole slew of things that we ought to be doing to address problems that the society has imposed upon groups of people or individuals who didn't have, you know, the power to be able to deal with these problems themselves and it's clear that no risk assessment process by itself can incorporate those. So there clearly have to be other values brought into the equation.

I mean, I think all we're really trying to do here is to say, to use Carol's terms, we have to kind of systematically assess from as much of a scientific perspective as we can what the problems are given one set of data. But that's not the only set of data that we can use to set priorities. I will say this, I mean, just to be straightforward about it. If we were to, you know, theoretically, totally theoretically, if with we were to go through a process of taking a look at the risks at a site and they were, say, this way, and whatever compliance agreement we were signed up to was taking us this way, it seems to me that that's something that we would want to have serious discussion with everybody around the site, including the regulators, and say, "Is this really the way we want to go; and if it is, why"? I mean, what are the specific reasons? So that, frankly, people like me in the congressional budget process can explain rationally why the risk might go there and the agreement goes here. Now, if we can't do that, then I think we have to be able to say to people, "Look, the Flat Earth Society can't rain." Maybe we just learned something by this experience and we'll have to relook at this again. I don't think we should be afraid of information in these processes. We have to come -- first of all, it seems obvious to me that we're involved in a generation-plus process of cleaning up these facilities. And in part of that generation 25, 30, 50 years experience, we are going to change course from time to time. We're going to change course because we're going to find out more things, we're going to understand problems better and we can't be afraid of change, and we can't sit here in 1994 and think that whatever we sign up to or whatever the knowledge base is now is what's going to be to the end of a particular cleanup. So I think all we're urging is that we bring in a systematic way another set of information into the game so that we can have a constructive dialogue.

MR. CONNOR: I don't dispute this at all. I want to close with just two points. One is I think on this slide you say risk assessments help make better decisions by, first of all, providing stakeholders with a mechanism for considering their cultural, socioeconomic, historical and 
religious values. I'd like to argue that that is too ambitious, that that is not something that you can do. That is not the discussion that risk assessment is the forum for. To me --

MR. GRUMBLY: Can I argue against that for a second, please, by doing it this way? I'm sorry. It's -- again, if you find that something is pointing straight out and yet, you know, your heart is saying we really ought to be over here, essentially what you're doing is finding a way to clarify why you believe, think, that something that -- a straightforward kind of quantitative or scientific approach, why do we not want to go down that path. So, in fact, I do think that by providing things, by providing this kind of information, that, in fact, it will help us clarify why people's cultural, socioeconomic, historic and religious values might take you in a different direction. But you need to know. It's important to know where the other approach would take you.

MR. CONNOR: I'm not arguing with that. I think the risk assessment is a good catalyst for that broader discussion. What I'm afraid of basically is that we're going to have a risk-based prioritization that's going to be put on the table, say "Based on health risks, given current parameters, this is what the priorities look to be from our machine, our system," and that is what I clearly hear Congress wanting to see. They want to know what are the current health risks out there. How would we, given -- let's put aside the cleanup agreements, the people's visions of their sites. What's the risk? What does it look like?

And why don't we look at that when we do appropriations? If this process goes forward with the clear understanding that there are other considerations out there besides risk that are very important and are vitally important to the visions for cleanup at those sites, then I have no problem with it. I mean, we're really saying the same thing. I'm just saying to try to portray risk assessment as incorporating an evaluation of things that can't be measured by risk assessment is a bit misleading and could complicate and escalate the problem. That's all I'm saying.

\section{CHAIRMAN ALM: Lynn?}

DR. ANSPAUGH: I had a little bit different viewpoint on risk assessment. I personally have long felt that there ought to be a lot more attention paid to risk assessment, and I think there have been too many agreements that have been made without regard to proper risk management or even to feasibility of whether or not some of these agreements could be fulfilled, and I will assert that if proper attention had been paid to risk assessment and to risk management that the St. Louis FUSRAP sites probably would be somewhere up at the top of the list and not at the bottom.

And I wanted also to make a point about the public involvement. I think I heard you say something about handing draft reports to the public. I don't think that's what the public wants. My impression is that the public wants to have full access to the input data, they want to assist in defining the pathways, and they want to be full participants in the risk assessment process itself, and I think that implies very clearly that you can't give the black box to a contractor to turn the crank, and the public wants to thoroughly understand the process whereby the results are 
calculated, and they really want to understand what they mean. And the communication at the end of the process is never going to work. It has to be at the beginning.

DR. HENRY: What I tried to say, it's really access, which is what you just suggested, access and responsiveness to, as your conceptualizing or as you're getting a draft of something together, that you're not trying to hide anything, trying not to hide things appears to me to be a major issue here, that there are certain folks going in the back room making decisions or coming up with a certain set of numbers or something like that, and that's not what we're going to do. So perhaps I didn't characterize it quite right. I mean, I know the public doesn't want to read all these reams. I know that. But if there are members of the public who want it, I also don't want to shut them down.

\section{MR. GRUMBLY: Dick.}

MR. BANGART: I'd like to return to the theme of integration with science technology. Integration of technology within your agency, I do support the view that it is important to identify uncertainties and to reduce those uncertainties, if possible. And I support the recommendation that came out in the NAS document that said do iterative kind of risk assessments. There is no one answer. There's a range of answers. And those ranges ought to be explained to people, and I think it helps with the credibility process.

But if you look at risk assessments or performance of a given site before or after cleanup, ideally you'd like to marry the site waste characterization with the risk assessment models and the information needs that they have. So I'd like to hear from you about the integration within DOE about risk assessment, risk management and the technological efforts that are going into technology development to characterize waste and sites, and I think that this problem is probably bigger than you may realize. I know that may seem impossible.

DR. HENRY: Pretty big in my mind.

MR. BANGART: Risk assessment shouldn't or probably will not stop with having a decision made on what you're going to do with any given site. After you remediate by whatever method, you likely will continue or society will continue to do risk assessments in the future, and if you do get better science you'll be able to better -- or society will better be able to understand whether the true risks to health or ecology is at the lower end of your initial set of estimates or at the high end or somewhere in the middle, and God forbid there may be some situations where there may have to be more remediation done based on the better assessments done in the future.

And the other thing that I think has really surfaced to me more recently with Jay on the committee is that there's probably, compared to human pathway exposure, my sense is there's much, much less known about information that would be needed for ecological assessment, and that's another factor I think that it just may cause this whole area of risk assessment and risk management to just mushroom in terms of complexity and difficulty to deal with. So I would 
encourage you to keep that integration within DOE with where you're going with the technology piece of this as well.

DR. HENRY: This is actually a task force -- I think we can try to address some of that. We are trying to do that. We may not be doing that adequately enough, but we are trying to do that. Mike Heeb is trying to organize such a group. But I would welcome the task force participation here so that on a regular basis with we could come before you and tell you how we're doing or where we're having problems and see if you could give us some advice or we decide that something isn't working or actually maybe something did work. Is that allowed to have something work?

CHAIRMAN ALM: Ron.

MR. ROSS: Thank you. Fist of all, I commend you on taking on a project of this scope.

DR. HENRY: I needed that. Thank you.

MR. ROSS: We've all tackled our impossible dream.

DR. HENRY: This isn't quite the Appropriations Committee, but it's close.

MR. GRUMBLY: And we've been a lot easier on you, Carol.

UNIDENTIFIED MEMBER: Yes, We don't have any money.

UNIDENTIFIED MEMBER: Yes, but they gave you a challenge.

MR. ROSS: I guess what I would like to say to you is I think you've heard all of what I would have said on the technical side of trying to put this risk assessment modeling process forward. We wrestled with it within the PEIS subcommittees to add nauseam to be honest with you at times because, you know, we argue over the inputs, the pathways, the assumptions, that kind of thing, and still I feel fairly naive about the whole process given that I'm not technically into that particular area. But I think what I'd like to do, and I'm somewhat setting you up into something -- and number one on your NAS recommendation, steps to stakeholder identification, I think that totally misses the mark from what's been said here today and from what I see at the sites.

I think, first, and Cindy basically said it, and that is you have a new paradigm which you're bring forward to the various sites. Tom also indicated that where you have legal agreements going one way and potentially risks and other factors, such as economics and physical constraints, that kind of thing, going in other directions, and you're trying to figure out which way the compass is really pointing or should be pointing here. And that is to define this whole thing in the whole paradigm that Tom is trying to take out to the public and to the sites, and that is that this is just one tool in attempting to address the issues out there. The equity issues and the environmental 
justice issues are going to eat you up here unless you do define that paradigm in such a way that this modeling and risk assessment process is not viewed as Congress' way of cutting the budget and cutting the strings to their legal mandates here. And I would suggest that you spend a bit more time on that at the front end. That's the communication point of that, and I'll quit preaching on that if I may.

I encouraged that you say environmental management and that this is a whole scoping of tools that you're using to bringing to bear on this, and I encourage you at the front end to bring in the communications people very, very early. It avoids a lot of confusion and black box wizardry here, and hopefully involves an understanding. I am, as you go through the new paradigm process, very interested to see how you're going to approach this on a site-by-site basis within the one, or little more than one year, that you have to develop this thing. And I think that we might be of help off of this group, but I'm also very interested in seeing you're going to work with the SSAB's and their counterparts because those are not available in every area.

DR. HENRY: Right. There's a diversity of approaches that's going to have to be taken because the sites are not all the same. And they are not developing --

MR. ROSS: I guess I'm saying be flexible, take the paradigm out and then be flexible in how you might implement it. Because I think Tom is on to a great new frontier here, if you may, and he's got some ways of trying to come up with answers, and I would hate to see that side tracked because of congressional mandate which is viewed with suspicion as nothing more than a budget cutting tool.

DR. HENRY: But I also don't think everybody should be so surprised that Congress would do that.

MR. ROSS: Nobody is surprised.

DR. HENRY: I think there's also sort of a dose of reality that Congress had asked us to do this and how can we most intelligently provide some answers back to Congress and yet still meet the obligations that we have.

MR. GRUMBLY: I actually think if we do this right, and that doesn't necessarily mean we'll have the whole thing finished by June of '95. If we do this right, if we look like we're approaching this in a responsible, directed fashion, it will give me actually the opportunity to argue for more money rather than less.

MR. ROSS: I was just going to say that.

MR. GRUMBLY: Because instead of them saying -- then it doesn't become a game in which a lot of the congressional people, particularly the appropriations people, view it as the citizens against them and who has the power in the game. 
And, you know, I have to tell you, whether we like to believe it or not, that if they turn it into a little power game they can probably beat anybody in the short run. All right? You have to sort of say, yes, you know, the system is embracing this and moving forward and trying to create the kind of thing in which we're all trying to get to the same corclusion. That will enable us to make a very powerful case for moving forward positively on the resource side rather than them saying, "You didn't do what we said, and now we're going to," you know.

MR. ROSS: You just took my conclusion, Tom.

MR. GRUMBLY: Sorry.

\section{CHAIRMAN ALM: Fred.}

MR. GRUMBLY: I think we have about five and ten minutes left for this discussion.

DR. DONATH: Some excellent points have been made with regard to risk assessment utilization. I wanted to comment on one aspect that I haven't heard much said, although Lynn came very close to it, and perhaps I can elaborate a little bit on what he was saying.

The point is -- that I wish to speak to is the reduction of the public apprehension regarding the use of risk assessment, and perhaps before I make my comments with regard to that fear, which, as with any fear, represents a lack of understanding, I should state that I was intimately involved in the development of the risk assessment methodology for the U.S. Nuclear Regulatory Commission high level waste program some years ago. Therefore, I have a full understandings of the complexity of undertaking such an exercise and coming up with some hopeful, meaningful results. However, what underlies any type of analysis of that nature is often overlooked as one gets into the details. Invariably it's based on model, and model represents a number of different things, and I should point out, as most of you around the room recognize, that there are physical models, there are conceptual models, numerical models, computational models. Now, in coming to the point I wish to make in reducing apprehension in the public, I think it's absolutely essential to their understanding and acceptance, and I might add as an afterthought here, perhaps even some of those who are exercising these risk assessment analyses or taking them, that it is not difficult to convey a conceptual model. And that is the heart. If that is incorrect, as with anything else in analysis, if you do not have an understanding of the processes first, and then if you do not put correct values in for the parameters that represent those processes or are involved in those processes, obviously you're not going do have very positive and meaningful results. But the conceptual model is something, if properly defined and properly presented, I think any intelligent -- perhaps I should say any interested person can understand. And I think that's where one might start in the process of education in parallel with denotation of results.

Now, having said that, I should point out that I have a great concern with regard to what underlies some of those models, and perhaps I should speak in very general terms here. When one is talking about pathways, one wants to be certain that you put in also pathways that are often overlooked because of the lack of involvement of certain experts. And I'm obviously sensitive to 
those geologic patbways, which vary. The high level waste program, we're talking about much more complex type things. But certainly here, you may insist Weldon Spring is a good example where you're dealing with geological pathways. One wants to be sure that that aspect of the underlying modeling is characterized properly or adequately, and there's a lot of problemistic aspects of that that need to be considered. But having defined properly those pathways, then obviously we need to define pathways to humans, and from there the results. And I think if the results are tied to a logical conceptual development of a system of processes and values it represents, the values that represents those processes and the values that are attached to those, I think one can get an understanding to the level at least where there's confidence and the lack of black box approach to the process.

CHAIRMAN ALM: Ben, do you have a relatively short comment?

MR. SMITH: I'll try to make it brief. Carol, your chart with the boxes and your statement that you're about fixing the risk management box rather than the risk assessment box has helped me understand this a lot. But as I think about the risk management box, I realize that the regulatory system that we have in place is the current risk management box. It is the tried and true, take true in quotes, risk management box, and I think you could help explain your initiative a lot better if you were trying to -- if you would explain whether you're trying to set up a system that is parallel and in competition with that risk management function that is already going forward. You know, most of the laws in this country are enforced at the state and local level. Those enforcers or those regulators are the risk managers. And the ones that I know are always thinking about have I used the assessment technology that might be available to me, have I thought about environmental justice, have I listened to the public. They are truly risk managers that are trying to bring in all of these factors together. Now, if you're trying to set up a separate and parallel and in competition system that is going to reflect upon the system we already have, that might be a real difficulty. But if you're looking at the system we already have, the regulatory system we already have to suggest how those managers in the field can do a better job of risk management, how they can more explicitly incorporate all of the factors that they need to incorporate, then I think you'll be able to sell your program much better. I think there's some fear that you're setting up a separate thing over here.

DR. HENRY: I think that's a very good way to characterize. One -- I mean, I recognize that, that it's the regulatory community that's driving.

MR. SMITH: They're the risk managers in this system now.

DR. HENRY: Right.

MR. SMITH: And if you're about bringing them the technologies that will help them do their job better, they'd be happy. You know, they worry about their ability to integrate all of these things and make these risk management decisions. But they are making them now. They have to be made in the absence of having all of the stuff appropriately integrated. If you can come up 
with a system that helps them integrate all of these factors better and is not a system in competition with the regulators, then great. They all want to do their job better.

MR. GRUMBLY: Yes. I mean, I think our sole objective here is to try to provide what I would say is a new and better language of information to communicate among us so that we can get to the point where we clearly all understand what's important and can persuade our colleagues in the political processes of the nation, who don't participate in this on a daily basis, you know, who kind of duck into it a couple of times a year, that all of us who are involved in this know what we're doing, that we're making decisions based upon the best information that, you know, reasonable people can come to agreement on. And I agree exactly with the way that you just characterized it. We've got to make that kind of partnership.

CHAIRMAN ALM: If I may give a little bit of a parody us. If we could, l'd like to Jill Lytle up right now, and then Tom wanted to discuss the budget priorities with you all. We would probably have some time, in fact, we would have some time this afternoon if we want to talk a little bit more about this subject, so I'd rather move ahead with these items and then we can come back to any unanswered questions or not stated views. Jill, do you want to come up and talk to us about the spent fuel program?

\section{MR. GRUMBLY: An easy problem.}

DR. DONATH: Jill, I hope you've got the answers because my Governor's office and my Senator's office have all been calling about this morning about this. I'm committed to taking answers back from your presentation.

MR. GRUMBLY: The answer is probably you're not going to be aware of it.

DR. FREUDENBURG: Beware, Jill, it's the Ides of March.

MR. GRUMBLY: Since I am going to have to fly the coop a little bit early today, I wanted to get your advice about this, about how we're going on this very tough program and give you a sense of how difficult a problem we have as a society. While all the issues we've been talking about in terms of risk assessment are important, we have several immediate problems with respect to things that I regard as immediate risks in the system related to spent fuel. So we've asked Jill to bring her presentation before you. Then we'll have a break, by the way, after this.

MS. LYTLE: What I'd like to do is spend a few minutes talking about the entire spent fue program, and I'm going to concentrate on the item that Tom mentioned, and that is the immediatc issue that we're dealing with right now, which is taking back some foreign research reactor spent fuel and the question of the decision that needs to be made in the very near future. But what I would like to do is to introduce the topic because I believe we're going to be -- we're going to be talking about this for some time. Spent fuel program is a big program. It's complex. It's relatively new to us. We were not in charge of the spent fuel program up until two years ago. 
Let me just talk for a minute about what it was in the past, what are we doing right now and what will we be doing in the future.

What it was, is that up until two years ago, the spent fuel program was really involved with the production of materials for the weapons program with research reactors. It was not part of the waste management program. The fuel that was used up in these reactors for these various reasons was being for the most part reprocessed, although some of it could not be reprocessed because we didn't have the technology. But for the most part we were reprocessing it. The storage that we had was intended for short-term storage just long enough to stage it into the reprocessing facilities. It was wet storage, almost entirely.

Right now, what has happened because of the decision mainly in 1992 to phase out reprocessing in the Department of Energy, is we are storing this fuel. We are storing more of it now. It's building up in these wet storage facilities that we have. We have an intense program to upgrade our storage right now to make sure we don't have vulnerabilities in the storage of this fuel so we will continue to store it safely. And we just put out the first part of an action plan to deal with the vulnerabilities that were identified last year in a program that Tara O'Toole undertook to survey all of these storage locations, and I think that was an excellent thing to do to make sure we understood what the safety issues were in those facilities and that we got on the issues that needed to be dealt with right away. We have our phase one action plan being executed that is taking care of any of the issues that need to be dealt with immediately, and we're moving on to deal with the other parts of the program. For the future, we need to look into the far future. We are going to have this fuel for many years. We need to look at where we are going to store it, how we are going to store it, and probably looking at dry storage, and how we are further down the road going to be eventually treating it, conditioning it, in some way to get it disposed.

Just by way of background, I learn something every time I do one of these. This is one of those cute little inside the beltway, inside baseball, as Tom calls it things, MTIHN. It's the unit that they use in this program, metric tons initial heavy metal. That's what it is. It means how much uranium there was in the fuel originally when the fuel element was put together. And that's the -- it's a weight that they use to deal with how much of it we have. This is the total that we have right now. And as you can see, the great majority of it

MR. GRUMBLY: I think the civilian program uses that, the same terminology.

MS. LYTLE: They do.

MR. GRUMBLY: It's just metric tons of heavy metal. Don't use the I. The I is --

MS. LYTLE: Yes. Understood. They don't use it I believe because they don't have the same issue of trying to recover the high-enriched uranium or the plutonium that we were from there, but I tell you the truth, I don't really know how we came to this one with the initial. I'll look and I'll go find out, like I said. It's just one of those things, like I said, everytime I put a presentation together like this, I learn. 
Over 80 percent of the spent fuel that we have is at Hanford. The main reason for this is that the end reactor was run as a power reactor for many years and the fuel from that part of the process was not reprocessed because we did not need the plutonium out of that run. We were focused on getting the plutonium that was being produced for a weapons grade. And so there's a lot of fuel at the Hanford site that was not reprocessed in the past that is being stored. The main other sites, of course, are Savannah River, where we have

DR. SORENSON: Jill, is that low burn-up?

MS. LYTLE: That's the --.

DR. DONATH: You said used for power. Was it low burn up, or was it potential for reprocessing at some time?

MS. LYTLE: It was high burn up fuel. They had it in the reactor for much longer than they normally would have put it in just to produce the plutonium because during that period of time they were actually not needing it.

DR. DONATH: They had no intent of reprocessing it?

MS. LYTLE: I don't know whether eventually there might have been a reason for reprocessing it. I just don't know whether that was the focus at the time. But I do know it was a high burn up fuel, not as high as in our normal commercial power reactors, but it was much higher than the weapons grade.

At Savannah River, this is the fuel that was left that was not reprocessed when we discontinued the use of the canyons. Of course, there's still an issue related to what, if any, material will be put through the canyons at Savannah River. At Idaho, this represents some fuel we have had for some years because we did not have the technology to reprocess it, and also the decision to shut down the Chemical Processing Plant at Idaho.

Looking out over the next ten years of what might be occurring in this program, we have no intention of having any further spent fuel for the production program. There's a little bit of commercial. Commercial is like -- this is mainly Fort St. Varain fuel that is being evaluated to go to one of the DOE sites. A little bit from our own reactors. Quite a bit from the Naval Propulsion Program, which that fuel used to go to the Idaho Chemical Processing Plant and be reprocessed so we were not storing Navy fuel in the past.

So this would represent a significant additional amount of fuel. And if we were to execute the proposal to continue to take back foreign research fuel over another ten-year period and to continue to take back fuel from our research reactors in this country, that would also add another 14 metric tons to this. Now, this is not to scale, of course. The amounts we have is a great deal more than the amount we're talking about adding. But I just wanted to give you a flavor for 
where these things came from in the first place and where we would anticipate additional spent fuel coming into our program in the future.

MR. CHRISTEAN: Jill, you say if we take that fuel back or the reactors.

MS. LYTLE: Yes.

MR. CHRISTEAN: That is more than an if; isn't it? That's a probability. Almost a certainty; isn't it?

MS. LYTLE: When we -- later in the presentation this morning, I'm going to talk about the first step in that. We have an environmental assessment that proposes to take back about 400 elements. We feel there is an urgent need to take back these 400 elements or so to keep the program alive that is connected with this, and we'll talk about that. As far as taking back the additional up to 15,000 elements over the next ten years, depending on who you talk to -- I mean, the state department, the people involved in the nonproliferation issues, absolutely believe we need to do that. We are proceeding to go through the process to discuss that decision, but that is a decision that has to be made in the environmental impact statement process. We cannot say today, "We will take it back." What we say today is we believe we need to take it back. I don't know if it's a total of 15,000 that's going to even up being the amount. But like anything else, I mean, there are values here. What we are going to lay out is that nonproliferation, we believe, is a very important value and that this program is needed to support that good that can be done. But I can't say absolutely we're going to do it.

We're engaged now in a series of environmental impact statements, you know, policy reviews and so forth that are trying to answer some of these questions. The Programmatic Environmental Impact Statement on spent fuel is basically focused on the question of where will we store this fuel in the future, all of it, the fuel that's now here at our sites, the fuel that could come over the next ten to 15 years. The how will it be stored is going to be answered in NEPA documents that are tiered from that environmental impact statement. The issue of what kind of treatment these fuel elements might need is one that for the most part we're not in a position to answer right now because we need to do a whole lot of research in order to determine what exactly has to be done to this fuel to get it into the repository. Like I said, for years we did not have a program focused on getting this fuel into the repository. This fuel was being reprocessed and we were focusing on getting the result of that, that's the high level waste, and we have a very mature program to do that, but this is a new area for us. And then what additional fuel could come into the program, and we just talked about one of the key ones.

I'm going to spend the rest of the time talking about the foreign research reactor program. If there are any issues that people would like to raise right now about the general spent fuel program, I'd be glad to talk about those. 
MR. CHRISTEAN: I'd like to just ask a question. I know it's not part of the foreign fuel reactor program, but the fuel that's available in Russia, the plutonium, seems like there's some -not a connection, but it's kind of a close --

MS. LYTLE: Yes, there is a connection, and we are -- the whole idea of taking fission material out of international commerce, that is the basic foundation behind the whole nonproliferation effort, of which this spent fuel takeback that we're talking about, is a part. So the State Department is obviously working with the former Soviet Union now to get them to do the kind of things that will take their highly enriched uranium, keep it out of the commercial market. That is a real problem and one that, you know, there were just some actions done to bring back some highly enriched uranium from the Soviet Union into the United States, so, yes, it is all part of the same program.

MR. SMITH: Jill, before you get started into the foreign reactors, on your bar chart you've got foreign and U.S. university research lumped together. What's the relative proportions there?

MS. LYTLE: There's about right now three metric district tons of the foreign fuel and about two and a half of the U.S. fuel, and that moves up to, say, eight and a half more on the foreign fuel and about six -- I was remembering the numbers -- on the U.S. So it's about a ratio of three to two or so.

MR. SMITH: Three to two foreign to domestic?

MS. LYTLE: Right. Right. About that. And this is anticipating we would take back another 15,000 fuel elements, which is kind of the total over the next ten to 15 years. That will be reviewed in the environmental impact statement.

MR. GRUMBLY: Jill, did you discuss the Idaho situation at all?

THE WITNESS: No, I didn't actually. I could talk about that for a few minutes.

MR. GRUMBLY: Just, I mean, since Ben has his card up, and since what we're doing with respect to the Idaho spent fuel situation involves the state of Tennessee --

MS. LYTLE: Right.

MR. GRUMBLY: -- we should probably talk to him about it. I mean, back in, what was it, June, end of June, early July, we got an injunction, as you know, from a judge in Idaho that basically said we could no longer send Navy fuel to Idaho until we had done a full environmental impact statement.

MR. SMITH: This was precipitated, though, because of Idaho's objection to St. Vrain?

MR. GRUMBLY: That's right. 
MR. SMITH: That precipitated the --

MR. GRUMBLY: That's right. That's right. Yes, l'm not going all the way back in this history of this. But so we're operating under the court's order and subsequent agreement that we made with the State of Idaho that we could send a very limited number of shipments of fuel to ensure that the Navy could keep refueling its ships. Particularly, it needs to make room for the aircraft carrier Eisenhower, which is the big refueling that has to go on in 1998, that we could send some fuel shipments, but, you know, tied to a very strict set of conditions. And one of those strict set of conditions was that in the environmental impact statement we would have to evaluate sites other than what you might call the usual suspects for placement of the fuel. And so we on Friday, late, essentially announced the sites that were under consideration. And in addition to Hanford, Idaho and Savannah River, we indicated that we would, you know, take a look at both Nevada and Tennessee.

I think it's important that we all understand that that activity, you know, is to ensure that we're in compliance with not only the environmental laws but to make sure that we don't lose the Idaho case twice because we have to go back before the judge to ensure that we've done the kind of detailed analysis with respect to where we would take this fuel so that we can come to a rational choice in the matter. But, as you know, the State of Tennessee has been looked at before for other sorts of things and has been judged to be really not an ideal place to put this fuel, and since much of the same analysis is going to go on this time, I think, you know, the probability of it going to the State of Tennessee is quite low.

MR. SMITH: Just to fill a piece into the history there. During the time that the Department of Energy was negotiating with the State of Idaho, the Navy shipments were about to come in.

\section{MR. GRUMBLY: Yes.}

MR. SMITH: Was the issue of foreign reactor fuel in that mix at all in those negotiations? Is this something that has emerged?

MR. GRUMBLY: I mean, the foreign reactor fuel crisis, and, Jiii, correct me if I'm wrong, but it came on us quite separately, close to the same time, but really quite separate events in that foreign reactor reactivation happened as a result of a letter in early July that we received from Secretary Christopher basically asking us to reconstitute the program, and that we have an obligation under law, quite frankly, to reconstitute. But it was a separate event from the Idaho situation. As we do the environmental impact statements, you obviously get a tiering and an interweaving of these various things. It's complicated. It will be interesting to see how well it comes out.

MR. SMITH: One of the things the State of Tennessee has longed for generations has been more of a connection with Navy. It's just because of our geography that we have not been able. 

telephones.

MR. GRUMBLY: So are you saying you would like to take the spent fuel? Run to the

MS. LYTLE: Thank you, Ben.

MR. SMITH: Since we've never been able to make this connection in the past, we're wondering how we're going to be able to struggle through and make it now. And so it seems that if it weren't for the foreign reactor fuel we wouldn't have much of a relationship to this program. So I'm trying to separate the part, the foreign reactor fuel.

MR. GRUMBLY: The foreign reactor fuel issue doesn't have anything to do in the near term with the Idaho EIS except that it obviously limits the options for where we bring the fuel. We can't bring as much fuel to Idaho as we might otherwise bring, so we've gotten focused in on the Savannah River site with respect to the foreign reactor fuel issue because it's the only, frankly, near-term site that's available to us.

MS. LYTLE: There are two pieces of the foreign reactor. One is the environmental assessment, which is the immediate action to take the $\mathbf{4 0 0}$ or so fuel elements back. That one has to be focused on Savannah River because it's the only site that has available storage. But in the EIS, in what is now the Programmatic Spent Fuel EIS, it happens to be combined the Idaho site EIS for an arcane reason that has to do with the court decision.

But in that document you will see all of the options, all of the foreign fuel going to Hanford, all of the foreign fuel going to Idaho, all of the foreign fuel going -- I mean, the extreme options are all explored as well as other combinations that are lower. Oak Ridge gets into the dialogue in the spent fuel arena in part because there are some reactors at Oak Ridge, small reactors, but nonetheless some expertise on reactor issues. And then when the judge challenged us to go further in our looking at sites, Oak Ridge then came in and Nevada, the Nevada Test Site, which has no infrastructure at all, was then put in just to do a site which is and has been in the past disconnected from this program.

MR. SMITH: Alright.

CHAIRMAN ALM: I should remind you, Ben, that the Tennessee River is navigable up to Knoxville, so you might have a connection with the Navy.

MS. LYTLE: We have many opportunities if people want connections. Oh, the Eisenhower thing? May not be any harder than what we're trying to do here.

The basic questions that come to us on the foreign research fuel, and even more so than any other spent fuel program that we are involved in, is why do we have it in the first place, why do we need to take any more and what is this urgency about taking some right away? So let me just go over that for a bit here. 
The history starts with the Atoms for Peace program back in the '50's actually when the United States encouraged these European countries to get involved in peaceful uses of nuclear power, but also as part of that, to work with us on controlling the highly enriched uranium that was involved in these various research reactors.

In 1968, the Department issued a formal policy on taking back the spent fuel that has the highly-enriched uranium still in it. And the purpose -- there was a dual purpose there. First, to continue to support this research program in atomic energy, but also to control the highly-enriched uranium. So we wanted to have it come back so it wouldn't be in storage in all these many countries that were involved in the research program.

In 1978, it took an even stronger twice toward the nonproliferation of bases, and in that year, this was under the Carter administration, a program was launched called RERTR, Reduced Enrichment for Research and Test Reactors, and the idea was let's get these research reactors out of using highly enriched uranium, get them to use low enriched uranium in their research reactors. Now, there's a penalty in that. It doesn't work as well. It costs them money to convert. They don't get as good results, but the value is from a nonproliferation viewpoint you get this highly-enriched uranium out of this civilian program. And that was launched and announced in 78 with a ten-year -- as a ten-year program.

We made an attempt in 1987 -- Now, the history I won't -- most of the people in this room can better than I go over the Department's approach to NEPA, its lack of success, and the various things that we are doing now to try to go back and correct things that exist today because we did not do environmental impact statements on a lot of our decision-making. This is one of them. An attempt was made in 1987 to renew this policy under an environmental assessment, not a full environmental impact statement. The policy was extended for a year to do that. It did not succeed. It was never completed. The policy expired in 1988, and for a variety of reasons this continued to be discussed and agonized over inside the government, and the policy and the NEPA documents that continued to be worked on in that period of time never did get completed, and the policy was never renewed. In 1992, another piece of this that we've already mentioned, came in, and that is that we announced we were no longer going to reprocess. We were going to phase out reprocessing at all of our sites.

In 1993, as Tom mentioned, the State Department -- and they were all along becoming more and more alarmed at the amount of time that was going by and we were not taking back any spent fuel. This is a positive thing to remember, that since 1988 these spent fuel elements have been building up in these research reactors. They wrote a letter to the head of the Department of Energy, to Secretary O'Leary, raising this issue again and saying that we must do something to deal with this issue, we must do it now. And she wrote back saying we will address it and laying out a process by which we could address the immediate problem of taking back some elements, as well as the longer term problem in which we were committing for the first time to do an environmental impact statement to deal with this. As I said, you know, earlier when we were talking about how did we get to this point, that is a key part -- really the cornerstone of this whole issue is that the European reactors that have this highly enriched uranium were brought -- we are 
trying to bring those people or keep those people in our program to go to low enriched uranium. The quid pro quo for them doing that, which is a penalty for them -.. and, again, they get lower performance. They have to pay more. They have to pay to convert. They have to deal with their spent fuel. The quid pro quo there was to say we will help you by taking back the spent fuel, so you do not have to deal with that, and in doing so we will get the highly enriched uranium back here. Now, another part of this program was to take back the low enriched fuel. We had not only offered to take back highly enriched, but also the low enriched. Again, the same quid pro quo. If you will bring down enrichment in your reactor and you will stay in a low enriched mode, we will support that by taking back your low enriched spent fuel. Ultimately the whole concept comes back to getting the highly enriched uranium out of the civilian programs, where it is a proliferation risk.

MR. GRUMBLY: Does everybody understand why it's a proliferation risk?

MS. LYTLE: The box we find ourselves in now is this. The best thing for us to do is to complete the environmental impact statement and not bring back any fuel until we do that. We know that and we support that. The problem we have is that we have not taken back any fuel since 1988, and there are reactors in this program that are up against the wall as far as storage. They are going to have to shut down or send their spent fuel for reprocessing. And some of them are likely to leave the program. And that is why we have proposed under environmental assessment to bring back a small number of spent fuel elements for now, to build a bridge to the EIS. That's the sole purpose of it.

And the reasoning, as I explained, is unfortunately if today we said to these reactors, "We are not taking your fuel back," they do not have time to build storage. Given enough time, they might be able to build storage at their own cites or come up with a European solution to this. They have processes they need to go through with their regulators and political processes to deal with it on their own, and so it's an issue of timing at the moment.

The other point is that if we force them to, some of these reactors can get their spent fuel reprocessed. If they do that in England, they will get back highly enriched uranium. They will stay in the highly enriched cycle. And, in fact, some of them, who are in the process of converting, have said to us we will not convert to low enriched because if we have to reprocess. The British only reprocess highly enriched fuel. They don't have the technical capability to reprocess low enriched. So we're perpetuating the policy that we've tried for years to change, the policy of staying in the highly enriched. We want them to go to low enriched.

MR. GRUMBLY: And we're maximizing the amount of material that would be in highly enriched uranium that would be bomb-grade material, and we're afraid there's going to be a market for this material in Russia because it can get sold there. And in two years we could have : proliferation of more bomb-grade material, which is exactly the opposite of the policy we want to pursue. 
DR. SORENSON: It may be the case that would be true for Russia, but would you expect that from our major European allies to be in the markets for selling weapons-grade if you think they're reprocessing as in England? I mean, the Dutch are not going to do --

MR. GRUMBLY: We would expect that the operators -- and certainly when I say we, the nuclear nonproliferation community, the Nuclear Control Institute, I mean the people who are experts at this and who, frankly, I respect very greatly, are quite concerned that at least some of the reactor operators will, in fact, let some of this fuel go and that we'll create a new market for which the Russians will be a major player.

MS. LYTLE: The issue is, even if the British don't actually sell the highly enriched uranium, the scenario might be -- first of all, the Russians could sell it, and they are, of course, in dire straits, and we've been doing everything to try to get them not to do this. This would put pressure on them by creating a market because these European reactors are a market. They would need highly enriched uranium. We can't give it to them anymore. Okay. There was a law passed last year that said we can only sell highly enriched uranium to reactors which cannot convert. If they can convert down to low enriched, we cannot give it to them. So they can't get it from us. But perhaps they could from the Russians, and then this would then spread out to the reactor operators in other areas, and I think Jim is a good one to answer to that one.

MR. WERNER: Jay, if I could respond to that question. You're exactly there, that we don't expect direct sales of HEU on the world market from some of our allies, but this is what's I call the NRA argument, that if we didn't directly sell the gun and the bullets to the people who dropped the bomb, then we're not culpable. Well, baloney. What we're talking about is a policy issue here, not simply a technical and sales one. Unless we do whatever we can to discourage people everywhere from marketing this material, then we haven't done enough. Frankly, I think is emerging as really a clear national security threat of the future. As Jill said, the threat is not so much that they're going to sell it to the Russians, although that's a current possibility. But more, there's so much HEU over there, and the announcement last year by Yeltsin that they have what we now think is more than twice as much HEU as we ever believed that they had, I think demonstrates the problem with the inventories and verification. The release we did last year on plutonium inventory you may recall, no information was released on HEU. There is no international inventory or transparency on this at all right now. I think we need to demonstrate to the world we are seeking to discourage the marketing of this material. We're in the active process of solving a problem Jill has mentioned a couple of times, which is the performance of the material, using low enriched material, we're trying to use research with our guys to develop high density low enriched material. It's sort of the difference from running to Philly to Boston in a car. You can get there in a 20-mile-an-hour car, but it's going to take twice as long, and you may decide not to take that car in terms of neutron flux.

DR. DONATH: I certainly agree in terms of the general nonproliferation policy and the desirability of keeping a lid on the proliferation of nuclear weapons, but isn't part the question the timing here and when the EA and EIS process is completed whether really we have to have a policy of bringing in fuels from European allies that really are -- 
MR. WERNER: Let's be specific. We only came into this program talking about threats. I'm now hearing and thinking about the opportunities. Penton reactor, okay, a reactor where they are clearly running out of space. They did not have faith in our program. They were going to drop out of the entire program -- They were not going to get into the program. They were going to continue with an HEU market over there. They are now indicating they have faith in our program they will get into it, if we can make certain arrangements with them that they will get back into it. So I think it has worked.

MR. GRUMBLY: Can I suggest, let's let Jill continue her presentation? We probably need to take a short break then because we've held a lot of people at the table for three hours, and we'll come back and continue the discussion.

MS. LYTLE: The last point I want to make is that there an issue of credibility that the State Department has explained to us is broader even than this immediate nonproliferation issue with highly-enriched uranium, and that is that we need the support of these countries in the nonproliferation treaty debate which is going on now, focused on 1995, and this whole issue of commitments and the program to get these reactors to lower their enrichment in return for our taking back the fuel is a very important one that we can't lose sight of.

When we got to laying out the EA itself, the environmental assessment, that we called the Urgent Relief Environmental Assessment, what do we have to take back now? I think this was the question that was raised here. If we have to take back some limited number, how many, which reactors are really in this situation where they will either shut down or have to reprocess? How many elements are we talking about? What are the choices as far as ports and transportation mode and where we can store them, and I already mentioned that the answer to the last one is, Savannah River, is the only site that can take it now. Now, when we're talking about a year and a half from now, after the EIS, there are other possibilities on that.

The criteria that we laid out for deciding whether a reactor is in or out -- this is the criteria here. That is, if we do not accept their spent fuel, they will either leave the program, the REP, the Reduced Enrichment Program, so they will either stop converting or terminate their future plans to convert or reconvert back because some of them are already on low enriched. They will be forced to reprocess in Europe or they would be forced to shut down. And we can come back. I think there's some comments on this number two. But those are the criteria that we used.

We sent a team to Europe to look at it firsthand because there was an issue that was raised that we had not first seen firsthand the storage pool situation and really understood where they were. This was the original request that the reactors made of us before, earlier when we put out the first version of this environmental assessment, which was in October of last year. 953 element: were involved. After we went through our series of visits and discussions with them, the request was at four hundred -- actually not the request, but the proposal was at 448 . We determined, for example, that the Australians could store their own fuel. They had actually gotten into the position where they could store it now, and so we would not be proposing to take back any of 
theirs. And the Germans, frankly, had gone ahead and reprocessed in England, so there wasn't anything we could do to stop that, and we took them out of the proposal.

There's also in the environmental assessment, for those of you who may have looked at it, there are some other issues related to whether we take back full or partial casks, and another column which shows if we did encourage the reprocessing in England, which we have lots of reasons we don't want to do, but if we were to take that criteria out, there would be a lower number if some of them were allowed to or were forced to reprocess.

I want to spend a few minutes on the port selection because it turns out this is really where it hits home. This is where the issue comes to roost on how is this going to affect the local citizens. We started with 151 ports. We used six criteria, which I will go through. They came from either the Defense Authorization Act, which Congress gave us some guidance this year on how to do this, or from a workshop that we got together of people who are expert in this from the Merchant Marine Academy.

Starting with the Defense Authorization Act, this is the wording from the act. It talks about economic feasibility to the maximum extent practicable and then provides some criteria related to low population density, close proximity to the site and appropriateness necessary and experience, and I will tell you right off the bat that there is no one port that best meets all of these criteria. So what we did is we approached it this way. We started with the use of economic feasibility as an exclusion criteria, and that has been questioned since that time. So I'll talk a little bit about what's happened to that. But that's the way we approached it in the draft environmental assessment that we put out in February. If you start with that, it turns out that commercial ports can be accessed at a lower price because there are commercial carriers that go to these ports, and you don't have to have a special ship. You don't have to have a chartered ship. If you go to other ports, like military ports, you have to have a chartered ship, you have to pay more. That brought the 151 down to 19. If you look at proximity to the Savannah River site, some of these 19 were on the west coast, for example. So sort of by logic you end up quickly getting from the 19 to 12 , which are in reasonable proximity to the Savannah River site, and then there was one that the Merchant Marine people explained to us, which is that you don't pick a port that's very high up a river where you might have to deal with the navigability of the river, and so that brought 12 down to nine.

Having gotten to this nine, set of nine, we then applied these other criteria related to lower population -- lowest population density, experience, and service by a commercial carrier. Now, it turns out that there are none that are excluded by that. All the commercial carriers are willing to go to those ports. So you get down to seven, and these are the seven that we ended up with in the EA that was published in February, on February 10th. The reason I put Sunny Point, North Carolina down there as an additional one now under consideration is we got feedback that our interpretation of the Defense Authorization Act was not correct and we should not have started with economic feasibility. If you don't do that, if you don't take that as a first cut, then the military ports come in, and there is a military port, mainly Sunny Point, North Carolina, which has some advantageous features. First of all, it is close, fairly close to the Savannah River site. You 
can see some of the distances here. The population density in the city, in the town, is very low. But more significant is the population density right around the port because when you calculate who is exposed in an accident, that will end up having a very low number in that column. Also as far as total number of people exposed on the route, if you look at the whole route, that also has a fairly low number there. As far as experience, however, they don't have experience. They've never handled commercial fuel, but they do have emergency preparedness and so forth. So right now we're in the process of looking at this. This is how the numbers came out when we ran them.

There's no -- as I said, there's no single port that actually meets all of the criteria, that best meets all of them. Some of them that have very low, for example, distance or population, for example, say a port like Savannah, Georgia is another one, or Charleston has no experience in the spent fuel handling. So there are all of these different trade-offs. With some trepidation, after Carol Henry's very good presentation this morning and very good discussion, I will put this one up. The EA itself is full of those numbers, ten to the minus fifth, ten to the minus seventh. All I'm trying to say with this is no matter what port you pick, no matter what route you pick, the highest dose rate that comes out of a non-accident scenario, these are the rates that come out if you pick the highest rate. There isn't a lot of difference between the scenarios if you run them at these various different ports, so there will have to be some way of distinguishing and choosing a port. It's not likely to be the question of this issue of dose or risk as far as harm to the workers or the public.

As I mentioned, we talked about marine.

MR. SMITH: Your analysis of ports only relates to this emergency situation of 407 ?

MS. LYTLE: Yes. Yes. This analysis is only on this 450 or so elements.

MR. BRECKEL: Jill, before you leave that last point, population density city, population density port, what's the difference there?

MS. LYTLE: I'm glad you asked that because yesterday I had a long discussion with the guys on this. This is the density of the whole city, and this is the density within about a ten-mile radius around the port. And the difference -- Actually, this first column doesn't matter. I mean, it's not a significant one. But people are interested in that number so they put it in there. In other words, the density in a city, if you take the whole city of, say, Wilmington, North Carolina, is only 693, but if you look right around the port they have quite a few people living right around the port, so when you calculate the accident at a port there are more people exposed, and that's why they made that differentiation. figure?

MR. BECHTEL: Excuse me. The population on the truck route, is that also a ten-mile

MS. LYTLE: That includes -- they said that includes the ten-mile figure. So it's the whole distance. 
Where this makes a difference, I was listening to the discussion before, is that if you believe the probabilities, you look at it one way. If you say, "But I want to assume that it's a probability of one that this accident is going to occur," if you look at it that way, then the number of people who are right around the port becomes a much larger issue in your mind. So it does -- it matters a lot how you view the probability and whether that makes a difference in the way you look at it.

I think I mentioned, I won't spend much time on it, there is an issue of commercial ships versus chartered. It has to do in part with the cost. Chartered ships cost more. We've been trying to work that through. At first we thought it was going to cost quite a bit more, up to three times as much, but there may be ways that a chartered ship could be worked so as not to be such a difference in the price, and that allows you to lean more in favor of the military port because you must have a chartered ship to go into a military port.

Let me talk just for a moment on the public outreach because over time -. I'll tell you I've been in this program a long time, and I have never been in a situation where I have felt less comfortable as far as our ability to explain this to people and our ability to dialogue with them on an issue before a decision is made especially where there's environmental assessment. We're up against the wall on the timing. The commitments we've made call for a decision to be made by the end of this month. We've tried over the last six months to do more than our regulations say we have to do with an EA, but that's not really the issue here. We had two public comment periods. We did distribution. We had specific meetings. In fact, we held one that was very interesting on environmental justice after we got the comments on February 10th with a group down in South Carolina, and that was very -- I thought that was a very interesting dialogue. We were only able to hold one of those meetings.

We obviously haven't gone far enough. We are still getting a lot of feedback saying, "We've not been informed. A press release does not inform the people. A letter to a port official does inform the people." So we have a long way to go I think in this area of how with we deal with the interaction with the public in this.

But, as I said, right now we're struggling with trying to meet a commitment which is the end of this month, trying to juggle these different parameters that need to be looked in the decision of how many elements do we take back, the question of whether we do force reprocessing in Europe, which the lower the number, ports, the mode and so forth, what we can do even in the very short-term to inform people better about what's going on.

Let me just close by saying, as I opened, we are going to be in this a long time, and I'm very much looking forward to your input as we go forward over the long run.

CHAIRMAN ALM: Jay, we're about ready to take a break. Jay, do you have a --

DR. SORENSON: You're obviously aware of the fact you're living with a lawsuit and the Sierra Club is about to bring one. Now, how do I go back and talk to them, impart -- really to communicate? You communicate all of that, but really -- 
CHAIRMAN ALM: I think this probably leads into the discussion. If you wouldn't mind getting back right after the break.

Jill, let me ask one question. You're mainly interested in advice on the foreign research reactor part of it? You've got a whole series of questions before us.

MS. LYTLE: Right. Right. Yes. But I feel that this decision is so close that I don't ever want to be coming to you again in the future with a decision that's this close and asking for your input. That's really not the way we want to operate. But we are upon that decision, and any feedback that you have at this point I would be very glad to have, and also for the future, as we go through, the foreign research reactor issue is going to be -- we're going to continue to debate that over the next year and a half, so foreign research reactors in general or the spent fuel program. But you need to, I guess, focus because you don't have a lot of time today.

CHAIRMAN ALM: I think maybe today we could focus more on the FRR, and then I think we need to figure out how we can be helpful to you on a longer basis. Why don't we take a ten-minute break? Can we all get back here in ten minutes?

(Whereupon, there was a brief recess.)

CHAIRMAN ALM: Why don't we begin with comments on the spent fuel program, particularly the foreign aspect of it. Jay, I think you're first.

DR. SORENSON: There was a letter to you, Tom, from Robert Deagan, and there are actually three parts to it. One was the original suggestion on his part for the chartering of a ship and the use of Sunny Point, which apparently has been considered. The second is the creation of the site-specific advisory boards at the sites. And then the third is a discussion of the Russian shipments.

Jill and I were talking at the break, and it may very well be that there is a compromise possible to avoid this lawsuit that is impending, and that would be a transition period. If it would be possible, really, to complete the negotiations with the Department of Defense on Sunny Point and use a dedicated ship, that might really be a temporary solution. It may be possible to offset the complaints about high costs by just waiting out that period and then going to perhaps a different system once you have completed the time period necessary to complete the EA. I would like to reiterate what Deagan -- the point that he makes, and that is that we're really not opposed, and we do not enjoy really finding ourselves in an argument with our own NRDC friends and the NRDC on the nuclear weapons nonproliferation policy. We are for that, but there's the problem of meeting the EA and the EIS requirements.

MR. GRUMMBLY: I guess the best thing I can say, Jay, is we've paid very careful attention to Mr. Deagan's testimony as well as letter, and, frankly, we are trying to craft an approach that, you know, takes into account the helpful suggestions that he made, and I think you'll see that, I hope, in our final policy. 

hand.

DR. SORENSON: Well I, would like to be able to be helpful and to go back and to lend a

MR. GRUMBLY: What I'd like you to convey to him is that -- I mean, I'm not in a position, because this is obviously a decision that the Secretary of Energy is going to make in terms of what we're ultimately going to do here, and it's one that we need to make in consultation with our colleagues in the States, particularly in the State of South Carolina, but all I can say is that Bob Deagan's words as well as his views on paper have had a strong impact in the direction of the analysis, as you could see from Jill's presentation, and I wish you would convey to him.

DR. SORENSON: I'd be glad to do that.

\section{CHAIRMAN ALM: Bill.}

DR. FREUDENBURG: Jill, there may be a difference between the kind of analysis that would be appropriate for the EIS and that you immediate for the current case. In addition to the ones that come immediately to mind, I think you'll find that your proposed multiple ports of entry chart with all the numbers in it really has very little to do with what the National Defense Authorization Act says. I prefer your way of doing it, with population density and so forth, but the act as I read it in English doesn't say has the lowest human population density in the area, but it says they want the port that has the lowest population. So, for example, Los Angeles has a low population density compared to Milwaukee, but it has a much higher population in the port area, you know. The standard metropolitan statistical area would be the way I would normally go. And the law doesn't say anything about the population density along the truck route or the train route. It just says the lowest population in the area surrounding the port of entry.

And so it may look to some people as though you're trying to change the subject or to avoid doing exactly what the law tells you to do, even though from where I stand and certainly for the long term looking at population density would be a smarter way to go.

MS. LYTLE: Jill. Yes.

MR. GRUMBLY: If you applied your criteria, just for the hell of it, which of the sites, if any, do you think would most closely match the criteria as you read the congressional criteria?

DR. FREUDENBURG: I don't know what the population is of Sunny Point, North Carolina, but I imagine it's lower than that of the cities I've heard of.

MR. GRUMBLY: Close to zero. There's nobody there. It's a military base.

DR. FREUDENBURG: Okay. So that wins big time. The problem would be experience in --

MR. GRUMBLY: Right. 
DR. FREUDENBURG: -- receiving spent nuclear fuel. It doesn't say commercial spent nuclear fuel. It just says experience in receiving spent nuclear fuel. So if that facility has experience in receiving military spent nuclear fuel.

MS. LYTLE: Actually they haven't.

MR. GRUMBLY: One of the problems, as Jill has pointed out to me, is that there is no place that exactly meets all the criteria.

DR. FREUDENBURG: Sure. True. But then what I would do, if you've got a couple of places where it's just about a toss-up, and there's one where you won't be sued, that has a certain logic to it.

CHAIRMAN ALM: Okay.

MR. GRUMBLY: Of course, I mean, if we think we can win, but never mind. That's a different -- The (inaudible) we'll clean your clock if you sue us.

MR. SJOBLOM: This is I think the first or at least certainly the clearest time for this board, that the critical link between the cleanup program, and in particular the DOE facilities that used to be in the defense program's orbit, and are now in the EM orbit and nonproliferation issues. I for one think we need to take the foreign fuel back.

Regarding storage, twice I've looked in depth into wet and dry storage of spent fuel from a technical level. Both times I came away firmly convinced that from a scientific and engineering point of view there are excellent options which happen to be relatively inexpensive and relatively quick to build for long-term dry storage of spent fuel. This, of course, begs the question of where the fuel should be brought in and over what routes it should be transported from the port to the storage location. And the questions have confirmed my view that this is likely to be the issue of greatest concern, not only to this board but to any potential neighbors of this.

But I would expect this would be a manageable issue both for the near-term relatively small amount of foreign fuel and for the larger amount as well, and I restate my position. I think it's our fuel. In this case, you don't blame it on the prior administration, Tom, you blame it on the administration, a Republican administration that started Atoms for Peace. It's our fuel. We've got an obligation to take it back. Nonproliferation concerns convince me we must take it back. in.

MR. GRUMBLY: If we can work with our colleagues in the States to actually get it back

CHAIRMAN ALM: Okay, Jerry.

MR. CHRISTEAN: I know that right now you're not looking for any long-range fixes of your immediate problem, but it might help in the discussion in terms of public relations to talk 
about some, at least to some extent, possible uses for some of that fuel besides storage. For example, you know, we have the problem of Russia, for example. I don't think it would be impractical to talk about that plutonium problem and sort of get it in the mix in terms of having people, you know -- having people in the public have a reason to want to support what DOE is doing that needs to be done and done in their self interest, not a selfish thing at all, but I really believe if we were talking about, wow, we've got some of this stuff, we can generate some power and get something out of it, something's that's of value, I think that might be a useful thing to do because, I mean, it's there. It isn't like we invented it. It's there. Okay.

\section{CHAIRMAN ALM: Okay.}

MR. BRECKEL: Tom, you mentioned about working with your friends in the States to try and resolve this issue. You know, I for one believe that the States want to help resolve this issue. But I think, as I've mentioned to a couple of your staff, this needs to be viewed on a broader perspective. You know, in the past I think the States have focused principally on getting the waste on their sites cleaned up, you know, the most immediate threat to the environment of their states and to the health and safety of the workers at the sites and the adjacent public. But there are a number of issues out here that I think beg a national dialogue in a sense. We look at those at Hanford as this worn reactor fuel, the issue of the Navy fuel, your whole issue of spent fuel basically. Navy wants to dispose of more reactor compartments. We've got low level mixed waste. We're going to have low level and DOD waste from a variety of sites. And they're a national problem that need to be addressed. And I don't think you're going to find governors, quite frankly, that are going to differentiate or want to look at these individually. They're going to want to say what does this mean for my state collectively? What does it mean for the DOE sites in my state collectively? What does it mean for the cleanup of those sites? Am I being asked, you know, to bear an unfair burden in terms of trying to resolve what are really national issues, and I'd throw, you know, the ultimate disposition of plutonium in that basket as well. It's big and it's heavy, and no state is going to step forward and be very cooperative in terms of working with you because they're afraid if they cooperate in one area they are.going to get screwed in the other seven. And I guess I don't know how to be anymore blunt about that.

MR. GRUMBLY: No. I think you're right. I think what we have to do is over the next two years, and I say two years because I think that's how long it will take to do a reasonable analysis. It's also I think the amount of time that it's going to take the Department to examine this plutonium disposition issue with some degree of care. That what we have to do is bring together the PEIS that's being done here, the defense PEIS, these various kind of what I would say issue-specific environmental impact statements and use all of these impact statements as the vehicle for examining what our national options are with respect to how we're going to deal with spent fuel because, you know, we are obviously struggling at the moment to deal with 440 elements that are about this long and this big, and I don't know, frankly, whether we're going to be able ultimately to sustain the RERTR policy. I mean, I hope we can, but I'm not sure at the moment, and I think it will only be sustained -- I think if it turns out that this program is the catalyst, because of the difficulties that we're having forcing us to take the kind of national look that you're talking about, it's only in that context that it will be successful. I think, for example, 
right now we have to -- and we are beginning to think very hard about what's the future of Savannah River site, because it's -- I sympathize very greatly with the people in South Carolina who say we don't want to be a nuclear waste dump. We've got to create a vision for the future of that site that the people who live in the State of South Carolina can buy into if we expect them to accept these kinds of materials. I think at least we have to do that nationwide over the next couple of years.

MR. BRECKEL: I agree. I have some concerns with the use of the PEIS as a process to frame these discussions.

MR. GRUMBLY: Well, I only mean by that -- pardon. I mean we are going to derive a lot of information from the PEIS that's going to be useful in other contexts. That's all that I mean by that.

MR. BRECKEL: I guess my concern is how the PEIS is proceeding and the methodology there might actually be counter-productive to a good, open and flexible dialogue on the public policy issues at hand.

MR. GRUMBLY: That's a weighted statement that I need to get into more with you probably later,.

MR. BRECKEL: I don't want to take up any more time, you know, but l'd be willing to discuss with you why I think the PEIS, its current approach, doesn't support the type of discussion.

CHAIRMAN ALM: Dick, I think you were next.

MR. BANGART. Most of the debate seems to be centering around port of entry and where the elements go for storage in the initial term, but if I look at the number 448 elements, what I haven't heard is much discussion about that number and how you arrived at it, and don't you help yourself if that number is indeed the absolute minimum number of elements that you need to bring in the shorter term. And so that leads to the question it looks to me from at least the presentation that the determination of 448 , was based primarily on whether the research reactor in the foreign country will have to shut down or not, but also factored into that is the need that the reactor is serving also reflected in these numbers. If it's just a research reactor, maybe it isn't so bad if it shuts down, if it does basic physics research or whatever, but if it's medical radioisotope production, that's a different story. Was that factored go the 448 ? If not, why not?

MS. LYTLE: The issue of the commitment to the reactor operation is not based on what $i$ these reactors and go into research, medical isotopes.

MR. GRUMBLY: And to take our fuels. Let's remember who owns this. This is our fuel. MS. LYTLE: We said we would take it back. 
MR. BANGART: It's not a question of taking it back; it's when.

MS. LYTLE: I understand your point. All these things might influence the willingness of the public to support it, that if they were involved and let's say a very rare medical isotope wasn't being produced anywhere else in the world that might, in fact, sway. We did not go to that level.

MR. SMITH: They're producing an isotope that's in competition with a isotope being produced in the U.S., so we're taking their fuel so they can continue to compete with us.

MS. LYTLE: I understand what you're saying.

MR. WERNER: Some of those isotopes have such short life that, in fact, we addressed the question, in fact, whether or not we are even supporting more reactors in Europe than are necessary. And the answer came back, well, that's true for some isotopes, but some of them are very short-lived where you've only got a matter of hours to use them. So you're right, but it sort of depends.

MR. GRUMBLY: Let me associate myself with just the basic point that was made over here, though, that Richard made, is that our objective is and must be to get to the minimum number of elements that we absolutely have to bring back to keep this program a viable program until we can get to the end of the EIS. I absolutely think that's right.

\section{CHAIRMAN ALM: Ron. I mean Ken. Excuse me.}

MR. WERNER: While she's moving, Jill and her team I think have done a great job of heading to that principle, and in doing so they ran into a very practical issue, which is causing some other problems of can you return half empty casks, or not half, but partially full ones, and they said yes. You see the partially full casks, which leads you to that number.

MS. LYTLE: This is the more complete table is actually in the environmental assessment, and as you can see, we not only have that one that I had before on 448 , but if, as Jim points out, if the casks are not filled up, if you only use the absolute minimum number that they need to deal with their storage problem, we don't allow them to put additional fuel into the casks to fill the casks up. That ends you up at a lower number. Actually if you allow, not allow, but actually force the reprocessing, certain countries can reprocess in England. Some can't. And if you allow or force the ones that can, you end up with a lower number also. But that is a policy issue, a very serious policy issue because that, as we were talking before, actually keeps them in the highly-enriched uranium cycle. But this is the full range that's looked at in the environmental assessment all the way from the 953 down to the 148 .

MR. SMITH: Am I hearing this right? That England does not support our efforts to get people into the low enriched uranium cycle? They are willing to enrich it to high enriched and they don't support our policy? 
MS. LYTLE: No. I think it's more subtle than that.

MR. GRUMBLY: I think that would be too strong a statement.

MR. WERNER: They are not enriching anything. They are reprocessing. And this is a private industry, Doonray AA, which is sort of a government, quasi private.

MR. SMITH: But they'll do it in violation of our policy?

MR. WERNER: I have had a number of discussions.

MR. GRUMBLY: It's not a violation. We're not a sovereign nation.

MR. SMITH: They will do it, and it's out of the spirit of what we're trying to do.

MR. GRUMBLY: I think to flip it over, our own State Department's, our own nation's policy in this area is that we have a lot of fish to try with our European allies, that we want to encourage them not to reprocess, but so far they haven't been willing to go the next step and say we actively discourage them from reprocessing because they believe that to do so would undermine other elements of our nonproliferation policies together. Now, whether we all believe that or not is, you know essentially irrelevant because that's the policy of the President at the moment.

MR. WERNER: That's a very, very touchy issue that came up in a Presidential Decision Directive 13 articulated before the United Nations on September 27th last year where there appear to be two contradictory sentences. One, we do not reprocess anything ourselves, but we don't interfere with existing relationships. All you need to do is look at what happened in Japan with Perkosho and Monju to read the tea leaves about where this thing is going. The market is going south big time, so I think things will work out there frankly.

CHAIRMAN ALM: Ken, you were next.

MR. KORKIA. I guess I've already anticipated the answer to this question has to do with it's our fuel, we want it back, and also we don't want the proliferation of it. It just seems that there must be some logic to the possibility, as Glen was saying, that you can build long-term dry storage areas, and why not help these reactors that are in eminent danger of having a shutdown because they have no more storage capacity to build some of these long-term dry-storage areas and then provide the security to prevent steeling of material or whatever needs to be done to make sure that it remains our material, but keep it on the foreign soil instead of bring it back to our soil.

MS. LYTLE: That's one of the issues that we will lock at it in the environmental impact statement. The problem we have right now is that there is not enough time. Glen didn't go into the details. I think when he spoke about it's relatively straightforward to build dry storage, it can't 
be done in the period of time that we're talking about here. It can't be done in weeks or months. regulatory process.

And so I believe that's a very important option that needs to be looked at for the longer term question of do we continue to take back spent fuel for the next ten or 15 years. I agree.

CHAIRMAN ALM: Jeff, I think you're next.

MR. BRECKEL: I'm through.

DR. SORENSON: A quick question. What happened in England that led to this change in policy and in decision and led them really to decide to start the reprocessing? I mean, that's a relatively - that's a turnabout.

MR. WERNER: They've been reprocessing for quite some time, and, in fact, recently, as you may know, completed construction on an additional reprocessing facility known as Thorpe in order to fulfill contractual obligations they undertook in the early 1980's with a number of western European allies. But the facility we're talking about is different. We're really getting into some fascinating detail. This is not new. And, in fact, the only thing that's new is these folks are more desperate than ever to cook up more business.

DR. SORENSON: It's dollars.

MR. WERNER: Because they don't see any money coming into them. In fact, I met with the foreign ministry over in London trying to work something out, and they indicated if they don't get something after these Belgians in the next two and a half months now, they've got a problem.

MS. LYTLE: I think the other part that is new is that these country's in the RERTR program, in this program with us, we made the commitment to take back their fuel so they were not sending it to England for reprocessing. However, as years and years went by since 1988 and we failed over and over again to take it, some of them have gone ahead and said, "Well, we just can't wait any longer" and the Germans sent a shipload and then the Belgians recently did. So I think what we're seeing is the erosion of this program that we're trying to protect.

DR. SORENSON: Can I have follow up? And it relates to your question on Japan. And you say the market is heading south, but with the North Korean decision, there is sentiment developing in Japan that surfaced in the '70's that was best expressed by a former Prime Minister, Nakasoni, who basically argued that Japan should have an indigenous nuclear weapons capability or it couldn't be a great power simply on the basis of its own economic might, but needed a military capability ability as well. Do you see any of that playing into this factor, and will it make really this whole policy of trying to prevent nonproliferation irrelevant in importing of these fuels back. 
MR. WERNER: Jay, I think that's not relevant here because the rate limiting factor is the supply of the fissile material, and they have as adequate supplies there to fabricate a warhead if they chose already. They've got a significant shipment of reactor grade plutonium last year. I mean, this is not a problem for them.

\section{CHAIRMAN ALM: Glen.}

MR. SJOBLOM: If you all think highly enriched uranium is fun, wait until you start thinking about plutonium. This is a summary of a very recent report from the National Academy of Science, which some of you may have seen and some of you may not have, which is quite readable as these things go, and which perhaps the staff should get and circulate to the full board, but before that happens, there probably should be a discussion by the staff with Tom as to how much of these kinds of issues should come before this board.

I mentioned earlier there are clear lineages, but we're constituted to focus more on the cleanup, less on special nuclear material and so on. Several of us are interested in this. Some of us have been interested in it for a lot of years. So maybe it's a reasonable problem, but I think Tom should specifically decide how much of that set of issues he wants to come before us on a routine basis.

CHAIRMAN ALM: That's probably a good point. Jill, you've had bits of insight. I would say it's probably not a coherent set of suggestions yet. I don't suspect you're going to jump on the plane and figure your problem's over. I wonder if you had questions you wanted to ask people here. How could we be most helpful to you in this decision?

MS. LYTLE: I think at this point it's been helpful to listen to the reactions and the questions and focusing on the port. Are there any other reactions related to the issue of the selection of a port or a route because that seems -- again, the port issue seems to be one that's driving the problem, and the other one is a much more general issue and that is getting a state to accept some additional burden. I think that's one that we will probably talk about in many other contexts over time, because that's a much broader one and it affects all of the whole waste management program. I mean, it's one I'd appreciate input on, but I don't want to take your time now.

CHAIRMAN ALM: Jill, one question I had is the assumption that the wastes would be stored in Savannah River. Is that the going assumption?

MS. LYTLE: That's the only option we have for these 450 elements. We can't bring it into Idaho because wore enjoined and Richland does not have the space to store it. They don't have appropriate storage. So Savannah River is the only option for that. I mean, you move on to the Environmental Impact Statement and look at the next ten to 15 years, you're talking about new storage that's when Glen's issue about building dry storage comes in, and then dry storage car be built at any of those sites, so those options become -- 
CHAIRMAN ALM: You're talking about just the near-term decision.

MS. LYTLE: The near-term decision. Really, if there are any other thoughts on, let's say, the choice of a port or how one explains how you would make a decision like that.

CHAIRMAN ALM: Bill, go ahead.

DR. FREUDENBURG: Three suggestions real quickly. One is that you not only include in the EA, but plate in gold almost exactly the words from the Sierra Club letter, that this is not in any way a precedent for what you plan to do for the long-term, and that has to be a commitment that you mean. But that has to be in there very clearly.

The second is that 448 does not equal 359 , and there seemed actually do be a little confusion, or maybe I was confused because I heard Jim say that the 448 you'd already assumed that these were going to be not full canisters. As I read your table up there, it goes down to 359 if you ship partially full casks.

MS. LYTLE: I'm sorry. Let me go over that again. 448 is full casks, no reprocessing. In other words, we don't force anyone to reprocess and we allow them to fill up the casks. 359 is if you ship partially full casks. In other words, we do not allow them to fill up the casks. So that's the difference between those two. The last two columns deal with reprocessing. They deal with whether or not we force the reprocessing.

DR. FREUDENBURG: Since 359 is not the same as 448 . Unless there is a huge financial difference to the Department or a huge technical difference to the people in Europe, I would suggest you go with the $\mathbf{3 5 9}$ just to underscore the fact that this is not trying to sneak the nose of the camel under the tent.

The third thing I would suggest is that given the explicit wording of the defense authorization law, whatever it's called, I would pay a whole lot of attention to the technical difficulties presented by the fact that Sunny Point, North Carolina doesn't seem to have facilities rights now for handling spent nuclear fuel, or experience with it rather. If that is a huge problem technically and physically in the short-term, then that would be reasonable to go to some other port. But if it's not, I would say there is no reason under this law you would go to anyplace other than Sunny Port for this one-time exclusion, even though it might be a really stupid place to bring the stuff in the long run. And that, too, would help underscore the fact that you're not trying just to get the nose of the camel under the tent.

\section{MS. LYTLE: I appreciate that.}

CHAIRMAN ALM: Okay. Shira.

MS. FLAX: Sorry. I just want to go back to the question that $\mathrm{Al}$ posed to you, Jill, which is in coming before this committee, what sort of help did you want from this committee? 
MS. LYTLE: Actually at this point, I really was looking for some reactions. You all have thought about these kind of issues, have been together for a while looking at them, and if there were any insights for this immediate decision, I would appreciate them, and I got some and they will be helpful. For the long term, I really need -- We need to deal with the equity issue, the equity issue that Jeff articulated, which is in the waste management program right now we're fundamentally unable to move any waste from one site to another site. You know, the barrier is extremely high. We're trying to deal with this in the Federal Facilities Compliance Act process for mixed low level waste. We are going to have this issue in spent fuel if we continue to have the Navy program bringing in fuel to some site and the foreign reactor program sending fuel to some site. So over the longer term, I need some help and input on how we deal with this overall issue of equity, receipt of waste at any site, movement of waste or spent fuel between one site and another, and how the public can play into that.

MS. FLAX: I think you said some very important things, and I think what I would like to do is to reserve time towards the end of this committee meeting to talk about things like when agenda items are placed before the committee, what does the DOE staffer -- or how can we help the DOE staffer, and if I had known that what you wanted was reaction to a certain specific decision that was about to be made and then articulation of a broader issue that you would like the board's input in as time goes by.

MS. LYTLE: I think that's a very good idea. I was a bit ambivalent about today. As I said, we're too close to this decision to fairly bring it before you to give input to us, and so I was asking for whatever, you know, reactions you might be willing to have at this point, understanding that it's really much too close.

On the longer term, I think we need more time to lay it in front of you, so I'm not really expecting you to assist us with the longer term today at all. I'm just infusing the subject.

CHAIRMAN COSTLE: As I remember, the meetings we had this came up as an action item to get back to the committee on.

MS. LYTLE: Right. To introduce the subject really, explain more about it.

CHAIRMAN ALM: I think one thing that would be helpful, if we have time later today to talk a little bit about how we might assist Jill in the longer term, and indeed the question Glen raised, you know, whether this is within our charter. But, if so, this kind of thing I think probably deserves a more concerted effort than to try and sort of talk about it at a meeting without some kind of subcommittee action.

I think the next I have is Ron Ross.

MR. ROSS: Thanks. Jill, am I sensing that you're looking for some way to differentiate here? Is there one more thing you think you need as far as differentiating, say, between really it comes down to Jacksonville or Sunny Point, and Sunny Point seems to be the choice at this time, 
such as -- I know you looked at all the populations and previous experience, but like along the route if they've seen prefer shipments, are they prepared for these? Are you going to run into political barriers even there for preparation along the route? Have you shipped there before? Have you provided the emergency responders with the training? Have you provided whatever planning and that kind of thing? That would give you maybe an additional factor. I'm interpreting what you're asking, and the point's been brought up here as to what we want to focus in on, but I guess I'm asking you a question at this point. Is that what you're looking for from us as a response, one more response item?

MS. LYTLE: That's fine. That's helpful. We have looked at emergency response at the port and do they have the capability to respond, and I will go back and look at the issue of the route.

MR. ROSS: Along the routing. Given that Sunny Point probably has none because they have not seen any shipments, but going back to just your straight numbers, you're sorting this thing down to one or two ports. I'm assuming that's enough for an options and peer review.

MS. LYTLE: I guess the other reaction -- and I guess I have had that today from you -- is the question of does -- putting the law aside for a moment, does population density, should population density be a determining factor in making a decision like this? I mean, in a sense the Congress helped us to focus our look at that.

MR. ROSS: From a political point of view, I think they're probably coming from a correct point. From another point of view, larger cities and larger ports tend to have more resources to focus in on these things, and I'm not aiming at anything here. I'm just making an observation that some of the bigger cities we deal with have a better capability of responding than taking it through a lot of smaller communities, which, yes, a smaller population's affected, but they are not prepared for anything coming at them. So it's just an observation, and use it as you may.

CHAIRMAN ALM: Let me if we could just finish with -- I guess Ben you had your placard up and Jay and Dennis, and then if we could after that plan to have some lunch.

MR. SMITH: I'm wondering how broadly you cast your net to look for alternatives to doing this thing that's difficult, and I've got a really off the wall one I'd like to ask you about. Your answer will sort of help me understand how broadly you have cast the net. In Idaho when we toured the site, we saw a lot of transport rail casks sitting on sidings there near the Naval facility, and we were told, I believe, that they were empty casks, and I believe the situation there in Idaho now is that the shipments are shut down to a large extent. They are not moving as much of that fuel as they were. Has there been any look at temporary use of shipping casks, for instance? This isn't a lot of material. Moving a shipping cask that's sitting on a rail siding in Idaho to one of these places and getting it in some secure dry storage that we can contribute to the security for and handling the problem on a temporary basis? Were those kind of makeshift ways of doing it? 
MS. LYTLE: We have looked at the ability of the reactors to get dry storage casks at their reactor. I don't know specifically -- I'm pretty sure they didn't look at those specific casks, but they did look at putting it temporarily in casks. The regulatory system does not support that, I mean, putting it temporarily -- You can keep it in a shipping cask, but I believe that the standard is something like 30 or 60 days that you're supposed to keep this in a shipping cask, and that's it. Those casks weren't made for long-term storage.

MR. WERNER: Those casks are already called for unfortunately --

MS. LYTLE: Those specific ones.

MR. WERNER: -- are spoken for. And, in fact, when that deal was negotiated last summer, we were there counting every cask and every slot and every cask and checking when the refuelings of the different submarines and aircraft carriers were coming back in, and they're scheduled.

MS. LYTLE: They were used for the Navy's solution in Idaho. Your question is good one, though, on the dry cask storage in Europe. They did look at whether they could keep it in the shipping casks that we going to be sent over, could they leave it in it for a year, for example, and the answer was they would not be allowed to leave it in those casks for a year.

CHAIRMAN ALM: Okay. Jay.

DR. SORENSON: A couple of quick points. You have really a request from Deagan to start really with advisory boards, site-specific advisory boards at the sites. You're asking for how really the public could be involved and help. I would urge you to try to facilitate that process. I would also note that he is prepared really to agree to a reasonable one-time compromise, and that does involve the Sunny Point. I think he has looked into the question of emergency preparedness along the way. I know he certainly -- I've talked to him, and he certainly has with regard to Sunny Point, and he feels it's there. So I think another conversation with him would be a good idea. With regard to the large port facilities, I'd like to call everyone's attention to the fact that Seattle has said no way, that the longshoremen will not agree to it.

MS. LYTLE: I do think, though, that Ron's point is part of the ports --

DR. SORENSON: I agree with that.

MS. LYTLE: -- that the larger ports, even though I do understand Portland has taken that position, they do have a capability. They are much more experienced.

DR. SORENSON: In terms of the general point, I certainly would agree.

CHAIRMAN ALM: Okay. Dennis, you're going to have the last word. 
MR. BECHTEL: One question, one comment. The port selected for the EA, will that also be the port considered for the long-term solution?

MS. LYTLE: There's no connection. The one selected for the EA does not in any way make it more likely or less likely to be selected for the final, for the EIS, for the larger number shipments.

MR. BECHTEL: I guess the comment I have is I appreciate your comments about the equity issue, but if DOE is sensitive to the equity question, why is Nevada considered as part of the long-term solution? Another land-locked state. I mean, that just seemed to pop up. We're very sensitive to that right now obviously because of Yucca Mountain interim storage and some other things. It seems to be sort of an automatic. I'd appreciate your comments on why.

MS. LYTLE: Well, I think that talking about the overall equity issues related to repositories, storage of waste and so forth, that we do need to deal with them no matter what state we're talking to. I think Tom was speaking to the immediate issues that might have to be dealt with South Carolina in this case. But we are -- As Jeff said, the equity issue has to be brought to the table no matter what decision we're making somehow.

CHAIRMAN ALM: Okay. I'd like to see if we could get back here within an hour. We're going to be eating at the hotel. I think we'll quickly find out whether an hour is feasible by the service in the hotel. I guess we'll all be in the same area, so we'll at least have a general sense. This afternoon I'd like to start with the Environmental Management budget priorities, and, Jim, I guess you will have to do without your cohort, and then we'll get to the project performance with Randy Scott and the EH plan to move DOE under OSHA with Randy and Joe Fitzgerald, and then beyond that, if any of you want to bring up other issues, why don't you hit me at lunch and see how many of those -- I mean, come up and we can talk a little about how we could help Jill in the longer term on spent fuel management. And I think -- and I also said if there's anything additional we wanted to discuss with regard to risk assessment in the SSAB's, the floor would also be open for that, and then finally we'll have a little session called other business, and then we'll. see what comes up there. So I'm looking forward to seeing you all promptly in an hour.

(Whereupon, the meeting adjourned for lunch.)

CHAIRMCHAIRMAN ALM: Let me tell you what. We've got a very, very tight schedule, and I'll go through the whole schedule when I get everybody here. But you've got till 2:15. And so if I talk at twice the speed of light for 35 minutes, we'll be back at 2:15. It's just money. You'll be rewarded on how you're able to present this brilliantly and tersely.

MR. WERNER: And what exactly is the reward, Doug?

MR. COSTLE: What is that?

MR. WERNER: What exactly is the reward? 
It looks like we've got most of the people. Well, let's just begin.

I'm here to talk about this, money basically. This is all I've got here. The budget is a lot more than just money. The budget is how we accomplish the things we want to accomplish. The budget is how policy is expressed, and as they said in Watergate, "Follow the money and you find out what's going on."

And so I think that's what we really hope to talk about is what's going on, and that of course could lead us off into hyperspace if we're not careful, but I think that is exactly the way I want to structure the talk is really in those two parts: Present what we're requesting in the fiscal year 1995 budget, and what that means, and what we plan to do with that money. And then secondly move on to a broader discussion about the environmental management program strategy overall. And what do these dollars really represent? What are you going to accomplish with them, and where do you expect to go from here?

Because if we can't articulate a path foreward, we're going to get shut down, folks. There isn't going to be any EMAB. There isn't going to be an environmental management program, because the intolerance on Capitol Hill right now is very, very high. It's not one site versus another. It's all these sites versus other people who were angling for that money right now on Capitol Hill.

And we have a hearing tomorrow before the Armed Services Committee, and for those folks who aren't familiar with the budget process in Washington, the money comes from two places, from the Appropriations Committee, it comes from the Energy and Water Subcommittee appropriations which shares its responsibilities with -- we share a responsibility there with the Army Corps of Engineers, with the worthy water projects and dams and canals.

And the authorization for our money goes to the Armed Services Committee, which of course is a much larger budget, about $\$ 260$ billion dollars this year.

So with that brief introduction, let's get into the fiscal 1995 budget. And of course I'll have to have the slides.

I think Barry said the contractor -- or the engineers like slides better because you feel like it's backed up with stuff. And hopefully you'll find out that true.

This is the presentation that we're doing before Congress that we've done in numerous briefings already and is essentially in our testimony. And what we're laying out for folks is the fac that this budget is flat for this year.

After several years of increases of almost 30 percent an average of 29 percent a year, the FY '95 budget of $\$ 6.28$ billion is essentially the same as last year. In fact, it's less than the amoun of money requested last year, and it's only 1.7 percent or so above the appropriated amount from last year, fiscal ' 94. 
So there is -- what I'd like to do is get into explaining, well, what is this money being used for, and what's our strategy for the future of using it? But I did want to point out in the context of the Department's overall budget, it's now more than a third of the Department of Energy's total budget. And for the first time it really is clearly surpassing the amount of money that the Department of Energy is requesting on defense programs by a significant amount.

Now, where is that money split out from? And this is -- we can spend virtually the whole discussion on this, but there's -- this is teased out into a series of other details too. As most of you know, most of our budget is not spent on what most people think of as cleanup.

Nearly half of our budget is spent on waste management, and of that nearly half of that is spent on simply babysitting waste or storing it safely, hopefully in compliance with requirements. The cleanup portion that gets so much attention is 20 percent -- 27 percent of our budget, less than a third, and of that 27 percent of the FY' 95 budget more than half of that is still in the assessment phase, that is just doing studies and planning for cleanup. That's all pre-ROD money or pre record of decision.

The interesting thing I learned just recently about that number is -- by the way, that includes interim removal responses, so, Jeff, when we're trying to take credit for doing some expedited responses that we've been working with cooperatively at Hanford, we've got to make sure that those dollars are accurately reflected.

But essentially you can see of that 27 percent of the budget we are still -- the lump is yet to go through the snake, in other words in terms of large-scale construction. And it's sort of working its way through now.

The only part of the budget that really grew this year is this area called facility transition, and I want to get into that and describe what is facility transition in a minute. But right now let's just take a look at what a significant portion of the budget that is. It's 13 percent.

And we have some other cats and dogs in here. The transportation you'll hear -- maybe -- I don't know what it was on the agenda is. It is now organized in a different area. And technological development is six and a half percent.

And that of course is of interest to folks following Marilyn Lloyd's legislation that would require it to be a minimum of 10 percent. Well, is this enough money? That's always a big question. We've got a big part of Congress saying it's too much money, and then we have another group of people saying it's, you know, not enough money. 
Selective modification to some enforceable agreements. This does not mean willy nilly, carte blanc just unilaterally going out and stuffing states. That's not what that means, as some people have seen happen in the past, like certain FAX's that came in at eleven o'clock at night some of us watched a few years ago. That is not what's happening here.

In the case of Hanford we had a very intensive process that was successful in bringing in folks and starting at the higher level of what are people really interested in? What is their biggest concern? Such as protecting the Columbia River. And then working down to deal with the real issues and the real milestones.

The other things that are going on here is, Rocky Flats is really the big other negotiation that's going on. We can't claim that there's a heck of a lot else going on there right now for the budget. That's all that means right there. 
Superfund Reauthorization. There's some folks who have said, if Superfund goes through, you can get savings of about $\$ 110$ million. We're saying that even if Superfund does not go through, we have found a lot more willingness in some of the EPA regions to work on new ways of operating with some interim guides. That is, moving ahead with some expedited removal actions before you finish the whole RIFS.

In some cases let's go out and do some stabilization, let's do some hot spot removal, do what makes sense. And we're seeing a lot about -- a lot of real common sense cooperation, and that's what it takes in the field on the ground.

Finally, probably the most important thing and one that -- Randy, I'm not trying to put you on the spot. He's going to be an important person for doing worker training and working cooperatively with other folks doing hiring. This idea is as you can see hiring about 1200 new trained environmental professionals, not people who are coming in for another program in many cases, but people who really know the environmental business, in particular project managers who know how to deal with environmental projects, know how to deal with the public and people who as Tom says can think out of both sides of their brain, can do cost estimations for projects, and really oversee contractors. So the Department of Energy and the federal people are in charge for the public interest and not contractors.

Not that we're not going to be -- obviously we'll use contractors, but you've got to have people supervising the contractors, and that balance has not been good. And then the last one, and this is going to be an important one for the long run, is using more efficient technologies. Not just more efficient technologies really; effective technologies, because in too many cases we're using technologies that just don't make any sense and don't do the job for the long run.

So that's all -- a fair amount of time is spent, but I think it's important to go through what are the assumptions in building this budget. And of course any other changes you have to work with local stakeholders. I want to next highlight two particular areas of the budget in explaining where is this money going? And as I mentioned, the technologies is one area, and the facility transition is the other.

The technology development is more than just paperwork now. And I know I've served on some committees in the past with a number of folks here, the Western Governors Association, the DOIT Committee, and worked on the assertive business -- the Strategic Environmental Research Defense Program's initiatives a number of years ago.

And there's been some frustration about getting that going. Well, there is actually a lot of things happening in the field right now, a lot of new technology. Some of these have been commercialized already, the multiple depth well sampling, the work up at Hanford that saved a lot of money, the work at Fernald, using a minimum volume of waste stabilization. So there are things happening all around the country on the ground to really save money. 
The next one I want to spend a little more time on. This is sort of a fuzzy area. I mentioned this is the only area of the budget that grew last year, what's called facility transition. Well, what is a facility transition? It's sort of an odd duck. So I'm going to take a moment to try to describe that.

It is not just cleanup in the traditional sense of the word. One could say that it's stabilization money. One could say that it is babysitting money. You could say it's paying the rents and landlord. But it means some very specific things in terms of examples.

The Rocky Flats plant for example. The Environmental Management Program now has taken ownership of virtually all of the buildings and structures at that facility in terms of being the landlord and running them. And that means dealing with some of the 'fissile' material, the unstable plutonium that's at the site.

And for folks who haven't dealt with plutonium, it can be pretty nasty stuff as an understatement. It can burn spontaneously in contact with air in the right form. It is very dangerous stuff. There's a vault, just one vault containing some of this stuff where the maintenance on that was $\$ 30$ million a year because of all the safeguards and securities that would have to be up to international standards.

And in fact I spent some time earlier this week although it's only Tuesday -- it seems like a long week already -- working out a deal with the Russians to bring them over to demonstrate our safeguards and securities.

So the point is, the Environmental Management Program, the so-called cleanup program is doing a heck of a lot more than just cleanup. And we're an important player in the international safeguards movement.

At Hanford we did a cleanout of a uranium trioxide facility, a UO-3 plant. We're now doing an environmental impact statement of the plutonium finishing plant, and I'll show you a picture of that in just a moment, to look at new technology for stabilizing this material.

And as Tad knows some of my favorite plants, the Purex and the Chem Plant, are now completely under the control of the environmental management, both financial and management -technical management of it. So I think we're able to do the right thing with that money instead of perpetuating some of the old missions, and then at INEL, that's where the Chem Plant is, we're actually cleaning out some of those lines where you've actually had lines that were leaking or at risk of leaking.

And let me just quickly run through some images of -- what are we talking about plutonium? People think about plutonium. Well, isn't this that gleaming classified shape that goes into a warhead? That's kind of neat. No, this is some of the plutonium we deal with in the environmental management program. This comes through in sludges. 
This is a very, very difficult thing to deal with. And all of this material that's attached to it is now contaminated transuranic waste. Well, in fact I'm not sure if it would be considered 'transuranic' waste because it's so extraordinarily contaminated. It would not meet our waste acceptance criteria. And so it couldn't be disposed of in its form right now.

Here is an image of one of the canyons at the plutonium finishing plant. This is about 80 feet long, 50 feet high, 30 feet wide. These columns on either side are filled with nitric acid with $\mathrm{pH}$ less than one. The whole thing is coated with plutonium oxide dust in large quantities. There are rooms somewhat like this at Rocky Flats.

Many of you heard they're called the infinity rooms because nobody can ever go in them for the foreseeable future. You can't go in to sample them. You can't go in to clean them out. We don't know what to do with them. These are very difficult problems. Many of them have the door -- the doors have been welded shut so that no one can go into these infinity rooms.

The infinity comes because there are no meters that can read the level of contamination in them. You folks would bring in a meter and it would go into infinity on the meter at even the highest scale setting. That's what we call infinity rooms.

All right. A glove box at PFP. We don't know how exactly to get in there. We've got what are called fondly the ice cream containers with plutonium scrap in them. And some of the plutonium --

This is just a random drum that folks at Hanford, Jeff -- Talk to those guys -- they ship down to Los Alamos to deal with to treat in some way, and just you open up the drum, and out tumbles out this stuff. It's a great place.

UNIDENTIFIED SPEAKER: Good work, Jeff.

MR. WERNER: Another glove box of PFP. But you get a sense we are not dealing with your classic New Jersey dump sites with drums littered about. All right? This is the education here. And I think that's what was helpful about just spending some time with Jill. This is not just cleanup in the traditional sense. Anybody who came in from the Superfund program, welcome to DOE.

Before I move on to the strategies, some of the specific things we do all the time with the $\$ 6.28$ billion we're going to spend next year. We're pushing to get a hundred interim removal actions done and 'volustration' things, 16 remedial action projects we hope to complete, or are committing to complete.

But we have some very specific measures of outcomes with that money so we can be held accountable. And similarly in the technological developments and the facility transition area where we have specific actions that we'll be able to accomplish. 
But the thing about the facility transition, I mean just again lingering, you can tell that's important because it is a growing part of our budget, but that is one area if somebody has to be talking to somebody in the Appropriations Committee -- I'm not allowed to encourage lobbying here -- but if you happen to be talking to them, that is one area of the budget -- if you cut that budget, that is the one area that could have clear, near-term, tangible safety impacts on workers.

There are workers out there dealing with these facilities right now. The things we've -- we have moved some dirt in FY '94, just in the past year a few more. The uranium mill tailings program has moved enough dirt -- and I forgot the specific number -- and if you had a traffic jam between Birmingham, Alabama, it would stretch all the way to Los Angeles. That's how much dirt we've moved just in the UMTRA program, stabilizing some of that contaminated material.

CHAIRMAN BARRICK: That's pretty small compared to how far your money goes. You ought $"$, do some ratios.

MR. WERNER: But the trucks aren't filled with dollar bills though. The dollar bills were stretched end to end one layer deep.

So that's our budget for ' 95 . But let's take a look at where we are and where we think we're going to end up in terms of the strategy of the overall program, and what I think we all need to be a part of changing, and all of the ways we need to change our way of doing business.

We are right there now, that is in ' 95 the budget is 6.28 billion. We've been told by the Office of Management and Budget that we can expect no increases for next year. We've been told by some people on Capitol Hill, in fact you're going to be lucky to get your request. Yet we foresee some of the preliminary -- the estimates coming in, and these are still preliminary estimates, going way out. So that there is a significant gap, what we call the train wreck, is about to occur in the years coming.

And some of that we can make up with actions we did just this past year, productivity improvements, better technology, different ways of doing business. Yes, there are some things we can do given the current outlines of this -- the program as it is.

But the fact is, as this thing gets further out here and as in particular more projects go to construction where that lump works through the snake and you start doing more construction after having these studies pile up, the budget just seems to go up, and OMB is saying it's going to be level

And many of us heard this whining from OMB for years saying, "Well, we don't think we can afford more money," yet the next year we were able to get a few extra hundred million dollars out of them, so -- and then the next year they say, "Well, we're not going to give you more money," but then they get another few hundred million dollars.

That didn't happen this year. They saw what Congress did. They got support, and the budget is flat. And it's really difficult to see how it will increase, although I have a couple ideas 
I'd like to finish with your help on. So that really is the problem we're faced on -- with is increasing out year estimates and limited funds.

And what we'd like to do is, first, take a look at where we are right now. People discussed earlier, we really don't have a handle on the risks. We don't know what they are. And many people don't have any trust in DOE to come up with any estimates of that yet.

We're using technologies that just aren't working. We're barely in control. And some people would say the contractors are not in control of DOE, as the hearing on December 1st last year amply demonstrated. And in some of the cases there's malicious compliance going on within the system with all kinds of things, from the agreements to safety issues.

What we're hoping to get to is a new strategy where we do have a better handle on what the risks are that there's a consensus on that people have some faith and trust in. We're not there yet clearly, try to incorporate some of the new technologies into the agreements, get a better handle on project management, so that we're using federal FTEs, working in the public interest to manage these projects and renegotiate when circumstances warrant it if, you know, people are interested in renegotiating it with us.

But, fundamentally, I think what we've learned, and Tom has said this many times in testimony, is a number of lessons from the Superfund program from the 1980s and from our own program in the last few years.

Just take a look at the facts that we've learned over the past 10 or 15 years. Number one, we don't have adequate effective remedial technologies at many of these sites. It's just not working for the long run. Number two, even if you had the technologies, we don't know what the risks are at the site. And even if you knew what the risks are, you don't know what your goal is, how clean is clean is. It's just an incredible series of problems.

And even if you had the technologies, even if you knew how to measure the risks, and even if you knew what risks were tolerable, there are way too many sites to deal with at one time anyway.

So the whole strategy to get -- after getting control of the system is to build stabilized sites so that we know that people are not being exposed, workers or residents anywhere, invest simultaneously in new technologies so that we get a better handle on what the risks are, work cooperatively with people about what the tolerable risks are, and invest in a new technology so we can do a better job of cleaning up the sites. And finally getting that in place, identify what the urgent risks are and to -- as the new technologies get into place to invest in those sites using newer technologies or using the technologies to clean the sites out permanently.

This is a strategy I think that can succeed for all of us. And I think this is what we -similar to what what of many of us want. But to get there I think we're going to have to all work together, and the idea of this year's budget is in a sense a place holder so we can get on with this 
kind of a new strategy, something we can all work together on generally and at our own individual sites.

But unless we get this budget frankly, and this is the pitch we're making in Congress, unless we get the budget this year, we're not going to have the credibility of the states to come back to the table in negotiating the agreements. We're just not going to be able to do it.

The States are going to start coming after us with some justification, because there's a lot of impatience out there. And let me just finish with Tom's -- with the six goals. We're trying to keep repeating the six goals. It's what we're all going after.

And I think this is something that if we keep people in the field focused on it and people sitting around doing work and spending this $\$ 6.28$ billion, we keep asking ourselves, are we spending money to achieve these goals and get results, reduce risks, protect workers, change the way we do business, invest in technologies, and invest in partnerships? If we're not doing that, we need to cut it out.

With that I -- we've got -- I can talk about more individuals sites, but I figured the cards would start coming up. Maybe we can have the people who don't have questions raise their cards.

CHAIRMAN ALM: Well, I guess the one comment I would make is that this is basically a briefing of what your budget is now. One of the questions is the extent to which EMAB would be involved in the budget process in the future and whether you'd indeed desire such help. Have you thought about that at all, Jim?

MR. WERNER: Oh, yes, I have. But I think the question is, what does EMAB want to do also. And $I$ think we can't just presume to enforce an agenda here.

CHAIRMAN AIM: Well, I was going to ask them right now I think.

MR. WERNER: Okay.

CHAIRMAN ALM: But I wasn't going to ask if I didn't -- if you said the --

MR. WERNER: Well, part of the answer, Al, is, if you go back to the Keystone agreement that was negotiated after two years of work in December of '92, it outlined a specific process for. different advisory committees to be involved in the budget.

CHAIRMAN ALM: Um-hmm.

MR. WERNER: And Chapter 4 lays that out pretty clearly. And I think we need to really put that in place and start using it.

43

44

CHAIRMAN ALM: Yes. 
MR. WERNER: I think that is a useful project, and to the extent EMAB can help resolve problems and hiccups and potholes on that road, I think there is a useful way, sharing - in fact the Hanford Agreement specifically provides for that even a step further that is very helpful where we're sharing budget information as the budget is being developed.

CHAIRMAN ALM: Okay. I guess we can go on for maybe 10 more minutes, then we've just got to cut it off, or we're not going to get through our business. Let me just tell you what I see as a business for the rest of today, carrying this on till about 2:25, then with Randy Scott, his two hour project performance and the moving DOE under OSHA. We carry that until about 3:00.

And then Jay Sorenson had some slides he wanted to show us which would take I guess five minutes or thereabouts. Then I think we need to talk a little bit about how we can assist on the -on the spent nuclear fuels program about 3:30.

Then 3:30 to 4:00 we need to do other business including deciding where our next meetings are going to be. So it's a very, very tight schedule at this point in time.

Now that I say that, let me start with you, Dennis. I don't want to intimidate anybody.

MR. COSTLE: You didn't.

MR. BECHTEL: I was at a -- I was at a --

MR. WERNER: This is coming out of the five minutes.

MR. BECHTEL: Jim, I was at a hearing several weeks ago for a nuclear waste plant, and Bennett Johnston had indicated to Secretary O'Leary that she will get \$150 million for the Yucca Mountain program somewhere out of the budget. There were other requests for uranium enrichment.

How realistic is your budget? And do you think you're going to be able to get what you feel you have need of this year?

MR. WERNER: The sharp knives are coming from all directions. So if you folks have any opinion on where they'd like those knives to cut, I can help them outside with the names of the staffers on the subcommittees who will be making those decisions in the next four weeks.

That's one of the places to sharpen. But I mean $\$ 150$ million, that's easy to deal with. We're talking about a billion dollars. If the Armed Services Committee decides to go after a new aircraft carrier, that's a billion dollars right there. If they decide that they want to keep, you know, any number of things, if we have a new dam or a canal or something --

MR. BECHTEL: Okay. 
MR. WERNER: -- it's coming out of this.

MR. SMITH: Jim, I like your analogy of the lump in the snake. That's a good southern analogy, but you know, like you sort of equated that to some of the ER projects reaching construction.

MR. WERNER: That's the Federal Facilities Compliance Act.

MR. SMITH: The other lump is the Federal Facilities Compliance Act. And I'm wondering, right about this time of year I think you're actually looking at budget years two or three years down the pipeline. I know you've got to fight these battles in Congress right now, but your beginning discussions with OMB about budget implications two or three years from now, you've seen these conceptual site treatment plans come out. You must be getting an inkling that this is another lump in the snake .-

MR. WERNER: That's right.

The FFCA doesn't even kick in terms of big construction. We sould see another slope coming up like that out there. Who knows what it --

MR. SMITH: How are you showing it kicking in the year 2000? I have a feeling some state compliance agreements will bring it up a bit quicker than that.

MR. WERNER: Yes, sure, there will be a few things in here, but it's needs compared to the big time, really big construction to really pay for stuff -- a lot of stuff coming through all at once. This is an issue in terms of -- I can't answer your -. I think if I heard your question, it is how much and when.

MR. SMITH; What are you doing to prepare? What are you doing to get ready?

MR. WERNER: Okay. Well, obviously the Federal Facilities Compliance Act process that has to get through, I think the past will serve if anything that useful process in estimating and planning if we do it right and make sure it's meaningful.

There's always what's called -- what we affectionately call the beam - the baseline the Environmental Management requested by Congress last year to establish the total cost of the Environmental Management Program over the next 30 odd years, and look at some of the options of, you know, what are going to affect those costs.

And I think that's where we're going to be able to do the full estimation for the Federal Facilities Compliance Act --

CHAIRMAN ALM: Okay. Tom? 
MR. WINSTON: Jim, it's been a historic problem as facilities would shut down of the burden of being transferred over to EM, and -- outside stakeholders have been watching that for at least five years of looking at the budget. This budget more than any in the past really recognizes that problem. But there were also -- there were some decisions, production shut-down decisions, late in say the December-January time frames?

MR. WERNER: Like Mound?

MR. WINSTON: Like Mound, really in the Albuquerque field office area. And, you know, we're real concerned about once again, you know, a decision to in a sense turn the key and then have all of the liability, you know, passed on to EM.

MR. WERNER: Right.

MR. WINSTON: And our folks in DOE in the State are often being told to, you know, get that back from -- from regulatory lenience on the commitments you've made already, and that's really troubling.

MR. WERNER: We could go into that, but as I mentioned early out, that is the really the only area of our budget that's really growing. That's it. Facility transition. And that's not new scope.

In fact, that's the same scope the defense programs mostly used to have under their mail code that we are now expected to carry on for less money.

And I fought that battle as Tad and some of other folks can tell you for many years. That used to be hidden under the waste management budget. You know, at least now we have some transparency in the budget where the money is going but that --

MR. WINSTON: But that fight's still not over. I mean that's --

MR. WERNER: Oh, absolutely not --

MR. WINSTON: It is going to happen --

MR. WERNER: Big time.

There was a memo in fact -- curiously enough signed on November 3rd of 1992, that turned over, or dated the 2 nd. It was -- turned over responsibility for a large number of Defense Programs facilities through a Memorandum of Understanding with Environmental Management without the money to go along with it. We swallowed that then.

We've got some very good cracker jack staff that are engaged in that battle to make sure that doesn't happen again. Unfortunately these stupid bureaucratic battles pitted in Washington, 
D.C. in the Forrestall Building are leaving some folks out in the field like Miami's (inaudible) and in Mound just left hanging dry. You know, and suddenly somebody pulls it out of their budget, and they worry about, well, it's not my mail code; we'll let somebody else worry about it. It's a problem. It's a very serious problem.

UNIDENTIFIED SPEAKER: We're ready to help you.

CHAIRMAN ALM: Vicky?

MS. DASTILLUNG: I was looking at the charts at the end of the overheads that we were given, and between fiscal year '94 and ' 95 most of the amounts from State to State went down a little bit or up a little bit?

MR. WERNER: Okay. I didn't want to get into -- it's I'm actually in the footnotes. If anybody wants to turn to this level of detail. The amount going down is an artifact of -- the technology and development has not yet been distributed yet on individual sites.

MS. DASTILLUNG: Okay. Well, that's not -- that's just the beginning. The big question is, there's one item on here that went way up, and it was a headquarter's budget.

MR. WERNER: The Headquarter's budget went down significantly. then? No.

MS. DASTILLUNG: Am I misunderstanding this? Or is that a totaling of everything

MR. WERNER: I don't know.

MS. DASTILLUNG: Because headquarter's total, I mean it went up like $\$ 250$ million?

MR. WERNER: No. In fact that's been something we have been loud about on Capitol Hill is the program direction money going down.

MS. DASTILLUNG: This is on page 20 of the overhead.

MR. WERNER: I don't have the same thing right now, but I can go over it with you after that. It actually goes -- goes down in '95.

MS. DASTILLUNG: Okay. Maybe we can get together and you can make me understand the numbers. Seems way out of wack.

CHAIRMAN ALM: Okay. Bill?

MR. WERNER: Yes. It doubled -- no, from '93 to '94 it almost doubled. We took it down by 35 percent. 
CHAIRMAN ALM: Okay. Tim? questions.

MR. CONNOR: Yes. This is one of those "What the hell are we doing here?" Kind of

MR. WERNER: Um-hmm.

MR. CONNOR: Early in this meeting I --

MR. WERNER: I --

MR. COSTLE: Wrong number?

CHAIRMAN ALM: Let the record show that Jim denies the numbers.

MR. WERNER: It's not my mail code.

CHAIRMAN ALM: And, Tim?

MR. WERNER: So what are we doing here, Tim?

MR. CONNOR: Well, what I wanted to get at is the relevance of this committee's existence and its work to this process. Having been involved in the early stages of the Programmatic EIS, I understand why it was initiated. I understand the forces. I understand the interests in requesting that document.

It seems to me in my view that the purpose of that from my perspective has essentially become obsolete because of events.

I just want to know from your perspective as the Director of Strategic Planning and Analysis how relevant the Programmatic EIS is on a scale from 1 to 10 to strategic planning at the Department of Energy.

MR. WERNER: Eight. Okay. You said 1 to 10 ?

MR. CONNOR: Yes.

MR. WERNER: I actually -- I actually disagree that the sort of suggestion that is totally irrelevant. I do believe that, you know, as circumstances change you've got to recast sometimes your planning activities. And I think that's a classic example.

As you suggested, and just for the purposes of other people who haven't borne these scars I was in the -- involved in the early part of the PEIS. The Programmatic Environmental Impact 
Statement was initiated in December of 1988 in response to a report at the time we call the yellow book that planned for the construction of an entirely new complex of facilities to build and design and develop and test nuclear warheads in the United States.

In response to that the number of environmental organizations wrote a notice of intent to sue letter in December of '88. There was no response at all. In June of '89 a lawsuit was filed, and for the rest of that year there was litigation back and forth of, you know, the normal kinds of motions and briefs and things like that.

In January of ' 90 instead of the one comprehensive analysis that was requested on the reconfiguration of the nuclear weapons complex, the Department at that time decided to do two Programmatic Environmental Impact Statements.

And I think that the negotiations with the Justice Department will show that that was not satisfactory to the plaintiffs at the time, but eventually by October of that year -- it only took 10 months to finally settle on that -- it was done because the initial interest was one on the weapons complex. And now we have one on the Environmental Management Programmatic Environmental Impact Statement.

And as you indicated, a number of things have happened since that time. I've mentioned already, the baseline of the Environmental Management report is being done. The Federal Facilities Compliance Act has been passed, and we have a very sophisticated process working with the States. Well, sophisticated -- it's big anyway, working with the States. We'll seen how successful it is. That's the important part.

MR. CONNOR: Okay.

MR. WERNER: And that is of course using a lot of the analysis that's been done under the PEIS. A lot of that is very good success. So I don't think we can just say it's totally irrelevant. But I think that you're right; there is a warranted, you know, taking a look at exactly how we can make the PEIS as meaningful as we possibly can. And I think that, you know, we're already doing that.

CHAIRMAN ALM: Jim, we need to move on.

MR. WERNER: Okay.

CHAIRMAN ALM: Jerry?

MR. CHRISTEAN: Well, this is because I'm naive about the budgeting process in the Federal government. But as someone who's done some negotiating, why in the hell would you start out with what is your minimum requirement to get the job done? I mean why in the hell not start out at an inflated number, so you've got a little moving room? Because you're going to start at the point that you think you need to survive at, and it may be somewhat less. 
MR. WERNER: Right. Well, and if -- if I were buying a horse I'd be doing exactly that. But in this case that's not the species we're buying, and we're working in the --

MR. CHRISTEAN: But on the other hand, Jim --

MR. WERNER: -- overall federal budget process. The folks that are working in the EPA around the table know that you don't have that wiggle room. When you go after them, they give you a mark. Period. We know it's not an option.

MR. CHRISTEAN: But, Jim, I think your analogy of a horse is very good, because someone explained that the difference between a horse race and Congress is that in a horse race they got the whole horse.

MS. FLAX: Jerry, you're not listening to him. What Jim said is that OMB gives him a mark --

MR. WERNER: Yes, that's it.

MS. FLAX: And you just cannot -- you don't negotiate with OMB.

MR. WERNER: Jerry, I'm not allowed to encourage people to lobby, but let me just stop, recount the history of -- in FY '91 -- or FY' 90 and FY '90 the Department came in with a mark, and FY '90 the Congress chose through whatever influence to add \$325 million above the Administration's mark. It was taken out of other programs. And in FY '91 they chose to add $\$ 385$ million above that mark. I have --

MR. CHRISTEAN: But you don't --

MS. FLAX: I wouldn't --

MR. CHRISTEAN: Excuse me. But you don't have the expectation of that happening this time around? You said so. Didn't you say you didn't expect --

MR. WERNER: I think it's going to be a tough fight. That's all.

CHAIRMAN ALM: Can we try and --

Ken?

MR. KORKIA: Thanks. Jim, because we have a regulation framework and it has its certain priorities, and that the officials at the local EPA level and the local state department are sworn to uphold the law, and so that's what's going to be part of the agreements. And they don't want to give that up. 
And so how do you -- what's your advice in the renegotiating in this case, especially the Rocky Flats agreement, and how do you incorporate other things because I see the big problem as the fact that the States can't regulate radionuclides, and so they're going to regulate what they can. But that doesn't address the greatest risk. That doesn't address this process of waste loads that are going to sit there with plutonium in them, the tanks that have the liquid residues in them. That won't be addressed because we're going to have to go by the regulatory breakup that's going to (inaudible) organics and ground water 'that's not moving off site'.

MR. WERNER: You just asked about five questions in one. Very good.

MR. KORKIA: I'll quit.

MR. WERNER: That must be a record for your committee.

In terms of advice, I'm not going to offer anything specific on Rocky Flats. That would be imprudent. I guess I would offer the example that was set at Hanford where again you start with some fundamental high-level principles and work things out. But that can only happen if you have trust, and you're not going to have trust unless we get this budget; okay? We need that. And we need to sit down at the table.

And that sitting down at the table is not just a one-time big event thing. People have to be willing to regularly look at it and see, What makes sense for this site?

Do we have the technologies on line? We have arrived -- we've come up to the point where we can make the choice between doing something that doesn't make a lot of sense or holding off and doing something else, or not waiting at all and moving ahead faster.

So I think there are lots of opportunities for renegotiating in many circumstances, not just the big, you know, three-ring operation that happens, you know, right now at Rocky Flats where there's a lot of tension.

Unless you've got that trust, it ain't going to happen. And then you've slipped in the self-regulation part I noticed, and you're exactly right. That is a problem, and the Department has already gone on record to eliminate that and, you know, in phases.

The Secretary last year in May said, We're going to get out of self-regulation with regard to worker health and safety and come into OSHA compliance in three to five years.

And unfortunately our colleagues in the Environmental Safety and Health were not able to make it here today. And we can get some more details on that. So I'm not sure what Randy could offer on that. There is already support within the Department for what's known as the Defazio Amendment, D-e-f-a-z-i-o, that is now before the House of Representatives on the Clean Water Act, that would eliminate sovereign immunity and redefine pollutant under the Atomic Energy Act to include special by-product materials, so there's an opportunity. 
And then the Miller Bill would look at broader elimination of self-regulation on radionuclides. And I think those are the sorts of steps that will go in that direction to deal with it. It's not going to be an overnight thing, but those are some of the steps we can take in solving the problems.

UNIDENTIFIED SPEAKER: Do you support the Miller --

MR. WERNER: Excuse me?

UNIDENTIFIED SPEAKER: Do you support the Miller part --

CHAIRMAN ALM: Answer no.

MS. FLAX: Right. Answer no.

MR. WERNER: Our testimony -- we just had the testimony on that. It's not a one-word answer. Sorry. I was just told I can answer a one-word answer.

MS. FLAX: Yes or no. You can answer. This is on the record now.

CHAIRMAN ALM: Yes.

MR. WERNER: Could somebody with the committee, somebody who handles such things -- it's the testimony of Charlie Curtis before the Congress, Miller's Committee on Natural Resources?

MR. SMITH: It is in the board's briefing books.

CHAIRMAN ALM: Okay. Jim, we're going to have to move on.

MR. WERNER: Oh, yes, here's the answer to your question.

CHAIRMAN ALM: I need to move on to Randy Scott. I think the question that we need to think about at the committee is the extent to which we participate in the budget area process as an advisory committee.

MR. KUCERA: Mr. Chairman, I had a very short question. Could I ask it?

CHAIRMAN ALM: Let's see how short it is. Go ahead.

MR. KUCERA: Okay. Jim, did you have a cut list that you were unable to get through? Or are you afraid to go with a cut list?

MR. WERNER: What do you mean by -- a cut list? 
MR. WERNER: What is that?

MR. KUCERA: A list of programs where because they're not active yet or because they've -- you're simply babysitting them and they may be overbudgeted, you think that there could be savings. Like WIPP I see down at $\$ 185$ million, and it's probably pretty hard to justify that.

I notice Westinghouse having trouble justifying that, but yet it's in there at $\$ 185$ million. Do you have a list of those things?

MR. WERNER: No.

MR. KUCERA: Have you tried to put together a list of those things?

MR. WERNER: No. We're going to try to get this budget through Congress. And even if we don't get it we're going to try to meet it. And the question you raised is, what do you do if you don't get the money? And the first question is, it goes back to the very beginning. What is the strategy of pushing down a budget?

You get savings by forcing savings. You get people to do things more efficiently by giving them less money sometimes. You'd be amazed how much we have gotten out of the system. I'm not trying to be unrealistic or dodge the question because at some point, as I think I very clearly put up with that train wreck slide, that tough question is going to have to be answered. What do you do when there is limited amounts of money and too many mouths to feed? And I think that suggests getting back to the question that was raised here. What does EMAB want to do with regard to helping out on the budget process?

I can suggest one thing. What will not work is if we, you know, get into this process of trying to cut according to, you know, some -- some perceived need so that folks around this table cut or you develop another black box computer model. They didn't work before and they're not going to work now.

That's why in this risk presentation you saw completely that it's not going to be an inter-site risk analysis. There's just no way to sustain that.

CHAIRMAN ALM: Thank you very much, Jim. I appreciate it.

UNIDENTIFIED SPEAKER: They had a very interesting conversation, but he's got to figure it out.

DR. DONATH: I think Jim already knows as he pointed out in your first summary here, on page 18, you show that the Headquarter's amount is seven forty-three five seventy -- sorry -- 
five forty-seven ninety twenty-six, and then the lower number which does have an asterisk shows that that amount is going to be contracted among the --

MR. WERNER: So it's technologies development.

UNIDENTIFIED SPEAKER: But the point of concern is that on page 20 it shows as a headquarter's the sum of those two, nine ninety-five o one seven, and there's no footnote there or indication.

So if you add the two, you can see the correlation.

MR. WERNER: The Headquarter's function that people think of at technologies and development is not spent largely at Headquarters. That's all over the country as I showed on that map.

DR. DONATH: One versus 84 . So if you look at page 4, I think, your slides.

MS. DASTILLUNG: Is the concern that if they go down through the States, and they would get to the last that headquarters has increased their budget -happen.

MR. WERNER: In my wildest dreams they'd help us in that detail. It ain't going to

MR. CHRISTEAN: Are you going to be around for a while?

CHAIRMAN ALM: Okay. Randy, go ahead.

Randy, can you finish within about -- in terms of including all the questions and everything about 10 after 3:00?

MR. SCOTT: I'll do my best.

CHAIRMAN ALM: With both topics.

MR. SCOTT: I think Jim's talk gave a good lead-in to what I'm going to talk about, because the Project Performance Study and the EM's response to it are going to help although not fix the train wreck slide that Jim had up here on where the budget's headed.

And I think we are talking about how to do -- get more for the same amount of money and just be more efficient in the way we do business.

So I want to talk about the Project Performance Study. I was due to talk about that in December and didn't get on. I want to talk about the EM-wide "Stand Down", then we cannot get 
in the response to that and the Quality Improvement Teams we developed, and then have a summary.

The first slide -- I just want to mention what the study, Project Performance Study, was all about. Tom Grumbly asked that we do this back in August, '93. We all had an intuitive feeling that we weren't being as efficient in the EM program as maybe the private sector and maybe even other Federal agencies were being and we wanted to check that out.

We went with a group called Independent Project Analysis, Inc., which has a database of

So that really kind of awakened the whole Department to the fact that the part of the Department with the biggest budget really had some room for improvement and for cost savings. One of the things the study did for us was to provide a benchmark of performance so we could measure improvement as we move ahead.

Cutting to the chase so to speak, I'll talk in a minute about the database that gave us these results. But basically as I said, it was looking at private sector and other government agencies doing cleanup work primarily, but also waste management and capital project comparisons.

A lot of people when they first saw these results had a lot of explanations for them. But in fact the study really did do a fairly decent apples to apples comparison of our projects with others, matching up technologies applied and the size of the projects, the kind of contaminants we were dealing with, and receptors and pathways and so on.

So these numbers may not be precise, but they're close enough to tell us we have significant room for improvement.

And just working across real quick, cost performance in that column is for environmental restoration projects only, not wasie management. You're just looking at a similar project if it was done by us versus the private sector would cost about 32 percent more for us to do it than somebody on the outside. The rther governments are down there around 115.

And the fact that we appear on the top of each of these scales does not mean we're number one; it means the opposite. 
Cost overrun. What we estimated the cost would -- project would cost. And what we ended up with, we're up close to 50 percent. Other government and private sector are fairly close together in terms of ER. The private sector for ER is for capital project.

And as we expect capital projects, we're doing better in most of these categories because we did have a better experience base to work with schedule performance, what we anticipate the time will be to get these things done.

We're up there in the 122 area, 22 percent more than our cohorts in the private sector. Schedule slip, 52 percent, 16 percent for the private sector. For that one we're looking at the start of engineering through completion.

How do we do in te. of the amount of time it takes to get the job done? The database. We looked at 233 environmental restoration projects that were other than ours in the Department. We looked at 951 capital projects to do our comparisons with the waste management performance.

In terms of the DOE projects, we're just looking at 58 environmental restoration projects, 7 waste management projects. In waste management we don't have statistical significance, but we have an indication of where we needed to go to improve, and we will be collecting more information and getting a better sample for those projects.

The data that fed this study included standardized work sheets that have been tested fairly thoroughly by the group that did the study, and interviews with all the project team members.

We had very good cooperation with the people that we interviewed out in the field. And for the most part, the folks that we talked to agreed we had the conclusions and welcomed the kinds of recommendations that were being made.

How we picked the projects? Most of them we were trying to get completed projects. We tried to get all the field offices included, and we got all of them but Nevada. Project completion date, we have the median completion date of ' 88 or ' 99 or ' 99 .- or ' 89 for all of the different projects we looked at, both our own, government, private sector and capital projects.

So we have a very, very good comparison in that respect. We're not looking at projects done in the ' 60 s versus the ' 90 s.

Here's one of the biggest unpleasant surprises. Our project management costs were four times the private sector and almost double the other government agencies. And we feel it's due in part to the -- we have project management costs and responsibilities being split on the same site. We've got redundancy and excessive administrative costs we think. It's a big target.

DR. FREUDENBURG: You've got cost controls under everything else though; right? 
MR. SCOTT: Right. But looking back at Jim's slide on the train wreck, I mean here's a big target where we think we can find some savings to help close the gap between the money we expect to get in the near term or in the next several years and what we're going to have on the plate in terms of work to do.

Project cost growth comparisons.

CHAIRMAN ALM: As to other government projects, how many of those are Corps of Engineers?

MR. SCOTT: I don't know the exact number.

\section{CHAIRMAN ALM: Substantial?}

MR. SCOTT: It was split between the private sector and the Corps of Engineers and EPA. Those were the other government projects we looked at.

We have got in addition to having more cost growth than other government and private sector counterparts, we also have a bigger variance in our cost growth. It makes it difficult to predict our outcomes with when we have changes to a project management system.

We feel like it's probably due to poor project definition. We don't have the kind of cost controls on our projects we would like. Unrealistic estimates. Maybe our contingencies aren't what they ought to be in terms of anticipating problems as we move through the project also.

In terms of project definition, this poor, fair, good and best is a quantitative rating of how well projects are scoped and understood at the beginning of their design versus where they end up. Needless to say, nobody is doing great, because the performance ranges are a little better than poor to a little better than fair.

Unfortunately, once again we're on the wrong end of the pack. But this is due in part to the -- this is strict -- this slide by the way is strictly environmental restoration, so we're talking about what happens admittedly in ar evolving industry, and everybody is learning and not doing wonderfully in terms of defining projects well on the front end.

Project definition. How are we doing over time? We don't seen a clear trend. We unfortunately see large variance in certain years in quality in our project definition. '90, '91 and '92 in particular don't look too good.

The most upsetting thing about this chart is when you think about the fact that most of our projects dealing with environmental restoration have been relatively simple, scooping up dirt and putting caps over contamination. We haven't gotten to the real complicated stuff yet. 
So unless we can make some big improvement here, we're going to be in real trouble. The only pattern we can see, if there is one at all, is absolutely downward. And catching our attention

DR. FREUDENBURG: Is there something about those projects that changes?

MR. SCOTT: Not that the we were able to detect.

DR. FREUDENBURG: Because there's a very obvious trend up to '91, and suddenly it pops up there.

MR. SCOTT: Well, we have fewer projects except for ' 88 in any given year than ' 90 and '91 and '92, but I don't have any other explanations for it.

This graph represents how well we come to closure with -- Excuse me -- our regulators before we start making commitments to our project -- cleanup projects. Clearly, impacts late in the project cycle are much more costly than impacts early on. And we actually have the -- we're on that again performing in the optimum way in this slide, but we're probably backwards, because we've got the most impacts when we're in the construction phase and the least when we're in the assessment and design phase.

And if you were going to be affected from impacts from regulation in negotiations, you'd want it in the assessment and design phase, because you can afford to make mistakes then. You get nailed costwise later on.

We need to work better with our regulators in understanding what they want and having them understanding what we're proposing and really coming to closure on what we're going to do before we make resource commitments.

The next three slides are the basic recommendations from the study. Project definition is felt to be the most controllable aspect of a project system. So it's an opportunity to do better than we've been doing, and we really want to work on this.

We don't have a consistent system across the complex for defining projects. We want to put one in place. Industry has some systems that we can look at. We don't need to reinvent the wheel. And we really need to improve in this area.

Project measurement program, I mean that's what the study is all about. We're doing that. And there have been no consequences for project management teams in the past when project costs and schedules weren't met. So we need to hold folks accountable for their work. I want to reform project management control. 
Activity Data Sheets were not intended to be project-monitoring devices, but they probably have been used for that, and we want to be direct in saying that that is not a good use for those tools and find better ones.

We need to set goals for project systems improvement. And once again we need to monitor our performance and measure it.

Finally, contracting strategy. We need to think about how many people it ought to take to do a certain kind of job, both Federal and contractor. One of the suspicions we have about our cost is that as Defense Programs activities are winding down, folks may be getting moved over to EM projects, whether they're really needed or not, to get the job done. So we want to take a hard look at that.

One of the conclusions from the EPA study was that DOE was not -- or EM was not fulfilling its ownership responsibility. We weren't in charge. When they went and looked at the -went and interviewed the project team members, they have didn't find a lot of DOE folks on the scene. And we need to react to that.

One of the things -- you're familiar with the fact that we have got OMB approval to hire new Feds with the expectation that we'll replace some contract people with those people and be in a better position to manage the rest of our contractors with those people.

And we have an aggressive program underway to get -- to recruit some really high quality folks to help us out in that area.

Excuse me. We need to set our contracting strategies based on contract objectives. We've been doing -- once again we've been doing things counter to what you would intuitively expect. We've been having fixed price contracts for not well-defined projects. We need to reverse that.

We've got to look at the situation as I mentioned earlier with respect to 'M\&Os' and 'A\&Es' on the same site. Unclear responsibilities are creating redundancy and overlap and adding to our administrative costs.

And as mentioned in the previous slide as well, we've got to make folks accountable for what the products are that result from their efforts.

Now, with that background let me talk a little bit about what's going on with regards to the "Stand Down" and these Quality Improvement Teams.

In January we basically had everybody in the DOE complex who was working on EM projects take two days to -- to stop their normal work and take a look at how they might improve the way they do their work. They were all briefed on the results of the EPA study, the performance measure study. And we had facilitators and went into groups, work groups to try and figure out a path forward given the deficiencies that the study had identified. 
We had the Secretary of Energy and Tom Grumbly and Rich Guimond on videotape making various presentations about the support they felt towards this initiative. And in addition to that we had some success stories from the private sector on folks who had used the Performance Study Review as a way of -- to figure out how to improve their business.

Basically the private sector companies that used this group to analyze their performance were trying to improve their competitiveness with the rest of their respective industries or just to figure out how to be more efficient in the cleanup projects that they were undertaking themselves.

We've developed some action plans to figure out how to move forward, what we need to do to embrace these recommendations. And each of the sites has developed an action plan.

Each of the deputy assistant secretaries in Headquarters with program responsibilities developed an action plan. And in addition to that we were putting together a cross-cutting umbrella action plan that deals with a number of cross-cutting issues, and I'll talk about that in a minute.

We're trying to reach some goals that Tom Grumbly has set forth. One of them is for 20 percent improvement in project costs over the next couple of years. We want to get our project management costs for example at least equal to what the other government agencies are experiencing within a couple of years. And we want to be as -- we're shooting to be as good as the best that was marked on those earlier slides within the next five years.

In terms of the stand down results, what we found closely paralleled with what the EPA study told us. But it was gratifying that people that weren't necessarily well versed in the EPA study came to roughly the same conclusion.

The stand down involved as I said the working people out in the field, the ones that were actually going to implement the improvements, and they ended up pretty much where the EPA study did.

The stand down included some good team building benefits I think, and it also provided an opportunity for some people to do some healthy venting of their frustrations within the structure that we work in.

And we're also implicitly looking for what the barriers were to success, that the DOE administrative personnel and other systems appeared to be preventing frustration, doing so so that we could try and overcome those barriers.

But the results, roles and responsibilities and authorities were not well defined. That's one of the big problems we have in EM. We have a meeting with field representatives next week to address that, and it really is critical that we solve the mystery of who's responsible for what. 
The reason for the confusion if you're not familiar with the Department is, first of all, the Secretary when she came in did some reorganizing and some reorienting of responsibilities. And one of those things included a desire to have decentralization, more authority in the field to make decisions and to get things done.

Unfortunately the Department has a system has not yet really come to grips with exactly what that means. And until we do that we're going to be floundering a little bit.

Current budget cycle drives -- drives premature decisions. What we're -- when we're asked to make an estimate of what something's going to cost with a high degree of uncertainty, the inclination is to guess high of course, and as we go down the pike we then make those inflated estimates come true by hook or crook.

Coordination among DOE organizations. We didn't get to talk about the reorganization in EM, but some of the things Tom's doing in that area are designed specifically to fix this problem. We find ourselves within EM and across the department sending mixed signals to the field. And we need to -- we need to fix that.

In EM we need to be spending one message of what the EM corporate policy is, what guidance is on a given subject, and not three or four versions of that.

Technical and managerial staff is not sufficient nor adequately qualified. Basically we're outgunned by the contractors. We don't have the resources to manage them the way we need to and to responsibly manage the system. We need to -- the 1600 Feds are going to help us fix that.

Orders and regulations are often outdated, duplicative, and encourage a zero risk mentality. We need to change a lot of the DOE orders, but we also need to look more carefuliy at the existing orders and make sure we're not imposing requircments on ourselves that aren't really there.

For example, all the ES\&H orders -- or most of the ES\&H orders in the Department include the graded approach concept explicitly. We aren't taking advantage of that. We're still doing gold-plated safety reviews and documentation for activities that don't merit it. And we really need to take risks if you will. Not worry about whether somebody will come in and second-guess you, but make some recent decisions about what the complexity of a project is and apply the requirements accordingly.

We talked about the -- okay. The Headquarters reviews. The field folks will tell pretty impressive horror stories about wave after wave of regulators from headquarters and OMB and GAO and the Defense Nuclear Facility Safety Board and Congress piling on, looking over their shoulder.

They really need the time to do the job without having to deal with the auditors or regulators every other day. And we need to at least be more rational in sending out these waves 
and not having redundancy and overlapping for what's being covered by the folks that are going out to look at it.

Contracting policies are not flexible and results oriented. The M\&O system and some of the other things we've done in the Department over the years probably made good sense for what the Department was all about at the time. It may not -- it may not make good sense given our new mission and our new priorities.

CHAIRMAN ALM: Randy, can you sort of wrap-up in a minute or two?

MR. SCOTT: Yes. Let me dance over this one and just say that we -- I mentioned earlier we had this cross-cutting quality improvement team. It was -- the field teams and the QIT teams for the deputy assistant secretaries were trying to figure out how they could improve in response to this study.

One of the things they recognized was that there were certainly things that were out of their control in order for them to improve, and we had them identify those. And we've got this cross-cutting team that will develop an action plan to cut across these problems to just address barriers to success.

And real quickly some of those include project management control, information systems and reporting. They're not flexible enough. They don't give us what we need to get the job done.

Project definition. We've talked about that. We're not -- we're not doing a good job at front-end loading if you will on these projects.

Training and qualification. We've talked about that. The last group, I guess we've covered that one well enough as well. The one thing that we didn't mention was the perception. Admittedly we expect a different perception from our folks than from you.

Our folks perceive that they aren't given enough opportunity to apply risk-based decision making to the projects that we undertake, so that was one of the big things that came out of the review.

There's a bunch of things going on in the Department. We're going to work real hard to be sure that we're not overlapping and redundant with those.

There's a lot of cost savings initiatives. And then we're working carefully with the folks that are involved with those to make sure that what we're doing and what they're doing mesh as well as possible.

I guess to real quickly close up on this, the Department is notorious for what I would call the initiative of -- the initiative dejour or the hot project of the month. And invariably we don't follow through on those. 
We are going to follow through on this. Tom Grumbly and Rich Guimand and myself are going to stay on this one. And the proof of that is the fact that every six months for the foreseeable future we're going to go back and look at how we're doing, what kind of progress we're making against the benchmark that the project study has laid down for us.

So I really feel like this is going to happen. It's not just go going to fall off the table like so many similar headquarters initiatives do. The one thing I'd ask from you folks is, I'd like either today or at another time your feedback on this.

I guess you've all gotten copies of the Project Performance Study previously, so maybe you've had a chance to look at that. We're particularly interested in thoughts you have on how to come to closure with our regulators. It's a real problem. It's really influencing our cost, excessive costs. And if anybody's got any ideas, we're receptive to those.

In the interest of time, I guess I'll take questions if there are any, and then I'll talk about OSHA real quickly.

MR. SMITH: I think coming to closure with the regulators has to do with what we talked about this morning on risk management. As I said, the regulators I know are always worrying about whether they've considered everything, you know, whether they've heard the public, whether they've considered environmental justice, whether they've found the right type of risk assessment to use. And, you know, they do drag their feet and delay decisions, because there's a certain amount of uncertainty in having considered everything they should have considered before they give an okay for something.

If there is a way of systematizing the gathering of that information and putting it in a form that gives more confidence to the regulators to do their job better, I think you'll find closure coming a little earlier, you know.

And as I understood from Carol's presentation this morning, they want to improve that process too. So it might have some benefits in the cost containment area as well.

MR. SCOTT: This particular -- just so you understand, this particular issue is not a complaint by DOE about how long it takes to come to closure; it's a recognition that there are cases where we have not fully come to closure but have moved forward and done things that frankly the regulators hadn't agreed to on the assumption that we could sell it to them, and then when we didn't it cost us big bucks.

So this one is not a complaint about how long it takes. It's an acknowledgement that you better dot all the I's and cross all the T's before you move forward.

MR. SMITH; That's the worst thing you can do.

MR. SCOTT: You know, we do a lot. 
CHAIRMAN ALM: Tim, I think you're next, and then Jeff. Tim?

MR. CONNOR: Oh!

CHAIRMAN ALM: I didn't mean to wake you up.

MR. CONNOR: No. I thought you said Jim --

CHAIRMAN ALM: Oh, no.

MR. CONNOR: -- which is a problem with my siblings. They call me by my brother's name often.

I guess the advice I would have on that last question is to use stakeholders and the public in that process. I think not always but one of the problems is that regulators in many circumstances will tend to be conservative for fear that they'll be publicly criticized.

So I think that's -- that's part of what we envision when we propose a site advisory board idea. The problem now of course is that not all of the site advisory boards will have all their priorities and energies to devote immediately to these kinds of problems.

But that doesn't mean that the process shouldn't begin, even if it doesn't go through the site advisory board. I mean I think that is key in getting some -- in getting other heads at the table. Theoretically the public represents both the customer in terms of cleanup action and the taxpayer in terms to make sure that the solution is cost effective and makes sense. So anyway that would be my --

MR. SCOTT: To say the advisory boards were more of a figment of our imagination at the time the study came out than they are now, and I think that's a valid possible solution for the problem. I think they can really help us in that area.

MR. CONNOR: I hope so.

CHAIRMAAN ALM: Okay. Jeff?

MR. BRECKEL: I guess I could second what Tim said, but I'd kind of also like to note that we found a number of instances where DOE interprets our regulations more stringently than we do and, you know, we've made recommendations as to, you know, when we think a Volkswagen solution will do but the DOE comes to us and the contractors come to us with the Mercedes so to speak.

We've tried to address that here over the year. And I think the key to that is getting the regulators involved earlier in the planning process so if DOE and the contractors are not well down the planning program, committed to a particular course of action and as you say, you know, 
in the belief that they will sell it to the regulators, that they develop those work plans, they develop those actions in closer consultation with the regulators and with the public so the expectations are developed as we go through so everyone knows where we're coming from. It can be pretty effective.

And I think we're also committed and have made specific commitments. How we integrate some of the regulatory programs, you know, we have to reduce redundant or duplicative regulatory processes without jeopardizing public involvement in the decisions or, you know, the substantive goal of actually cleaning up the site.

CHAIRMAN ALM: You know, you raise an interesting point, and that is that in my sense DOE does overreact to regulators and to NEPA requirements. And it may be that because DOE came rather late to regulation. You know, it was a decade ago -- roughly a decade ago DOE was complaining they were not under RCRA. And so it's been more of a recent phenomena. There might have been a certain amount of overreaction once in the system --

MR. SCOTT: We're very risk reverse when it comes to trying to figuring out how to comply with regulations, be it their own or external.

CHAIRMAN ALM: I think you came in with such a hostile and congressional stance there, I think that that probably created sort of an overreaction.

\section{Shira?}

MS. FLAX: I just want to stay with what you just said, Al. I observed this whole thing when DOE stated they did not have to comply with RCRA, and actually it wasn't until ' 89 when they signed the Hanford agreement that we had a first real commitment to a cleanup agreement in a -- whatever. I think I disagree with you a little bit.

My perception is that DOE has a long history of self-regulation, and it's very hard to give that up. But let's set that aside. What I want to do is ask a question to really head way into another issue that you're -- the broader issue of the committee business, which is, Randy, I think it would have helped me a little bit if you had begun your presentation with how you wanted this advisory board to help you. You know, what were the issues? Because I sort of got lost.

And there was a tremendous amount of information being presented. And I think it would have been a wonderful focus for me if you could have said, you know, up front just what sort of help you wanted this committee to do.

And to set down into the committee business issue that Al's beginning to discuss with us, $\mathrm{Al}$, just as you raised the issue before the committee, if we wanted -- if the advisory board wanted to get involved in the DOE budget process, let's all raise the similar question of if the advisory board wants to get involved in this initiative, you know, shall we do that? Because it -- and l'll jus leave it at that. 

make --

This was again --

CHAIRMAN ALM: Um-hmm. No, I'm talking about Randy's presentation.

MR. SJOBLOM: It was provided as a document I believe in December and intended to be covered, but because of the press of time it didn't at that time --

CHAIRMAN ALM: Um-hmm.

MR. SJOBLOM: -- so it was kind of a carryover agenda.

CHAIRMAN ALM: Well, I am going to get into -- as soon as we get two other pieces of business into the question of the spent nuclear fuels program. And that may be at least an example of how we might attack substantive programs areas. That may be the best want to talk about the EH plan, the DOE under OSHA.

I wanted to talk about the EH plan, the DOE under OSHA.

MR. SCOTT: Joe --

CHAIRMAN ALM: Very, very briefly, and I gather you don't have a long statement tc.

MR. SCOTT: Well, Joe Fitzgerald -- first of all, I don't know how he got the top billing on this subject, because he is very -- he's the Assistant Secretary for Environmental Safety and Health's area of responsibility. Joe Fitzgerald who is the Deputy Assistant Secretary, is there, and Steve Galson, who is special assistant to Tara O'Toole, who is working the OSHA issue, both told me that basically it wasn't worth the plane trip out here, because all they had to say was that there's not much to say.

OSHA is not interested in talking details until the funding mechanism is clarified, and that's work for Congress. 

come out of DOE's hide to fund OSHA, so they can staff up and informally regulate us. And our question is, why does there need to be pain inflicted in order to make OSHA whole? So we're hopeful that that won't be the final solution.

But the OSHA stands today notwithstanding the fact that Tara O'Toole and Joe Deere, who is the director of OSHA, have agreed in concept that this is going to happen, that the people immediately below them haven't made any progress because the OSHA folks don't want to talk details until the dollars are sorted out.

\section{CHAIRMAN ALM: Okay.}

MR. SCOTT: And I can give you Steve Galson's phone number if you want it, and if you want to talk to him directly. He told me to say that. But there's not a heck of a lot more to say at this time.

CHAIRMAN ALM: Does anybody want Steve Galson's phone number? Okay.

MR. SCOTT: (202) 586-6151.

CHAIRMAN ALM: Let me -- why don't I cover the next two -- well, obviously Shira is just out of the room right now.

Jay, do you want to do your slides very briefly? If you can do these in about five minutes, I'd really appreciate it.

DR. SORENSON: Yes, I'll do these as quickly as I can, but I would like for us to say that this presentation has been possible by virtue of the effort that the staff undertook last night. And I am in their debt. And they worked really from very rough material. But I'm responsible for any inaccuracies or distortions that may occur.

I'd like to start with this larger question, because I think really the issue has been in the debate, the green fields debate everything has been basically stood on its head, and it is really fundamentally the question of how clean is clean. And that really involves a social bargain. It is not a technical question, but it involves a social bargain and fundamentally is the question of who gets what.

And the anger that you -- you encounter, the lack of confidence, the resistance, is often the fact that people are not particularly happy with the bargain that they're being asked to take.

For those of you who remember when nuclear energy first came in, we were told we were getting a better Faustian bargain, an infinite supply of energy. Essentially you can argue that the question that we're faced with now is really a question of health or wealth, and the question is, 
what bargain are we going to arrive at? And will the risks be high or low, and what really will determine that they're acceptable?

But fundamentally it is a question of consent and equity. What I would like you to do -I'm going to jump around here quite a bit, but if you take a look at some of these -- at the handout that you have, then you will see essentially where I'm coming from.

Cleanup goals and remedy selection have traditionally driven protection standards. And under Superfund or ARARs, the cleanup goals are spoken of as "protection of health and the environment".

And fundamentally they're not the same, but the Department of Energy has often used the terms interchangeably. And if you really look, our next super Superfund as well.

And if you look, there's not really almost nothing on genetics, biodiversity, nutrient cycling, soil development or water budgeting. There are really no ecological standards. The health standards have been carefully thought out, but you find that the ecological standards are not.

The health factors are based on human considerations, invariably mortality and morbidity criteria. Death by disease has traditionally been considered the indicator of high levels of risk.

When you get into the natural catastrophes, hurricanes, cyclones or earthquakes, you are down really in the area of low-level risk, but death is the indicator of high-level risk.

Environment is ambiguously used, and we can use it really to mean all of the external and biological conditions, including any part of the ecological system, individuals, populations, communities, and the ecological system itself.

The point is, the referent for protection depends on ecological standards rather than on the human health considerations. If so, the values are distinctive and have different implications for cleanup.

The cleanup to a health standard based on mortality or morbidity criteria involves public risks, and under ARARS or CERCLA you're talking about ranges for safety in the area of one in a million.

Remediation where human health is the primary consideration is based on the contaminant levels in the environment. And cleanup is required to a defined usable level, but not necessarily to the original condition of the land.

Now, this is really where I think things begin to get interesting, and there's a lot more that I can offer, but I borrowed this definition from the Society for Ecological Restoration. They are really archaeologic -- architectural engineers and landscape engineers, and it really means the process of intervention to "establish a defined, indigenous, historic ecosystem." 

system."

The goal is to "emulate the structure, the function, diversity, and dynamics of the specified

And risk doesn't exist unless there's an adverse effect. In other words, you are again talking about harm, but instead of harm to human beings, you are talking about harm to ecological systems.

And it basically means that risks to humans may not be the primary consideration. Genetic diversity, biota interactions, nutrient cycling, soil development, water budgeting, flammability may be the principal considerations.

Primacy may also be assigned to the dynamics of the ecosystem so that it is self-regulating, self-sustaining, and capable of recovery from external man-made and natural forces, fires and storm events. Fires can also be human.

And these intrinsic processes may cause continual change in that biotic composition and structure or internal flux, rather than the substantive and permanent alteration of the system.

If matched -- if matched with future use cleanup targets of unrestricted land use treatment, semi-restricted, the implications for remediation and restoration are clear. You clean up a DOE facility in a residential area, you remediate it, then you may have to do it for unrestricted use. It may be severe. It may be very costly. And it may require very quick action.

In contrast, an area restored to an ecological standard, one that's going back in public ownership, Forest Service or BLM, you may really have much more latitude. And it may really also turn out to be less costly, and it may be more elastic.

The distinctions have far-reaching implications for the question of how clean is clean, and the blurring of the differences have contributed to significant disputes.

My contention is that it may very well be that we have stood the entire argument of how clean is clean on its head. The green field argument has been misunderstood and to the detriment of all of us, and essentially restoration may prove to be a much more viable proposition.

The problem in many respects is the Department of Energy has had remediation projects, some of which are very good, but they have stopped remediation and have not readily considered some of the ecological restoration issues that were at stake.

What I'm trying to do next time is to have more for you. That's about as quick as I think I can do it. The Society for Ecological Restoration gives you something to chew on.

CHAIRMAN ALM: Well, it certainly is a lot of food for thought, and I think this is something that we can, you know, focus on in more depth at the next meeting. 
Let me move to -- Tim?

MR. CONNOR: I don't want to get into another discussion, but just to clarify my question, I don't understand how restoration is far more elastic than remediation. It seems to me that you define restoration as a given outcome. It can mean only one thing.

So I don't see the elasticity in that. To me that seems very, very defined as to what it is.

DR. SORENSON: Very, very quickly, let me use a concrete illustration. If you were going -- were you going to clean up for ground water and other contaminants, you would have to clean up because of population considerations. You would have to remediate to the stringent standard of cleanup for unlimited use.

Whereas in the eastern part of the base, you have an area that really fundamentally has been withdrawn from the Forest Service and may very well go back.

The ability really to remediate there is the -- or to restore is going to be a lot easier and cheaper. You may not have to do as much. You may not have to go in and do all of the severe and intensive work that you would have to do in an area like the south part of the base where you have a population center.

To that extent you have greater elasticity and you can buy time. You can preserve it for -as a wildlife sanctuary and you can have some trails in it, but you can buy historic time, and you can allow nature in part to help you go in and do some of the cleanup work, and you can work with whatever remediation techniques you want in a very elastic way, very targeted, spread out over time.

There's a lot of flexibility in what you do. And you end up really with a restored ecosystem rather than just a remediated one.

I don't know if that helps.

MR. CONNOR: It helps.

CHAIRMAN ALM: Okay.

MS. FLAX: Jay, when we return to this subject at our next meeting I really think we ought to look at the Rocky Mountain Arsenal decision, which used your logic to justify lower cleanup, and there are a lot of problems with that.

But let's -- let me just mention that, and then let's get back to that at our next meeting.

DR. SORENSON: Right. Okay. I would agree we should look at it, and I would suggest that that's not the same logic, but next time. 
CHAIRMAN ALM: Okay. Okay. Let's focus a little bit on our upcoming meetings, which is a question of where and when.

I gather, Jim, we -. the windows we have where everybody is free is -- for the meeting in May is $5 / 16$ through $5 / 20$ ?

And what were we going to do now? Just choose a day or just -- what is the next step? You've given me the windows. Whai do we do about them?

\section{Glen?}

MR. SJOBLOM: Associated with this agenda, I had indicated I would get back to you on what would be available to be sent to you by the end of April, and that's coming around. Based on what I see here, it's my judgment that a two-day period is appropriate where you'd come in late one evening and then spend the full next day and then three quarters of the following day.

Now, I'm assuming that Tom Grumbly doesn't want to interject agenda items, programmatic agenda items, into the thing when I say that. And I'll have to work a little bit and then get back with Tom and Al to try to sort out whether that's the case. Right now it doesn't seem so.

But roughly a two-day - I think about all at this point -- there's usual- -- we usually try to have our meetings in the beginning, fairly early in the beginning of the week. And my thinking is that this meeting shouldn't be connected with the site visit or a trip to any of the sites.

So our thought would be to have it someplace where it's easy for all of you to get to and get back from, such as a hotel right at the Chicago airport or right at the Dallas airport that is more or less central in the country.

We do have -- we do have experience with a hotel right at the Chicago airport where you literally walk off the plane and walk underground and check in at the hotel.

CHAIRMAN ALM: Yes.

MR. SJOBLOM: And it's a good place to stay and good meeting rooms. And so that's sort of where I'm thinking at this point on that one, on that May meeting.

MR. CONNOR: This virtually assures that we can do a meeting without ever being exposed to fresh air. What a concept!

MR. SJOBLOM: There's another option. There's the Airlie House outside of Washington if you want to get to a country model.

CHAIRMAN ALN: Okay. And you're -- go ahead. 
DR. PAULSON: I vote for Chicago. And to just abuse Tim of his idea, if it's held in Chicago on behalf of my wife and I, we will invite the whole committee and staff over to our house for cocktails and a buffet dinner one of the evenings that we're meeting. And we are right by Lake Shore Drive and right by the lake, so you can take a stroll and look at the sailboats.

CHAIRMAN ALM: Okay. Chicago?

MR. CHRISTEAN: And Glenn's fallback position is Wyoming. in the week.

CHAIRMAN ALM: Well, how do you people feel? Anybody feel differently than

DR. PAULSON: I hat has to be early in the week though, because I have a conflict later

CHAIRMAN ALM: Okay. Are we talking about the first of the week thing, maybe Monday and Tuesday, like this time?

DR. PAULSON: Tuesday and Wednesday. Come in late Monday.

CHAIRMAN ALM: Okay. Tuesday what, the 17th? Is that right?

DR. ANSPAUGH: And on the 16th.

CHAIRMAN ALM: Yes, the night of the 16th, which would be Monday, and the 17th and 18th, which would be Tuesday and Wednesday. I guess we'd get done about 3:00 or 4:00 so everybody can get back to where they're going?

DR. ANSPAUGH: Right.

CHAIRMAN ALM: Maybe three o'clock?

CHAIRMAN ALM: Yes, I think you're right. You are at the airport though I guess?

MR. ROSS: Well, I was just going to suggest someplace near the airport -- you know, taking that road down to Glenn's place, to the Hilton or something there right across from the fountain might give a break for some people too. And it's not that far if we look at the --

MR. SJOBLOM: We can look at options and optimize this whole thing --
DR. FREUDENBURG: There's no place to eat or drink -- I just encourage a hotel with a bar in walking distance.

DR. PAULSON: Chicago we're talking about? The bars are open till 4:00 a.m. You can -- 
CHAIRMAN ALM: Okay. Now, the idea for the second meeting was the July -- let's see, June 24th through July 1st? Do we need to pin that one down now?

MR. SMITH: On that one, that's -. In our subcommittee meeting the other night we identified that there would be key pieces that wouldn't be ready by then, so that seems way too early.

MR. SJOBLOM: We were thinking of August.

MR. SMITH: There's a July window there that's --

CHAIRMAN ALM: Is that the one that's July, the 14th through the 15th?

MR. SMITH: Yes, right.

UNIDENTIFIED SPEAKER: Would everybody be ready then?

MR. SJOBLOM: That's our current best shot.

UNIDENTIFIED SPEAKER: July?

MR. SJOBLOM: If we're planning for success, that's the best I can do right now.

CHAIRMAN ALM: So that would be again for the PEIS?

MR. SJOBLOM: Yes. Now, remember this is the one where we're sort of having an idea at the Piney Point in Maryland where we talked about that.

MR. SMITH: Could we add a qualifier that that date should be scrubbed if we don't have absolutely everything to look at? I mean there's no use in pulling us together without seeing some of those important conclusions and comnarisons among sites that will need to be reviewed by everyone.

MR. SJOBLOM: Right.

CHAIRMAN ALM: I would agree.

MR. SJOBLOM: That's a given.

MR. SMITH: So what date is that?

41

42

43

44 Friday?

CHAIRMAN ALM: The 14th and 15th. What days of the week are those? Thursday and 
MR. SJONLOM: Now, recognize if we do that, there will be about a 15-day concentrated period for DOE that this will be a part of, so --

CHAIRMAN ALM: Can you tell me where Piney Point is?

MR. SJOBLOM: It's down near the mouth of the Potomac and Patuxent, in that vicinity.

MR. SMITH: Near the Solomons area?

MR. SJOBLOM: Near Solomon. It's right across the point essentially from Solomons.

CHAIRMAN ALM: How long does it take you to get there?

MR. SJOBLOM: It's about an hour drive from the airport, from National. I would recommend you try to come into National for that one.

DR. SORENSON: I'm sorry. I missed the July dates.

UNIDENTIFIED SPEAKER: The 14th and 15th. Did you hear? The 14th and 15th.

MR. SMITH: We should have everything mailed to us July 1 ?

MR. SJOBLOM: Yes. That's what we've got. We've got to shoot for something, so I can --

MR. SMITH: Wouldn't you rather -- be more comfortable with an August 14, 15 day?

MR. SJOBLOM: No, because then I can't get the document out in August.

MR. SMITH: What's the driver for getting it out in August?

MR. SJOBLOM: We need to submit Site Treatment Plans supported by this to the States by February of ' 95 .

MR. SMITH: Well, now those draft Site Treatment Plans --

MR. SJOBLOM: Come out in August.

MR. SMITH: They come out in August. And those are supposed to be reflective of negotiations and consultations with the States. It would seem that if we slowed this process down a little bit and had those negotiations and consultations having a chance to be reflected in this draft PEIS that you'd be better off having that come after the -.. 
MR. SJOBLOM: Recognize again we're not going to have a preferred alternative for mixed waste treatment in the PEIS. It is simply an array of the full range of options and the relative impacts associated with all of those.

MR. SMITH: I understand. But I feel like you may have some analyses in there that sort of would tend to color the negotiations and consultations with the States. And if those come out earlier, then the site treatment plans, that could sort of -- as though --

MR. SJOBLOM: If they come out earlier it would come out together.

MR. SMITH: Together.

MR. SJOBLOM: In August? That they're currently in the same time frame.

MR. SMITH: Okay.

MR. SJOBLOM: The analyses are working together. The documents are working together.

MR. SMITH: If they work absolutely together, I think that might work.

CHAIRMAN ALM: You know, one of the things that's going to be very, very difficult to explain, no less understand, is how all these things are fitting together. You've got the spent nuclear fuel and the INEL, EIS coming out in June. This will come out in August, the programmatic. There's something else I can't remember that's coming out soon.

'95?

And then the site specific advisory boards will begin to crank up, what, some of them in

MR. SJOBLOM: Oh, they're -- for the site risk assessments?

CHAIRMAN ALM: Yes.

MR. SJOBLOM: Yes, I would assume before then they'll be getting going.

CHAIRMAN ALM: So the program will be in a very fluid state, right?

MR. SJOBLOM: Very.

CHAIRMAN ALM: Throughout this whole period of time you'll have analyses so that the

MR. SJOBLOM: Is the broadest of all of them. 

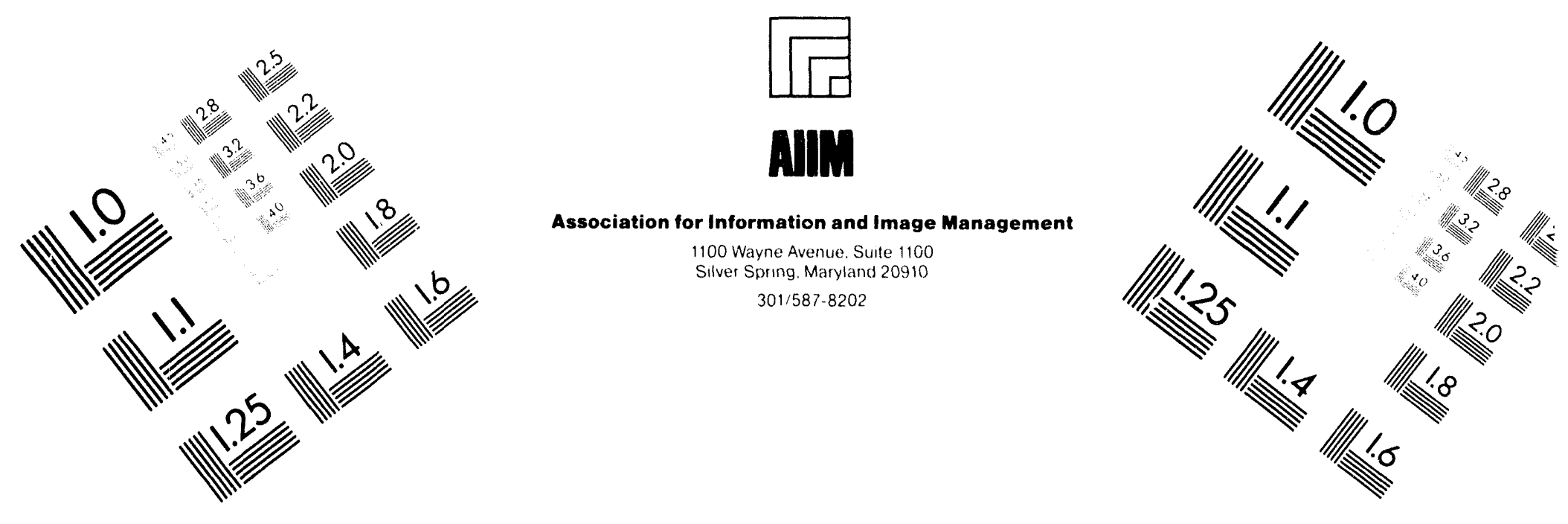

\section{Centimeter}

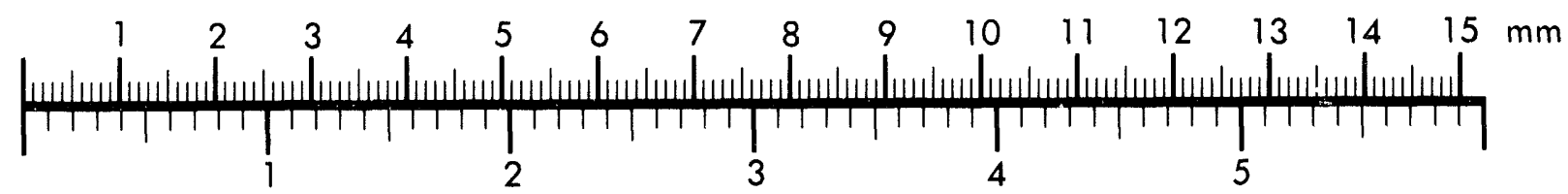
Inches
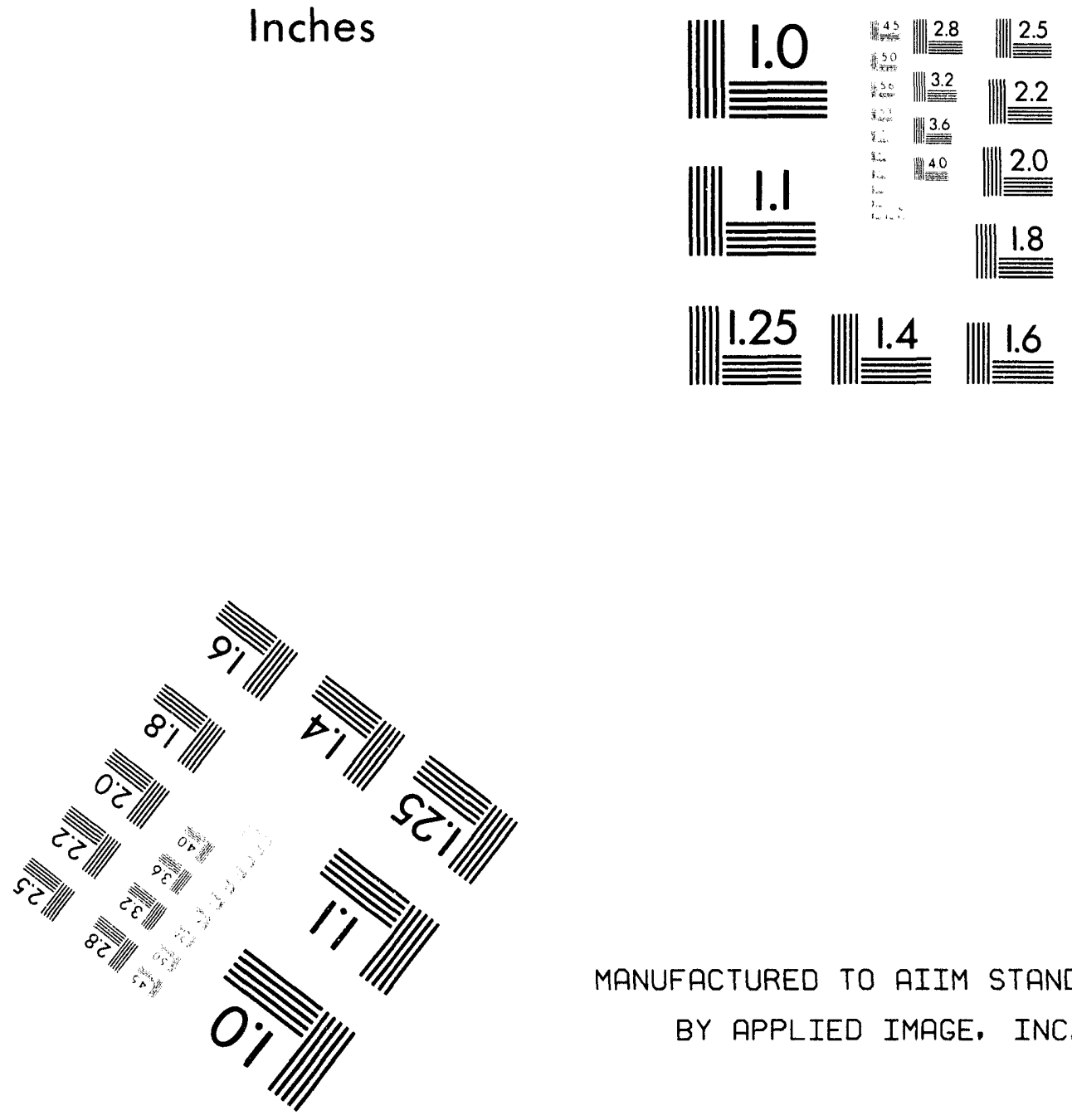

MANUFACTURED TO AIIM STANDARDS

BY APPLIED IMAGE, INC.

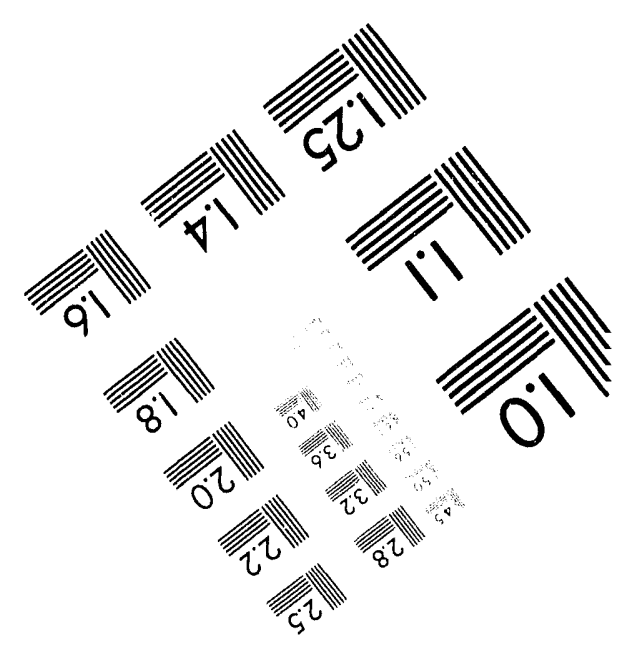



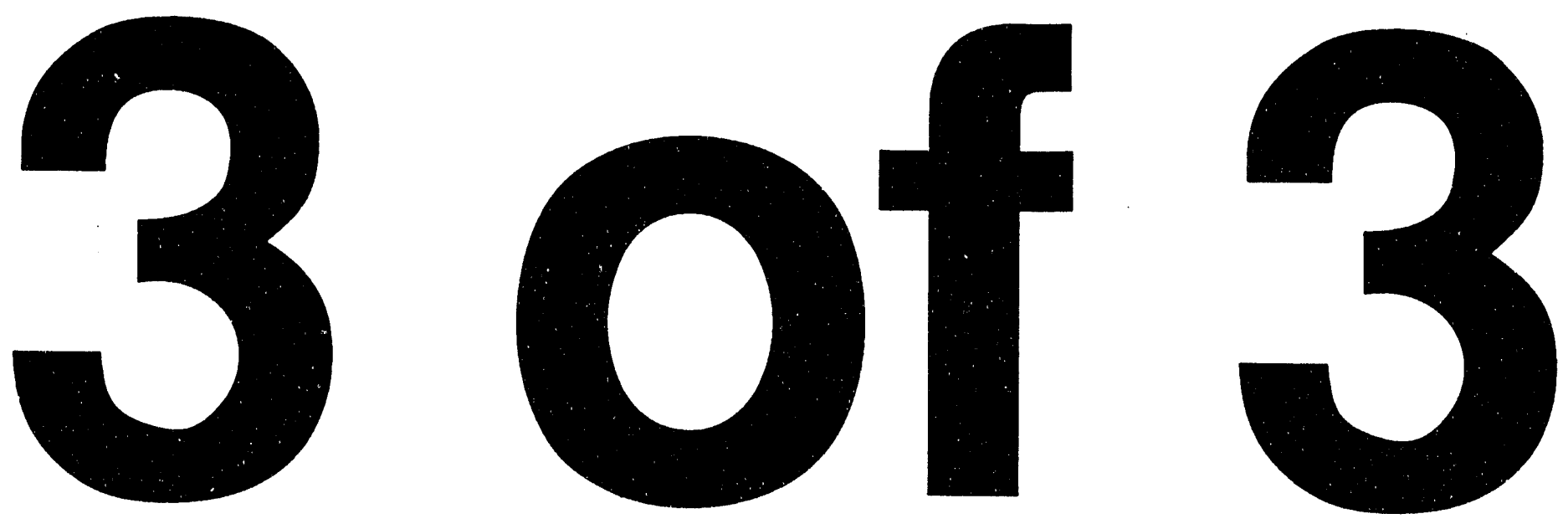
MR. SJOBLOM: And, you know, recognize that we're -- we've been running in the spent fue! impacts into the cumulative impact section of the EIS just so that it's sort of all there.

CHAIRMAN ALM: Well, how does the committee know that we've figured all this out? How does the committee feel about the dates $7 / 14,7 / 15$ ?

DR. FREUDENBURG: Let's do it.

CHAIRMAN ALM: How do you feel about Piney Point?

DR. FREUDENBURG: Let's do it. suggestion?

DR. FREUDENBURG: No, it's a futile hope that in July we could avoid the Washington, D.C. area, which I understand the restraints here. It was only intended as a futile --

MR. CHRISTEAN: By the seashore would be wonderful.

DR. FREUDENBURG: Right.

MR. SJOBLOM: And it is air conditioned at Piney Point.

UNIDENTIFIED SPEAKER: We'll get you a fan.

CHAIRMAN ALM: I think we beat this one into the ground now. I guess the next question I had is in July, obviously asking us for some help. What Jill presented was of massive proportions. I mean it's hard for us to absorb that, much less in a few minutes come up with a coherent set of recommendations.

The question I have is, assuming she's interested, and I think she is, on getting some more help, should we consider a subcommittee on the issue of spent nuclear fuel?

CHAIRMAN ALM: People are nodding, but not with great vigor.

MR. AYERS: I have a question on that.

CHAIRMAN ALM: Yes? 

that?

MR. AYERS: I guess for the initial short-term EA, she's really not asking for help on

CHAIRMAN ALM: Well, she got whatever help she got today.

MR. KORKIA: What's the time frame then on the EIS, for the rest of it?

CHAIRMAN ALM: Well, the EIS will be out in June or so, and I mean there will be a lot of time after that. There will be a draft. So the extent to which we wanted to have an input into the program, there would be a lot of time.

Not to get into the EIS but rather, you know, the final direction. And there's a whole bunch of options being considered from centralization to decentralization.

Jim, what are you nodding on?

MR. WERNER: Sounds familiar, doesn't it, Al?

CHAIRMAN ALM: Right.

MR. WERNER: Again the committee has to decide for itself what it chooses to get involved with, but could I suggest that at least the committee consider then that there's a larger spent fuel problem afoot, that, you know, folks like Ben know all too well and there's OCRWM committees, there's technical boards looking at that, and this committee might want to consider how -- you know, what is unique about this?

There are an abundance of committees already looking at different spent fuel and the waste problem. Of course Glenn's doing it. We've got to be very careful about how we get into it.

But the committee has to consider, you know, fundamental questions such as to what extent should the EM be building a separate institutional infrastructure to address these problems that are, you know, held in common by other parts of the federal government, particularly the OCRWM radioactive waste problem, should they be consolidated? How should we define what we do technically, institutionally?

Those are the questions that could be asked as the committee deliberates. But I don't presume to tell them what to do.

\section{CHAIRMAN ALM: Okay.}

DR. SORENSON: With regard to what could be done on the EA, I would beg to differ, that in fact there other things that committee members could do individually too to educate people out there. There is a lot of -- there's a lot of confusion out there on this program. It's moving quickly. It's complicated. And I think we spent more time today looking at it. 
us who the other players are and what their basic charters are to see whether there's a useful role for us, whether there's a gap between the cleanup needs, the waste side, and the special nuclear materials that we can use to refill.

And conceivably we can get that kind of investigation presented in a white paper to us relatively soon so we then could decide what to do.

CHAIRMAN ALM: Um-hmm.

DR. PAULSON: And it's an area of intense interest to many of us as individuals. It's just I'm not sure that it's a good assignment for this board right now. And I don't think we know enough to make that decision right now.

\section{CHAIRMAN ALM: Glen?}

MR. SJOBLOM: I just wanted to make a suggestion that the programmatic- -- a programmatic issue is really this issue that really parallels for spent fuel the issues related to waste types, and it's this issue of inter- -- interregional equity associated with, Where is this stuff going to go on an interim basis until it is dealt with as a disposal?

When the PEIS had spent fuel in it, you were directly involved in those issues through that mechanism. The Idaho EIS is now the carrier of the programmatic spent fuel coverage as well as all of the site specific kinds of things that a site-wide EIS would cover.

There is a single volume in the Idaho EIS that deals with the spent fuel alternatives. And while I'm speaking without a specific charter to do so here, it may well be that that's the most programmatic aspect of spent fuel in addition to the foreign one that you've dealt with here a little bit today, that the Defense Nuclear Facility Safety Board is in conjunction with us and in conjunction with the office of Tara O'Toole's office looking at the safety, the on-site safety issues of inproving the site specific storage conditions in Idaho that you saw the Buildings 603 at Hanford, the K-East and K-West basins and at Savannah Kiver.

Those are I think things that this committee really can't delve into in a great deal of detail, but the programmatic issues there, I think it would be useful to the Department to have some counsel on that. Because as several of you pointed out, that those things have to be part of the bigger -- the bigger systematic equation of how this all fits together.

So in some way I would recommend that you try to tie into that particular programmatic issue.

CHAIRMAN ALM: Glen?

MR. SJOBLOM: And I think Tom agreed when that comment was made earlier that those things need to be looked at together. 
And I think that time with Jill Lylte was golden to get educated about it so people can go back and spread the word that this ain't a United States subsidy problem to bail out other countries solely, that this is our stuff. We sent it over. There is something different going on here. This is highly enriched uranium material.

CHAIRMAN ALM: Jay?

DR. SORENSON: Oh, I guess I do favor the creation of a task force or a subcommittee to help. I guess the question that I was asking was whether really it's on the non-proliferation part of the question, and the importing of the fuel. It becomes the domestic part in the long-run future and the building really of the dry cells or both.

MR. WERNER: Thanks to the --

CHAIRMAN ALM: There are really three kinds of options that are out. I mean a narrow one is the non-proliferation issue. The second one is the spent nuclear fuel, the issue as raised by Jill and as would be covered in the EIS.

And then Jim Werner threw out a third option, which is to look at the waste disposal problem in its broadest sense, high-level waste, 'transuranic', et cetera. So those were the options. Anyone want to comment on them? Glen?

DR. PAULSON: I don't think -- Well, let me preface it by saying that big hunks of these did not come up in the group's prior discussion of priorities that it wanted to look into. That's just a reminder.

\section{CHAIRMAN ALM: Um-hmm.}

DR. PAULSON: My observation is that I don't think that collectively we have spent enough time thinking through this complex set of topics, either in principal and in general, and then in particular what role we could play that would be useful that's not duplicative of what other groups are saying.

I very much agree with what Jim said a minute ago about the number of ad hoc and continuing organizations within and without the government that we're looking at various pieces of this, and without some investigation as to what their charters are, what they're doing, what they've done, I don't know that we would be helpful. There's a risk that we might be harmful.

With all due regard, with Jill coming to us and in the spirit of Tom's asserting that we're the board of directors and so forth, I just don't think we know enough.

And my suggestion for my last point is that perhaps we need to ask the staff, and it's -- I don't think it's just the traditional staff that we regularly see here but the staff broadly defined, including those whose prime job is to interact with the Defense Board, for example -- to array for 
MR. SMITH: Just to build on what Glen just said and to sort of round out that broader programmatic picture that we need to look at, I'd like to include Greater Than Class C waste and to see whether the definitions, the definitional boundaries between these waste types, really makes sense and our -- and our past efforts to sort of separate the management of that waste from high-level waste and spent fuel, whether that's a really good way of dividing the management or whether, you know, we should have a more integrated management of those waste streams.

We asked for that to be addressed in the programmatic EIS, but it's awfully difficult to deal with there. I don't know how far you're going to get with it, Glen. We thing -- I think the store-- I think the policy on Greater Than Class $C$ waste should go beyond just laying out a storage kind of scenario without knowing what the ultimate disposal will be.

And maybe if we dealt with these issues in an integrated fashion, we could work out a coherent policy.

CHAIRMAN ALM: Any other comments? Well, my sense of it is that we ought to follow Glenn's suggestion in the sense of getting back to DOE and see what kinds of things that they felt would be helpful in a tangible way. You know, the most interesting set of studies would be to take a look at the comprehensive waste program, but that could be quite an undertaking.

And, you know, if we're not committed to do it and to make that happen in the interim, really make a very large effort, the thing could easily fall flat. I don't think that's what we want to happen to our early efforts.

So I think that we need to scope this out a little bit more, get an idea of what could be helpful, put it on the agenda for the next meeting about what precisely we could do if we wanted to do it, and make sure we can generate enough enthusiasm to make a success of it. We have really needed a champion to make something like that succeed.

All right. Any other business? Jerry?

MR. CHRISTEAN: I've been thinking about something. It's obvious that we're doing more and more subcommittee meetings in the interim between our regular meetings. And as just a matter of I guess efficiency, I would like to suggest that about a week before a scheduled subcommittee meeting that the staff be asked to poll the members of the committee, the subcommittee, to see who would -- who is going to attend and who is not.

And the reason I make that suggestion is because if the meeting is going to come up short with attendees, it looks to me like that's kind of a waste of money to have people come from out of town and meet and then have more than a majority of the committee not present. So that's just a suggestion I'd like to make to staff. That doesn't take a motion or anything I wouldn't assume.

CHAIRMAN ALM: Okay. Dick? 
MR. BANGART: I'd like to return to the next meeting. I hope it's understood, and if not

CHAIRMAN ALM: Yes. That's a good point. Who do we have in mind to be the facilitator? I'd like to suggest it, that a draft chapter of the PEIS be facilitated.

MR. SJOBLOM: We have a capability to bring a facilitator. And given the particular type of facilitation, I don't want to choose at this point exactly who that would be. I want to -- I want to find out which of the possibilities are the most capable of facilitating this particular type of thing.

Now, you've had two sessions with Harold Kurstead, and for what you were trying to do at those sessions he was excellent in my opinion. I have to talk with him and others to see whether that's the right choice for this -- for this particular type of interaction that we're planning here, but I will -- we will try to get a facilitator to help, or even more than one, to try to help get the job done here.

\section{CHAIRMAN ALM: Jay?}

DR. SORENSON: Oh, I would just hope the committee would join with me in thanking the staff for the marvelous help that they're providing.

CHAIRMAN ALM: I was going to do that. I've written myself a note to do that too, but since you beat me to it, I think we'll all give them a hand of applause.

\section{(Applause.)}

Tom?

MR. WINSTON: I wanted to make the board aware that there is a program that Tom Grumbly started, and all new employees will receive a number of training modules, one of which is stakeholder training. And for some reason, and I don't know if they went down through the alphabet and got down to W, because all of the rest of you said no, but l've been asked to go and present EMAC's agenda at a training session for new employees on April 20th.

So if someone else would like to do that instead of me, you're certainly welcome. I've been working with staff to identify -- they also want to have sort of a break-out session where we would either do some role playing and -- or else a case study.

And I think right now I'm targeting some of our efforts on the PEIS and some of the comments that came in in December as sort of a very good opportunity. So I've been working with Jim a little on that, but I just wanted to make people aware of that.

CHAIRMAN ALM: I think you'd be super. 
Tad?

MR. MCCALL: I would like to commend the citizens of St. Louis for their participation. This is really one of the most helpful, meaningful public interactions I've ever had. I think it was for all of us.

I'd like to note that the staff member who's been helping us on the Technology Barrier Subcommittee, Peter O'Rourke, is going to Africa, and he's going to take a leave of absence to do something really significant to help this world, and wish him well.

I would like to also say to my subcommittee, Technological Development, if you can hold the time open, then we're going to have the full committee meeting. We're going to try and do our subcommittee meeting at that time.

And if I'm unable to make the meeting, I'd like I like to stress, it's not because of the PEIS issue. I'm hoping to be in the Philippines on a fact-finding issue to help the Philippines out on a hazardous waste issue that's been left by United States forces there.

MR. SMITH: We'll still appreciate your written comments on that.

MR. McCALL: I may be back.

MR. COSTLE: And you'll owe us a cake in July.

MR. MCCALL: Yes.

\section{CHAIRMAN ALM: Ron?}

MR. KUCERA: I just want to thank everybody for finally getting to St. Louis to see a facility and a site that's a little bit different than the standard, and I also wanted to say that with respect to our presentation that Health and Safety had asked for -- on the critical path to OSHA oversight, since the next two meetings are going to focus so heavily just on the PEIS, I would hope that this DOE and staff would not lose site of our continued interest in seeing if DOE is really going to be able to pull off this transfer to OSHA oversight similar to that which the private industry is now under, which is the secretary's intent I believe.

We're still interested, and when we get through these PEIS-intensive meetings, I would hope that we might be able to have a presentation that is somewhat illuminating on how we're going to get from the Point A to Point B.

Just a reminder so we don't forget this.

CHAIRMAN ALM: Okay. Tad? 
MR. McCALL: I'll be real brief. I just wanted to commend to the committee Barry Breen and Tim Fields for possible new membership. I work with them at EPA. They are tops. And we're really going to be lucky to have them join us. I'm heartily hoping that they'll be with us as soon as possible.

CHAIRMAN ALM: Shira, and then Glenn?

MS. FLAX: I want to raise a major issue at an unfortunate time, because we're just two minutes away from adjourning the meeting. I am very concerned that we have gone back to meetings of being briefed by DOE, agendas full of being briefed by DOE, which is something that the committee in 1992 asked that it be stopped. For that reason we convened an Agenda Committee.

And I don't know whether that Agenda Committee has continued to meet. But I would like to suggest reconvening an Agenda Committee. And if you do that, I have certain -- instead of going on and on and on now because the time is short, I have certain -- certain questions I would like the chair of that committee to ask DOE when an agenda -- when items are placed on our agenda.

\section{CHAIRMAN ALM: Was there not discussion with the Agenda Committee?}

MR. SJOBLOM: Yes. The two chairs sent the proposed agenda for this meeting out and asked that any additional ideas be provided back through the agenda committee chair.

And I believe, Dick, you did also send out a note to the Agenda Committee of some sort. I am -- I am not wanting to suggest that a lot was added as a result of that, and I can't think of specifics there, but there was some interaction through that committee though, because DOE did take some items left over from last -- the last meeting, and some that frankly Tom Grumbly wanted to put on the agenda and did more -- more take the lead this time. You're observation I think is correct.

We also want to keep at least part of the agenda development process within the committee itself, and Tom does not want to make it just a one-directional thing. And I think that it would be healthy for the committee to try to look for issues that we're not bringing and ask them to be brought to the committee.

CHAIRMAN ALM: I think there are two issues that are implicit in what Shira is saying. One is how the agenda is set, who sets it. And two, what the meeting is -- how you structure the meetings.

Many of these briefings basically cover almost the whole time allotted. And I think, frankly, a lot of them if we merely said we want 10 minutes or 5 minutes, and then we could leave most of the time open for discussion. 
You know, I think briefings tend to expand with the amount of time available. And if you basically ask for a ten-minute briefing, you'll probably get 80 percent of the substance and you'll have a lot more time to interact among ourselves.

Now, does that make sense to you all?

UNIDENTIFIED SPEAKER: Yes, it does.

MR. SJOBLOM: Part of what we tried to do this time in scheduling a session this morning was to create a block of time where we could actually get into something and get some real interaction. And I think to some extent it worked.

Tom preempted a little of that because he felt, I think appropriately, that given the kind of session we had last night that we really owed some time this morning to reacting to that. $\mathrm{He}$ wanted to know how people felt about it. $\mathrm{Al}$ and I sort of briefed him on it. But he wanted a chance to respond and to react, and I think that worked out fine.

Well, I guess I have a question, and that is whether -- I mean one thing -- one complaint that was fairly evident in our December meeting was that we were trying to cover too much in each meeting.

And part of that was because it was kind of an appropriate show-and-tell time for Tom. He had gotten his new team on board. He was trying to take the Department in a different direction. We needed to kind of get a snapshot up to date on that. But it was not his intention that he would pre-empt us in any fashion in terms of how we structured future agendas.

So I guess two questions: One is, how do you feel about trying to take at least a recognizable block of time at each of these meetings where we can among ourselves decide what the issue is or ought to be and just really focus on that and maybe try to cover fewer things better?

And then, secondly, you know, how do you want to proceed in terms of identifying some future agenda items?

It seems to me that the next meeting, maybe two meetings, are kind of locked up in the PEIS to a large degree, and that is -- was originally the charter responsibility of putting this group together. So it seemed to me -- seems to me that's in one sense deliverable on our part that we have to focus on and make sure we get done and help as best we can.

But we're really -- I certainly feel quite open on the issue of what the agendas ought to be, but I think from time to time -- I mean this is Tom's committee, and from time to time he is going to have things. 
We tried to cram a lot in this time, and it resulted in a very long day yesterday for which I wanted to thank everybody in terms of their patience and stamina. But, you know, this is quite flexible, you know.

MS. FLAX: I really appreciate what you had to say, and I just want to remind the committee that Dick wrote a memo right after Assistant Secretary Grumbly took over as assistant secretary where he had outlined issues that the committee had previously topics that the committee had previously identified that it wanted to pursue with goals and objectives that Tom Grumbly had just articulated to the advisory board.

And maybe we can --

MR. SJOBLOM: Go back and take a look. That's a good idea.

MS. FLAX: -- go back and look at this memo.

CHAIRMAN ALM: Why don't we do that? Why don't we take a look at those? And we'll get a meeting with Tom and just go over the agenda.

MR. COSTLE: I mean that's a good way to organize our work, because it gives us a sort of consistency over a period of time.

CHAIRMAN ALM: Tad? Did you have a comment? Ben?

MR. McCALL: I think we're starting to --: Excuse me, Bill and Ben.

MR. MCCALL: I think we're starting to get really what Shira wants. We had the subcommittee meetings first this time. I think that was very know constructive. I would like to have had a little more time with that.

CHAIRMAN ALM: Um-hmm.

Mr. McCALL: And then I think that subcommittee work is going to lead to the bulk of the discussion with the full committee as we're going with the PEIS. By the time we're done with those two PEIS subcommittee reports, I'm going to have something queued up. I think I'm going to want the committee to (inaudible).

So I think we're starting to evolve, but we still need to have Tom have some time to feed us so we know what's going on in DOE and to put his agenda on the idea -- on the schedules.

I would say that this agenda we had was a model that's getting towards where we want to go. I think we're getting pretty close. 
CHAIRMAN ALM: I think we're talking about three things. I think you're absolutely right. Long-term the subcommittee work will take a fair amount of time of the committee.

And second of all, Doug, I think you're right that as the agenda committee works we ought to find topics that we can get into and identify, and third, topics we want to get caught up on.

I think if we just change the focus so we get very short briefings and have some time for discussions, if we do all of those things, we'll be coming a hell of a lot more efficient.

MR. COSTLE: Yes.

MR. SMITH: You know, this committee went through a pretty long exercise of doing some priority setting of the agenda items we felt were important. In a large way, a lot of those priorities have been addressed except for one, and that is the Atomic Energy Act priority that we set before.

We had a paper that came around, which after looking at it I find to be a pretty satisfying approach for the -- from the Department of Energy to address this issue. It does beg for interaction with groups that are interested to come up with a strategy for possibly changing the Atomic Energy Act over the next year.

I'm hoping that in the meeting right after the July meeting we can find that way of examining how this committee can relate to that initiative and picking back up that priority that we set earlier of spending some time on the Atomic Energy Act and how it affects our ability to manage the cleanup program.

So I would make a specific request that at the meeting following the July meeting that we have some time to examine that particular issue and see how this committee can interact with initiatives that were ongoing in Congress, or by that time it may be this Administration Task Force that's operating and how we can sort of link up with that and have some continuity for that issue.

MR. COSTLE: Go ahead. Did you want to respond?

MR. SJOBLOM: Yes. Let me -- there is a little piece of information that is the second in line behind Tab 13 of your briefing books this time, which put several little pieces in there that are related to the two concerns on the Atomic Energy Act that the committee had.

And one was the information availability the declassification program is attempting to address. And then the Miller bill, draft Miller bill package, and a little -- a copy of the -- let's see. That was in a subsequent handout. I'm sorry. We added it actually.

CHAIRMAN ALM: It's been a handout already. 
MR. SJOBLOM: We handed out the testimony by Charles Curtis, which I think addresses all of those issues in one very concise testimony that was just given. And I would recommend you look at that.

MR. SMITH: The pieces are there, Glenn. We just haven't had the processing time --

MR. SJOBLOM: Right.

MR. SMITH: -- to talk about it. Maybe there's one piece missing, and that's sort of the white paper that we discussed out in Denver of having someone on the general counsel staff go through and show each part -- each section of the Atomic Energy Act that impacts upon the cleanup program. We don't have that piece in front of us yet.

MR. SJOBLOM: Right. And you won't believe how many times I've been clamoring on general counsel to be more responsive on that one.

CHAIRMAN ALM: Why don't we just set something up for the agenda for the July meeting? Anything wrong with that as suggested?

MR. SJOBLOM: Let me see if I can get the paper out, and then you can proceed.

CHAIRMAN ALM: Wait a minute. Just for -- we'll do a progress report in July; okay?

MR. SMITH: Let's leave the progress some time and discussion of how this committee may interact with that issue.

CHAIRMAN ALM: Okay. I'd like to close off in just a few more minutes if we could. I guess we could --

DR. FREUDENBURG: Not quite yet.

CHAIRMAN ALM: Okay. Go ahead.

DR. FREUDENBURG: Two comments. One is, it would be nice if we would have at least had the appearance of responsiveness to our previous comments. An example of that might be if, Glen, you could try to see that, you know, since we get a side foot of paper every time we come to one of these meetings, maybe you could ask your staff to see if they could sift out to five or ten pages of paper that somebody is going to be briefing us ought to have to read.

An 'example of that actually is Randy Scott's presentation, which is terrific, excellent stuff. But, you know, somewhere in there is buried what were the barriers to technology implementation, et cetera. 
Tad McCall has been working real hard on that. I don't know if you're even aware of that. He happened to be out of the room during that part of your discussion so he missed it, although now I've mentioned it to him he'll be talking here. But it would be nice if the folks that came to talk to us would do a little homework.

I mean we -- you know, nothing is more frustrating than supposedly giving advice and then having somebody come in and do something which, even if it is basically consistent with the advice, shows no evidence whatever that people are even cognizant that that advice has ever been offered in the past.

The second thing is that we did pass a sort of -- or we sort of had an agreement in principle earlier in this meeting, which is probably hard to remember given all the things we were doing. We were going to try to do something on risk.

And I think Shira even forgot it herself, even though it was her idea, because she's gone now, which is why I wish I could have gotten your attention earlier. But I'm trying to be polite today because it's the Ides of March I guess. But perhaps it is something that we ought to be having somebody work on between now and our next meeting to decide what we want to do.

CHAIRMAN ALM: I agree with that. And that is a high priority. I mean it's the one particular issue that came out of this meeting. We would set up a committee. Let us take that as a responsibility. We'll get something out to the members. That's a good point.

\section{Dick?}

MR. BANGART: I support the need to have more time during our meetings to discuss areas that we think are important for the committee to address or for the board to address as well as those that are brought to us by the DOE.

There is another one also, Ben, that we should establish as a priority that we haven't addressed, and that's DOE management effectiveness as a general topic. And that's been lying for a couple of meetings now as well.

If we do resurrect the previous list of priorities as well as the new things that we've either agreed to adopt or on our own initiative have decided it would be appropriate for us to evaluate, maybe we need to put together a consolidated list if we do go out with something and I hate to say re-rank them but at least try to get some ideas as to where now since it's been a couple of meetings since we last went through the facilitated prioritization exercise to get some more recent feedback.

Because things have dramatically changed, at least in my view. The meetings themselves are -- the two-day meetings are much more focused. The days aren't any shorter necessarily, but I think we are more focused in our own deliberations, and I think we've come a long way in that. And I'm pleased to see the committee working more effectively. 
MR. COSTLE: Yes, actually, Jerry, you raise a good point. One of the things that $\mathrm{Al}$ and
ably need to do is to sit down with Tom and sort of get his take on -- I mean my sense when DR. PAULSON: That is confusing. I just wanted to join Tad's comments about the quality
of the testimony last night at the public meeting and note for the record that we did receive today a memorandum addressed to Doug Costle as chairman for Meredith Hunter, regarding the Weldon Springs water releases, which I thought was a very helpful addition to my understanding of that issue, and I'd like for the record to show that the committee in fact received that.

\section{CHAIRMAN ALM: Jerry?}

MR. CHRISTEAN: A couple of things I'd like to say. Number one, I think one thing that would help us in our meetings -- and I want to compliment the staff at the same time -- I thought this briefing book was better than anything we've had in the past in terms of kind of consolidating stuff, even though it was pretty thick.

And bringing to our attention it's given us backgrounds on issues that we were going to talk about today. I think further work on that by the staff would be very helpful to us, because we've got to acknowledge a couple of things. We're meeting less days. We've got Tom Grumbly -- Tom -- I mean it's going to be kind of hard to plan our meetings without Tom Grumbly in the middle of us. And thank God he is.

I mean I personally -- I'm damn happy that we've got the top guy in the EM with us in our meetings practically every meeting at least some of the days. And I think that's great for us.

I think the -- and I mean I don't know about you, but I'm sure that I speak for you when I say -- but having said that, it's a little hard to plan too. So let's recognize that it's not going to be as neat and dainty and as orderly as maybe we'd like to have it because of those kinds of problems. 
he walked out of here is that he was pretty well wired in terms of what we're doing and what he sees happening and his sense of our relevance to him.

But, you know, at the same time he's going to be going through some rough spots coming up, because the train wreck -- I'm not sure I like the analogy but -- and depending on what some of the numbers are that start coming out on the PEIS, could change the character of some of his priorities in terms of a much larger national debate on prior- -. on priorities.

So that we will undertake -- I mean really it's part and parcel of what you were saying, to touch base with Tom on all this as well.

And one of the things I think we need to be conscious of is that as this activity rolls forward, we may need additional kinds of -- we may want to take another look at staffing issues too in terms of seeing that we're adequately staffed. I mean that can make a heck of a difference in terms of efficiency in the use of our time.

I mean Tom's ultimately the judge of our relevance. We have to be a husband of our own efficiency. And the staff has really worked very, very hard to make this come off smoothly. And we're very grateful to all of them. And I know in Glen's case he is going to be -- really is going to have his hands full with the PEIS process.

And so I think it may be time for us to start thinking about getting him some more arms and legs in some fashion.

CHAIRMAN ALM: Okay. This might be a good spot to end before we lose our quorum. People are drifting out. I just wanted to -- I just wanted to reiterate a couple of points. One is, I was impressed with the subcommittee's work.

MR. COSTLE: Um-hmm.

CHAIRMAN ALM: I think all of the subcommittee's are really doing good work, and I think that's going to pay off big time, because there we're really putting in the time and effort, and I think we'll be shaping some very useful products for the Department.

I just want to concur with all the kind words about the staff. This is a momentous undertaking. There's virtually limitless things that can go wrong. And the fact that they didn't really means that people worked their tails off and really deserve a lot of credit.

I agree that having Barry Breen and Tim Fields, both of whom I know from my stint at EPA, is going to be very, very useful to the committee.

And finally I thought the people from DOE had given a lot of thought to preparation and have taken this seriously. Even if we'd like the men to be a little briefer in their presentations, they certainly gave a lot of thought and effort and deserve a lot of credit. 
And most of all you all have been terrific. I mean you are much better than me sitting through all this, 35 people last night and today. And I think everybody has been very helpful in working in a spirit of cooperation and public interest, so I think that's very encouraging.

Doug, would you like to say anything?

MR. COSTLE: No, I think you just said it all.

CHAIRMAN ALM: All right.

MR. COSTLE: I think we ought to entertain a motion to adjourn unless somebody else has got additional business.

(Motion made to adjourn.)

MR. COSTLE: Second it?

(Motion to adjourn seconded.)

MR. COSTLE: All in favor?

(Chorus of ayes.)

MR. COSTLE: The motion carries. Thank you, all. 

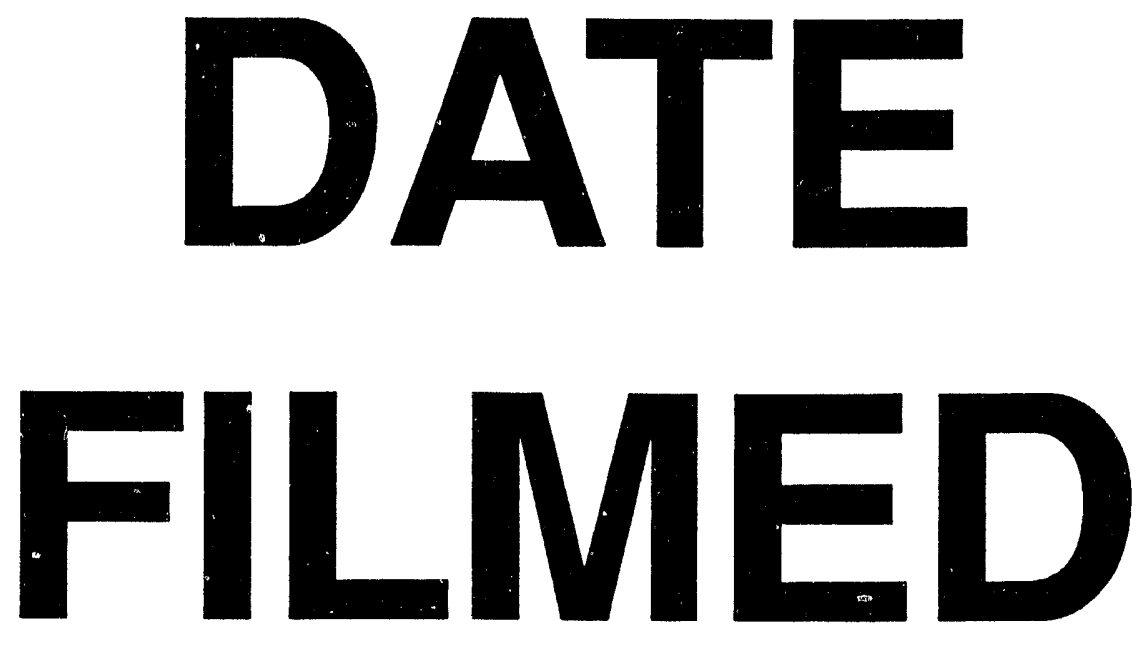

$6 / 17 / 94$
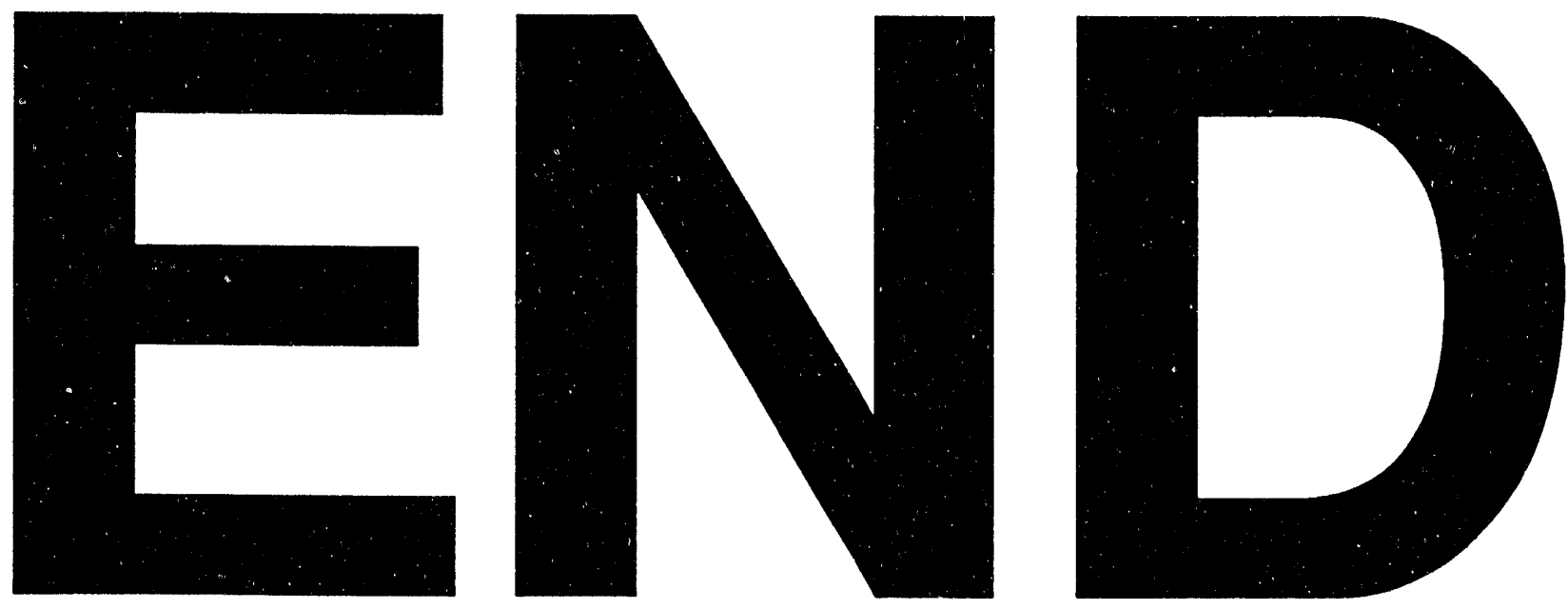
